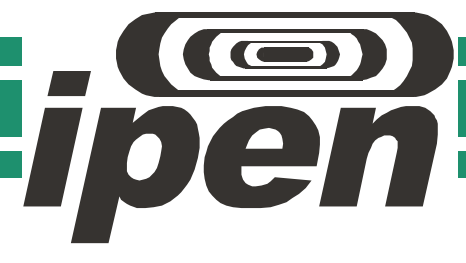

AUTARQUIA ASSOCIADA À UNIVERSIDADE DE SÃO PAULO

\title{
EVOLUÇÃO TEMPORAL DAS DISTRIBUIÇÕES DOS RADIONUCLÍDEOS NATURAIS U-238, Th-234, Ra-226, Ra-228, Pb-210 E Po-210 NO ESTREITO DE BRANSFIELD, PENÍNSULA ANTÁRTICA
}

\author{
FLÁVIA VALVERDE LAPA
}

Dissertação apresentada como parte dos requisitos para obtenção do Grau de Mestre em Ciências na Área de Tecnologia Nuclear - Aplicações

Orientadora:

Profa. Dra. Joselene de Oliveira 
INSTITUTO DE PESQUISAS ENERGÉTICAS E NUCLEARES

Autarquia associada à Universidade de São Paulo

\title{
EVOLUÇÃO TEMPORAL DAS DISTRIBUIÇÕES DOS RADIONUCLÍDEOS \\ NATURAIS U-238, Th-234, Ra-226, Ra-228, Pb-210 E Po-210 NO \\ ESTREITO DE BRANSFIELD, PENÍNSULA ANTÁRTICA
}

\author{
FLÁVIA VALVERDE LAPA
}

Dissertação apresentada como parte dos requisitos para obtenção do Grau de Mestre em Ciências na Área de Tecnologia Nuclear - Aplicações

Orientadora:

Profa. Dra. Joselene de Oliveira

Versão Corrigida

Versão Original disponível no IPEN 
Dedico este trabalho à minha amada familia, Pai, Mãe e irmás, por todo amor e união. Vocês representam o meu melhor. Amo vocês! 


\section{AGRADECIMENTOS}

A Deus, por me acompanhar e amparar em todos os momentos felizes, tristes e, principalmente, naqueles em que estive distante. Obrigada pela tua presença em minha vida.

A minha amada família, pais, Ronaldo e Maria Aparecida, e irmás, Carla e Fernanda, por todo amor, dedicacáa, apoio, incentivo e companheirismo. Agradeço-os também pelos ensinamentos e questionamentor sobre a vida, ética e valores. Pais e irmas, somos diferentes ao mesmo tempo somos iguais, vivemos nossas vidas de forma independente ao mesmo tempo viremos nossas vidas como se forse uma única vida, nos conhecemos apenas pelo othar, ficamos felizes pelas nossas conquistas e sofremos pelas nossas derrotas, sempre foi assim, uma familia unida. Com vocês descobri o significado de amor e família. E essa é a melhor familia que eu poderia ter, amo-os incondicionalmente.

À minha orientadora Dra. Joselene de Oliveira, pelo aprendizado, orientação e dedicação a nosso trabalho, por toda compreensão e confiança, por compartilhar experiências que vão além de um simples laboratório. Obrigada pela nossa amizade e carinho que crescen e se fortaleceu no decorrer deste trabalho. Sou grata por ter tido a oportunidade de conviver com vocé.

À Alice Miranda Ribeiro Costa, amiga querida, por todo auxílio, questionamentos, contribuiçóes e discussöes referentes à nossa pesquisa. Obrigada por tudo, pelas conversas, descontraçóes, por compartilhar inseguranças e por estar sempre presente. O segredo da nossa amizade é que duplicamos as alegrias e dividimos as tristezas, que continue sempre assim. 
Ao Instituto de Pesquisas Energéticas e Nucleares (IPEN) da Comissão Nacional de Energia Nuclear (CNEN), pela infraestrutura acadêmica, laboratórios e equipamentos disponíreis.

Conselho Nacional de Desenvolvimento Cientifico e Tecnológico (CNPq), pelo financiamento do Projeto CARBOTHORIUM - Edital MCT/CNPq w23/2009 - PROANTAR - Processo w557125/2009-0 e pela concessão da bolsa em núvel de Mestrado - Processo 0159119/2010-3.

À marinha, pela oportunidade de realizar pesquisa cientifica em um local tão hostil de maneira segura. Agradeço toda tripulação do Navio de Apoio Oceanográfico Ary Rongel pela dedicação e comprometimento com a pesquisa, por todo cuidado e respeito com $\sigma$ material de trabalho, e acima de tudo, pela preocupação, bem-estar e seguranca que tiveram com a equipe durante o período em que esteve embarcada.

Ao Laboratório de Radiometria Ambiental (LRA) da Gerência de Metrologia das Radiaçóes (GMR) do IPEN, pela infraestrutura e pelos laboratórios, of quais foram fundamentais no desenvolvimento e sucesso da pesquisa.

À Dra. Celina Lopes Duarte do Centro de Tecnologia das Radiaçóes (CTR) do IPEN, por disponibilizar seu tempo e atenção para a realização da extração de carbono por ultrassom.

A Dra. Elâine Arantes Jardim Martins do Centro de Química e Meio Ambiente (CQMA) do IPEN, pela disponibilidade, comprometimento, atenção e dedicação na realização das análises de carbono.

À Dra. Cátia Heloisa Resignoli Saucia, por ter me dado à oportunidade de iniciar na área acadêmica. 
A Lucilaine Silva Francisconi, amiga querida, pelo período em que trabalhamos juntas, pelas conversas, risadas, companhia e, por compartilhar duvidas e inseguranças. Obrigada pela nossa amizade.

Ao Dr. Lucio Leonardo, por toda amizade e carinho, pelas análises de 210 Po, conversas e discussöes sempre pertinentes e muitas vezes engraçadas, pelas preocupaçöes e contribuiçōes. Obrigada por sempre me ouvir, por compartilhar conversas, experiêcias e boas risadas.

Ao Dr. Paulo Sérgio Cardoso da Silva, pela amizade e carinho, por estar sempre disposto a ensinar e auxiliar independentemente da circunstância. Obrigada pelas discussões e contribuiçōes a núvel científico, profissional e pessoal, e pelas conversas descontraídas.

A Dra. Sandra Regina Damatto, por toda amizade e carinho, pelas análises de 210Po e ensinamentos obtidos durante a iniciação científica. Obrigada pelas conversas, contribuiçöes e preocupações.

Aos colegas do LRA, Dr. Ademar de Oliveira Ferreira, Dra. Brigitte Roxana Soreanu Pecequilo, Camila Dias Cazula, Dra. Erika Reyes Molina, Lúvia Fernandes Barros, Luciano Hasimoto Malheiro, MSc. Marcelo Bessa Nisti, Dr. Marcelo Francis Máduar, MSc. Marcos Medrado de Alencar, MSc. Paulo René Nogueira, Raquel Borolini, MSc. Reginaldo Ribeiro de Aquino, Michelle e Sandro. Agradeco a todos pela convivéncia e amizade, e por fazerem parte da minha vida acadêmica el ou pessoal.

As pessoas não citadas, porém não menos importantes, que de alguma maneira passaram pela minha vida e contribuiram para o meu crescimento pessoal el ou profissional.

Sentirei saudades de todos, de cada instante. Saudade é o amor que fica. 
"Pior do que passar frio, subindo e descendo ondas (...), seria não ter chegado até aqui. Ou nunca ter deixado as águas quentes e confortáreis (...). Mesmo que fosse apenas para descobrir o quanto elas eram quentes e confortáveis. Eu sentia um estranho bem-estar ao contornar gelos tão longe de casa.

Hoje entendo bem (...) um homem precisa viajar. Por sua conta, não por meio de histórias, imagens, livros ou TV. Precisa viajar por si, com seus othose pés, para entender $\sigma$ que é seu. Para um dia plantar as suas próprias árvorese dar-thes valor. Conhecer o frio para desfrutar do calor. Eo oposto. Sentir a distância e o desabrigo para estar bem sob $\sigma$ próprio teto. Um homem precisa viajar para lugares que não conhece para quebrar essa arrogância que nos faz ver $\sigma$ mundo como imaginamos, e não simplesmente como é ou pode ser. Que nos faz professores e doutores do que não vimos, quando deveríamos ser alunos, e simplesmente ir ver. (...) 'Não adianta, não serve para nada, é preciso ir ver.' (..) Pura verdade, o mundo na TV é lindo, mas serve para pouca coisa. É preciso questionar o que se aprendeu. É preciso ir tocá-lo." 


\title{
EVOLUÇÃO TEMPORAL DAS DISTRIBUIÇÕES DOS RADIONUCLÍDEOS NATURAIS ${ }^{238} \mathrm{U},{ }^{234} \mathrm{Th},{ }^{226} \mathrm{Ra},{ }^{228} \mathrm{Ra},{ }^{210} \mathrm{~Pb}$ E ${ }^{210} \mathrm{PO}$ NO ESTREITO DE BRANSFIELD, PENÍNSULA ANTÁRTICA
}

\author{
Flávia Valverde Lapa
}

\section{RESUMO}

Pesquisas versando sobre a distribuição de radionuclídeos naturais na Antártica são raras e desta forma, há grande interesse em se conhecer sua ocorrência e os fatores envolvidos com sua mobilização, transferência e acúmulo neste ambiente extremamente frágil. Os radionuclídeos naturais têm sido intensamente utilizados como traçadores no meio ambiente oceânico, auxiliando na compreensão de processos como afundamento, remoção e ressuspensão de partículas, mistura de massas d'água e circulação oceânica. $O{ }^{234} \mathrm{Th}\left(\mathrm{t}^{1} / 2=24,1\right.$ dias) é um radionuclídeo partículo-reativo produzido continuamente na água do mar pelo decaimento radioativo de seu precursor solúvel e de caráter conservativo com a salinidade ${ }^{238} \mathrm{U}\left(\mathrm{t}^{1} / 2=4,510^{9}\right.$ anos). Como apresenta meiavida relativamente curta, $0{ }^{234} \mathrm{Th}$ é apropriado para quantificar processos que ocorrem em escala de tempo de dias a semanas. O desequilíbrio ${ }^{234} \mathrm{Th} /{ }^{238} \mathrm{U}$ nas águas superficiais do oceano tem sido utilizado para determinar o fluxo de carbono orgânico que afunda via material particulado. O fluxo de partículas produtivas biologicamente para além da zona eufótica no Oceano Austral tem destaque especial devido à sua importância no controle das concentrações de $\mathrm{CO}_{2}$ na atmosfera. Os radionuclídeos ${ }^{210} \mathrm{~Pb}\left(\mathrm{t}^{1} \frac{1}{2}=22,3\right.$ anos) e ${ }^{210} \mathrm{Po}\left(\mathrm{t}^{1} / 2=138\right.$ dias) também são partículo-reativos. O desequilíbrio ${ }^{210} \mathrm{Po} /{ }^{210} \mathrm{~Pb}$ tem sido 
utilizado para estimar os fluxos de partículas exportadas no oceano em uma escala de tempo de várias semanas. Os isótopos de Ra de meias-vidas longas, ${ }^{226} \mathrm{Ra}\left(\mathrm{t}^{1} 1 / 2=1.600\right.$ anos) $\mathrm{e}{ }^{228} \mathrm{Ra}\left(\mathrm{t}^{1} / 2=5,75\right.$ anos) são solúveis na água do mar exibem propriedades únicas que os tornam bons traçadores de massas d'água. Este trabalho teve por objetivos estudar as distribuições dos radionuclídeos naturais ${ }^{238} \mathrm{U},{ }^{234} \mathrm{Th},{ }^{226} \mathrm{Ra},{ }^{228} \mathrm{Ra},{ }^{210} \mathrm{~Pb}$ e ${ }^{210} \mathrm{Po}$ no Estreito de Bransfield, durante duas campanhas realizadas no Verão Austral de 2011 (OPERANTAR XXIX e $X X X)$. 


\title{
TEMPORAL EVOLUTION OF NATURAL RADIONUCLIDES DISTRIBUTIONS ${ }^{238} \mathrm{U},{ }^{234} \mathrm{Th},{ }^{226} \mathrm{Ra},{ }^{228} \mathrm{Ra},{ }^{210} \mathrm{~Pb}$ AND ${ }^{210} \mathrm{Po}$ IN THE BRANSFIELD STRAIT, ANTARTICA PENINSULA
}

\author{
Flávia Valverde Lapa
}

\begin{abstract}
Research on the distribution of natural radionuclides in Antartica is rare and thus, there is great interest in to know their occurrence and factors related to its mobilization, transference and accumulation in this extremely fragile environment. Natural radionuclides have been used intensively as tracers in the ocean, helping to better understand processes as sinking and particle ressuspention, water masses mixture and oceanic circulation. ${ }^{234} \mathrm{Th}\left(\mathrm{t}^{1} / 2=24.1\right.$ days) is a particle-reactive radionuclide produced continuously in seawater by the decay of its soluble precursor conservative with salinity ${ }^{238} \mathrm{U}\left(\mathrm{t}^{1} 1 / 2=4.510^{9}\right.$ years $)$. Since ${ }^{234} \mathrm{Th}$ presents relatively short half-life, it is used to quantify processes that occur in temporal scale varying from days to weeks. The disequilibrium ${ }^{234} \mathrm{Th} /{ }^{238} \mathrm{U}$ in the surface ocean has been applied to estimate carbon fluxes exported via sinking material. The flux of particles biologically productive out of the euphotic zone in the Southern Ocean has special attention due to its importance in the control of $\mathrm{CO}_{2}$ atmospheric concentrations. The radionuclides ${ }^{210} \mathrm{~Pb}(\mathrm{t} 1 / 2=22.3$ years) and ${ }^{210} \mathrm{Po}\left(\mathrm{t}^{1} / 2=138\right.$ days $)$ are also particle-reactive. The disequilibrium ${ }^{210} \mathrm{Po} /{ }^{210} \mathrm{~Pb}$ has been used to estimate fluxes of particles exported in the ocean in the time scale of weeks. The long-lived $\mathrm{Ra}$ isotopes, ${ }^{226} \mathrm{Ra}(\mathrm{t} 1 / 2=1,600$ years) and ${ }^{228} \mathrm{Ra}(\mathrm{t} 1 / 2=5.75$ years) are soluble in seawater, presenting unique properties that make them excellent tracers of water masses. This research work had the aim to
\end{abstract}


study the distributions of natural radionuclides ${ }^{238} \mathrm{U},{ }^{234} \mathrm{Th},{ }^{226} \mathrm{Ra},{ }^{228} \mathrm{Ra},{ }^{210} \mathrm{~Pb}$ and ${ }^{210} \mathrm{Po}$ in the Bransfield Strait during 2 samplings carried out in the 2011 Austral Summer (OPERANTAR XXIX and XXX). 


\section{SUMÁRIO}

Página

1. INTRODUÇÃO 01

1.1. Antártica 01

1.2. Processos físicos e biológicos marinhos …………………………………......... 03

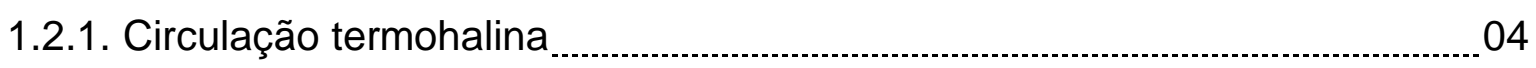

1.2.2. Ciclo do carbono

1.3. Distribuição dos radionuclídeos naturais no oceano ........................................... 09

1.3.1. Radionuclídeos naturais partículo-reativos ………...................................... 11

1.3.1.1. Tório $\ldots$

1.3.1.2. Chumbo

1.3.1.3. Polônio

1.3.2. Radionuclídeos naturais solúveis _................................................................ 14

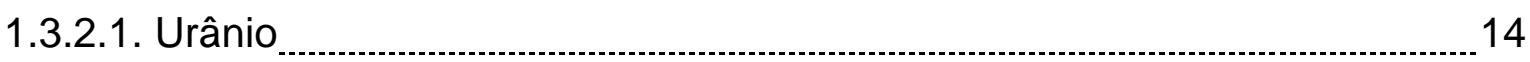

1.3.2.2. Rádio

1.4. Desequilíbrio isotópico de ${ }^{234} \mathrm{Th} /{ }^{238} \mathrm{U},{ }^{210} \mathrm{Po} /{ }^{210} \mathrm{~Pb},{ }^{228} \mathrm{Ra} /{ }^{226} \mathrm{Ra}$ no oceano e suas aplicações

2. OBJETIVO

3. ÁREA DE ESTUDO

4. MATERIAS E MÉTODOS

4.1. Amostragem

4.1.1. Amostragem para determinação de ${ }^{234}$ Th total .............................................. 32 
4.1.2. Amostragem para determinação de ${ }^{210} \mathrm{Po}$ e ${ }^{210} \mathrm{~Pb}$ particulado........................ 32

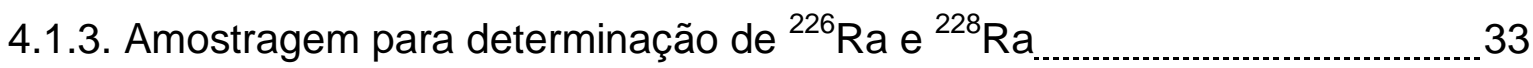

4.1.4. Amostragem para análises complementares …............................................... 33

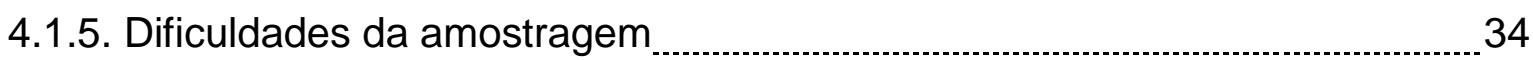

4.2. Determinação radioquímica de ${ }^{234}$ Th total em amostras de água do mar ....... 35

4.2.1. Princípio do método 35

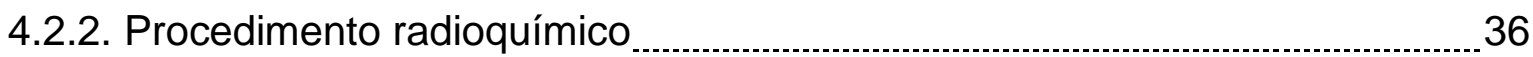

4.2.3. Cálculo da concentração de atividade de ${ }^{234}$ Th total ..................................... 38

4.2.4. Validação da metodologia para determinação de ${ }^{234} \mathrm{Th}$ total .......................... 39

4.3. Estimativa das concentrações de ${ }^{238} \mathrm{U}$ em amostras de água do mar a partir

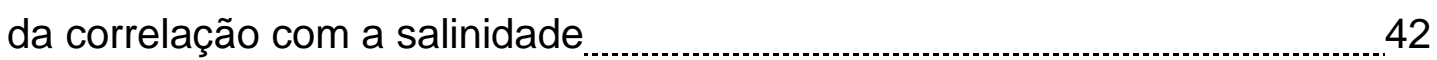

4.4. Determinação radioquímica de ${ }^{210} \mathrm{Po}$ em amostras de água do mar................ 42

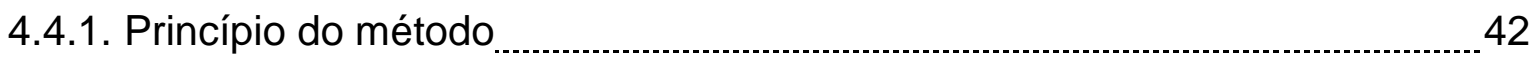

4.4.2. Procedimento radioquímico utilizado para a determinação de ${ }^{210} \mathrm{Po}$ nas amostras da Operantar XXIX (Damatto et al., 2009)

4.4.3. Procedimento radioquímico utilizado para a determinação sequencial de ${ }^{210} \mathrm{Po} /{ }^{210} \mathrm{~Pb}$ nas amostras da Operantar XXX (Nieri Neto, 1996) .....................45

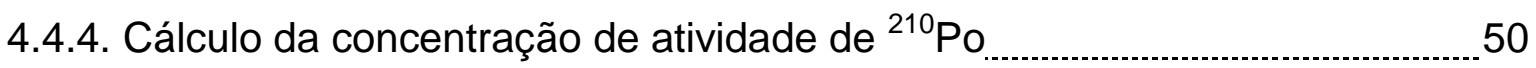

4.4.4.1. Determinação da eficiência de contagem alfa para a quantificação de ${ }^{210} \mathrm{Po}$ 50

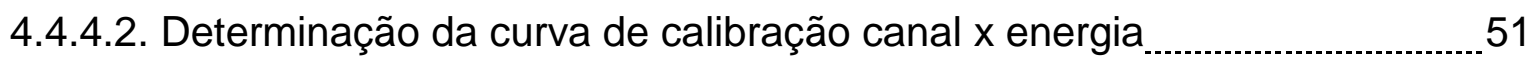

4.4.4.3. Determinação da radiação de fundo ............................................................. 52

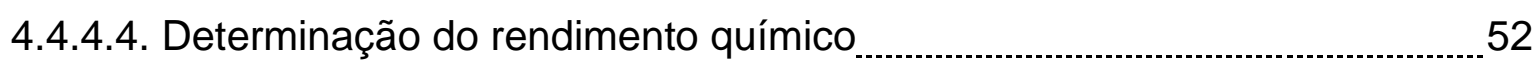

4.4.4.5. Determinação do limite inferior de detecção (LID) ....................................... 53

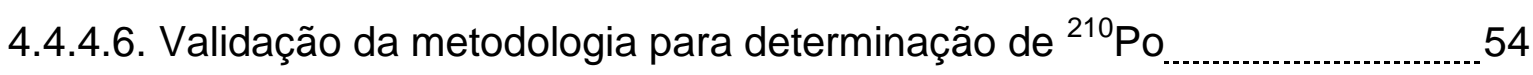

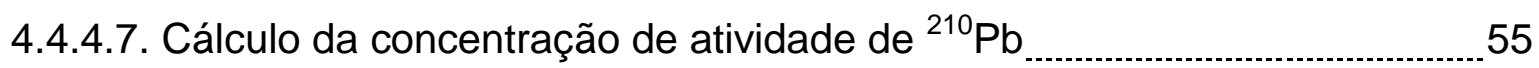

4.4.4.8. Determinação da eficiência da contagem beta total de ${ }^{210} \mathrm{~Pb}$......................5 55

4.4.4.9. Determinação da radiação de fundo, rendimento químico gravimétrico e limite inferior de detecção do método ..........................................................56

4.4.4.10. Validação da metodologia sequencial para determinação de ${ }^{210} \mathrm{Po} /{ }^{210} \mathrm{~Pb}$

4.5. Determinação radioquímica de ${ }^{226} \mathrm{Ra} \mathrm{e}^{228} \mathrm{Ra}$ em amostras de água do mar. 57

4.5.1. Princípio do método. 
4.5.3. Cálculo da concentração de atividade de ${ }^{226} \mathrm{Ra}$ 60

4.5.4. Estimativa da eficiência da contagem alfa total para a determinação de ${ }^{226} \mathrm{Ra}$

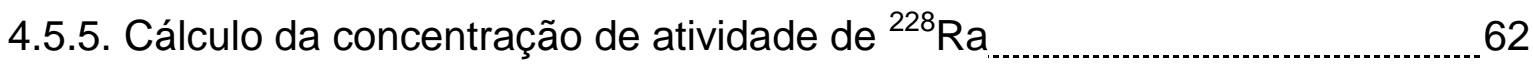

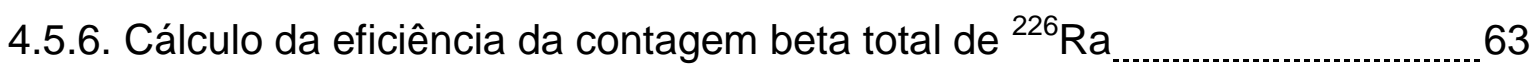

4.5.7. Cálculo da eficiência da contagem beta total de ${ }^{228} \mathrm{Ra} \ldots 64$

4.5.8. Determinação da radiação de fundo, rendimento químico gravimétrico e limite inferior de deteç̧ão do método. 65

4.5.9. Validação da metodologia para determinação de ${ }^{226} \mathrm{Ra} e{ }^{228} \mathrm{Ra}$ 65

4.6. Determinações complementares 66

5. RESULTADOS E DISCUSSÃO 67

5.1. Distribuição superficial 75

5.2. Análise de correlação 92

5.3. Estimativa dos fluxos de POC, ${ }^{234} \mathrm{Th}$ e ${ }^{210} \mathrm{Po}$ exportados via material particulado 104

6. CONCLUSÕES 108 


\section{LISTA DE TABELAS}

\section{Página}

TABELA 1 - Coordenadas geográficas e data da coleta das estações superficiais de água do mar amostradas durante as expedições OPERANTAR XXIX e XXX

TABELA 2 - Estações superficiais de água do mar que compreendem cada perfil radial horizontal amostrado para a determinação de ${ }^{226} \mathrm{Ra}$ e ${ }^{228} \mathrm{Ra}$ durante a OPERANTAR XXIX

TABELA 3 - Resultados do exercício de intercomparação da determinação de ${ }^{234} \mathrm{Th}$ em água do mar utilizando-se 3 diferentes métodos

TABELA 4 - Resultados da validação da metodologia de quantificação do ${ }^{210} \mathrm{Po}$, pela participação no IAEA-CU-2007-09 54

TABELA 5 - Resultados das concentrações de ${ }^{210}$ Po determinadas no material de referência IAEA-385 55

TABELA 6 - Valores das eficiências de contagem beta total para ${ }^{210} \mathrm{~Pb}$ 56

TABELA 7 - Valores das eficiências de contagem alfa total para ${ }^{226} \mathrm{Ra}$. 62

TABELA 8 - Valores das eficiências de contagem beta para os filhos do ${ }^{226} \mathrm{Ra}$ 64

TABELA 9 - Valores das eficiências de contagem beta para os filhos do ${ }^{228} \mathrm{Ra}$ 65 
TABELA 10 - Dados de distância da costa e profundidade total e, valores de temperatura e salinidade - nas estações da OPERANTAR XXIX

TABELA 11 - Dados de distância da costa e profundidade total e, valores de temperatura e salinidade - nas estações da OPERANTAR XXX

TABELA 12 - Concentrações de carbono inorgânico $(\mathrm{Cl})$, carbono orgânico total (COT) e carbono total (CT) - nas estações da OPERANTAR XXIX

TABELA 13 - Concentrações de carbono inorgânico (Cl), carbono orgânico total (COT) e carbono total (CT) - nas estações da OPERANTAR XXX

TABELA 14 - Concentrações de ${ }^{234} \mathrm{Th}$ total, ${ }^{238} \mathrm{U}$ dissolvido, ${ }^{210} \mathrm{Po}$ particulado e razão de atividade ${ }^{234} \mathrm{Th}$ total $/{ }^{238} \mathrm{U}$ dissolvido - nas estações da OPERANTAR XXIX 72

TABELA 15 - Concentrações de ${ }^{234} \mathrm{Th}$ total, ${ }^{238} \mathrm{U}$ dissolvido, razão de atividade ${ }^{234} \mathrm{Th}$ total $/{ }^{238} \mathrm{U}$ dissolvido, ${ }^{210} \mathrm{Po}$ particulado, ${ }^{210} \mathrm{~Pb}$ particulado e razão de atividade ${ }^{210} \mathrm{Po} /{ }^{210} \mathrm{~Pb}$ - nas estações da OPERANTAR XXX 73

TABELA 16 - Concentrações de ${ }^{226} \mathrm{Ra},{ }^{228} \mathrm{Ra}$ e razão de atividade ${ }^{228} \mathrm{Ra} /{ }^{226} \mathrm{Ra}-$ nas estações da OPERANTAR XXIX 74

TABELA 17 - Concentrações de ${ }^{226} \mathrm{Ra},{ }^{228} \mathrm{Ra}$, razões de atividade ${ }^{228} \mathrm{Ra} /{ }^{226} \mathrm{Ra}$ e ${ }^{210} \mathrm{~Pb} /{ }^{226} \mathrm{Ra}$ - nas estações da OPERANTAR XXX 74

TABELA 18 - Matriz de correlação dos parâmetros estudados na OPERANTAR XXIX, os valores em destaque apresentaram nível de significância $p<0,05$ 102

TABELA 19 - Matriz de correlação dos parâmetros estudados na OPERANTAR XXX, os valores em destaque apresentaram nível de significância $p<0,05$ 103 
TABELA 20 - Estimativas dos fluxos de ${ }^{234} \mathrm{Th}$ removido pelo material particulado $\left(\mathrm{dpm} \mathrm{m}^{-2} \mathrm{~d}^{-1}\right)$ e carbono orgânico particulado (POC) exportado $\left(\mathrm{mmol} \mathrm{C} \mathrm{m} \mathrm{m}^{-2} \mathrm{~d}^{-1}\right.$ ) e razão $\mathrm{POC} /{ }^{234} \mathrm{Th}$ total $\left(\mathrm{mmol} \mathrm{C} \mathrm{m}^{-2} \mathrm{~d}^{-1}\right)-$ nas estações da OPERANTAR XXIX 106

TABELA 21 - Estimativas dos fluxos de ${ }^{234} \mathrm{Th}$ removido pelo material particulado $\left(\mathrm{dpm} \mathrm{m}^{-2} \mathrm{~d}^{-1}\right)$ e carbono orgânico particulado (POC) exportado $\left(\mathrm{mmol} \mathrm{C} \mathrm{m}{ }^{-2} \mathrm{~d}^{-1}\right.$ ) e razão $\mathrm{POC} /{ }^{234} \mathrm{Th}$ total $\left(\mathrm{mmol} \mathrm{C} \mathrm{m}^{-2} \mathrm{~d}^{-1}\right)$ - nas estações da OPERANTAR XXX 107

TABELA 22 - Estimativas dos fluxos de ${ }^{210} \mathrm{Po}$ removido pelo material particulado $\left(\mathrm{dpm} \mathrm{m}^{-2} \mathrm{~d}^{-1}\right)$ e carbono orgânico particulado (POC) exportado $\left(\mathrm{mmol} \mathrm{C} \mathrm{m} \mathrm{m}^{-2} \mathrm{~d}^{-1}\right)$ e razão POC/210 Po total $\left(\mathrm{mmol} \mathrm{C} \mathrm{m}^{-2} \mathrm{~d}^{-1}\right)$ - nas estações da OPERANTAR XXX 


\section{LISTA DE FIGURAS}

Página

FIGURA 1 - Representação dos processos que controlam o ciclo do carbono, "bomba biológica" e "bomba física"

FIGURA 2 - Ciclo global da circulação termohalina 05

FIGURA 3 - Representação simplificada da bomba biológica 07

FIGURA 4 - Séries radioativas naturais do ${ }^{238} U,{ }^{232} T h$ e ${ }^{235} U$ 09

FIGURA 5 - Diagrama esquemático do decaimento radioativo e de processos de transporte no oceano e atmosfera que podem ser traçados utilizando radionuclídeos adequados

FIGURA 6 - Mapa de localização da área de estudo, o Estreito de Bransfield 22

FIGURA 7 - Mapa da localização dos Mares Weddell e Bellingshausen e das subbacias oriental, central e ocidental do Estreito de Bransfield

FIGURA 8 - Mapa da circulação superficial ao longo do Estreito de Bransfield com a predominância de Água Zonal Transicional influenciada pelo Mar de Belligshausen (TBW) e Água Zonal Transicional influenciada pelo Mar de Weddell (TWW) 25

FIGURA 9 - Navio de Apoio Oceanográfico Ary Rongel da Marinha do Brasil......28 
FIGURA 10 - Mapa da localização das estações de amostragem superficial realizadas durante a OPERANTAR XXIX

FIGURA 11 - Mapa da localização das radiais realizadas durante a OPERANTAR XXIX

FIGURA 12 - Mapa da localização das estações de amostragem superficial realizadas durante a OPERANTAR XXX

FIGURA 13 - a) Precipitação das amostras de água do mar; b) Filtragem a vácuo em sistema Manifold; c) Filtros com microprecipitado de $\mathrm{MnO}_{2}$; d) Secagem dos filtros em estufa; e) Resfriamento dos filtros em dessecador; f) Filtros na geometria de contagem; g e h) Detector proporcional de fluxo gasoso de baixa radiação de fundo, modelo Berthold LB 770

FIGURA 14 - a) Filtragem das amostras a vácuo em sistema Manifold; b) Filtros com material particulado; c) Secagem dos filtros em estufa; d) Pesagem dos filtros em balança analítica; e) Lixiviação dos filtros; f) Abertura total das amostras; g) Banho-maria com agitação constante para deposição espontânea dos isótopos de Po em disco de Ag; h) Amostras de Po depositadas em disco de Ag; i) Espectrômetro alfa de barreira de superfície, modelo Alpha Analyst da Canberra 44

FIGURA 15 - a) Filtragem a vácuo das amostras em sistema Manifold; b) Filtros com material particulado; c) Secagem dos filtros em estufa; d) Resfriamento dos filtros em dessecador; e) Pesagem dos filtros em balança analítica; f) Lixiviação dos filtros; g) Abertura total das amostras; h) Diluição das amostras com água purificada e adição de reagentes; i) Amostras sob aquecimento em chapa aquecedora; j) Amostras precipitadas com $\mathrm{Na}_{2} \mathrm{~S} 1 \mathrm{M}$; k) Filtragem a vácuo das amostras em sistema Millipore; I) Dissolução dos filtros sob aquecimento em chapa aquecedora; $m$ e n) Banho-maria com agitação constante para deposição espontânea dos isótopos de Po 
em disco de $\mathrm{Cu}$; o) Amostra de Po depositada em disco de $\mathrm{Cu}$; p) Espectrômetro alfa de barreira de superfície, modelo Alpha Analyst da Canberra 46

FIGURA 16 - a) Dissolução do $\mathrm{PbSO}_{4}$; b) Precipitação das amostras com $\mathrm{Na}_{2} \mathrm{CrO}_{4} 30 \%$; c) Filtragem a vácuo das amostras precipitadas em sistema Millipore; d) Filtros com precipitado de $\mathrm{PbCrO}_{4}$; e) Secagem dos filtros em estufa; f) Resfriamento dos filtros em dessecador; g) Pesagem dos filtros em balança analítica; h) Filtros na geometria de contagem; i e j) Detector proporcional de fluxo gasoso de baixa radiação de fundo, Berthold LB 770 . 49

FIGURA 17 -a) Percolação da amostra pela fibra em recipiente vazado b) Tambores para coleta das amostras de água do mar e percolação da amostra pela filbra na coluna; c) Fibras de acrílico impregnada com $\mathrm{MnO}_{2}$ após percolação das amostras; d) Amostras sob aquecimento em chapa aquecedora para redução do $\mathrm{Mn}^{+4}$ a $\mathrm{Mn}^{+2}$; e) Filtragem das amostras em sistema comum; f) Precipitação das amostras; g) Filtração a vácuo das amostras em sistema Millipore; $h$ e i) Detector proporcional de fluxo gasoso de baixa radiação de fundo, Berthold LB 770 . 59

FIGURA 18 - Distribuição superficial de temperatura, em ำ - OPERANTAR XXIX 75

FIGURA 19 - Distribuição superficial de temperatura, em ${ }^{\circ} \mathrm{C}$ - OPERANTAR XXX 76

FIGURA 20 - Distribuição superficial de salinidade - OPERANTAR XXIX 77

FIGURA 21 - Distribuição superficial de salinidade - OPERANTAR XXX 77

FIGURA 22 - Distribuição superficial de carbono inorgânico, em $\mathrm{mg} \mathrm{L}^{-1}$ OPERANTAR XXIX 
FIGURA 23 - Distribuição superficial de carbono inorgânico, em $\mathrm{mg} \mathrm{L}^{-1}$ OPERANTAR XXIX

FIGURA 24 - Distribuição superficial de carbono orgânico total, em $\mathrm{mg} \mathrm{L}^{-1}$ OPERANTAR XXIX

FIGURA 25 - Distribuição superficial de carbono orgânico total, em $\mathrm{mg} \mathrm{L}^{-1}$ OPERANTAR XXX

FIGURA 26 - Distribuição superficial de carbono total, em $\mathrm{mg} \mathrm{L}^{-1}$ - OPERANTAR XXIX

FIGURA 27 - Distribuição superficial de carbono total, em $\mathrm{mg} \mathrm{L}^{-1}$ - OPERANTAR $X X X$

FIGURA 28 - Distribuição superficial de ${ }^{234}$ Th total, em dpm L ${ }^{-1}$ - OPERANTAR XXIX

FIGURA 29 - Distribuição superficial de ${ }^{234}$ Th total, em dpm L ${ }^{-1}$ - OPERANTAR XXX

FIGURA 30 - Distribuição superficial de ${ }^{238} \mathrm{U}$ dissolvido, em $\mathrm{dpm} \mathrm{L}{ }^{-1}$ OPERANTAR XXIX

FIGURA 31 - Distribuição superficial de ${ }^{238} \mathrm{U}$ dissolvido, em dpm $\mathrm{L}^{-1}$ OPERANTAR XXX

FIGURA 32 - Distribuição superficial da razão de atividade ${ }^{234}$ Th total/ ${ }^{238} \mathrm{U}$ dissolvido - OPERANTAR XXIX

FIGURA 33 - Distribuição superficial da razão de atividade ${ }^{234}$ Th total/ ${ }^{238} \mathrm{U}$ dissolvido - OPERANTAR XXX. 85

FIGURA 34 - Distribuição superficial de ${ }^{210} \mathrm{Po}$ particulado, em dpm L $\mathrm{L}^{-1}$ OPERANTAR XXIX 
FIGURA 35 - Distribuição superficial de ${ }^{210} \mathrm{Po}$ particulado, em dpm $\mathrm{L}^{-1}$ OPERANTAR XXX.

FIGURA 36 - Distribuição superficial de ${ }^{210} \mathrm{~Pb}$ particulado, em $\mathrm{dpm} \mathrm{L} \mathrm{L}^{-1}$, OPERANTAR XXX

FIGURA 37 - Distribuição superficial da razão de atividade ${ }^{210} \mathrm{Po} /{ }^{1210} \mathrm{~Pb}$ OPERANTAR XXX

FIGURA 38 - Distribuição superficial de ${ }^{226} \mathrm{Ra}$, em dpm $100 \mathrm{~L}^{-1}$ - OPERANTAR $\mathrm{XXX}$

FIGURA 39 - Distribuição superficial de ${ }^{228} \mathrm{Ra}$, em dpm $100 \mathrm{~L}^{-1}$ - OPERANTAR XXX

FIGURA 40 - Distribuição superficial da razão de atividade ${ }^{228} \mathrm{Ra} /{ }^{1226} \mathrm{Ra}$ OPERANTAR XXX

FIGURA 41 - Distribuição superficial da razão de atividade ${ }^{210} \mathrm{~Pb} /{ }^{1226} \mathrm{Ra}$ OPERANTAR XXX

FIGURA 42 - a) Correlação da concentração de atividade de ${ }^{234} \mathrm{Th}\left(\mathrm{dpm} \mathrm{L}{ }^{-1}\right)$ em função da concentração de atividade de ${ }^{238} U$ (dpm L $\left.{ }^{-1}\right)$; b) Correlação da concentração de atividade de ${ }^{210} \mathrm{Po}\left(\mathrm{dpm} \mathrm{L} \mathrm{L}^{-1}\right)$ em função da concentração de atividade de ${ }^{210} \mathrm{~Pb} \quad\left(\mathrm{dpm} \mathrm{L} \mathrm{L}^{-1}\right)$; c) Correlação da concentração de atividade de ${ }^{210} \mathrm{~Pb}\left(\mathrm{dpm} 100 \mathrm{~L}^{-1}\right)$ em função da concentração de atividade de ${ }^{226} \mathrm{Ra}\left(\mathrm{dpm} 100 \mathrm{~L}^{-1}\right)$; d) Correlação da concentração de atividade de ${ }^{228} \mathrm{Ra}\left(\mathrm{dpm} 100 \mathrm{~L}^{-1}\right)$ em função da concentração de atividade de ${ }^{226} \mathrm{Ra}\left(\mathrm{dpm} 100 \mathrm{~L}^{-1}\right)$

FIGURA 43 - a) Correlação da concentração de atividade de ${ }^{234} \mathrm{Th}\left(\mathrm{dpm} \mathrm{L} \mathrm{L}^{-1}\right.$ ) em função da profundidade total (m); b) Correlação da concentração de atividade de ${ }^{238} \mathrm{U}\left(\mathrm{dpm} \mathrm{L}^{-1}\right)$ em função da profundidade total $(\mathrm{m})$; c) Correlação da concentração de atividade de ${ }^{234} \mathrm{Th}\left(\mathrm{dpm} \mathrm{L} \mathrm{L}^{-1}\right)$ em função da distância da costa (km); d) Correlação da concentração 


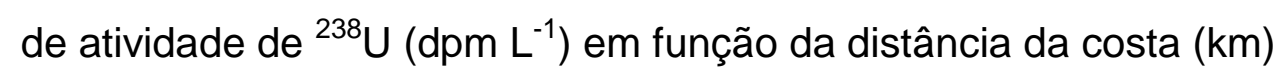

FIGURA 44 - a) Correlação da concentração de atividade de ${ }^{210} \mathrm{Po}\left(\mathrm{dpm} \mathrm{L}{ }^{-1}\right)$ em função da profundidade total (m); b) Correlação da concentração de atividade de ${ }^{210} \mathrm{~Pb}\left(\mathrm{dpm} \mathrm{L} \mathrm{L}^{-1}\right)$ em função da profundidade total (m); c) Correlação da concentração de atividade de ${ }^{210} \mathrm{Po}\left(\mathrm{dpm} \mathrm{L} \mathrm{L}^{-1}\right)$ em função da distância da costa (km); d) Correlação da concentração de atividade de ${ }^{210} \mathrm{~Pb}\left(\mathrm{dpm} \mathrm{L} \mathrm{L}^{-1}\right)$ em função da distância da costa $(\mathrm{km})$ 95

FIGURA 45 - a) Correlação da concentração de atividade de ${ }^{226} \mathrm{Ra}\left(\mathrm{dpm} 100 \mathrm{~L}^{-1}\right)$ em função da profundidade total (m); b) Correlação da concentração de atividade de ${ }^{228} \mathrm{Ra}\left(\mathrm{dpm} 100 \mathrm{~L}^{-1}\right)$ em função da profundidade total $(\mathrm{m})$; c) Correlação da concentração de atividade de ${ }^{226} \mathrm{Ra}$ (dpm $100 \mathrm{~L}^{-1}$ ) em função da distância da costa (km); d) Correlação da concentração de atividade de ${ }^{228} \mathrm{Ra}\left(\mathrm{dpm} 100 \mathrm{~L}^{-1}\right)$ em função da distância da costa $(\mathrm{km})$. 96

FIGURA 46 - a) Correlação da concentração de atividade de ${ }^{234} \mathrm{Th}\left(\mathrm{dpm} \mathrm{L}{ }^{-1}\right)$ em função da temperatura $\left({ }^{\circ} \mathrm{C}\right)$; b) Correlação da concentração de atividade de ${ }^{238} \mathrm{U}\left(\mathrm{dpm} \mathrm{L}^{-1}\right)$ em função da temperatura $\left({ }^{\circ} \mathrm{C}\right)$; c) Correlação da concentração de atividade de ${ }^{210} \mathrm{Po}\left(\mathrm{dpm} \mathrm{L}{ }^{-1}\right)$ em função da temperatura $\left({ }^{\circ} \mathrm{C}\right)$; d) Correlação da concentração de atividade de ${ }^{210} \mathrm{~Pb}\left(\mathrm{dpm} \mathrm{L}{ }^{-1}\right)$ em função da temperatura $\left({ }^{\circ} \mathrm{C}\right)$; e) Correlação da concentração de atividade de ${ }^{226} \mathrm{Ra}\left(\mathrm{dpm} 100 \mathrm{~L}^{-1}\right)$ em função da temperatura $\left({ }^{\circ} \mathrm{C}\right)$; f) Correlação da concentração de atividade de ${ }^{228} \mathrm{Ra}\left(\mathrm{dpm} 100 \mathrm{~L}^{-1}\right.$ ) em função da temperatura ( ${ }^{\circ} \mathrm{C}$ )

FIGURA 47 - a) Correlação da concentração de atividade de ${ }^{234} \mathrm{Th}\left(\mathrm{dpm} \mathrm{L}{ }^{-1}\right.$ ) em função da salinidade; b) Correlação da concentração de atividade de ${ }^{210} \mathrm{Po}\left(\mathrm{dpm} \mathrm{L}{ }^{-1}\right)$ em função da salinidade; c) Correlação da concentração de atividade de ${ }^{210} \mathrm{~Pb}\left(\mathrm{dpm} \mathrm{L} \mathrm{L}^{-1}\right)$ em função da salinidade; d) Correlação da concentração de atividade de ${ }^{226} \mathrm{Ra}$ 
(dpm $100 \mathrm{~L}^{-1}$ ) em função da salinidade; e) Correlação da concentração de atividade de ${ }^{228} \mathrm{Ra}\left(\mathrm{dpm} 100 \mathrm{~L}^{-1}\right)$ em função da salinidade 98

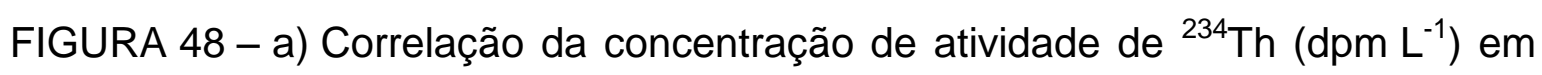
função do carbono inorgânico $\left(\mathrm{mg} \mathrm{L}^{-1}\right)$; b) Correlação da concentração de atividade de ${ }^{238} \mathrm{U}\left(\mathrm{dpm} \mathrm{L^{-1 }}\right)$ em função do carbono inorgânico $\left(\mathrm{mg} \mathrm{L}^{-1}\right)$; c) Correlação da concentração de atividade de ${ }^{234} \mathrm{Th}$ (dpm L $\mathrm{L}^{-1}$ ) em função do carbono orgânico total $\left(\mathrm{mg} \mathrm{L}^{-1}\right)$; d) Correlação da concentração de atividade de ${ }^{238} \mathrm{U}_{\left(\mathrm{dpm} \mathrm{L} \mathrm{L}^{-1}\right)}$ em função do carbono orgânico total $\left(\mathrm{mg} \mathrm{L}^{-1}\right)$. 99

FIGURA 49 - a) Correlação da concentração de atividade de ${ }^{210} \mathrm{Po}\left(\mathrm{dpm} \mathrm{L} \mathrm{L}^{-1}\right)$ em função do carbono inorgânico $\left(\mathrm{mg} \mathrm{L}^{-1}\right)$; b) Correlação da concentração de atividade de ${ }^{210} \mathrm{~Pb}\left(\mathrm{dpm} \mathrm{L^{-1 }}\right)$ em função do carbono inorgânico $\left(\mathrm{mg} \mathrm{L}^{-1}\right)$; c) Correlação da concentração de atividade de ${ }^{210} \mathrm{Po}$ (dpm L $\mathrm{L}^{-1}$ ) em função do carbono orgânico total $\left(m g L^{-1}\right)$; d) Correlação da concentração de atividade de ${ }^{210} \mathrm{~Pb}$ (dpm $\left.\mathrm{L}^{-1}\right)$ em função do carbono orgânico total $\left(\mathrm{mg} \mathrm{L}^{-1}\right)$. 100

FIGURA 50 - a) Correlação da concentração de atividade de ${ }^{226} \mathrm{Ra}\left(\mathrm{dpm} 100 \mathrm{~L}^{-1}\right)$ em função do carbono inorgânico $\left(\mathrm{mg} \mathrm{L}^{-1}\right)$; b) Correlação da concentração de atividade de ${ }^{228} \mathrm{Ra}\left(\mathrm{dpm} 100 \mathrm{~L}^{-1}\right)$ em função do carbono inorgânico $\left(\mathrm{mg} \mathrm{L}^{-1}\right)$; c) Correlação da concentração de atividade de ${ }^{226} \mathrm{Ra}$ (dpm $100 \mathrm{~L}^{-1}$ ) em função do carbono orgânico total (mg L $\left.\mathrm{L}^{-1}\right)$; d) Correlação da concentração de atividade de ${ }^{228} \mathrm{Ra}$ (dpm $\left.100 \mathrm{~L}^{-1}\right)$ em função do carbono orgânico total $\left(\mathrm{mg} \mathrm{L}^{-1}\right)$......... 101 


\title{
LISTA DE ABREVIATURAS E/OU SIGLAS
}

\author{
AQCS - Analytical Quality Control Services \\ CCA - Corrente Circumpolar Antártica \\ CHM - Centro de Hidrografia da Marinha \\ $\mathrm{Cl}$ - Carbono Inorgânico
}

CIRM - Comissão Interministerial para os Recursos do Mar

CNEN - Comissão Nacional de Energia Nuclear

CNPq - Conselho Nacional de Desenvolvimento Científico e Tecnológico

COT - Carbono Orgânico Total

CQMA - Centro de Química e Meio Ambiente

CT - Carbono Total

CTD - Equipamento eletrônico utilizado para medida simultânea de salinidade, temperatura e profundidade da área estudada

EACF - Estação Antártica Comandante Ferraz

EB - Estreito de Bransfield

EDTA - Ácido etileno diaminotetraacético 
GMR - Gerência de Metrologia das Radiações

HNLC - High Nutrient Low Chlorophyll

IAEA - International Atomic Energy Agency

ICP-MS - Inductively Coupled Plasma Mass Spectrometry

IPEN - Instituto de Pesquisas Energéticas e Nucleares

IRD - Instituto de Radioproteção e Dosimetria

LAQA - Laboratório de Análises Química e Ambiental

LID - Limite Inferior de Detecção

LRA - Laboratório de Radiometria Ambiental

MCTI - Ministério da Ciência, Tecnologia e Inovação

MMA - Ministério do Meio Ambiente

MRE - Ministério das Relações Exteriores

NAMEL - Marine Environment Laboratory Monaco

NELHA - Natural Energy Laboratory of Hawaii

NIST - Instituto Nacional de Padrões e Tecnologia

NTA - Ácido nitrilotriacético

OPERANTAR - Operação Antártica Brasileira

POC - Carbono Orgânico Particulado

PROANTAR - Programa Antártico Brasileiro

STF - Frente Subtropical 
TBW - Água Zonal Transicional influenciada pelo Mar de Bellingshausen TWW - Água Zonal Transicional influenciada pelo Mar de Weddell ZCS - Zona de Convergência Subtropical 


\section{INTRODUÇÃO}

\subsection{Antártica}

A Antártica tem atraído atenção da comunidade científica, por apresentar papel fundamental no clima global e ser considerada uma região extremamente sensível e vulnerável às mudanças climáticas globais (Tiwari et al., 2008; Villela, 2011).

A Antártica é o único lugar da Terra onde não há divisão geopolítica. No Ano Geofísico Internacional (1957-1958) houve a proposição do Tratado Antártico, que apenas em 23 de junho de 1961 entrou em vigor. Em 16 de maio de 1975, o Brasil filiou-se ao Tratado Antártico e realizou sua primeira expedição à Antártica (1982-1983), denominada Operação Antártica Brasileira (OPERANTAR). Isto deu início às pesquisas científicas brasileiras na Antártica e elevou o Brasil a categoria de membro consultivo do Tratado Antártico. Assim, em 1982, a Marinha do Brasil realizou o primeiro trabalho de reconhecimento hidrográfico, oceanográfico e meteorológico da região noroeste Antártica e selecionou o local onde seria instalada a Estação Científica Brasileira. Em 1984,

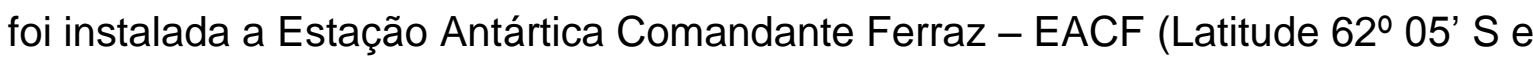

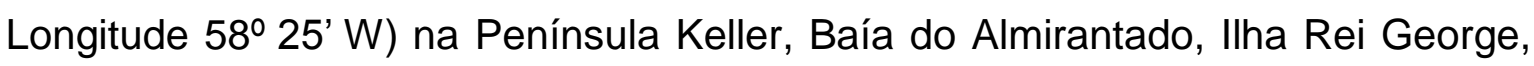
Ilhas Shetland do Sul (Souza, 2008; Tiwari et al., 2008).

Atualmente o Programa Antártico Brasileiro (PROANTAR) apoia a execução de pesquisas que tenham por objetivos ampliar os conhecimentos dos fenômenos antárticos e suas influências sobre questões de relevância global e regional. A implementação logística do PROANTAR está a cargo da Comissão Interministerial para os Recursos do Mar (CIRM), vinculada ao Comando da Marinha. Também são parceiros na execução do Programa o Ministério da Ciência, Tecnologia e Inovação (MCTI), o Ministério do Meio Ambiente (MMA), o Ministério das Relações Exteriores (MRE) e representantes do setor público, 
como a PETROBRAS. Ao Conselho Nacional de Desenvolvimento Científico e Tecnológico (CNPq) cabe a responsabilidade do financiamento das pesquisas científicas na Antártica.

O continente Antártico é circundado pelo oceano Austral, que é livre de barreiras físicas. Este oceano é formado pelo encontro das águas dos oceanos Atlântico, Pacífico e Índico, (Turner et al., 2009) limitado ao Sul pelo continente Antártico e ao Norte pela Frente Subtropical (STF) ou Zona de Convergência Subtropical (ZCS), englobando os Mares de Amundsen, Bellingshausen, Ross, Weddell, parte de Scotia e parte da Passagem de Drake. A ligação entre as três principais bacias oceânicas isola o continente Antártico da influência subtropical mantendo-o a baixas temperaturas durante todo o ano (Hanfland, 2002).

O Oceano Austral abrange cerca de $30 \%$ do oceano global e desempenha importante papel na regulação do clima da Terra devido à formação sazonal de gelo no mar ao redor da Antártica. Este fenômeno fornece grande impulso para a inversão da circulação termohalina global através da formação de águas intermediárias e profundas, e por ser considerado sorvedouro de dióxido de carbono $\left(\mathrm{CO}_{2}\right)$ atmosférico (Sarmiento et al., 1998). A região é uma das poucas áreas oceânicas onde é possível observar concentrações elevadas de nutrientes e baixas de clorofila (HNLC). Nestas regiões, especialmente na Antártica, vários fatores são considerados essenciais para tais condições como a limitação de luz e de micronutrientes como o ferro, a pastagem e a mistura física. A disponibilidade de ferro pode ser considerada um fator crítico para o crescimento da população fitoplanctônica em mar aberto (Figueiras et al., 1998).

A maior parte da vida na Antártica inicia-se no oceano, onde o plâncton é a base da cadeia alimentar marinha. As águas da Convergência Antártica Sul são ricas em nutrientes, fitoplâncton e zooplâncton, como o krill, que ocorrem em profusão durante o verão Austral. No período de inverno Austral, devido à cobertura de gelo extensiva, a produtividade nos oceanos é limitada (Tiwari et al., 2008).

O Estreito de Bransfield é uma das áreas oceânicas mais estudadas na Antártica, devido à localização, às condições climáticas e cobertura de gelo, e por 
ser considerada uma região altamente produtiva e muito dinâmica sob a influência de águas dos Mares de Weddell e Belligshausen (Tokarczyk, 1987; Niiler et al., 1991; García et al., 1994; Zhou et al., 2006).

Conhecer e entender como funcionam os processos biogeoquímicos que ocorrem no Oceano Austral é uma tarefa difícil, porém, de alta relevância científica que contribui para futuras tomada de decisão a respeito do clima da Terra.

\subsection{Processos físicos e biológicos marinhos}

O oceano é um dos maiores reservatórios de $\mathrm{CO}_{2}$ da Terra, e um dos maiores sumidouros de emissões antropogênicas (Riebesell et al., 2010). Como resultado do aumento contínuo da queima de combustíveis fósseis pelo homem desde o início da revolução industrial, a quantidade de $\mathrm{CO}_{2}$ na atmosfera aumentou consideravelmente. Este gás é conhecido como um importante contribuinte para o efeito estufa. A fim de entender melhor os problemas futuros decorrentes das mudanças climáticas globais, derretimento de calotas de gelo e aumento do nível do mar, é essencial compreender o ciclo global do carbono (Haas et al., 2002).

As concentrações de $\mathrm{CO}_{2}$ na superfície do oceano e de $\mathrm{CO}_{2}$ atmosférico podem ser controladas pela combinação de processos físicos e biológicos, que promovem a circulação de parte do $\mathrm{CO}_{2}$ da superfície para 0 fundo dos oceanos. Estes processos podem ser descritos como "bomba física" e "bomba biológica" (FIG. 1), ambos eficazes na transferência de $\mathrm{CO}_{2}$ da atmosfera para o interior dos oceanos (Turner et al., 2009).

A "bomba biológica" é o principal mecanismo de remoção de $\mathrm{CO}_{2}$ da atmosfera para o interior do oceano e é governada pela fotossíntese. Através da bomba biológica cerca de 20 a $40 \%$ do carbono fixado pelo fitoplâncton é exportado para o oceano profundo pelo afundamento de material biogênico. A 
"bomba física" é dirigida pela inversão da circulação oceânica (Eppley \& Peterson, 1979; Huntley et al., 1991).

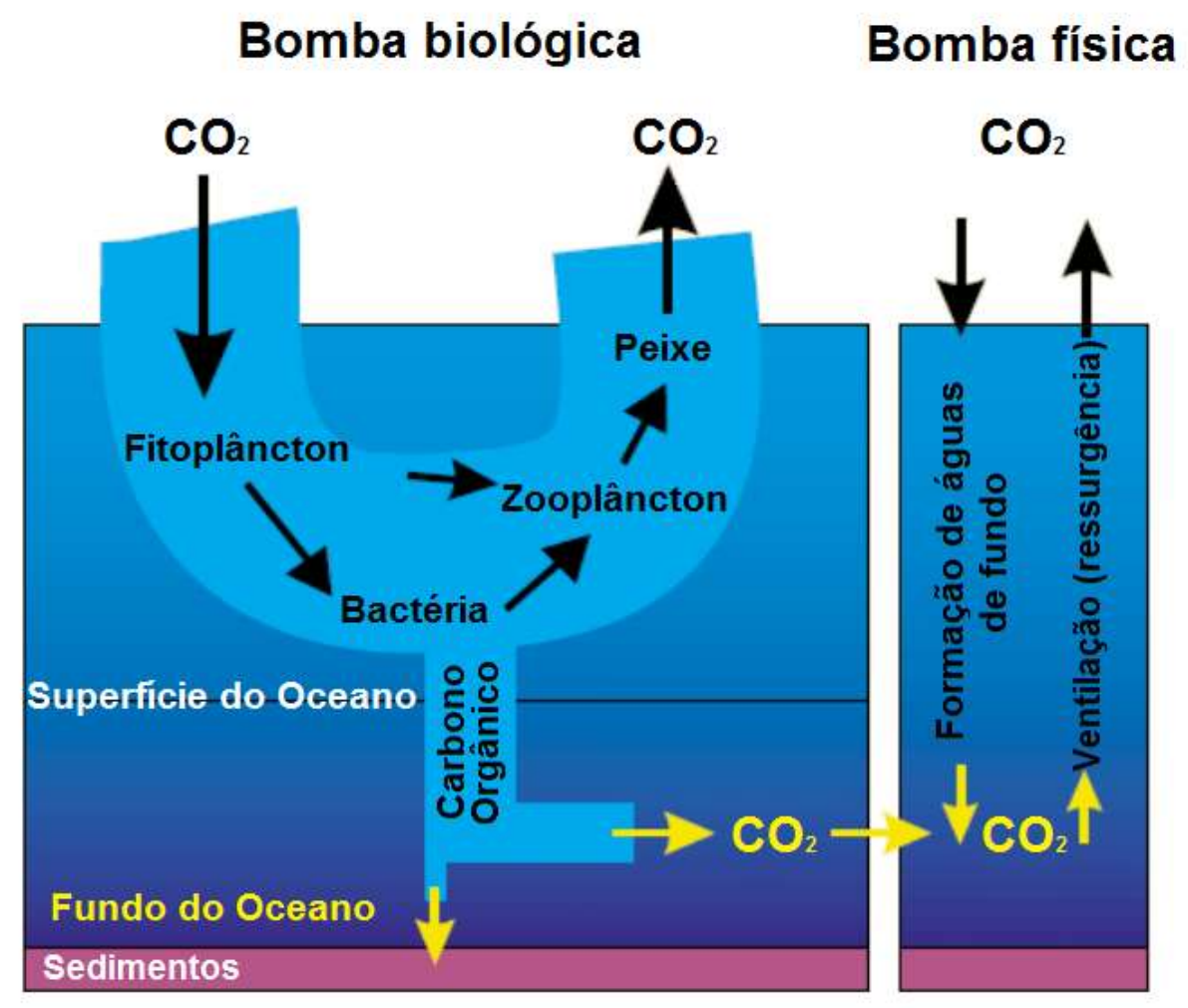

FIGURA 1 - Representação dos processos que controlam o ciclo do carbono, "bomba biológica" e "bomba física". Fonte: U.S. JGOFS, 2000.

\subsubsection{Circulação termohalina}

A bomba física é dirigida pela lenta inversão da circulação oceânica que transporta parte do $\mathrm{CO}_{2}$ para o fundo do oceano. $\mathrm{OCO}_{2}$ atmosférico que entra no oceano por trocas gasosas é dependente da velocidade dos ventos e das diferenças de pressão parcial entre a interface atmosfera-oceano. Além disso, a quantidade de $\mathrm{CO}_{2}$ absorvido pela água do mar superficial também é diretamente dependente da sua solubilidade, ou seja, a solubilidade aumenta à medida que as temperaturas decrescem, de modo que em águas frias $0 \mathrm{CO}_{2}$ é capturado com maior intensidade do que em águas quentes (JGOFS, 2000). 
As massas d' águas oceânicas mais frias e densas, particularmente no Atlântico Norte e Oceano Austral, absorvem mais $\mathrm{CO}_{2}$ atmosférico antes do seu afundamento para o interior do oceano. $\mathrm{O}$ afundamento de água é balanceado pela ressurgência (transporte vertical) em outras regiões. Quando as águas quentes ressurgidas atingem a superfície, aonde $\circ \mathrm{CO}_{2}$ torna-se menos solúvel, parte desse carbono é liberado de volta para a atmosfera, processo conhecido como desgaseificação (JGOFS, 2000). Regiões de resfriamento e aquecimento estão ligadas através da circulação oceânica, produzindo gradientes verticais e de transporte norte-sul de carbono dentro dos oceanos (IPCC, 2001).

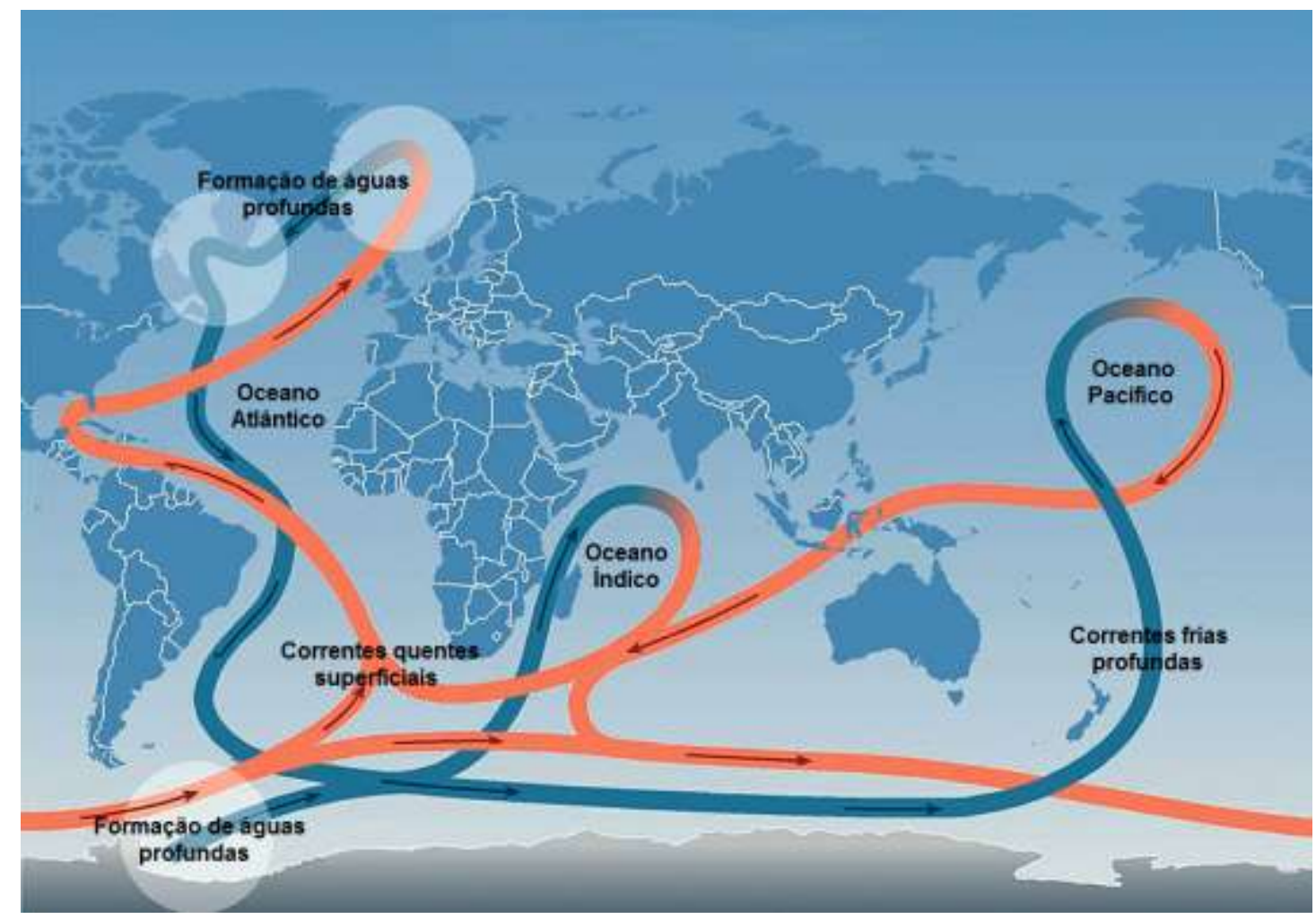

FIGURA 2 - Ciclo global da circulação termohalina. Em vermelho, águas superficiais quentes e de baixa salinidade. Em azul, águas profundas frias e bem oxigenadas. Fonte: modificado de Houghton et al., 2001.

A circulação termohalina (FIG. 2) (temperatura e salinidade controlada pela densidade) dos oceanos pode ser interpretada como uma corrente transportadora, que enfatiza as interconexões entre as águas dos oceanos do 
mundo. As águas superficiais salgadas e quentes que atingem altas latitudes do Atlântico Norte no inverno são resfriadas e afundam em grandes profundidades. Este processo é conhecido como "formação de águas profundas". A partir daí começa sua jornada em direção ao Sul, onde se junta às águas frias e profundas da Antártica. Parte dessas águas fluirá para o fundo dos oceanos nas bacias do Atlântico, Índico e Pacífico. Estas águas retornam ao Atlântico Norte como um fluxo de superfície, principalmente através de ressurgência nos Oceanos Pacífico e Índico. As águas profundas tornam-se enriquecidas com nutrientes essenciais e $\mathrm{CO}_{2}$ a partir da decomposição da matéria orgânica da água que sofre mineralização e sedimentação. Um ciclo completo da corrente transportadora leva cerca de 1.000 anos (JGOFS, 2000).

\subsubsection{Ciclo do carbono}

Fatores físicos tais como incidência de luz, temperatura e turbulência da água, podem influenciar os padrões de produtividade nas camadas superficiais do oceano. Entretanto, a capacidade de armazenamento de $\mathrm{CO}_{2}$ pelo oceano é fortemente afetada pela ocorrência de processos biológicos. Estes processos complexos ocorrem em escalas temporais que variam de poucas horas a alguns meses (Honjo et al., 2008; Riebesell et al., 2010).

A bomba biológica (FIG. 3) inicia-se na zona eufótica, no instante em que o fitoplâncton assimila $\circ \mathrm{CO}_{2}$ atmosférico e os nutrientes inorgânicos na sua estrutura através do processo de fotossíntese. A taxa em que este processo ocorre é denominada de produtividade primária (JGOFS, 2000, 2001). Então, o $\mathrm{CO}_{2}$ é convertido de carbono inorgânico $\left(\mathrm{CO}_{2}, \mathrm{CO}_{3}^{-2}, \mathrm{HCO}_{3}{ }^{-}\right)$a carbono orgânico através da fotossíntese, e a quantidade de carbono fixado é proporcional à quantidade de nutrientes disponíveis na região (Lalli \& Parsons, 1997; Turner et al., 2009). 


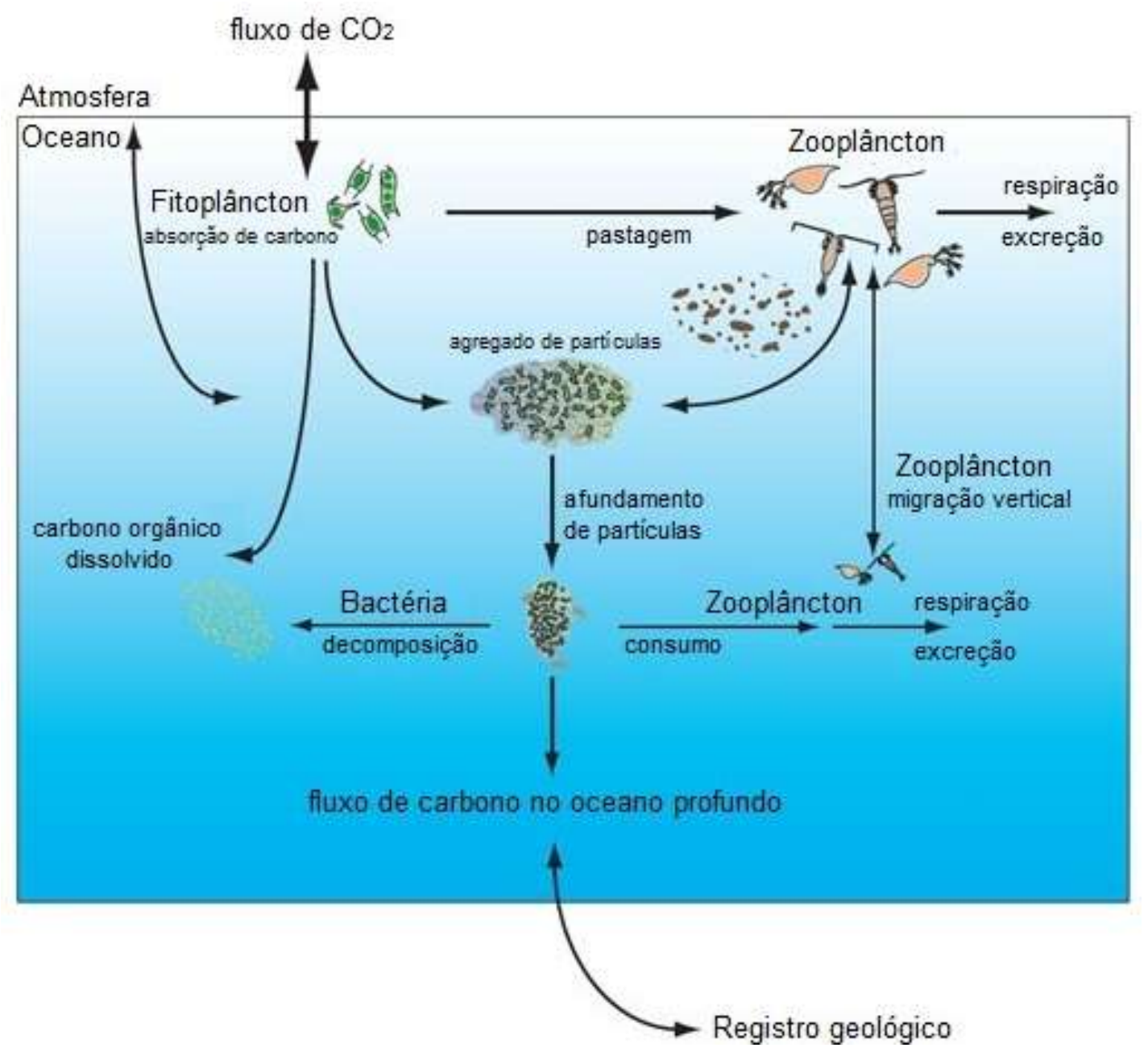

FIGURA 3 - Representação simplificada da bomba biológica. Fonte: modificado de U.S. JGOFS, 2001.

O fitoplâncton é pastejado pelo zooplâncton, o qual utiliza o carbono orgânico como fonte de energia, e parte desse carbono pode retornar a atmosfera pelo processo de remineralização ou respiração (nesse processo o carbono orgânico será convertido a inorgânico). A matéria orgânica produzida pelo zooplâncton (pelotas fecais e agregados de partículas) afunda rapidamente ao longo da coluna d'água sob a ação da gravidade e, será decomposta por bactérias, consumida por zooplâncton e peixes em águas profundas, ou remineralizada. No entanto, apenas uma pequena parte da matéria orgânica escapa do processo de remineralização e alcança o fundo do oceano, sendo estocada nos sedimentos por um longo período (Lalli \& Parsons, 1997; JGOFS, 2000, 2001; Haas et al., 2002; Turner et al., 2009). 
Quando esses organismos marinhos morrem formam conchas de carbonato de cálcio $\left(\mathrm{CaCO}_{3}\right)$ na forma cristalina de aragonita ou de calcita. Estas conchas de $\mathrm{CaCO}_{3}$ podem ser dissolvidas retornando novamente a carbono inorgânico ou afundam ao longo da coluna d'água, alcançando os sedimentos onde poderão ser estocados (Lalli \& Parsons, 1997; IPCC, 2001).

A eficiência da bomba biológica pode ser reforçada com a ressurgência de águas profundas que trazem nutrientes para águas mais superficiais, os quais são consumidos pelo fitoplâncton e transportados como matéria orgânica para o oceano profundo (Ducklow et al., 2001).

A disponibilidade de nutrientes tais como nitrogênio, fósforo e silício, geralmente, limita o crescimento do fitoplâncton. No entanto, em algumas áreas oceânicas, como no Oceano Pacífico Equatorial e em partes do Oceano Antártico, o fornecimento de nutrientes ocorre em excesso, indicando que outros fatores influenciam a produtividade primária. Estas regiões são caracterizadas por elevadas concentrações de nutrientes e baixas de clorofila, referidas como HNLC, evidenciando baixa atividade biológica (Lalli \& Parsons, 1997; JGOFS, 2000).

De acordo com diversos estudos, a baixa atividade biológica nas regiões HNLC pode estar associada, principalmente, à disponibilidade de ferro, incidência de luz e no controle da pastagem do zooplâncton (JGOFS, 2000).

A produtividade do oceano global é determinada em grande parte pela oferta de nutrientes a partir da ressurgência de águas profundas. Em regiões HNLC, o fornecimento de ferro é geralmente insuficiente, limitando a produtividade primária. Uma oferta adicional de ferro alcança a superfície do oceano, principalmente, através de poeira dos continentes trazida pelos ventos (Martin et al., 1990; IPCC, 2001; JGOFS, 2001).

A hipótese de limitação de ferro foi testada pela realização de experimentos in situ de fertilização em regiões HNLC. Alguns experimentos demonstraram claramente que a fertilização com ferro contribui para o aumento da biomassa fitoplanctônica e, também, evidencia um aumento do fluxo de 
partículas orgânicas que afundam nestas regiões (Martin et al., 1990; Buesseler et al.,2005; Parekh et al., 2006).

\subsection{Distribuição dos radionuclídeos naturais no oceano}

Os radionuclídeos das séries radiativas naturais do $U$ e do Th (FIG. 4) compreendem uma variedade de elementos com características e comportamentos geoquímicos distintos. Conhecendo-se as condicionantes físicas que afetam cada cenário, este sistema de isótopos fornece métodos de investigação do transporte destes radionuclídeos e outras espécies análogas através da interface continente-oceano. Os radionuclídeos partículo-reativos, por exemplo, são transportados e estão sujeitos ao fracionamento entre as fases dissolvida, coloidal e particulada.

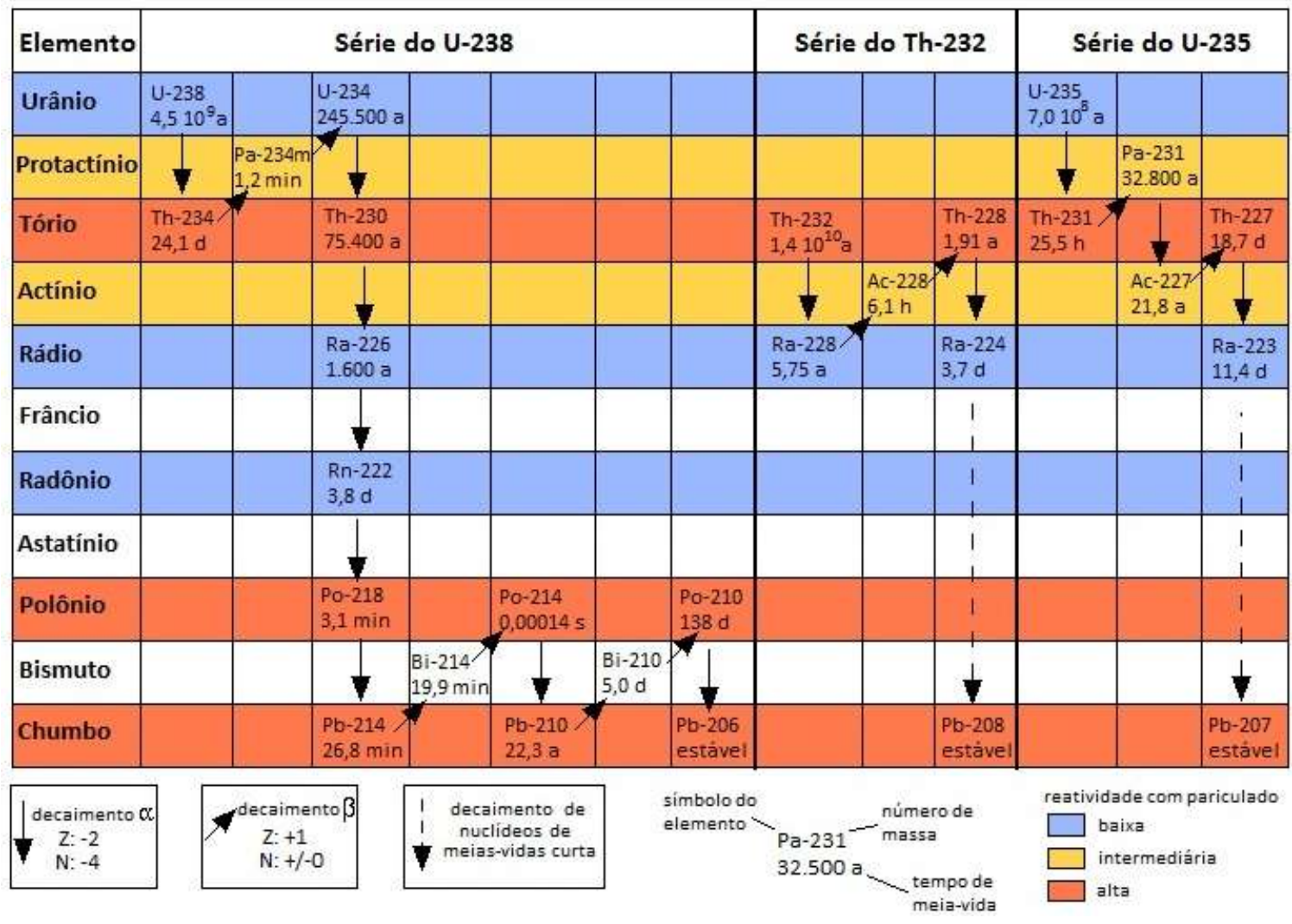

FIGURA 4 - Séries radioativas naturais do ${ }^{238} \mathrm{U},{ }^{232} \mathrm{Th}$ e ${ }^{235} \mathrm{U}$. Fonte: modificado de Rutgers van der Loeff, 2001. 
A natureza química variável dos radionuclídeos das séries do $U$ e do Th é evidente em suas distribuições no oceano. Tais radionuclídeos podem efetivamente servir como traçadores de partículas e coloides, assim como outros poluentes que se comportem de forma similar na coluna d'água e/ou nos sedimentos. Estes radionuclídeos apresentam uma vasta amplitude de meias-vidas, que podem ser utilizadas para se examinar processos que ocorrem em diversas escalas temporais.

A distribuição dos radionuclídeos no oceano (FIG. 5) é governada pelo seu fornecimento, decaimento radioativo, mistura de massas d'água e sua reatividade biogeoquímica.

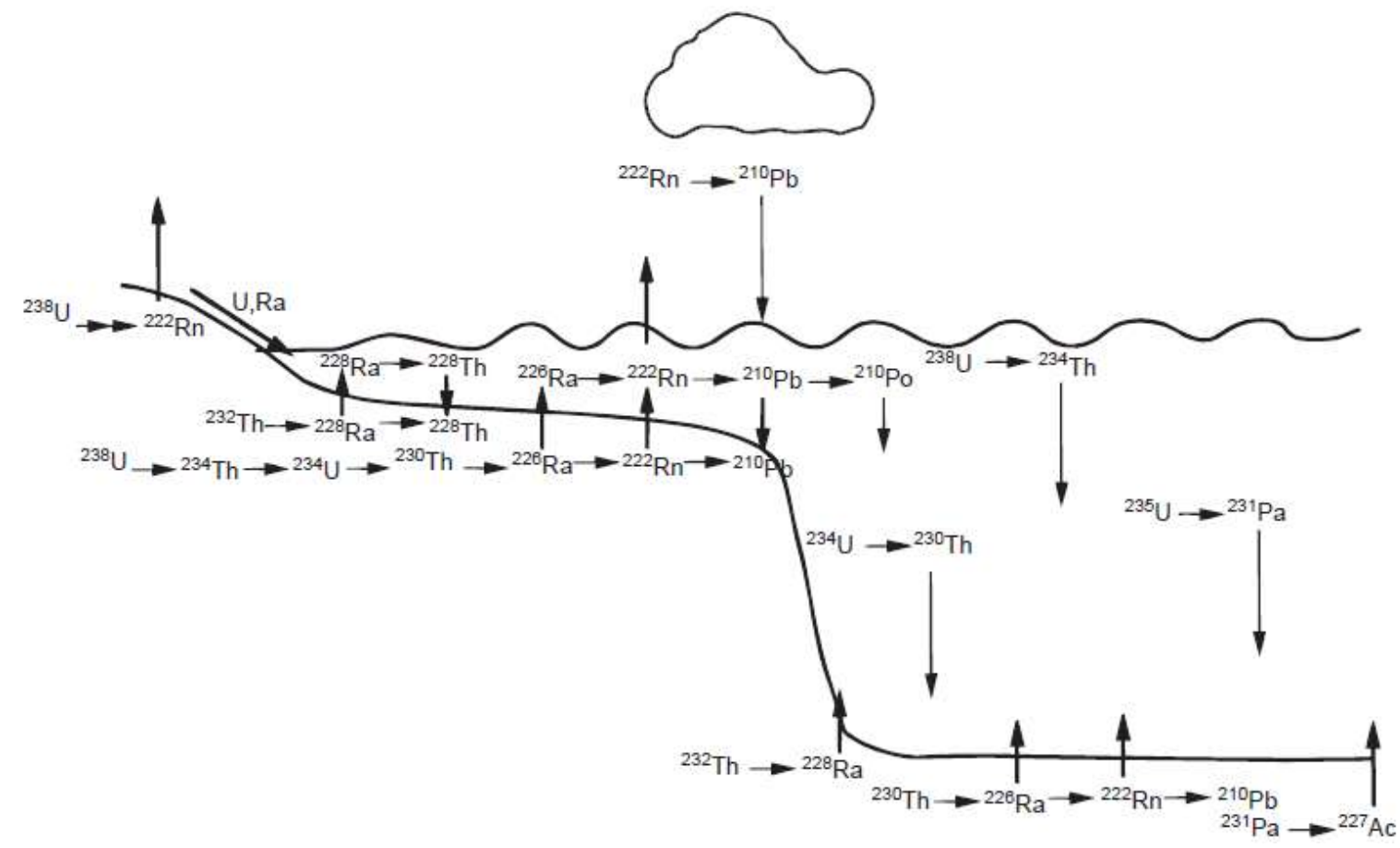

FIGURA 5 - Diagrama esquemático do decaimento radioativo (setas horizontais) e de processos de transporte no oceano e atmosfera que podem ser traçados utilizando-se radionuclídeos naturais (setas verticais) Fonte: Modificado de Ernst \& Morin (1980).

A circulação oceânica desempenha papel dominante na dispersão dos radionuclídeos solúveis, enquanto que a liberação e captação biológica, 
interações partículo-soluto e remoção química exercem um maior controle na distribuição de elementos partículo-reativos. Estudos sistemáticos desses radionuclídeos podem fornecer informações importantes sobre processos físicos e biogeoquímicos marinhos (Krishnaswami, 2001).

Como existe uma vasta deficiência de dados relacionados à aplicação de radioisótopos em estudos oceanográficos realizados no hemisfério Sul em comparação com os realizados no hemisfério Norte, este estudo tem como principal finalidade estabelecer um banco de dados brasileiro compilando concentrações de elementos-traço, nutrientes e radionuclídeos naturais no Oceano Austral.

\subsubsection{Radionuclídeos naturais partículo-reativos}

Os radionuclídeos naturais partículo-reativos utilizados como traçadores em pesquisas oceanográficas são produzidos no oceano e removidos pelo material particulado que afunda ao longo da coluna d'água, causando um desequilíbrio radioativo entre o elemento filho com seu respectivo pai. Este grau de desequilíbrio tem sido utilizado para se determinar taxas de exportação de material particulado no oceano (Buesseler et al., 2003).

\subsubsection{Tório}

O elemento tório (Th) foi descoberto pelo Jöns Jacobs Berzelius em 1828, pertence à série dos actinídeos, grupo 3 da Tabela Periódica, é considerado um metal natural radioativo e apresenta estado de oxidação +4 . Entre os radionuclídeos das séries radioativas naturais do $\mathrm{U}$ e Th, os isótopos de Th ( ${ }^{232} \mathrm{Th},{ }^{230} \mathrm{Th},{ }^{228} \mathrm{Th},{ }^{227} \mathrm{Th}$ e ${ }^{234} \mathrm{Th}$ ) são altamente partículo-reativos no ambiente marinho e por isso são os radionuclídeos mais amplamente utilizados como traçadores de processos oceânicos (Krishnaswami, 2001). 
O ${ }^{232} \mathrm{Th}(\mathrm{t} 1 / 2=14,05$ bilhões de anos) é um componente da crosta terrestre e está presente na fração litogênica do sedimento marinho. $O$ isótopo ${ }^{232}$ Th é o nuclídeo pai da série radioativa do Th. Como resultado da sua alta reatividade com o material particulado, ele é rapidamente removido da coluna d'água, porém, sua distribuição não é afetada pelo decaimento radioativo. Em oceano aberto as concentrações de ${ }^{232}$ Th são muito baixas, da ordem de $\mathrm{pg} \mathrm{L}^{-1}$, e nos sedimentos torna-se fonte de outros radioisótopos que podem ser mobilizados para a coluna d'água (Choppin \& Wong, 1998; Rutgers van der Loeff, 2001).

$\mathrm{O}^{230} \mathrm{Th}(\mathrm{t} 1 / 2=75.380$ anos) é fornecido à água do mar de forma quase que uniforme a partir do decaimento radioativo do ${ }^{234} \mathrm{U}$ dissolvido. Devido à sua característica altamente reativa, ele é rapidamente removido para os sedimentos através de interações com material particulado, apresentando um tempo de residência relativamente curto, da ordem de algumas décadas no fundo do oceano (Anderson et al., 1983; Rutgers van der Loeff, 2001).

$\mathrm{O}^{228} \mathrm{Th}\left(\mathrm{t}^{1} / 2=1,91\right.$ anos) é o produto de decaimento radioativo do ${ }^{228} \mathrm{Ra}$ e apresenta distribuição semelhante à do seu precursor, com concentrações elevadas próximo da interface continente-oceano e sedimento-água, decrescendo em função do aumento da distância da costa (Rutgers van der Loeff \& Geibert, 2008). É um traçador útil para estudo do fluxo de partículas numa escala de tempo sazonal ou interanual (Rutgers van der Loeff, 2001).

$\mathrm{O}^{227} \mathrm{Th}(\mathrm{t} 1 / 2=18,7$ dias $)$ é fornecido à água do mar pelo decaimento radioativo do ${ }^{227} \mathrm{Ac}$ e é considerado como um proxy do seu precursor, que é encontrado principalmente em águas profundas na interface com os sedimentos. Devido sua meia-vida curta, é pouco utilizado em estudos oceanográficos (Rutgers van der Loeff \& Geibert, 2008).

$\mathrm{O}^{234} \mathrm{Th}(\mathrm{t} 1 / 2=24,1$ dias) é um radionuclídeo altamente partículo-reativo produzido continuamente na água do mar pelo decaimento radioativo de seu precursor solúvel e de caráter conservativo com a salinidade, $0^{238} \mathrm{U}$. No oceano encontra-se em equilíbrio secular com seu pai, exceto em regiões de alta produtividade, onde ocorre maior remoção do ${ }^{234} \mathrm{Th}$ pelo material particulado e 
subsequente afundamento ao longo da coluna d'água. Isto ocasiona um déficit de ${ }^{234} \mathrm{Th}$ nas camadas superficiais do oceano quando comparado com a sua produção a partir do ${ }^{238} \mathrm{U}$, causando um desequilíbrio radioativo entre ${ }^{234} \mathrm{Th} /{ }^{238} \mathrm{U}$ nas águas de superfície (Moran et al., 2003). Este desequilíbrio é uma ferramenta importante para o estudo do fluxo de carbono orgânico particulado exportado no oceano (Benitez-Nelson \& Moore, 2006).

\subsubsection{Chumbo}

O elemento chumbo $(\mathrm{Pb})$ pertence à série dos metais de transição, grupo 14 da Tabela Periódica e é considerado um metal pesado natural. $\mathrm{O}{ }^{210} \mathrm{~Pb}$ ( $t 1 / 2=22,3$ anos) é fornecido para a água do mar pelo decaimento radioativo do ${ }^{222} \mathrm{Rn}$, filho imediato do ${ }^{226} \mathrm{Ra}$, e por uma pequena contribuição advinda da sua precipitação na atmosfera, produzido a partir do decaimento do ${ }^{222} \mathrm{Rn}$ emanado de rochas e solos terrestres (Livingston, 2004; Rutgers van der Loeff \& Geibert, 2008).

O isótopo de $\mathrm{Pb}$ radioativo, ${ }^{210} \mathrm{~Pb}$, é aplicado em estudos oceanográficos que utilizam o grau de desequilíbrio ${ }^{210} \mathrm{Po} /{ }^{210} \mathrm{~Pb}$ para estimar fluxos de partículas em uma escala de tempo de várias semanas, por ser um elemento de caráter partículo-reativo com tempo de residência de alguns anos no oceano aberto (Friedrich \& Rutgers Van der Loeff, 2002).

\subsubsection{Polônio}

O elemento polônio $(\mathrm{Po})$ foi descoberto pelo casal Pierre e Marie Curie em 1898, pertence à série dos semimetais, grupo 16 da Tabela Periódica. É considerado um metal volátil e todos os isótopos desse elemento desintegram-se por emissão de partículas $\alpha . \mathrm{O}^{210} \mathrm{Po}\left(\mathrm{t}^{1} / 2=138\right.$ dias $)$ é fornecido para o mar quase que exclusivamente pela sua produção do decaimento radioativo de ${ }^{210} \mathrm{~Pb}$ (Krishnaswami, 2001). 
O ${ }^{210} \mathrm{Po}$ é um radionuclídeo fortemente partículo-reativo. Desta maneira, em águas superficiais ele se encontra relativamente deficiente em relação ao seu pai, o ${ }^{210} \mathrm{~Pb}$, porém em regiões de alta produtividade essa deficiência é mais pronunciada. Em águas profundas geralmente é possível se observar os radionuclídeos ${ }^{210} \mathrm{Po} /{ }^{210} \mathrm{~Pb}$ em equilíbrio, exceto em regiões de atividade hidrotermal (Krishnaswami, 2001; Rutgers van der Loeff \& Geibert, 2008).

O ${ }^{210} \mathrm{Po}$ pode ser utilizado como traçador do fluxo de partículas que afundam sazonalmente no oceano, como resultado da sua forte reatividade com material particulado (Rutgers van der Loeff, 2001).

\subsubsection{Radionuclídeos naturais solúveis}

Os radionuclídeos naturais solúveis na água do mar são utilizados principalmente para se quantificar taxas de difusão, advecção e mistura de massas d'água no oceano.

\subsubsection{Urânio}

O elemento urânio (U) foi descoberto por Marin Klaproth em 1789, pertence à série dos actinídeos, grupo 3 da Tabela Periódica. É considerado um metal natural radioativo e apresenta estado de oxidação variando de +2 à +6 . Os isótopos desse elemento desintegram-se preferencialmente por emissão de partículas $\alpha$. Os isótopos ${ }^{238} \mathrm{U}$ e ${ }^{235} \mathrm{U}$ são os nuclídeos precursores das séries radioativas do Urânio e Actínio, respectivamente.

Os isótopos de interesse em estudos oceanográficos são ${ }^{238} \mathrm{U},{ }^{235} \mathrm{U}$ e ${ }^{234} \mathrm{U}$. Os isótopos de urânio formam íons complexos em condições oxidantes, principalmente na forma de carbonato de uranila $\left(\mathrm{UO}_{2}\left[\mathrm{CO}_{3}\right]_{2}^{-2}, \mathrm{UO}_{2}\left[\mathrm{CO}_{3}\right]_{3}^{-4}\right)$ e, desta forma, encontram-se dissolvidos na água do mar. Devido a seu comportamento conservativo, a concentração de ${ }^{238} \mathrm{U}$ na água do mar apresenta 
uma relação linear com a salinidade, podendo-se estimar prontamente sua concentração a partir de dados de salinidade (Chen et al., 1986). O estudo da distribuição de $U$ no ambiente marinho é essencial para uma melhor compreensão do desequilíbrio radioativo entre ${ }^{238} \mathrm{U} /{ }^{234} \mathrm{Th},{ }^{234} \mathrm{U} /{ }^{230} \mathrm{Th},{ }^{238} \mathrm{U} /{ }^{234} \mathrm{U}$ e ${ }^{235} \mathrm{U} /{ }^{231} \mathrm{~Pa}$ (Krishnaswami, 2001).

\subsubsection{Rádio}

O elemento rádio $(\mathrm{Ra})$ foi descoberto pelo casal Pierre e Marie Curie em 1898, pertence à série dos metais alcalino-terrosos, grupo 2 da Tabela Periódica. É considerado um metal natural radioativo e apresenta estado de oxidação +2 . Todos os isótopos desse elemento desintegram-se por emissão de partículas $\alpha$, exceto o isótopo ${ }^{228} \mathrm{Ra}$, que se desintegra por emissão de partículas $\beta$.

Os quatro isótopos naturais de $\mathrm{Ra}\left({ }^{223} \mathrm{Ra},{ }^{224} \mathrm{Ra},{ }^{226} \mathrm{Ra}\right.$ e $\left.{ }^{228} \mathrm{Ra}\right)$ encontram diversas aplicações em estudos oceanográficos. Como um elemento alcalino-terroso, o Ra tem comportamento similar ao do $\mathrm{Ca}$ e ao do $\mathrm{Ba}$ (Rutgers van der Loeff \& Geibert, 2008). Os isótopos de Ra são introduzidos nas águas de fundo na interface com os sedimentos e se encontram dissolvidos na água do mar, sendo utilizados como traçadores de processos de mistura de massas d'água no ambiente marinho e costeiro (Smith et al., 2003; Oliveira et al., 2006; Moore e Oliveira, 2008).

$\mathrm{O}{ }^{226} \mathrm{Ra}(\mathrm{t} 1 / 2=1.600$ anos) é o isótopo de Ra com o tempo de meia-vida mais longo, sendo comparável ao tempo de mistura do oceano profundo. $\mathrm{O}{ }^{226} \mathrm{Ra}$ é produzido pelo decaimento radioativo do ${ }^{230} \mathrm{Th}$ presente nos sedimentos e, por sua vez, o Ra é liberado a partir de sedimentos marinhos para águas intersticiais que se difundem para as águas do mar sobrejacentes podendo ser mobilizado para a coluna d'água, principalmente, através do processo de ressurgência (Rutgers van der Loeff \& Geibert, 2008). As concentrações de atividade de ${ }^{226} \mathrm{Ra}$ são geralmente baixas em águas superficiais e tendem a aumentar com a profundidade. As águas subterrâneas apresentam atividades aumentadas de 
${ }^{226} \mathrm{Ra}$, o qual pode ser utilizado para se rastrear possíveis sítios de descarga de águas subterrâneas para o oceano (Krishnaswami, 2001; Rutgers van der Loeff, 2001; Oliveira et al., 2006; Moore \& Oliveira, 2008).

$\mathrm{O}{ }^{228} \mathrm{Ra}\left(\mathrm{t}^{1} 1 / 2=5,75\right.$ anos) é fornecido para o oceano pelo decaimento radioativo do ${ }^{232} \mathrm{Th}$, o qual se encontra presente em todos os sedimentos terrígenos, independentemente da profundidade. Em função da sua meia-vida relativamente curta e da sua produção a partir do ${ }^{232} \mathrm{Th}$, atividades elevadas de ${ }^{228} \mathrm{Ra}$ são observadas geralmente próximas aos sedimentos marinhos e no talude continental. Portanto, a sua concentração decresce com o aumento da distância da região costeira. $\mathrm{O}^{228} \mathrm{Ra}$ tem sido utilizado como traçador de águas que tenham tido contato com o continente e para derivar coeficientes de difusão horizontal turbulenta (Krishnaswami, 2001; Rutgers van der Loeff, 2001; Rutgers van der Loeff \& Geibert, 2008).

$\mathrm{O}{ }^{223} \mathrm{Ra}(\mathrm{t} 1 / 2=11,4$ dias $)$ e o ${ }^{224} \mathrm{Ra}(\mathrm{t} 1 / 2=3,66$ dias) são produzidos pelo decaimento radioativo do ${ }^{227} \mathrm{Th}$ e do ${ }^{228} \mathrm{Th}$, respectivamente. Os isótopos de Ra de meias-vidas curtas também são introduzidos no oceano principalmente por processos de difusão e por meio de descarga de águas próximas da interface sedimento-água. As distribuições desses isótopos, no entanto, estão restritas às regiões próximas do continente, por causa das suas meias-vidas curtas (Oliveira et al., 2006; Moore \& Oliveira, 2008; Rutgers van der Loeff \& Geibert, 2008). O ${ }^{223} \mathrm{Ra}$ e $\mathrm{o}{ }^{224} \mathrm{Ra}$ são úteis para o estudo de processos de mistura que ocorrem em escalas de tempo variando de alguns dias a algumas semanas, o que limita a sua utilidade para estudos costeiros (Krishnaswami, 2001).

\subsection{Desequilíbrio isotópico de ${ }^{234} \mathrm{Th} /{ }^{238} \mathrm{U},{ }^{210} \mathrm{Po} /{ }^{210} \mathrm{~Pb},{ }^{228} \mathrm{Ra} /{ }^{226} \mathrm{Ra}$ no oceano e suas aplicações}

Nas três séries radioativas naturais $\left({ }^{238} \mathrm{U},{ }^{232} \mathrm{Th}\right.$ e $\left.{ }^{235} \mathrm{U}\right)$, os isótopos relativamente solúveis como $\mathrm{U}, \mathrm{Ra}$ e $\mathrm{Rn}$ decaem e formam isótopos partículo-reativos como Th, $\mathrm{Pa}, \mathrm{Po}$ e $\mathrm{Pb}$ resultando em uma distribuição diferente para cada radionuclídeo ao longo da coluna d'água. 
Em um sistema fechado, após um intervalo de tempo suficiente, os radionuclídeos de uma série de decaimento atingem o equilíbrio, o que significa teoricamente que a taxa de produção de um nuclídeo está em balanço com sua respectiva taxa de decaimento radioativo. Contudo, em sistemas abertos como o ambiente marinho, processos químicos, físicos e biológicos dinâmicos causam a separação e a especiação dos radionuclídeos que apresentem comportamentos geoquímicos distintos. Uma vez ocorrida a separação, os radionuclídeos migram para diferentes compartimentos do sistema com os quais tenham maiores afinidades, alguns sendo incorporados às fases sólidas, enquanto outros permanecem em solução. Desta forma, o grau de desequilíbrio resultante da separação entre o radionuclídeo pai e radionuclídeo filho pode ser utilizado para estudar diversos processos que ocorrem no meio ambiente (Rutgers van der Loeff, 2001).

O conhecimento dos processos de adsorção de substâncias reativas por partículas e sua posterior remoção na coluna d'água por sedimentação é a base para grande parte das aplicações de radionuclídeos como traçadores em estudos oceanográficos. A aplicação mais utilizada para se quantificar taxas de remoção de partículas é o desequilíbrio radioativo, onde um radionuclídeo filho reativo se encontra deficiente na água do mar em relação à concentração que teria em equilíbrio com seu pai radioativo (Livingston, 2004).

Um estudo detalhado da distribuição dos isótopos de $\mathrm{Ra}$ de meias-vidas longas no Oceano Austral foi realizado por Hanfland (2002). No setor Atlântico Sul da Frente Polar, o autor relatou concentrações de atividade de ${ }^{226} \mathrm{Ra}$ elevadas em Águas Antárticas Superficiais e Giros de Weddell (150 dpm m ${ }^{-3}$ ) devido ao enriquecimento proveniente da extensa região de plataforma e de fenômenos de ressurgência. As concentrações de atividade de ${ }^{228} \mathrm{Ra}$ foram elevadas $\left(>20 \mathrm{dpm} \mathrm{m}^{-3}\right)$ apenas em regiões costeiras e de plataforma, com atividades muito baixas na Corrente Circumpolar Antártica (CCA) $\left(\leq 0,2 \mathrm{dpm} \mathrm{m}^{-3}\right)$.

No estudo realizado por Vieira (2011) foram observadas no Estreito de Bransfield concentrações de ${ }^{226}$ Ra variando de 19,1 a 43,3 dpm $100 \mathrm{~L}^{-1}$, enquanto 
que $0{ }^{228} \mathrm{Ra}$ apresentou concentrações relativamente elevadas em estações próximas das ilhas da Península Antártica.

Costa (2012) analisou isótopos de $\mathrm{Ra}$ de meias-vidas longas em amostras de águas superficiais no Estreito de Bransfield durante o início e final do verão Austral de 2011. Em ambos os períodos, foram observadas concentrações elevadas de ${ }^{228} \mathrm{Ra}$ em regiões relativamente rasas e próximas de ilhas devido a influência de degelo continental e dessorção de sedimentos terrígenos. No caso do ${ }^{226} \mathrm{Ra}$ as maiores concentrações foram determinadas no final do verão Austral, o que sugere maior aporte de águas provenientes de degelo, ressurgência e emanações vulcânicas.

O desequilíbrio ${ }^{234} \mathrm{Th} /{ }^{238} \mathrm{U}$ na zona eufótica do oceano foi observado pela primeira vez por Bhat et al. (1969), que atribuiu o fenômeno ao afundamento do material particulado ao longo da coluna d'água. A observação foi confirmada por medições subsequentes realizadas por Matsumoto (1975). Posteriormente, Coale \& Bruland (1985) realizaram diversas determinações de ${ }^{234} T h$ nas formas dissolvida e particulada e demonstraram que a taxa de adsorção de Th e a sua respectiva taxa de remoção no material particulado estavam correlacionadas com a produtividade biológica (Livingston, 2004).

Assim, uma razão de atividades ${ }^{234} \mathrm{Th} /{ }^{238} \mathrm{U}$ menor que 1 no oceano indica desequilíbrio do radionuclídeo filho em relação ao seu precursor, ocasionada por maior remoção e consequentemente exportação de partículas ao longo da coluna d'água (Bacon \& Anderson, 1982; Kaufman et al., 1981; Santschi et al., 1979; Tsunogai et al.,1986). Quando os valores de razão de atividade ${ }^{234} \mathrm{Th} /{ }^{238} \mathrm{U}$ são maiores que 1 , indicam zonas de acumulo de material particulado ou processos de remineralização (Waples et al., 2006). Razões de atividade ${ }^{234} \mathrm{Th} /{ }^{238} \mathrm{U}$ próximas a 1 evidenciam equilíbrio entre os radionuclídeos, ou seja, situação onde a produção de ${ }^{234} \mathrm{Th}$ a partir do ${ }^{238} \mathrm{U}$ está balanceada pela remoção e decaimento de ${ }^{234}$ Th. Normalmente, em águas profundas, a atividade total de ${ }^{234}$ Th estará em equilíbrio secular com a de ${ }^{238} \cup$ (Coale \& Bruland, 1985, 1987).

Em um estudo realizado no Mar do Mediterrâneo por Masqué et al. (2002b), as razões de atividade ${ }^{234} \mathrm{Th} /{ }^{238} \mathrm{U}$ em águas superficiais foram menores 
que 1 , variando de 0,39 a 0,86 , e o equilíbrio foi alcançado em profundidades entre 100 e $200 \mathrm{~m}$. Em alguns casos, valores da razão de atividade próximos a 1 foram observados imediatamente abaixo da região de desequilíbrio superficial, sugerindo a ocorrência de processos de remineralização no local.

No estudo realizado por Vieira (2011) ao longo do Estreito de Bransfield, foram observadas em algumas estações razões de atividade ${ }^{234} \mathrm{Th}$ total//238 $\mathrm{U}$ maiores do que 1 em águas de superfície. $O$ autor sugere que aumentos não conservativos das atividades de ${ }^{234} \mathrm{Th}$ total em relação às de ${ }^{238} \mathrm{U}$ dissolvido podem ser representativos de processos de ressuspensão ou do aporte de algas associadas ao degelo. Na literatura, existem relatos confirmando que valores da razão ${ }^{234} \mathrm{Th}$ total $/{ }^{238} \mathrm{U}$ maiores do que $1 \mathrm{em}$ águas superficiais, acima da termoclina, foram observadas no Estreito de Bransfield e estavam relacionadas a presença de algas associadas ao degelo (Rodriguez y Baena et al., 2006).

Desde que foi observado pela primeira vez (Shannon et al., 1970), o grau de desequilíbrio de outro par de radionuclídeos naturais com comportamento partículo-reativo, ${ }^{210} \mathrm{Po} /{ }^{210} \mathrm{~Pb}$, foi utilizado em diversos estudos no oceano, como a determinação de tempos de residência de aerossóis na atmosfera, remoção e afundamento de partículas ao longo da coluna d'água (Shimmield et al., 1995) e geocronologia sedimentar. Um trabalho realizado por Friedrich \& Rutgers van der Loeff (2002) utilizou ambos os desequilíbrios entre ${ }^{234} \mathrm{Th} /{ }^{238} \mathrm{U}$ e entre ${ }^{210} \mathrm{Po} /{ }^{210} \mathrm{~Pb}$ e demonstrou o potencial da combinação de traçadores diferentes, com propriedades químicas distintas. Neste estudo, os autores relataram que o ${ }^{210} \mathrm{Po}$ na CCA estava preferencialmente associado com partículas orgânicas, mas que o ${ }^{210} \mathrm{~Pb}$ e ${ }^{234} \mathrm{Th}$ eram menos seletivamente distribuídos em partículas orgânicas e silicosas (Livingston, 2004).

$\mathrm{O}{ }^{210} \mathrm{Po}$ é um radionuclídeo que pode ser absorvido pelos organismos marinhos, especialmente algas, enquanto ${ }^{210} \mathrm{~Pb}$ é adsorvido em partículas. Este comportamento leva a uma remoção preferencial de ${ }^{210} \mathrm{Po}$ em águas superficiais, que consequentemente, afunda em partículas como pelotas fecais (Masqué et al., 2002b). Devido à alta reatividade do ${ }^{210} \mathrm{Po}$, a razão de atividade ${ }^{210} \mathrm{Po} /{ }^{210} \mathrm{~Pb}$ na zona eufótica varia de 1 a 2 e frequentemente excede o valor do equilíbrio. Em 
águas profundas, $0{ }^{210} \mathrm{Po}$ e $0{ }^{210} \mathrm{~Pb}$ estão em equilíbrio, exceto em áreas de atividade hidrotermal, onde os óxidos de Fe e Mn causam remoção preferencial de ${ }^{210} \mathrm{Po}$, o que resulta em uma razão de atividade ${ }^{210} \mathrm{Po} /{ }^{210} \mathrm{~Pb}<1$ (Krishnaswami, 2001). 


\section{OBJETIVO}

Estudar a distribuição superficial de radionuclídeos naturais solúveis e partículo-reativos no Estreito de Bransfield durante duas expedições Antárticas ocorridas em 2011 (OPERANTAR XXIX e XXX), com a finalidade de aplicá-los como traçadores de processos costeiros e oceânicos regionais, uma vez que existem dados escassos na literatura destas distribuições no Hemisfério Sul e suas aplicações potenciais. 


\section{3. ÁREA DE ESTUDO}

A Península Antártica é a extremidade mais ao norte da Antártica, e entre a Península Antártica e o arquipélago das Ilhas Shetland do Sul encontra-se a área de estudo, o Estreito de Bransfield (EB), caracterizado como um corpo de água semi-fechado com aproximadamente $50.000 \mathrm{~km}^{2}$ de extensão. Gràcia et al. (1997) descreveram o EB como uma bacia extensional, vulcânica, sismicamente ativa (Yi et al. 2005). O EB (FIG. 6) estende-se da llha Clarence para o sudoeste por cerca de $460 \mathrm{~km}$ até a llha Low, é delimitado ao noroeste pelo arquipélago das Ilhas Shetland do Sul, ao sudeste pela Península Antártica, e ao sudoeste por pequenas ilhas e Estreito de Gerlache (Gordon \& Nowlin Jr; 1978, Grelowski \& Tokarczyk, 1985; Klinkhammer et al., 1996; Zhou et al., 2006; Morozov, 2007).

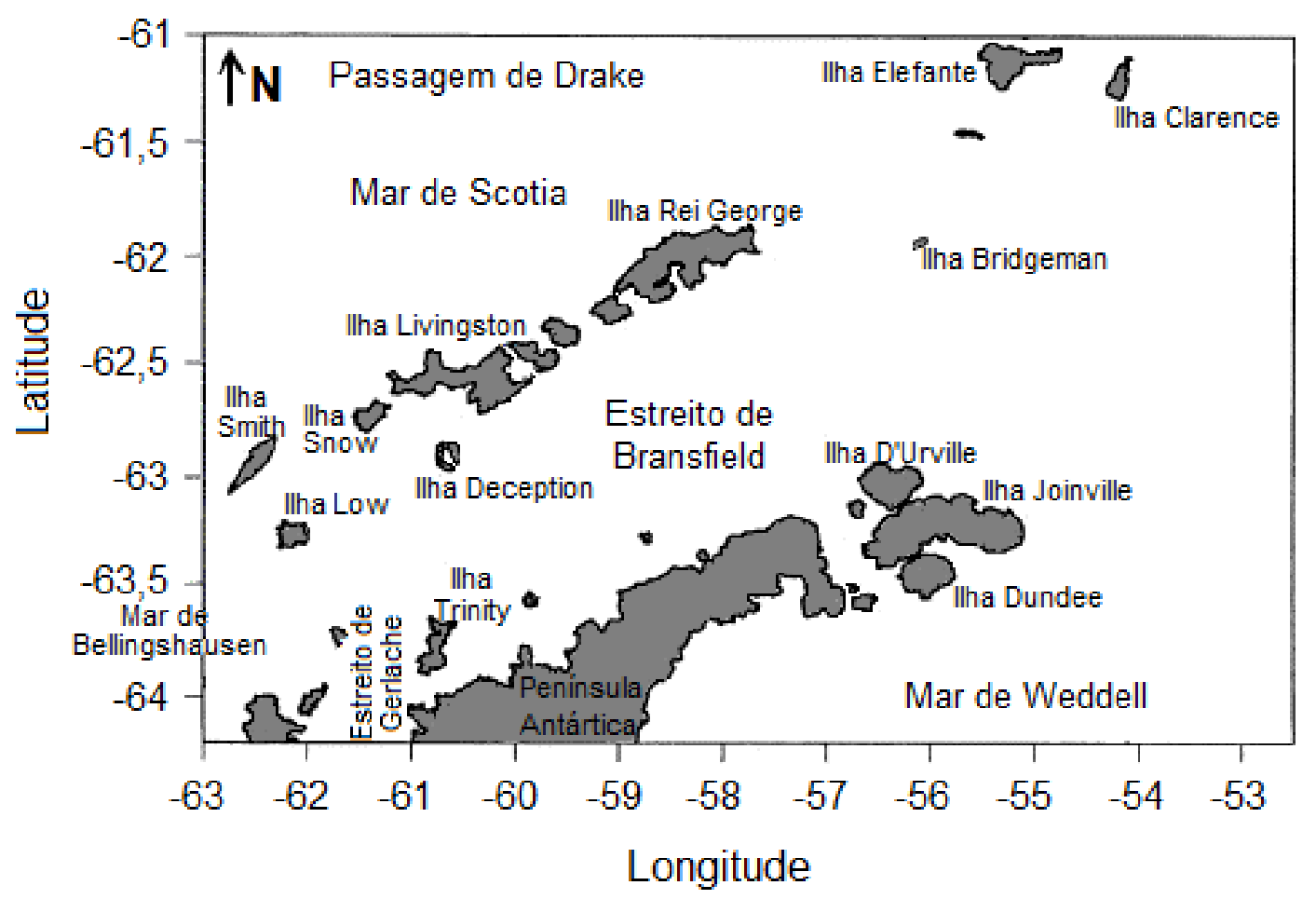

FIGURA 6 - Mapa de localização da área de estudo, o Estreito de Bransfield. Fonte modificado de López et al.,1999. 
O EB é influenciado por águas que fluem dos Mares de Bellingshausen e Weddell. As águas do Mar de Bellingshausen penetram no Estreito entre as Ilhas Low, Smith e Snow. A porção sudeste do EB é influenciada por águas do Mar de Weddell, que entram sobre a larga plataforma continental próxima das Ilhas d'Urville e Joinville. As águas do Mar de Weddell apresentam grande variabilidade na sua extensão ao longo do EB. Muitas vezes, essas águas fluem ao longo da costa da Península Antártica até a llha Trinity, onde, aparentemente, se misturam com as águas do Mar de Bellingshausen, que penetram no EB através do Estreito de Gerlache (Gordon \& Nowlin Jr, 1978; Grelowski \& Tokarczyk, 1985).

O EB é dividido em três sub-bacias, as quais estão interligadas através de uma plataforma com profundidade ao redor de $1.000 \mathrm{~m}$ (FIG. 7). As sub-bacias são denominadas como bacia oriental, central e ocidental (Gordon \& Nowlin Jr, 1978; Klinkhammer et al., 1996; López et al., 1999; Garcia et al., 2002; Yi et al., 2005; Sangrà et al., 2011), a elevação da Ilha Bridgeman separa a sub-bacia oriental da central e a elevação da llha Deception separa a sub-bacia central da ocidental.

A sub-bacia ocidental é mais irregular e mais rasa com profundidade máxima de $1.200 \mathrm{~m}$, cercada por plataformas estreitas de 20 a $50 \mathrm{~km}$ de largura (Canals et al., 2000). A sub-bacia central é mais regular com uma margem continental relativamente grande de cerca de $100 \mathrm{~km}$; entretanto, na margem das Ilhas Shetland do Sul há uma plataforma estreita $<20 \mathrm{~km}$ e um talude íngreme (Prieto et al., 1997), que apresenta profundidade máxima de $1.950 \mathrm{~m}$. A sub-bacia oriental é a mais profunda, com cerca de $2.500 \mathrm{~m}$ de profundidade, e apresenta margens continentais mais amplas variando de 50 a $125 \mathrm{~km}$ com plataformas de 40 a 80 km de largura (Gràcia et al., 1997; Canals et al., 2000; Yi et al., 2005).

A sub-bacia ocidental está conectada ao Mar de Bellingshausen através da passagem oeste das Ilhas Shetland do Sul e do Estreito de Gerlache, e ao norte está conectada a Passagem de Drake através do Estreito de Boyd. 


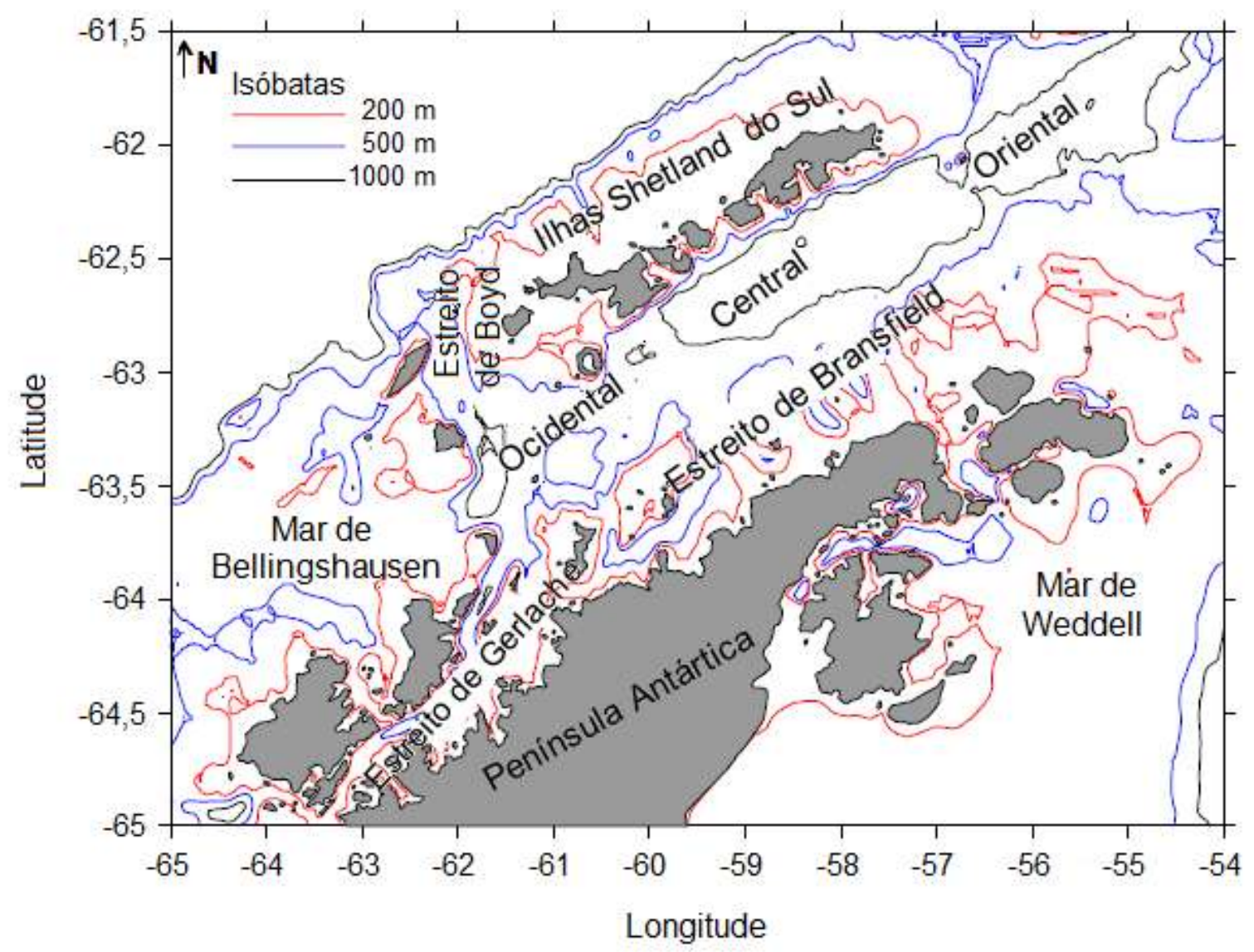

FIGURA 7 - Mapa de localização dos Mares Weddell e Bellingshausen e das sub-bacias oriental, central e ocidental do Estreito de Bransfield. Fonte modificado de Sangrà et al., 2011.

A sub-bacia oriental possui comunicação direta com os Mares de Weddell e Scotia. Do ponto de vista hidrográfico, o EB pode ser definido como uma zona de transição entre os Mares de Weddell e Bellingshausen (Masqué et al., 2002).

Tokarczyk (1987) observou, em uma análise cuidadosa, que as águas que fluem no EB mudam gradualmente suas características ao longo do seu percurso. Dessa maneira, Tokarczyk (1987) identificou as águas relativamente quentes e menos salinas como águas típicas do Mar de Bellingshausen e águas relativamente mais frias e mais salinas como águas típicas do Mar de Weddell, as quais foram renomeadas por Tokarczyk (1987) e García et al. (1994) como Água 
Zonal Transicional influenciada pelo Mar de Bellingshausen (TBW) e Água Zonal Transicional influenciada pelo Mar de Weddell (TWW).

A circulação superficial no EB (FIG. 8) consiste de uma entrada a oeste e pelo Estreito de Gerlache de águas relativamente quentes e menos salinas provenientes do Mar de Bellingshausen, e uma entrada a leste próximo a llha Joinville de águas mais frias e mais salinas provenientes do Mar de Weddell. As águas quentes e menos salinas (TBW) fluem a nordeste ao longo da metade norte do EB, enquanto que as águas mais frias e mais salinas (TWW) fluem a sudoeste ao longo da metade sul do EB (Grelowski et al., 1986; Hoffman et al., 1996; López et al. 1999; Garcia et al., 2002; Zhou et al., 2006).

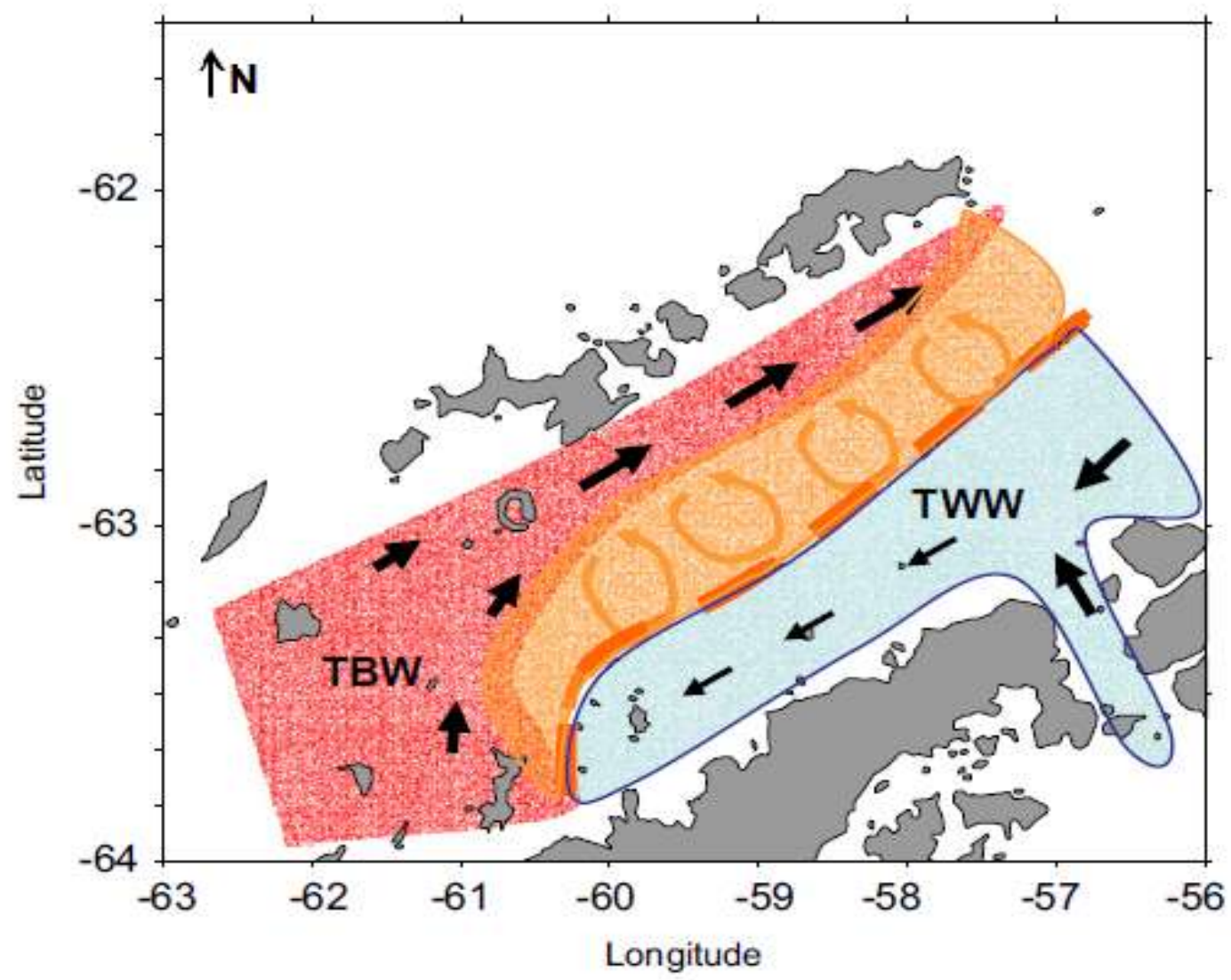

FIGURA 8 - Circulação superficial ao longo do Estreito de Bransfield com a predominância de Água Zonal Transicional influenciada pelo Mar de Belligshausen (TBW) e Água Zonal Transicional influenciada pelo Mar de Weddell (TWW). Fonte: modificado de Sangrà et al., 2011. 
A circulação profunda no EB está relacionada com a entrada de águas de plataforma densas do Mar de Weddell em torno da ponta nordeste da llha Joinville, que então afunda sobre a plataforma e desce o talude para a sub-bacia ocidental (Whitworth et al., 1994; López et al., 1999).

As águas profundas do EB são diferentes das águas adjacentes ao Estreito. Desta forma, concluiu-se que as águas profundas do EB são essencialmente formadas dentro do Estreito pela alteração termohalina das águas de inverno próximas à plataforma continental da Península Antártica (Gordon \& Nowlin Jr, 1978; Klinkhammer et al., 1996).

Os ventos predominantes na área estudada tem direção NNW, formando uma corrente que flui do sul ao longo da costa oeste da Península Antártica (Hoffman et al., 1996). Juntamente com o fluxo em direção ao norte da Corrente Circumpolar Antártica, a circulação resultante ocorre predominantemente no sentido horário no EB (Dinniman \& Klinck, 2004; Ducklow et al., 2007).

De maneira geral, o EB permanece livre de gelo durante os meses de dezembro a abril. O processo de congelamento se intensifica nos meses de junho e julho, deixando o Estreito totalmente coberto de gelo por um período de quatro meses, e só em meados de outubro inicia-se o processo de degelo, o qual se intensifica nos meses de dezembro e janeiro (Stammerjohn \& Smith, 1996).

Atividades hidrotermais foram observadas nas sub-bacias ocidental ao redor na llha Deception, e central próxima a llha Bridgeman. A atividade hidrotermal pode influenciar o fornecimento de nutrientes e elevação da temperatura de águas superficiais contribuindo para o aumento da produtividade primária da região (Klinkhammer et al., 1996).

Sarmiento \& Toggweiler (1984) sugeriram que tanto os ciclos biogeoquímicos como os padrões de circulação do Oceano Austral desempenham importante papel no controle dos níveis de $\mathrm{CO}_{2}$ da atmosfera. Diversos estudos realizados sugerem que o Oceano Austral atua como sumidouro de $\mathrm{CO}_{2}$ atmosférico. A margem continental da Antártica é considerada uma das áreas 
mais sensíveis às mudanças climáticas, e os sedimentos de fundo, portanto, são considerados registros importantes na investigação da evolução climática da região. O EB, é caracterizado pela sua elevada produtividade primária (Huntley et al., 1991, Álvarez et al., 2002), apresentando então um grande potencial como sumidouro de $\mathrm{CO}_{2}$ atmosférico (Anadón \& Estrada, 2002). 


\section{MATERIAIS E MÉTODOS}

\subsection{Amostragem}

Para os propósitos deste trabalho, foram realizados 2 cruzeiros oceanográficos durante o Verão Austral de 2011 a bordo do Navio de Apoio Oceanográfico Ary Rongel da Marinha do Brasil, compreendendo a área localizada entre as latitudes $63^{\circ} \mathrm{S}-60^{\circ} \mathrm{S}$ e longitudes $53^{\circ} \mathrm{W}-62^{\circ} \mathrm{W}$ (FIG. 9 a 12).

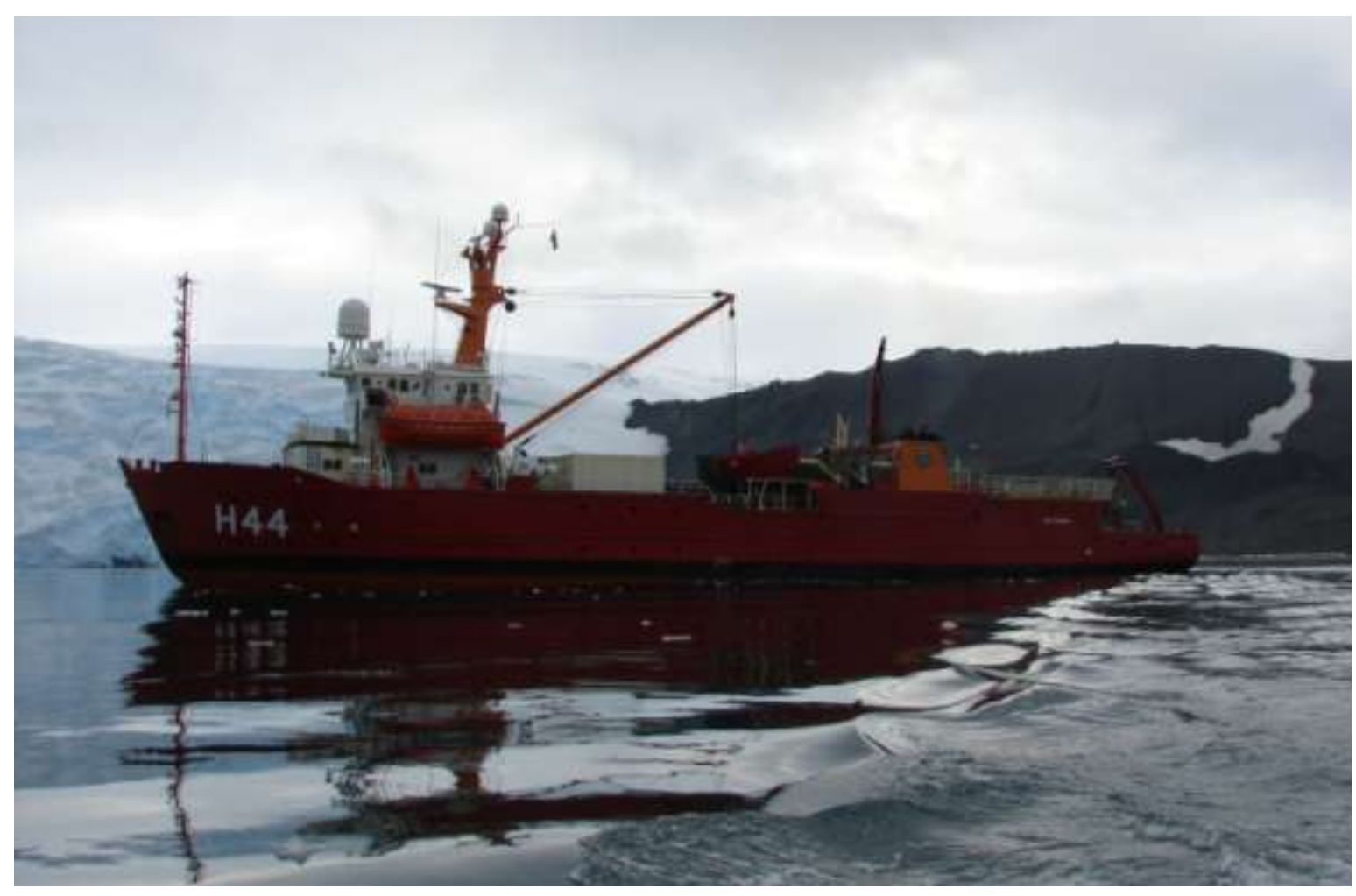

FIGURA 9 - Navio de Apoio Oceanográfico Ary Rongel da Marinha do Brasil.

A primeira campanha de amostragem foi realizada entre os dias 10 a 16 de março de 2011, durante o final do Verão Austral, na 6⿳亠丷厂 fase da OPERANTAR XXIX, onde foram estabelecidas 47 estações de amostragem 
superficial e 10 radiais horizontais superficiais (FIG. 10 e 11). A segunda campanha de amostragem foi realizada entre os dias 13 de outubro a 14 de novembro de 2011, durante o início do Verão Austral seguinte, na $1^{\text {a }}$ fase da OPERANTAR XXX, onde foram estabelecidas 17 estações de amostragem superficial (FIG. 12).

As amostras de água do mar coletadas são representativas da água de superfície. Tanto para a determinação dos radionuclídeos naturais quanto para as análises complementares, as amostras foram tomadas em frascos de polietileno com $2 \mathrm{~L}$ de capacidade, e em frascos estéreis com $250 \mathrm{~mL}$ de capacidade. As coordenadas geográficas das estações amostradas ao longo do Estreito de Bransfield são apresentadas na TAB. 1. A TAB. 2 descreve os perfis radiais coletados horizontalmente durante a OPERANTAR XXIX, representativos da amostragem passiva dos isótopos de Ra no percurso de navegação ao longo do Estreito de Bransfield.

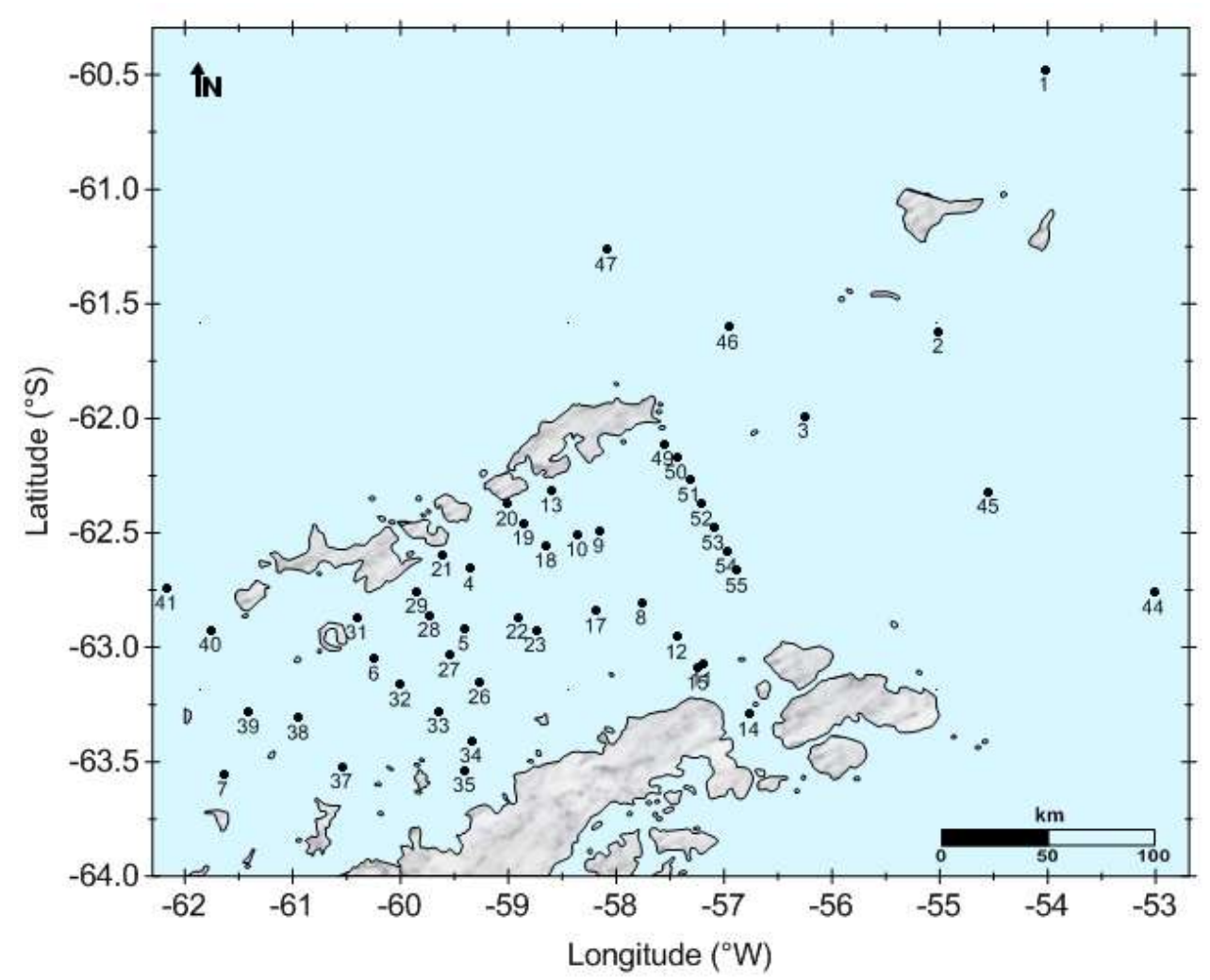

FIGURA 10 - Mapa da localização das estações de amostragem superficial realizadas durante a OPERANTAR XXIX. 


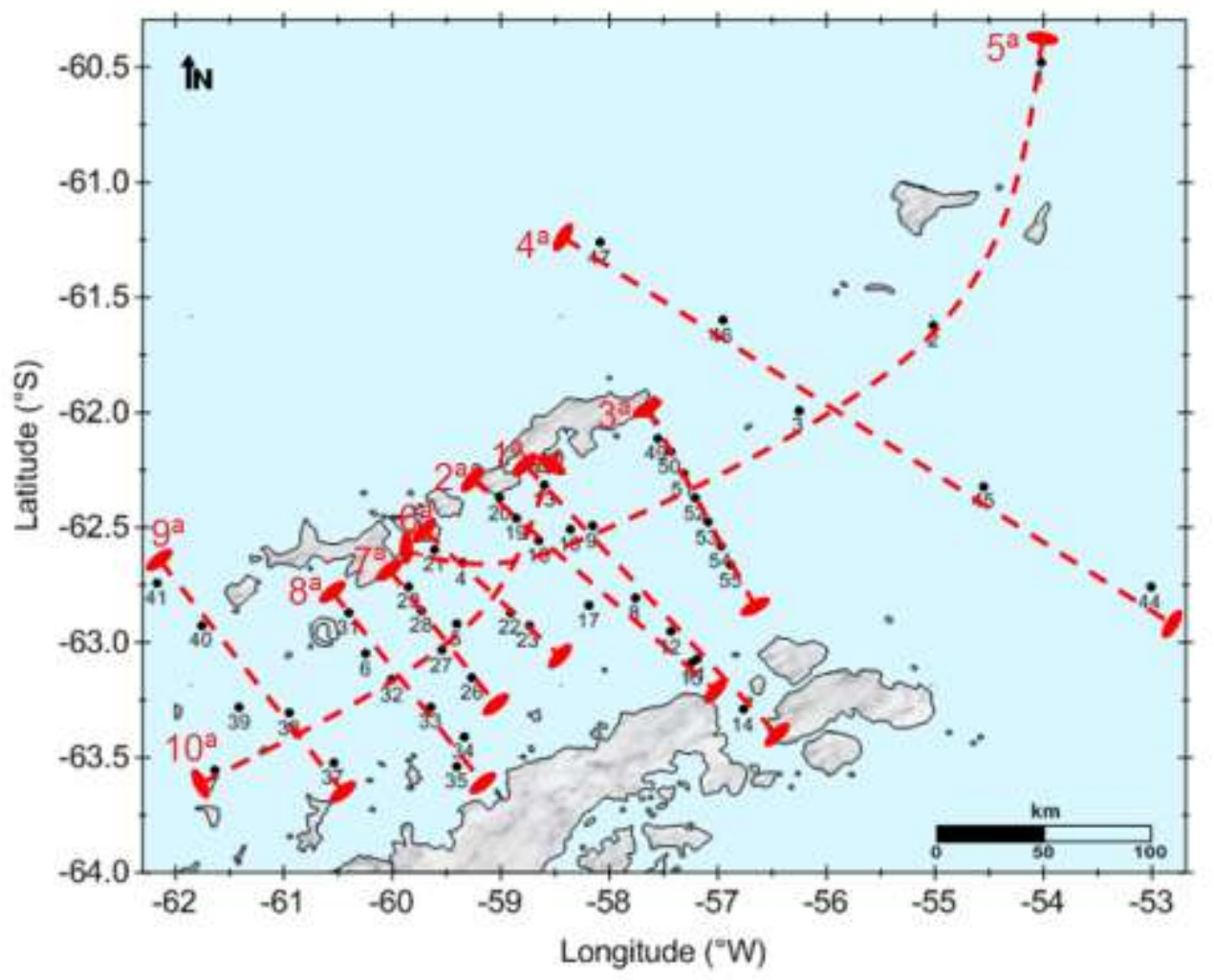

FIGURA 11 - Mapa da localização das radiais realizadas durante a OPERANTAR XXIX.

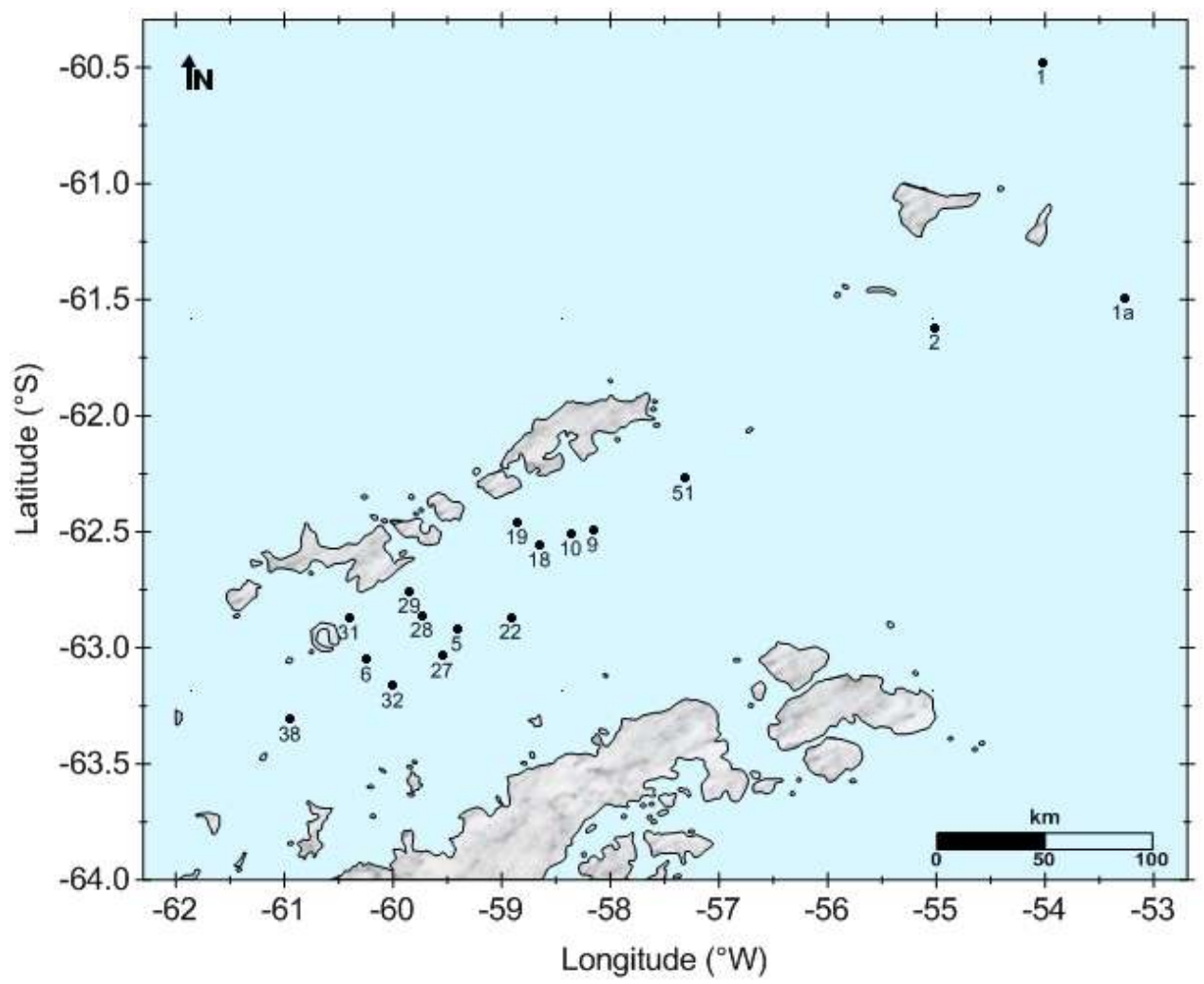

FIGURA 12 - Mapa da localização das estações de amostragem superficial realizadas durante a OPERANTAR XXX. 
TABELA 1 - Coordenadas geográficas e data da coleta das estações superficiais de água do mar amostradas durante as expedições OPERANTAR XXIX e XXX.

\begin{tabular}{|c|c|c|c|c|}
\hline & \multicolumn{2}{|c|}{ Coordenadas geográficas } & Operantar XXIX & Operantar XXX \\
\hline Estação & Latitude ( ${ }^{\circ} \mathrm{S}$ ) & Longitude $\left({ }^{\circ} \mathrm{W}\right)$ & Data coleta & Data coleta \\
\hline EB 001 & $60^{\circ} 27^{\prime} 99^{\prime \prime}$ & $054^{\circ} 01^{\prime} 30^{\prime \prime}$ & $14 / 03 / 2011$ & $29 / 10 / 2011$ \\
\hline EB 001 $\alpha$ & $61^{\circ} 28^{\prime} 89^{\prime \prime}$ & $053^{\circ} 16^{\prime} 24^{\prime \prime}$ & - & $29 / 10 / 2011$ \\
\hline EB 002 & $61^{\circ} 37^{\prime} 13^{\prime \prime}$ & $054^{\circ} 57^{\prime} 60^{\prime \prime}$ & $14 / 03 / 2011$ & $29 / 10 / 2011$ \\
\hline EB 003 & $61^{\circ} 59^{\prime} 24^{\prime \prime}$ & $056^{\circ} 15^{\prime} 20^{\prime \prime}$ & $13 / 03 / 2011$ & - \\
\hline EB 004 & $62^{\circ} 39^{\prime} 29^{\prime \prime}$ & $059^{\circ} 21^{\prime} 21^{\prime \prime}$ & $14 / 03 / 2011$ & - \\
\hline EB 005 & $62^{\circ} 55^{\prime} 43^{\prime \prime}$ & $059^{\circ} 23^{\prime} 45^{\prime \prime}$ & $16 / 03 / 2011$ & $30 / 10 / 2011$ \\
\hline EB 006 & $63^{\circ} 03^{\prime} 32^{\prime \prime}$ & $060^{\circ} 14^{\prime} 03 "$ & $15 / 03 / 2011$ & $31 / 10 / 2011$ \\
\hline EB 007 & $63^{\circ} 33^{\prime} 25^{\prime \prime}$ & $061^{\circ} 37^{\prime} 93^{\prime \prime}$ & $16 / 03 / 2011$ & - \\
\hline EB 008 & $62^{\circ} 48^{\prime} 30^{\prime \prime}$ & $057^{\circ} 45^{\prime} 42^{\prime \prime}$ & $11 / 03 / 2011$ & - \\
\hline EB 009 & $62^{\circ} 29^{\prime} 40^{\prime \prime}$ & $058^{\circ} 10^{\prime} 10^{\prime \prime}$ & $11 / 03 / 2011$ & $30 / 10 / 2011$ \\
\hline EB 010 & $62^{\circ} 30^{\prime} 10^{\prime \prime}$ & $058^{\circ} 31^{\prime} 60^{\prime \prime}$ & $14 / 03 / 2011$ & $30 / 10 / 2011$ \\
\hline EB 011 & $63^{\circ} 03^{\prime} 93^{\prime \prime}$ & $057^{\circ} 11^{\prime} 56 "$ & $11 / 03 / 2011$ & - \\
\hline EB 012 & $62^{\circ} 56^{\prime} 80^{\prime \prime}$ & $057^{\circ} 25^{\prime} 67^{\prime \prime}$ & $11 / 03 / 2011$ & - \\
\hline EB 013 & $62^{\circ} 18^{\prime} 59^{\prime \prime}$ & $058^{\circ} 35^{\prime} 44^{\prime \prime}$ & $11 / 03 / 2011$ & - \\
\hline EB 014 & $63^{\circ} 17^{\prime} 39^{\prime \prime}$ & $056^{\circ} 45^{\prime} 53^{\prime \prime}$ & $11 / 03 / 2011$ & - \\
\hline EB 015 & $63^{\circ} 05^{\prime} 26^{\prime \prime}$ & $057^{\circ} 14^{\prime} 18 "$ & $11 / 03 / 2011$ & - \\
\hline EB 017 & $62^{\circ} 50^{\prime} 33^{\prime \prime}$ & $058^{\circ} 10^{\prime} 61^{\prime \prime}$ & $11 / 03 / 2011$ & - \\
\hline EB 018 & $62^{\circ} 32^{\prime} 70^{\prime \prime}$ & $058^{\circ} 38^{\prime} 50^{\prime \prime}$ & $11 / 03 / 2011$ & $30 / 10 / 2011$ \\
\hline EB 019 & $62^{\circ} 30^{\prime} 15^{\prime \prime}$ & $058^{\circ} 50^{\prime} 36^{\prime \prime}$ & $11 / 03 / 2011$ & $30 / 10 / 2011$ \\
\hline EB 020 & $62^{\circ} 22^{\prime} 30^{\prime \prime}$ & $059^{\circ} 00^{\prime} 12^{\prime \prime}$ & $11 / 03 / 2011$ & - \\
\hline EB 021 & $62^{\circ} 35^{\prime} 46^{\prime \prime}$ & $059^{\circ} 35^{\prime} 74^{\prime \prime}$ & $14 / 03 / 2011$ & - \\
\hline EB 022 & $62^{\circ} 52^{\prime} 06^{\prime \prime}$ & $058^{\circ} 53^{\prime} 97^{\prime \prime}$ & $16 / 03 / 2011$ & $30 / 10 / 2011$ \\
\hline EB 023 & $62^{\circ} 55^{\prime} 31^{\prime \prime}$ & $058^{\circ} 44^{\prime} 31^{\prime \prime}$ & $16 / 03 / 2011$ & - \\
\hline EB 026 & $63^{\circ} 09^{\prime} 14^{\prime \prime}$ & $059^{\circ} 15^{\prime} 35^{\prime \prime}$ & $15 / 03 / 2011$ & - \\
\hline EB 027 & $63^{\circ} 01^{\prime} 00^{\prime \prime}$ & $059^{\circ} 33^{\prime} 03^{\prime \prime}$ & $15 / 03 / 2011$ & $31 / 10 / 2011$ \\
\hline EB 028 & $62^{\circ} 51^{\prime} 16^{\prime \prime}$ & $059^{\circ} 43^{\prime} 59^{\prime \prime}$ & $15 / 03 / 2011$ & $30 / 10 / 2011$ \\
\hline EB 029 & $62^{\circ} 45^{\prime} 32^{\prime \prime}$ & $059^{\circ} 49^{\prime} 52^{\prime \prime}$ & $15 / 03 / 2011$ & $30 / 10 / 2011$ \\
\hline EB 031 & $62^{\circ} 52^{\prime} 66^{\prime \prime}$ & $060^{\circ} 23^{\prime} 73^{\prime \prime}$ & $15 / 03 / 2011$ & $31 / 10 / 2011$ \\
\hline EB 032 & $63^{\circ} 09^{\prime} 13^{\prime \prime}$ & $059^{\circ} 59^{\prime} 69^{\prime \prime}$ & $15 / 03 / 2011$ & $31 / 10 / 2011$ \\
\hline EB 033 & $63^{\circ} 16^{\prime} 45^{\prime \prime}$ & $059^{\circ} 37^{\prime} 83^{\prime \prime}$ & $15 / 03 / 2011$ & - \\
\hline EB 034 & $63^{\circ} 23^{\prime} 94^{\prime \prime}$ & $059^{\circ} 19^{\prime} 74^{\prime \prime}$ & $15 / 03 / 2011$ & - \\
\hline EB 035 & $63^{\circ} 31^{\prime} 80^{\prime \prime}$ & $059^{\circ} 24^{\prime} 00^{\prime \prime}$ & $15 / 03 / 2011$ & - \\
\hline EB 037 & $63^{\circ} 30^{\prime} 81^{\prime \prime}$ & $060^{\circ} 31^{\prime} 78^{\prime \prime}$ & $15 / 03 / 2011$ & - \\
\hline EB 038 & $63^{\circ} 17^{\prime} 60^{\prime \prime}$ & $060^{\circ} 55^{\prime} 87^{\prime \prime}$ & $15 / 03 / 2011$ & $31 / 10 / 2011$ \\
\hline EB 039 & $63^{\circ} 16^{\prime} 60^{\prime \prime}$ & $061^{\circ} 23^{\prime} 72^{\prime \prime}$ & $15 / 03 / 2011$ & - \\
\hline EB 040 & $62^{\circ} 54^{\prime} 89^{\prime \prime}$ & $061^{\circ} 45^{\prime} 18^{\prime \prime}$ & $16 / 03 / 2011$ & - \\
\hline EB 041 & $62^{\circ} 43^{\prime} 95^{\prime \prime}$ & $062^{\circ} 09^{\prime} 47^{\prime \prime}$ & $16 / 03 / 2011$ & - \\
\hline EB 044 & $62^{\circ} 45^{\prime} 43^{\prime \prime}$ & $053^{\circ} 00^{\prime} 49^{\prime \prime}$ & $12 / 03 / 2011$ & - \\
\hline EB 045 & $62^{\circ} 19^{\prime} 16^{\prime \prime}$ & $054^{\circ} 32^{\prime} 45^{\prime \prime}$ & $12 / 03 / 2011$ & - \\
\hline EB 046 & $61^{\circ} 35^{\prime} 71^{\prime \prime}$ & $056^{\circ} 57^{\prime} 32 "$ & $13 / 03 / 2011$ & - \\
\hline EB 047 & $61^{\circ} 15^{\prime} 46^{\prime \prime}$ & $058^{\circ} 04^{\prime} 64^{\prime \prime}$ & $13 / 03 / 2011$ & - \\
\hline EB 049 & $62^{\circ} 06^{\prime} 50^{\prime \prime}$ & $057^{\circ} 33^{\prime} 37^{\prime \prime}$ & $12 / 03 / 2011$ & - \\
\hline EB 050 & $62^{\circ} 09^{\prime} 74^{\prime \prime}$ & $057^{\circ} 25^{\prime} 78^{\prime \prime}$ & $12 / 03 / 2011$ & - \\
\hline EB 051 & $61^{\circ} 15^{\prime} 45^{\prime \prime}$ & $057^{\circ} 18^{\prime} 94^{\prime \prime}$ & $12 / 03 / 2011$ & $30 / 10 / 2011$ \\
\hline EB 052 & $62^{\circ} 22^{\prime} 31^{\prime \prime}$ & $057^{\circ} 12^{\prime} 05^{\prime \prime}$ & $12 / 03 / 2011$ & - \\
\hline EB 053 & $62^{\circ} 28^{\prime} 43^{\prime \prime}$ & $057^{\circ} 04^{\prime} 96 "$ & $12 / 03 / 2011$ & - \\
\hline EB 054 & $62^{\circ} 34^{\prime} 57^{\prime \prime}$ & $056^{\circ} 57^{\prime} 67^{\prime \prime}$ & $12 / 03 / 2011$ & - \\
\hline EB 055 & $62^{\circ} 39^{\prime} 58^{\prime \prime}$ & $056^{\circ} 51^{\prime} 92^{\prime \prime}$ & $12 / 03 / 2011$ & - \\
\hline
\end{tabular}


TABELA 2 - Estações superficiais de água do mar que compreendem cada perfil radial horizontal amostrado para a determinação de ${ }^{226} \mathrm{Ra}$ e ${ }^{228} \mathrm{Ra}$ durante a OPERANTAR XXIX.

\begin{tabular}{|c|c|c|c|c|c|c|c|}
\hline & \multicolumn{7}{|c|}{ Estações } \\
\hline $1^{\mathrm{a}}$ Radial & EB 008 & EB 009 & EB 011 & EB 012 & EB 013 & EB 014 & \\
\hline $2^{\underline{a}}$ Radial & EB 015 & EB 017 & EB 018 & EB 019 & EB 020 & & \\
\hline $3^{\text {a }}$ Radial & EB 049 & EB 050 & EB 051 & EB 052 & EB 053 & EB 054 & EB 055 \\
\hline 4므 Radial & EB 003 & EB 044 & EB 045 & EB 046 & EB 047 & & \\
\hline 5a Radial & EB 001 & EB 002 & EB 010 & EB 021 & & & \\
\hline 6a Radial & EB 004 & EB 021 & EB 022 & EB 023 & & & \\
\hline 7aㅡ Radial & EB 026 & EB 027 & EB 028 & EB 029 & & & \\
\hline $8^{\mathrm{a}}$ Radial & EB 006 & EB 031 & EB 032 & EB 033 & EB 034 & EB 035 & \\
\hline 9a Radial & EB 037 & EB 038 & EB 039 & EB 040 & EB 041 & & \\
\hline $10^{\mathrm{a}}$ Radial & EB 005 & EB 007 & EB 013 & & & & \\
\hline
\end{tabular}

\subsubsection{Amostragem para determinação de ${ }^{234} \mathrm{Th}$ total}

Para a determinação de ${ }^{234} \mathrm{Th}$ total foram coletados $2 \mathrm{~L}$ de amostra de água do mar superficial em frascos de polietileno previamente limpos com solução de $\mathrm{HCl} 0,1 \mathrm{~mol} \mathrm{~L}^{-1}$. A bordo do navio as amostras foram precipitadas $\mathrm{e}$ posteriormente filtradas a vácuo em papel de filtro em microfibra de vidro Millipore AP20047 com porosidade nominal de 0,45 $\mu \mathrm{m}$. Em seguida as amostras foram secas em temperatura ambiente e armazenadas em placas de Petri Nalgene até retorno ao Brasil (Rutgers Van der Loeff \& Moore, 1999).

\subsubsection{Amostragem para determinação de ${ }^{210} \mathrm{Po} e{ }^{210} \mathrm{~Pb}$ particulado}

Para a quantificação de ${ }^{210} \mathrm{Po}$ e de ${ }^{210} \mathrm{~Pb}$ particulado foram coletados $6 \mathrm{~L}$ de amostras de água do mar superficial em frascos de polietileno previamente limpos com solução de $\mathrm{HCl} 0,1 \mathrm{~mol} \mathrm{~L}^{-1}$. A bordo do navio as amostras foram filtradas a vácuo em papel de filtro em microfibra de vidro Millipore AP20047 com porosidade nominal de $0,45 \mu \mathrm{m}$. Os filtros com material particulado foram secos em temperatura ambiente e armazenados em placas de Petri Nalgene até retorno ao Brasil (Rutgers Van der Loeff \& Moore, 1999). 


\subsubsection{Amostragem para determinação de ${ }^{226} \mathrm{Ra} e{ }^{228} \mathrm{Ra}$}

As amostragens de água do mar para determinação dos isótopos naturais de Ra de meias-vidas longas foram realizadas diferentemente em cada uma das campanhas de amostragem.

Durante a OPERANTAR XXIX, foram coletadas as amostras na forma de perfis radiais horizontais, com o auxílio de uma bomba submersível do próprio navio. A água foi bombeada (profundidade de $5 \mathrm{~m}$ ) diretamente em um suporte plástico vazado previamente preenchido com $25 \mathrm{~g}$ de fibras de acrílico impregnadas com $\mathrm{MnO}_{2}$. Dessa maneira as amostras foram pré-concentradas passivamente nas fibras durante o percurso de cada radial em um fluxo de $1 \mathrm{~L} \mathrm{~min}^{-1}$. Ao término de cada radial, as fibras pré-concentradas foram secas em temperatura ambiente e armazenadas em sacos de polietileno até retorno ao Brasil.

$\mathrm{Na}$ OPERANTAR XXX, foram coletados cerca de $200 \mathrm{~L}$ de água do mar superficial na profundidade de $5 \mathrm{~m}$ com auxílio de uma bomba submersível do próprio navio, que foram transferidos para barris de polietileno. Estas amostras foram pré-concentradas a bordo em colunas previamente preenchidas com $25 \mathrm{~g}$ de fibras de acrílico impregnadas com $\mathrm{MnO}_{2}$, utilizando-se bomba submersível e um fluxo de percolação de $1 \mathrm{~L} \mathrm{~min}^{-1}$. Ao término do processo, as fibras préconcentradas foram secas em temperatura ambiente e armazenadas em sacos de polietileno até sua chegada ao Brasil (Rutgers Van der Loeff \& Moore, 1999).

\subsubsection{Amostragem para análises complementares}

Para determinação de carbono orgânico total foram coletados cerca de $250 \mathrm{~mL}$ de amostra de água do mar superficial em frasco estéril Nalgene. A solução foi acidificada com $100 \mu \mathrm{L}$ de $\mathrm{HNO}_{3}$ ultrapuro Merck para evitar a adsorção da amostra nas paredes do recipiente e manter o $\mathrm{pH} \leq 2,0$. As amostras foram mantidas congeladas até seu retorno ao Brasil. Foram coletados cerca de $250 \mathrm{~mL}$ para a determinação de salinidade. 


\subsubsection{Dificuldades da amostragem}

Deve-se considerar que a pesquisa na Antártica é sempre incerta por ser uma região onde a mudança de clima acontece diversas vezes e com muita intensidade, e por mais que a equipe esteja preparada e que todo material esteja em perfeito funcionamento qualquer imprevisto é iminente. O continente Antártico é considerado o mais inóspito e prístino do planeta, sendo assim o trabalho de campo nesta região é complexo, e muitas vezes, é necessária a adaptação da pesquisa às condições da Antártica.

A princípio, na coleta da OPERANTAR XXIX deveriam ser repetidos cerca de 10 perfis verticais realizados em 2007 (Vieira, 2011), com algumas outras estações ao longo do Estreito de Bransfield para aumentar a malha amostral e se obter um melhor detalhamento da região de interesse. Entretanto, infelizmente, durante a campanha o CTD acoplado a Rosette do próprio navio foi danificado e por este motivo não foi possível a amostragem dos perfis verticais em função da profundidade da coluna d'água. Desta forma, na OPERANTAR XXIX foram realizadas 47 estações superficiais para a coleta de radionuclídeos naturais, carbono e nutrientes.

$\mathrm{Na}$ OPERANTAR XXX, havia-se novamente planejado reocupar os 10 perfis verticais de 2007 e algumas das estações realizadas na OPERANTAR XXIX que apresentaram dados mais relevantes. Contudo, antes mesmo do navio chegar a Antártica houve uma pane em um dos motores sendo necessário o reparo em Ushuaia (Argentina). Na continuação da viagem, logo na ocupação da primeira estação hidrográfica, o sensor CTD apresentou falhas e observou-se que o cabo de aço que sustentava a Rosette se encontrava comprometido, com o risco de perda do equipamento. Por estes motivos, a campanha amostral teve de ser modificada. Juntamente com os oficiais da Marinha, responsáveis pelo apoio e auxílio à pesquisa, decidiu-se que seriam repetidas as estações superficiais realizadas na OPERANTAR XXIX (47 estações).

No prosseguimento da OPERANTAR XXX ocorreu novo imprevisto que interrompeu a amostragem, devido a um incêndio no incinerador do navio. Além disso, alguns pontos amostrais próximos a Península Trinity e mais ao Sul do 
Estreito de Bransfield não foram coletados devido à presença de gelo. Por fim, a coleta teve de ser suspensa por causa de nova quebra do motor. Assim, apenas puderam ser coletadas 17 estações superficiais no Estreito de Bransfield, 1 estação fixa na Baía do Almirantado e 3 perfis verticais do $\mathrm{CHM}$ (Centro de Hidrografia da Marinha).

Uma nova tentativa de coleta ainda durante a OPERANTAR XXX seria estudada devido ao insucesso das amostragens anteriores, mas por causa do incêndio que ocorreu na EACF em fevereiro de 2012, não foi possível o retorno a Antártica.

Vale ressaltar que as duas campanhas amostrais foram realizadas em épocas diferentes. A primeira campanha amostral foi realizada durante a OPERANTAR XXIX no final do Verão Austral, quando a maior parte do gelo já havia derretido e os processos biogeoquímicos marinhos já estavam ativos, devido ao aumento de temperatura e disponibilidade de nutrientes. Porém, a segunda campanha foi realizada durante a OPERANTAR XXX na fase inicial do Verão Austral seguinte, aonde parte da região de interesse, principalmente, na porção Sul do Estreito de Bransfield, ainda estava em processo de degelo com os ciclos biogeoquímicos marinhos se iniciando. É evidente que para uma melhor interpretação dos dados as duas campanhas deveriam ter sido realizadas durante a mesma época, porém devido à logística do PROANTAR nem sempre isso se torna possível.

É importante destacar o apoio, o comprometimento e a dedicação da tripulação embarcada com a segurança da equipe de pesquisadores e dos tripulantes e com o sucesso da pesquisa. Apesar dos percalços, foi possível realizar pesquisa científica substancial.

\subsection{Determinação radioquímica de ${ }^{234}$ Th total em amostras de água do mar}

\subsubsection{Princípio do método}

A determinação de ${ }^{234}$ Th total nas amostras de água do mar foi realizada pelo método modificado descrito por Rutgers Van der Loeff \& Moore 
(1999). O método baseia-se na coprecipitação do $\mathrm{MnO}_{2}$, que arrasta preferencialmente $0{ }^{234} \mathrm{Th}$, deixando em solução outros radionuclídeos naturais eventualmente presentes. A medida de ${ }^{234} \mathrm{Th}$ é realizada pela detecção de seu produto de decaimento radioativo, o ${ }^{234 \mathrm{~m}} \mathrm{~Pa}$, emissor beta de alta energia, em um detector proporcional de fluxo gasoso de baixa radiação de fundo.

\subsubsection{Procedimento Radioquímico}

A bordo do navio, logo após a coleta foram adicionados às amostras de água do mar cerca de $250 \mu \mathrm{L}$ de $\mathrm{KMnO}_{4}\left(6 \mathrm{~g} \mathrm{~L}^{-1}\right)$ e $100 \mu \mathrm{L}$ de $\mathrm{MnCl}_{2} 4 \mathrm{H}_{2} \mathrm{O}$ $\left(40 \mathrm{~g} \mathrm{~L}^{-1}\right)$ e então a amostra foi homogeneizada e deixada em repouso por um período de 8 a 16 horas, para formação de um microprecipitado de $\mathrm{MnO}_{2}$ que coprecipita $0{ }^{234} \mathrm{Th}$ e quantidades desprezíveis de ${ }^{238} \mathrm{U}$. Os precipitados foram filtrados a vácuo em sistema Manifold, utilizando papel de filtro em microfibra de vidro Millipore AP20047 com porosidade nominal de 0,45 $\mu \mathrm{m}$. Após a filtração, as amostras foram secas e armazenadas em placas de Petri Nalgene até o retorno ao Brasil (FIG. 13 a,b,c).

No Laboratório de Radiometria Ambiental (LRA/GMR) do IPEN, os filtros com os precipitados foram secos em estufa a $100^{\circ} \mathrm{C}$ por 1 hora e resfriados em dessecador por 30 minutos para posterior pesagem em balança analítica. Este procedimento foi repetido até obtenção de peso constante para determinação da massa do precipitado (FIG. 13 d,e). 


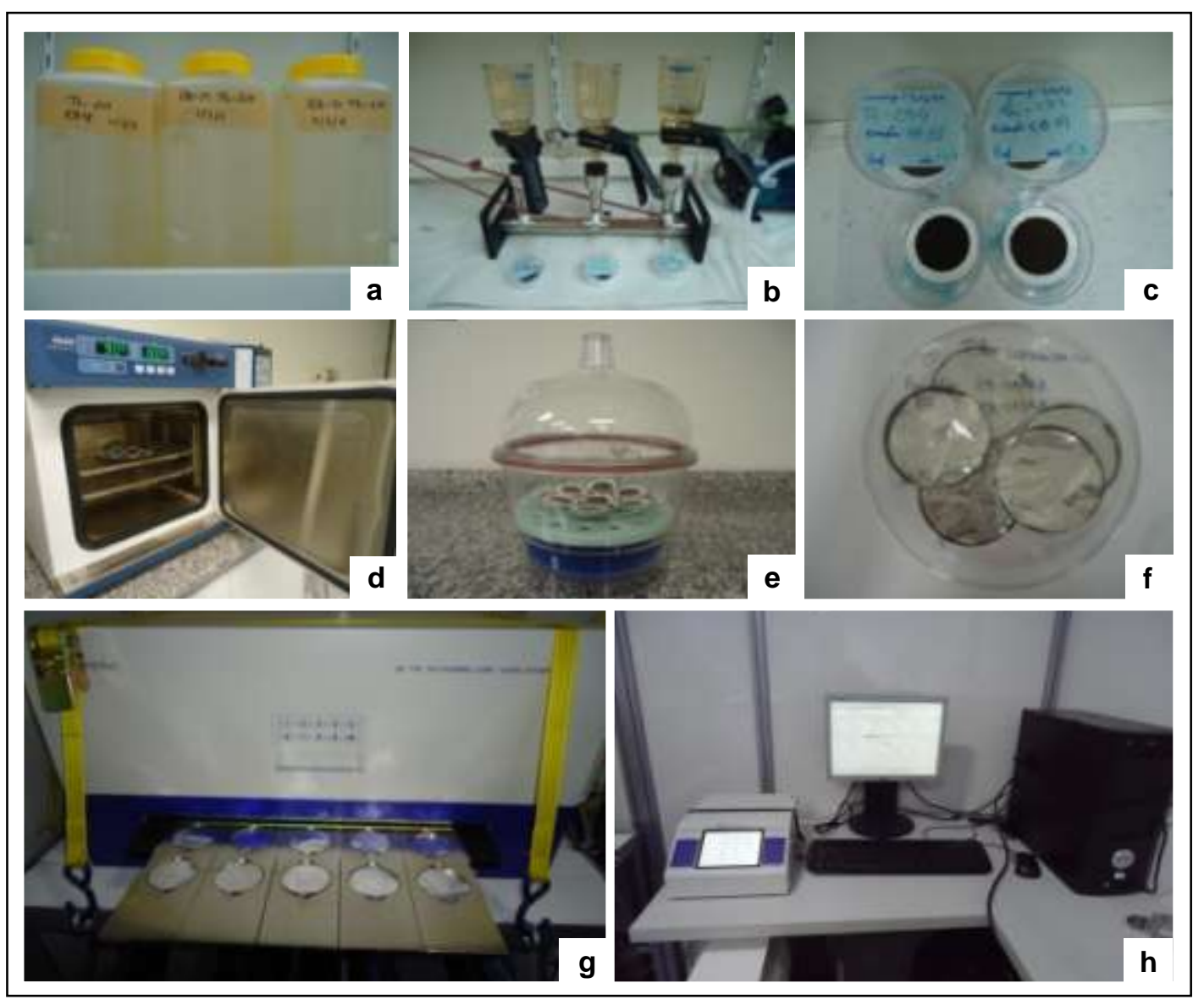

FIGURA 13 - a) Precipitação das amostras de água do mar; b) Filtragem a vácuo em sistema Manifold; c) Filtros com microprecipitado de $\mathrm{MnO}_{2}$; d) Secagem dos filtros em estufa; e) Resfriamento dos filtros em dessecador; f) Filtros na geometria de contagem; g e h) Detector proporcional de fluxo gasoso de baixa radiação de fundo, modelo Berthold LB 770.

Após a separação radioquímica, os filtros contendo o precipitado de $\mathrm{MnO}_{2}$ foram colocados na geometria de contagem, ou seja, foram colocados em plaquetas de aço inox e cobertos por 2 folhas de papel alumínio e 1 de plástico filme para barrar partículas beta de baixa energia (FIG. 13 f). A medida de ${ }^{234} \mathrm{Th}$ foi realizada pela detecção de seu produto de decaimento radioativo, o ${ }^{234 \mathrm{~m}} \mathrm{~Pa}$ ( $\mathrm{t} 1 \frac{1}{2}=1,17$ minutos), radionuclídeo emissor beta de alta energia (2,29 MeV) em detector proporcional de fluxo gasoso de baixa radiação de fundo, modelo Berthold LB 770, durante um período de 1 ciclo de 400 minutos (FIG. 13 g,h).

Passadas 6 meias-vidas do ${ }^{234} \mathrm{Th}(\mathrm{t} 1 / 2=144$ dias) as amostras foram novamente medidas para corrigir possíveis contribuições de outros radionuclídeos 
emissores beta eventualmente presentes na amostra e determinação da radiação de fundo da geometria de contagem. Em uma amostra padrão de água do mar contendo cerca de $2,5 \mathrm{dpm} \mathrm{L}{ }^{-1}$ de ${ }^{234} \mathrm{Th}$ e $0,15 \mathrm{dpm} \mathrm{L}{ }^{-1}$ de ${ }^{226} \mathrm{Ra}$, a contribuição dos produtos de decaimento do ${ }^{226} \mathrm{Ra}$ emissores beta e eventuais traços de ${ }^{238} \mathrm{U}$ coprecipitados no $\mathrm{MnO}_{2}$ é de cerca de $4 \%$ da taxa de contagem beta total determinada na primeira semana após a amostragem.

A metodologia foi implementada facilmente, com exatidão e precisão $\leq 5 \%$ (Benitez-Nelson et al.,2001).

\subsubsection{Cálculo da concentração de atividade de ${ }^{234} \mathrm{Th}$ total}

A concentração de atividade de ${ }^{234} \mathrm{Th}$ total foi calculada a partir da seguinte equação:

$$
A\left({ }^{234} T h\right)=\frac{R n-B G}{E F \beta \cdot R Q \cdot Q}
$$

Onde:

$\mathrm{A}\left({ }^{234} \mathrm{Th}\right)=$ atividade de ${ }^{234} \mathrm{Th}$ total na amostra de água $\left(\mathrm{dpm} \mathrm{L} \mathrm{L}^{-1}\right) ;$

$R Q$ = rendimento químico médio do processo de microprecipitação, determinado pela recuperação de um traçador de ${ }^{229} \mathrm{Th}$ em um conjunto de 104 amostras de água do mar. As amostras deste teste foram processadas no LRA do IPEN e encaminhadas para o Laboratório Marinho de Mônaco da Agência Internacional de Energia Atômica (IAEA-NAMEL), aonde as concentrações de ${ }^{229} \mathrm{Th}$ foram quantificadas por espectrometria de massas (ICP-MS). A maior parte dos resultados apresentou recuperação superior a $85 \%$, com rendimento químico médio final de $91,3 \%(n=104)$. Deste conjunto, apenas 19 amostras apresentaram rendimento químico inferior a $85 \%$, demonstrando que nestes casos houve perda do precipitado de $\mathrm{MnO}_{2}$ durante as etapas de separação radioquímica e filtração. 
$\mathrm{Rn}=$ taxa de contagem beta total da amostra de água na geometria de contagem, variando de 2 a $4 \mathrm{cpm}$, cerca de 1 ordem de grandeza maior que a radiação de fundo beta total do detector (cpm);

$B G$ = taxa de contagem da radiação de fundo do detector (cpm), que variou de 0,547 a 0,930 cpm, na voltagem de operação de 1.650 Volts.

$\mathrm{EF} \beta=$ eficiência de contagem beta total, cujos valores foram de cerca de $40 \%$ (com variações $<2 \%$ entre os 10 detectores utilizados) para a energia beta do ${ }^{234 \mathrm{~m}} \mathrm{~Pa}$ de $\left.2,0 \mathrm{MeV}^{(\mathrm{cpm} \mathrm{dpm}}{ }^{-1}\right)$;

$\mathrm{Q}=$ quantidade de amostra $(\mathrm{L})$.

\subsubsection{Validação da metodologia para determinação de ${ }^{234} \mathrm{Th}$ total}

A metodologia da determinação de ${ }^{234} \mathrm{Th}$ em $2 \mathrm{~L}$ de amostras de água do mar foi desenvolvida e validada por Benitez-Nelson et al. (2001). A validação envolveu uma série de determinações em laboratório e em campo. As vantagens desta metodologia da quantificação de ${ }^{234} \mathrm{Th}$ em pequenos volumes contemplam a sua facilidade de amostragem, processamento e baixas incertezas analíticas quando comparada com outras técnicas que envolvem a sua extração em cartuchos de acrílico impregnados com $\mathrm{MnO}_{2}$ e/ou a precipitação com $\mathrm{Fe}(\mathrm{OH})_{3}$ seguida de cromatografia de troca-iônica e espectrometria (Buesseler et al., 2001).

O principal exercício de intercalibração para validação do método foi realizado no "Natural Energy Laboratory of Hawaii (NELHA)". Neste laboratório, uma linha bombeou amostras de água do mar da profundidade de $600 \mathrm{~m}$, num fluxo de $64 \mathrm{~m}^{3} \mathrm{~min}^{-1}$. Este local foi considerado ideal para realização do experimento, por causa do fornecimento ininterrupto de água do mar, com composição química praticamente estável ao longo do tempo. As amostras foram coletadas e processadas para a determinação de ${ }^{234} \mathrm{Th}$ total utilizando-se diferentes métodos durante o período de 3 semanas. A salinidade da água do mar a $600 \mathrm{~m}$ de profundidade manteve-se constante $(34,381 \pm 0,033)$ e a 
concentração de nutrientes dissolvidos tais como nitrato e fosfato foram estáveis e típicos dos observados em outras águas profundas $\left(\mathrm{NO}_{3}{ }^{-}=39,9 \pm 2,3 \mu \mathrm{M} ; \mathrm{PO}_{4}{ }^{3-}=\right.$ $3,1 \pm 0,1 \mu \mathrm{M})$.

Para os fins da validação 3 diferentes metodologias foram utilizadas:

- a precipitação de ${ }^{234} \mathrm{Th}$ a partir do volume de $20 \mathrm{~L}$ de água do mar procedimento original descrito em detalhes por Rutgers van der Loeff \& Moore (1999);

- a microprecipitação de ${ }^{234} \mathrm{Th}$ com $\mathrm{MnO}_{2}$ a partir do volume de $2 \mathrm{~L}$ de água do mar (método utilizado neste trabalho) seguida da contagem beta total em detector proporcional de fluxo gasoso de baixa radiação de fundo;

- a precipitação do ${ }^{234} \mathrm{Th}$ com $\mathrm{Fe}(\mathrm{OH})_{3}$ a partir do volume de $20 \mathrm{~L}$ de água do mar (Anderson \& Fleer, 1982).

O estudo demonstrou que os 3 métodos radiométricos testados são os mais sensíveis para a determinação de ${ }^{234} \mathrm{Th}$ total em água do mar. Quando comparados entre si, todos os métodos testados produziram resultados médios da atividade de ${ }^{234} \mathrm{Th}$ total idênticos, considerando-se as incertezas globais. Em todos os casos envolvendo tanto espectrometria gama, quanto a contagem beta total, os erros da determinação de ${ }^{234} \mathrm{Th}$ foram reportados para $1 \sigma$ (na estimativa de incertezas associadas a estatística das contagens). Estes erros foram facilmente quantificados como a propagação da raiz quadrada do número total de contagens detectadas (Stevenson, 1965). Neste sentido, as amostras de $20 \mathrm{~L}$ de água do mar contadas imediatamente após a amostragem por longo período de tempo (espectrometria gama) apresentaram maiores contagens líquidas e os menores erros associados. Para os efeitos deste estudo, considerou-se a variabilidade entre replicatas e/ou o desvio padrão das medidas, como uma estimativa global da incerteza dos métodos avaliados. Esta variabilidade deve ser maior que o erro devido apenas à estatística de contagem, pois leva em conta a propagação dos erros associados à calibração dos detectores e processamento das amostras. 
A comparação dos resultados obtidos utilizando-se os 3 diferentes métodos é apresentada na TAB. 3. Pode-se observar que o menor desvio padrão relativo ( $5 \%$ ) foi obtido para a determinação de ${ }^{234} \mathrm{Th}$ total pelo método de coprecipitação com $\mathrm{MnO}_{2}$ e contagem beta total a partir do volume de $2 \mathrm{~L}$ de amostra. Em contraste, a determinação de ${ }^{234} \mathrm{Th}$ a partir do volume de $20 \mathrm{~L}$ utilizando a precipitação com $\mathrm{MnO}_{2} /$ contagem gama e precipitação com $\mathrm{Fe}(\mathrm{OH})_{3}$ apresentaram os maiores desvios padrão relativos. É interessante notar que o desvio padrão relativo foi geralmente 2 a 3 vezes maior que o erro de contagem, 0 que indica que as incertezas globais não dependem única e exclusivamente da estatística das medidas.

TABELA 3 - Resultados do exercício de intercomparação da determinação de ${ }^{234} \mathrm{Th}$ em água do mar utilizando-se 3 diferentes métodos (NELHA $-600 \mathrm{~m}$ de profundidade).

\begin{tabular}{cccccc}
\hline Vol. (L) & Método & ${ }^{234}$ Th $\left(\mathbf{d p m ~ L} \mathbf{L}^{-1}\right)$ & $\begin{array}{c}\text { Desvio } \\
\text { padrão }(\%)\end{array}$ & $\begin{array}{c}\text { Erro de } \\
\text { contagem }(\mathbf{1 \sigma})\end{array}$ & $\mathbf{N}$ \\
\hline 20 & Mn-ppt/ beta & $1,94 \pm 0,19$ & 9,8 & 2,6 & 18 \\
2 & Mn-ppt/ beta & $2,07 \pm 0,12$ & 5,6 & 3,4 & 4 \\
20 & Mn-ppt/ gama & $1,99 \pm 0,22$ & 10,9 & 3,5 & 7 \\
20 & Fe-ppt/ beta & $2,03 \pm 0,31$ & 15,5 & 3,9 & 6 \\
\hline
\end{tabular}

Para a determinação de ${ }^{234} \mathrm{Th}$ total, a metodologia que utiliza cartuchos de acrílico impregnados com $\mathrm{MnO}_{2}$ mostrou desvantagens significativas quando comparado com o método de pequeno volume ( $2 \mathrm{~L}$ ). Além de um esforço maior, a amostragem deste método é mais custosa e demorada, e muitas vezes, necessita que se use 2 cartuchos em série para a determinação da eficiência total do processo de extração. Estas eficiências podem variar de $10 \%$ a $30 \%$ entre um par de colunas em série. Isto resulta num acréscimo na incerteza global de $10 \%$ a $15 \%$. Por outro lado, um atributo positivo desta metodologia é que o ${ }^{234} \mathrm{Th}$ pode ser detectado diretamente por espectrometria gama, sem a necessidade de separações radioquímicas mais demoradas. 
Concluiu-se a partir deste estudo que a precisão e exatidão do método de coprecipitação de ${ }^{234} \mathrm{Th}$ a partir do volume de $2 \mathrm{~L}$ é igual ou melhor àquelas obtidas com outras metodologias.

\subsection{Estimativa das concentrações de ${ }^{238} \mathrm{U}$ em amostras de água do mar a partir da correlação com a salinidade}

Uma relação linear entre a concentração de ${ }^{238} \mathrm{U}$ e a salinidade é bem estabelecida na literatura, devido o ${ }^{238} \mathrm{U}$ ser um radionuclídeo de meia-vida longa de caráter conservativo na água do mar, à sua atividade variar pouquíssimo em função da profundidade e à pequena variação de salinidade em águas oceânicas da Antártica e do Ártico (Owens et al., 2011). A concentração de ${ }^{238} \mathrm{U}$ é proporcional à salinidade de acordo com a relação (Chen et al., 1986):

$$
{ }^{238} U\left(\text { dpm } L^{-1}\right)=0,069 \times \text { Salinidade }
$$

\subsection{Determinação radioquímica de ${ }^{210} \mathrm{Po} e \mathrm{em}$ amostras de água do mar}

\subsubsection{Princípio do método}

Neste projeto foram utilizadas 2 metodologias diferentes para a determinação de ${ }^{210} \mathrm{Po}$ nas amostras de material particulado (Nieri Neto, 1996; Damatto et al., 2009). A técnica para determinação de ${ }^{210} \mathrm{Po}$ consiste na deposição espontânea dos isótopos de $\mathrm{Po}$ em disco de $\mathrm{Ag}$, $\mathrm{Cu}$ ou $\mathrm{Ni}$ em meio $\mathrm{HCl}$ e a determinação da sua atividade é realizada por espectrometria alfa em um detector de barreira de superfície (IAEA, 2009). 


\subsubsection{Procedimento radioquímico utilizado para a determinação de ${ }^{210} \mathrm{Po}$ nas amostras da OPERANTAR XXIX (Damatto et al., 2009)}

A bordo do navio, após a coleta as amostras de água do mar (volumes de 2 a 6 L) foram filtradas a vácuo em sistema Manifold, utilizando papel de filtro em microfibra de vidro Millipore AP20047 com porosidade nominal de 0,45 $\mu \mathrm{m}$. A seguir, os filtros foram secos e armazenados em placas de Petri Nalgene até 0 retorno ao Brasil (FIG. 14 a,b).

No LRA, os filtros com o material particulado foram secos em estufa na temperatura $\leq 80^{\circ} \mathrm{C}$ por 1 hora e resfriados em dessecador por 30 minutos, para pesagem em balança analítica. Este procedimento foi repetido até obtenção de peso constante para determinação da massa do material particulado (FIG. 14 c,d).

Os filtros foram colocados em béqueres de teflon, aos quais foram adicionados $100 \mu \mathrm{L}$ do traçador de ${ }^{209} \mathrm{Po}\left(\mathrm{A}=2,0599 \mathrm{~Bq} \mathrm{~mL}^{-1}\right)$ e $2 \mathrm{~mL}$ de HF $40 \%$ para dissolução do papel de filtro. Em seguida as amostras foram levadas à secura em chapa aquecedora com temperatura controlada $\left(\leq 80^{\circ} \mathrm{C}\right)$ para evitar perdas do Po por volatilização (FIG. 14 e).

Para eliminação da matéria orgânica presente nos particulados, foram

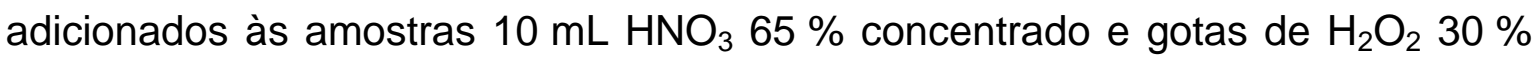
sob aquecimento (temperatura $\leq 80^{\circ} \mathrm{C}$ ). Este processo foi realizado até que se obtivesse uma amostra límpida.

Posteriormente, foram adicionados $10 \mathrm{~mL} \mathrm{HCl}$ concentrado sob aquecimento (temperatura $\leq 80^{\circ} \mathrm{C}$ ) até a secura. Este processo foi repetido 3 vezes e por fim foram adicionados $5 \mathrm{~mL}$ de $\mathrm{HCl}$ 6,25 M (FIG. $14 \mathrm{f}$ ).

As amostras foram filtradas à vácuo com funil de Büchner de porcelana e kitassato de vidro utilizando papel de filtro em microfibra de vidro Millipore AP20047 com porosidade nominal de 0,45 $\mu \mathrm{m}$. A solução filtrada foi transferida com água ultrapura para um tubo de centrífuga e o papel de filtro com as impurezas foi descartado em lixo radioativo. 


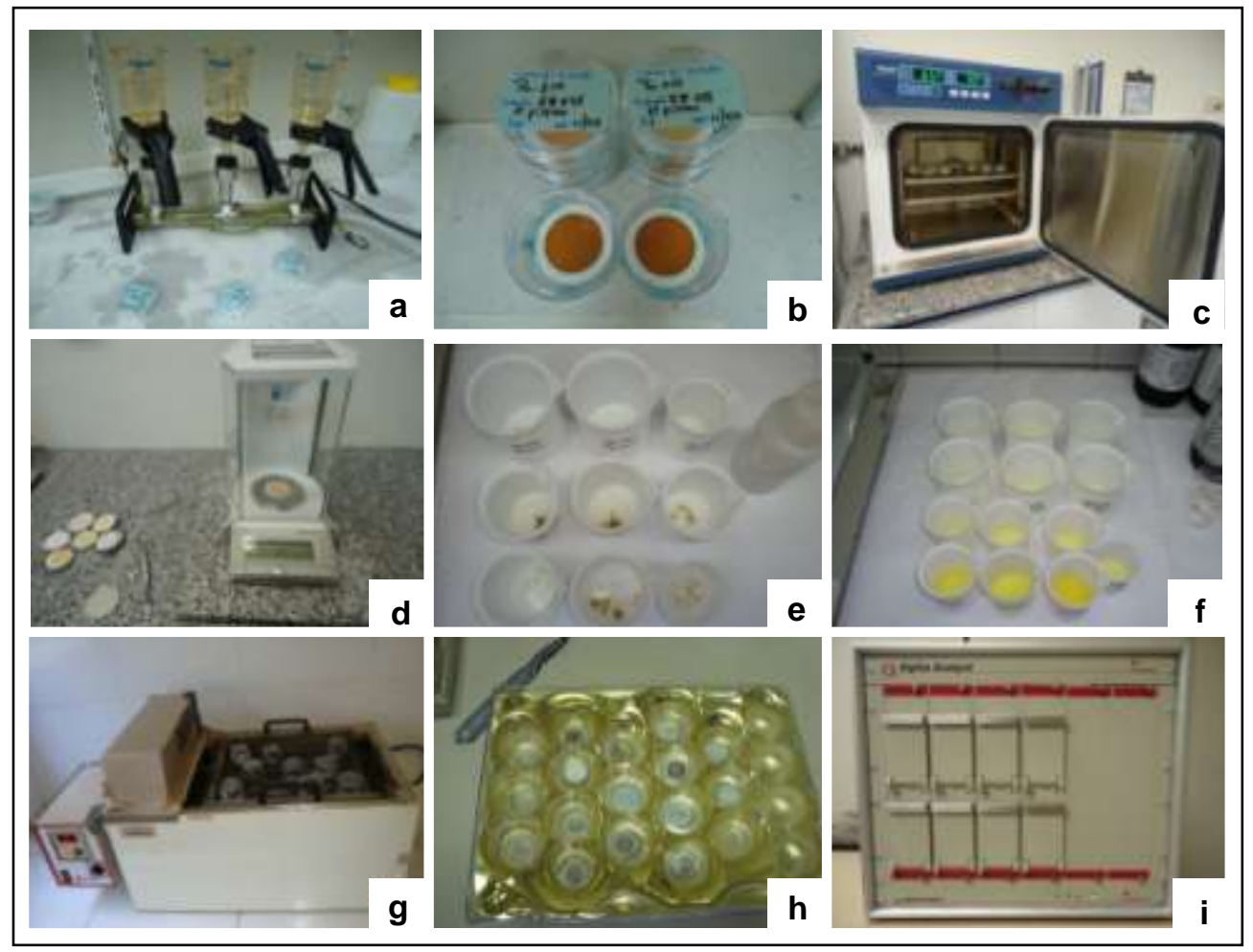

FIGURA 14 - a) Filtragem das amostras à vácuo em sistema Manifold; b) Filtros com material particulado; c) Secagem dos filtros em estufa; d) Pesagem dos filtros em balança analítica; e) Lixiviação dos filtros; f) Abertura total das amostras; g) Banho-maria com agitação constante para deposição espontânea dos isótopos de Po em disco de Ag; h) Amostras de Po depositadas em disco de Ag; i) Espectrômetro alfa de barreira de superfície, modelo Alpha Analyst da Canberra.

À solução filtrada foram adicionados $10 \mathrm{~mL}$ de cloridrato de hidroxilamina $20 \%, 10 \mathrm{~mL}$ de citrato de sódio $25 \%$, que atuam como agentes complexantes de $\mathrm{Fe}^{+3}$, diminuindo a deposição de interferentes no disco de $\mathrm{Ag}$, e $200 \mu \mathrm{L}$ de carregador de $\mathrm{Bi}^{+3}\left(50 \mathrm{~g} \mathrm{~L}^{-1}\right)$. A solução resultante foi diluída com água purificada até $100 \mathrm{~mL}$, e o pH foi ajustado a 1,5 com a adição de $\mathrm{HCl}$ 6,25 M e/ou $\mathrm{NH}_{4} \mathrm{OH}$.

Os discos de Ag foram devidamente polidos, lavados, secos, e foram presos em suportes de polietileno. A seguir, estes suportes foram colocados em tubos de centrífuga contendo a solução citada anteriormente.

Os tubos contendo a solução e os discos de Ag foram deixados em banho-maria, com temperatura controlada $\leq 80^{\circ} \mathrm{C}$ e agitação constante, por um 
período de 4 horas para que ocorresse a deposição espontânea dos isótopos de Po em disco de Ag. Após o período de deposição, os discos foram retirados, lavados abundantemente com água ultrapura e deixados secar em temperatura ambiente. Os discos foram contados em um detector de barreira de superfície, modelo Alpha Analyst da Canberra, para a realização da medida do Po por um período de 300.000 segundos (FIG. 14 g,h,i).

\subsubsection{Procedimento radioquímico utilizado para a determinação sequencial de ${ }^{210} \mathrm{Po} /{ }^{210} \mathrm{~Pb}$ nas amostras da OPERANTAR XXX (Nieri Neto, 1996)}

A determinação de ${ }^{210} \mathrm{Po} /{ }^{210} \mathrm{~Pb}$ foi realizada por um método radioquímico sequencial onde os isótopos de Po são depositados espontaneamente em discos de $\mathrm{Cu}$ em meio de $\mathrm{HCl}$. A atividade do ${ }^{210} \mathrm{Po}$ é determinada por espectrometria alfa em um detector de barreira de superfície. $\mathrm{O}$ ${ }^{210} \mathrm{~Pb}$ é coprecipitado como $\mathrm{PbCrO}_{4}$ e sua medida é realizada pelo seu produto de decaimento radioativo, o ${ }^{210} \mathrm{Bi}$, emissor beta, em detector proporcional de fluxo gasoso de baixa radiação de fundo.

A bordo do navio, após coleta as amostras foram filtradas a vácuo em sistema Manifold utilizando papel de filtro em microfibra de vidro Millipore AP20047, com porosidade nominal de $0,45 \mu \mathrm{m}$. Os filtros foram secos e armazenados em placas de Petri Nalgene até o retorno ao Brasil (FIG. 15 a,b).

No LRA os filtros com o material particulado foram secos em estufa (temperatura $\leq 80^{\circ} \mathrm{C}$ ) por 1 hora e resfriados em dessecador por 30 minutos para obtenção da massa em balança analítica. O procedimento foi repetido até obtenção de peso constante para determinação da massa do material particulado (FIG. 15 c,d,e). 


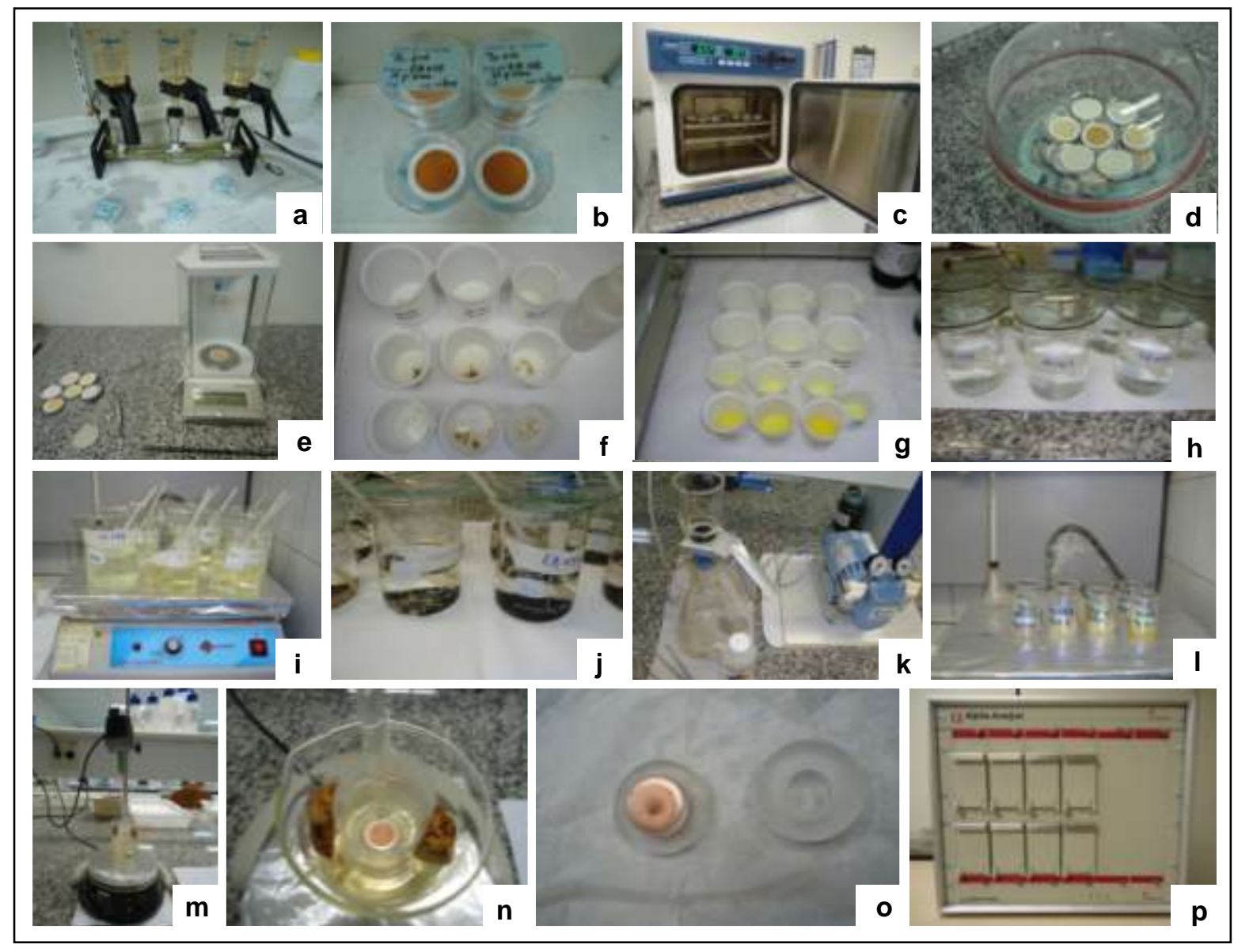

FIGURA 15 - a) Filtragem à vácuo das amostras em sistema Manifold; b) Filtros com material particulado; c) Secagem dos filtros em estufa; d) Resfriamento dos filtros em dessecador; e) Pesagem dos filtros em balança analítica; f) Lixiviação dos filtros; g) Abertura total das amostras; h) Diluição das amostras com água purificada e adição de reagentes; i) Amostras sob aquecimento em chapa aquecedora; j) Amostras precipitadas com $\mathrm{Na}_{2} \mathrm{~S} 1 \mathrm{M}$; k) Filtragem a vácuo das amostras em sistema Millipore; I) Dissolução dos filtros sob aquecimento em chapa aquecedora; $m$ e $n$ ) Banho-maria com agitação constante para deposição espontânea dos isótopos de Po em disco de $\mathrm{Cu}$; o) Amostra de Po depositada em disco de $\mathrm{Cu}$; p) Espectrômetro alfa de barreira de superfície, modelo Alpha Analyst da Canberra.

Os filtros foram colocados em béqueres de teflon e lixiviados com a adição de $2 \mathrm{~mL}$ de HF $40 \%$ para dissolução do papel de filtro. A seguir, as amostras foram levadas à secura em chapa aquecedora com temperatura controlada $\left(\leq 80^{\circ} \mathrm{C}\right)$ para evitar perdas do Po por volatilização (FIG. $15 \mathrm{f}$ ). 
As amostras foram ressuspendidas com $10 \mathrm{~mL} \quad \mathrm{HNO}_{3} \quad 65 \%$ concentrado e gotas de $\mathrm{H}_{2} \mathrm{O}_{2} 30 \%$ sob aquecimento (temperatura $\leq 80{ }^{\circ} \mathrm{C}$ ) até secura. Este procedimento foi repetido até eliminação total da matéria orgânica.

Após abertura total, as amostras foram transferidas para béqueres de vidro de $500 \mathrm{~mL}$ de capacidade com auxílio de água ultrapura e seu volume foi ajustado para $300 \mathrm{~mL}$. Nesta solução foram adicionados gotas de vermelho de metila, $10 \mathrm{~mL}$ de solução de $\mathrm{NaOH} 20 \mathrm{~mol} \mathrm{~L}^{-1}$ para ajuste de $\mathrm{pH}$ 7,0 (viragem de cor de vermelho para amarelo) e por fim foram adicionados $1 \mathrm{~mL}$ de carregador de $\mathrm{Pb}^{+2}\left(20 \mathrm{mg} \mathrm{mL}^{-1}\right)$ e $100 \mu \mathrm{L}$ de traçador de ${ }^{209} \mathrm{Po}\left(\mathrm{A}=1,7251 \mathrm{~Bq} \mathrm{~mL}^{-1}\right)$ (FIG. 15 $g, h)$.

A solução foi levada para aquecimento em chapa aquecedora com temperatura controlada $\left(\leq 80^{\circ} \mathrm{C}\right)$ e então foram adicionados $2 \mathrm{~mL}$ de $\mathrm{Na}_{2} \mathrm{~S}$ $\left(1 \mathrm{~mol} \mathrm{~L}^{-1}\right)$ para formação dos precipitados de $\mathrm{Pb}(\mathrm{Po}) \mathrm{S}$. A solução foi deixada decantar por uma noite (FIG. $15 \mathrm{i}, \mathrm{j})$.

As amostras foram filtradas à vácuo em sistema Millipore utilizando papel de acetato com porosidade nominal de $0,45 \mu \mathrm{m}$. Os filtros contendo 0 precipitado $\mathrm{Pb}(\mathrm{Po}) \mathrm{S}$ foram transferidos para béqueres de vidro de $50 \mathrm{~mL}$ de capacidade, aos quais foram adicionados $20 \mathrm{~mL}$ de $\mathrm{HNO}_{3} 65 \%$ concentrado sob aquecimento $\left(\leq 80^{\circ} \mathrm{C}\right)$ para oxidação de $\mathrm{S}^{-2}$ a $\mathrm{SO}_{4}{ }^{-2}$ e dissolução do papel de filtro (FIG. $15 \mathrm{k}$ ).

Terminada a oxidação do precipitado (coloração do precipitado muda de preta para branca) a solução foi levada a secura e posteriormente foram adicionados $0,5 \mathrm{~mL}$ de $\mathrm{HNO}_{3} 65 \%$ concentrado e $40 \mathrm{~mL}$ de água purificada (FIG. 15 I).

A solução foi transferida para tubo de centrífuga com auxílio de água ultrapura e posteriormente foi centrifugada por 15 minutos a $1.700 \mathrm{rpm}$. Nesta etapa, os isótopos de Po se encontram no sobrenadante e o $\mathrm{Pb}$ é separado no precipitado de $\mathrm{PbSO}_{4}$. 
Os discos de $\mathrm{Cu}$ foram previamente limpos com $\mathrm{HCl}$ concentrado, lavados, secos e presos em suportes de polietileno. A solução foi transferida para um frasco de polietileno contendo o disco de Cu preso no suporte, aonde foram adicionados cerca de $0,05 \mathrm{~g}$ de ácido ascórbico e $20 \mathrm{~mL}$ de $\mathrm{HCl} 2 \mathrm{M}$. O frasco foi colocado em banho-maria com temperatura controlada $\left(\leq 80^{\circ} \mathrm{C}\right)$ sob agitação constante por um período de 4 horas para que ocorresse a deposição espontânea dos isótopos de Po em disco de Cu (FIG. 15 m,n,o).

Ao término da deposição dos isótopos de $\mathrm{Po}$ em disco de $\mathrm{Cu}$, a solução foi transferida para seu respectivo tubo de centrífuga (contendo o precipitado de $\mathrm{PbSO}_{4}$ ) e o disco de $\mathrm{Cu}$ foi retirado, lavado abundantemente com água purificada e deixado secar em temperatura ambiente. A medida do Po foi realizada pela contagem no espectrômetro alfa de barreira de superfície modelo Alpha Analyst da Canberra por um período de 300.000 segundos (FIG. 15 p).

O sobrenadante (utilizado para a deposição do Po) e o precipitado foram transferidos para um béquer de vidro de $500 \mathrm{~mL}$ de capacidade e a solução foi avolumada para $300 \mathrm{~mL}$ com água ultrapura. À solução foram adicionados $4 \mathrm{~mL}$ de $\mathrm{CH}_{3} \mathrm{COONH}_{4} 40 \%$ sob aquecimento para dissolução completa do precipitado de $\mathrm{PbSO}_{4}$ (FIG. 16 a).

Em seguida a amostra foi filtrada em sistema comum em papel de filtro faixa preta (filtragem rápida). $\mathrm{O} \mathrm{pH}$ foi ajustado para 4,5 - 5,0 com a adição de $\mathrm{CH}_{3} \mathrm{COONH}_{4} 40 \%$ e então foi levada para aquecimento. Após o aquecimento foi adicionado à solução $1 \mathrm{~mL}$ de $\mathrm{Na}_{2} \mathrm{CrO}_{4} 30 \%$ para formação do precipitado $\mathrm{PbCrO}_{4}$ e a amostra foi deixada decantar por uma noite (FIG. 16 b).

As amostras foram filtradas com auxílio de solução de álcool etílico PA $50 \%$ em sistema Millipore utilizando papel de filtro em microfibra de vidro Millipore AP20047 com porosidade nominal de 0,45 $\mu \mathrm{m}$ (FIG. 16 c). 


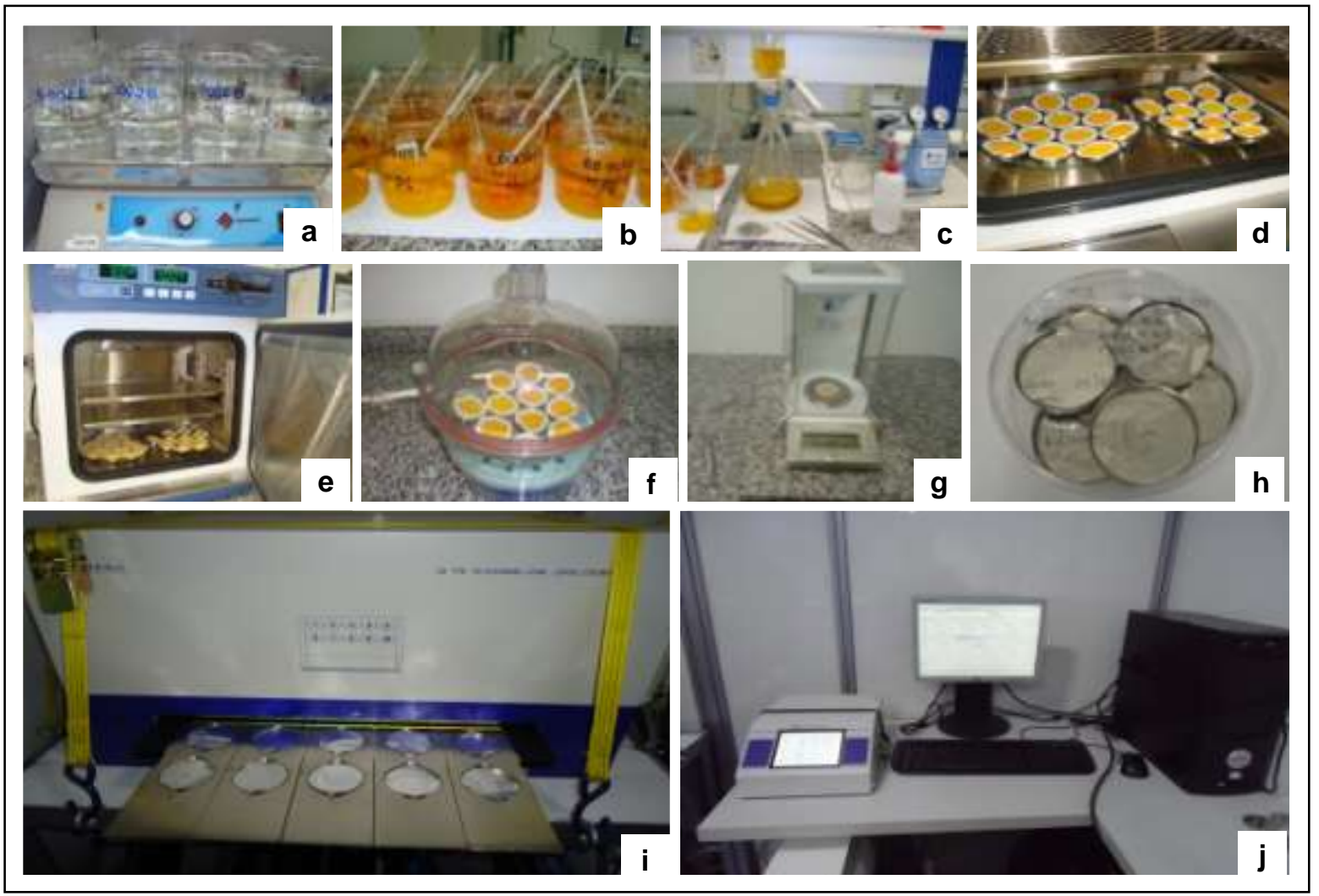

FIGURA 16 - a) Dissolução do $\mathrm{PbSO}_{4}$; b) Precipitação das amostras com $\mathrm{Na}_{2} \mathrm{CrO}_{4} 30 \%$; c) Filtragem a vácuo das amostras precipitadas em sistema Millipore; d) Filtros com precipitado de $\mathrm{PbCrO}_{4}$; e) Secagem dos filtros em estufa; f) Resfriamento dos filtros em dessecador; g) Pesagem dos filtros em balança analítica; h) Filtros na geometria de contagem; i e j) Detector proporcional de fluxo gasoso de baixa radiação de fundo, Berthold LB 770 .

Os filtros foram secos em estufa a $100{ }^{\circ} \mathrm{C}$ por 1 hora e resfriados em dessecador por 30 minutos, para posterior pesagem em balança analítica. $O$ procedimento foi repetido até obtenção de peso constante para determinação do rendimento químico do processo (FIG. 16 d,e,f).

Os filtros contendo os precipitados foram colocados na geometria de contagem, envoltos por papel tipo Contact, dispostos em plaquetas de aço inox e cobertos com uma película de poliéster aluminizada. A medida de ${ }^{210} \mathrm{~Pb}$ foi realizada pela detecção de seu produto de decaimento radioativo, $0{ }^{210} \mathrm{Bi}$, radionuclídeo emissor beta de alta energia em detector proporcional de fluxo gasoso de baixa radiação de fundo, modelo Berthold LB 770, durante um período de 1 ciclo de 200 minutos. A contagem foi realizada após 10 dias da data de 
precipitação, tempo este necessário para que $0{ }^{210} \mathrm{~Pb}$ atinja equilíbrio com $\circ{ }^{210} \mathrm{Bi}$ (FIG. 16 h,i,j).

\subsubsection{Cálculo da concentração de atividade de ${ }^{210} \mathrm{Po}$}

A concentração de atividade de ${ }^{210} \mathrm{Po}$ foi calculada a partir da seguinte equação:

$$
A\left({ }^{210} P o\right)=\left(\frac{R n\left({ }^{210} P o\right)-B G}{t \times E F \alpha \times R Q \times Q}\right) \times 60
$$

Onde:

$\mathrm{A}\left({ }^{210} \mathrm{Po}\right)=$ atividade de ${ }^{210} \mathrm{Po}\left(\mathrm{dpm} \mathrm{L} \mathrm{L}^{-1}\right)$;

$\mathrm{Rn}\left({ }^{210} \mathrm{Po}\right)=$ área relativa ao pico do ${ }^{210} \mathrm{Po}$ (counts);

$B G$ = área relativa à radiação de fundo do detector (counts);

$\mathrm{t}=$ tempo de contagem (s);

$E F \alpha=$ eficiência de contagem alfa $\left(\mathrm{cps} \mathrm{dps}^{-1}\right)$;

$R Q$ = rendimento químico do processo de deposição espontânea, determinado pela recuperação do traçador de ${ }^{209} \mathrm{Po}$;

$\mathrm{Q}=$ quantidade de amostra $(\mathrm{L})$.

\subsubsection{Determinação da eficiência de contagem alfa para a quantificação de ${ }^{210} \mathrm{Po}$}

Para determinação da eficiência de contagem alfa foi utilizada uma fonte de ${ }^{241} \mathrm{Am}$ com atividade nominal de $55,5 \mathrm{kBq}$ fornecida pela Amersham International, que foi contada em espectrômetro alfa por 300 segundos na mesma geometria de contagem das amostras. O cálculo da eficiência da contagem alfa foi realizado pela seguinte equação: 


$$
E F \alpha=\frac{C f}{A f \times t} \times 100
$$

Onde:

$\mathrm{EF} \alpha=$ eficiência de contagem alfa $\left(\mathrm{cps} \mathrm{dps}^{-1}\right)$;

$\mathrm{Cf}=$ contagem $\mathrm{da}$ fonte de ${ }^{241} \mathrm{Am}(\mathrm{cps})$;

$\mathrm{Af}=$ atividade corrigida da fonte de ${ }^{241} \mathrm{Am}(\mathrm{Bq})$;

$\mathrm{t}=$ tempo de contagem da fonte de ${ }^{241} \mathrm{Am}(\mathrm{s})$.

O valor médio da eficiência de contagem alfa do detector utilizado para determinação de ${ }^{210}$ Po nas amostras da OPERANTAR XXIX foi de 0,46 $\mathrm{cps} \mathrm{dps}^{-1}$, e o valor médio da eficiência do detector utilizado para determinação de ${ }^{210} \mathrm{Po}$ nas amostras da OPERANTAR XXX foi de $0,2297 \mathrm{cps} \mathrm{dps}^{-1} \pm 0,0073$.

\subsubsection{Determinação da curva de calibração canal $x$ energia}

A curva de calibração da energia em função do canal foi determinada a fim de se obter a localização exata dos picos correspondentes às energias das partículas emitidas pelos radioisótopos de interesse. Neste estudo os isótopos ${ }^{209} \mathrm{Po}$ e ${ }^{210} \mathrm{Po}$ emitem partículas com energias de $4,885 \mathrm{MeV}$ e 5,304 MeV, respectivamente.

Para obtenção da curva de calibração foi utilizada uma fonte tríplice (AMR 43) composta por ${ }^{241} \mathrm{Am} \quad(5,4856 \mathrm{MeV}),{ }^{244} \mathrm{Cm} \quad(5,8046 \mathrm{MeV})$ e ${ }^{239} \mathrm{Pu}$ $(5,1566 \mathrm{MeV})$ com atividade nominal de $5,55 \mathrm{kBq}$ fornecida pela Amersham International, a qual foi contada em espectrômetro alfa por 300 segundos na mesma geometria de contagem das amostras.

A equação da reta foi construída a partir das energias de ${ }^{241} \mathrm{Am},{ }^{244} \mathrm{Cm}$ $\mathrm{e}^{239} \mathrm{Pu}$ : 


$$
E=0,0067 \cdot C+0,033
$$

Onde:

$\mathrm{E}=$ energia $(\mathrm{MeV})$;

$\mathrm{C}=$ canal.

\subsubsection{Determinação da radiação de fundo}

Para determinação da radiação de fundo do detector foi realizada medida dos discos de Ag e Cu previamente limpos por 300.000 segundos na mesma geometria de contagem das amostras.

\subsubsection{Determinação do rendimento químico}

O rendimento químico do processo foi determinado pela recuperação obtida do traçador ${ }^{209} \mathrm{Po}$ adicionado no início de cada análise. As soluções de traçador ${ }^{209} \mathrm{Po}$ com atividade de 2,0599 Bq de ${ }^{209} \mathrm{Po} \mathrm{mL}^{-1}$ utilizada nas amostras da OPERANTAR XXIX e com atividade de $1,7251 \mathrm{~Bq}$ de ${ }^{209} \mathrm{Po} \mathrm{mL}^{-1}$ utilizada nas amostras da OPERANTAR XXX para determinação de ${ }^{210} \mathrm{Po}$ foram preparadas a partir de uma solução padrão de ${ }^{209} \mathrm{Po}$ fornecida pelo National Institute of Standards \& Technology (NIST).

A equação utilizada para calcular o rendimento químico do processo foi:

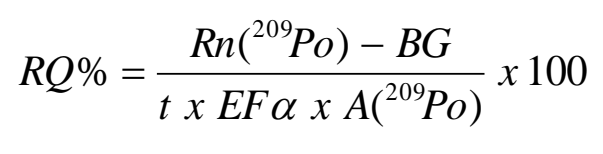

Onde:

$\mathrm{RQ} \%$ = rendimento químico (\%);

$\mathrm{Rn}\left({ }^{209} \mathrm{Po}\right)=$ área relativa ao pico do ${ }^{209} \mathrm{Po}$ (counts);

$\mathrm{BG}$ = área relativa à radiação de fundo do detector (counts); 
$\mathrm{t}=$ tempo de contagem (s);

$\mathrm{EF} \alpha=$ eficiência de contagem alfa $\left(\mathrm{cps} \mathrm{dps}^{-1}\right)$;

$\mathrm{A}\left({ }^{209} \mathrm{Po}\right)=$ atividade de traçador ${ }^{209} \mathrm{Po}$ adicionado à amostra no início de cada análise $(\mathrm{Bq})$.

O valor médio do rendimento químico das análises realizadas na OPERANTAR XXIX foi de $30 \%$, e na OPERANTAR XXX os valores estiveram entre 22,09 e $61,35 \%$.

\subsubsection{Determinação do limite inferior de detecção (LID)}

O cálculo do LID é dado por:

$$
L I D=\frac{4,66 \times \sqrt{R n\left({ }^{210} P o\right)}}{t \times E F \propto \times R Q \times Q}
$$

Onde:

LID = limite inferior de detecção;

$\operatorname{Rn}\left({ }^{210} \mathrm{Po}\right)=$ taxa de contagem do branco do processo (counts);

$\mathrm{t}=$ tempo de contagem (s);

$E F \alpha=$ eficiência de contagem alfa $\left(\mathrm{cps} \mathrm{dps}^{-1}\right)$;

$\mathrm{RQ}=$ rendimento químico (\%);

$\mathrm{Q}=$ quantidade de amostra de água purificada utilizada como branco do processo $(\mathrm{L})$;

4,66 = valor que corresponde a um risco pré-estabelecido de que existe determinado nível de atividade na amostra, quando na realidade não existe e de que não existe atividade presente na amostra quando na realidade existe, considerando um nível de confiança de $95 \%$. 


\subsubsection{Validação da metodologia para determinação de ${ }^{210} \mathrm{Po}$}

A metodologia utilizada para quantificar ${ }^{210} \mathrm{Po}$ na OPERANTAR $X X X$, que tem a vantagem de permitir a separação sequencial de ${ }^{210} \mathrm{~Pb}$ na mesma amostra, foi validada pela participação do LRA no teste de proficiência organizado pela IAEA, intitulado "The IAEA-CU-2007-09 world-wide open proficiency test on the determination of ${ }^{210} \mathrm{Po}$ in water". Um total de 3 amostras de água foram analisadas em triplicata utilizando-se a metodologia descrita por Nieri Neto (1996). As incertezas foram inferiores a $3 \%$ e a precisão $\leq 5 \%$. A avaliação geral dos resultados reportados nesta intercomparação indicou boa concordância com os valores de referência estabelecidos pela IAEA e não foram influenciados por erros sistemáticos. Os resultados obtidos são apresentados na TAB. 4.

TABELA 4 - Resultados da validação da metodologia de quantificação do ${ }^{210} \mathrm{Po}$, pela participação no IAEA-CU-2007-09.

\begin{tabular}{cccccc}
\hline Amostra & $\begin{array}{c}\text { Valor IAEA } \pm \\
\text { Incerteza }\left(\mathbf{B q ~ L}^{-1}\right)\end{array}$ & $\begin{array}{c}\text { Valor LRA } \pm \\
\text { Incerteza }\left(\mathrm{Bq} \mathrm{L}^{-1}\right)\end{array}$ & $\begin{array}{c}\text { Desvio } \\
\text { padrão (\%) }\end{array}$ & $\begin{array}{c}\text { Erro } \\
\text { relativo (\%) }\end{array}$ & N \\
\hline 1 & $52,8 \pm 1,4$ & $49 \pm 2$ & 4,9 & 7,2 & 3 \\
2 & $101,6 \pm 2,8$ & $96 \pm 3$ & 4,2 & 5,5 & 3 \\
3 & $52,8 \pm 1,4$ & $47 \pm 2$ & 5,0 & 10,9 & 3 \\
\hline
\end{tabular}

Para validação do método utilizado para determinação de ${ }^{210} \mathrm{Po}$ na OPERANTAR XXIX foram preparadas 5 amostras de material de referência - Irish Sea Sediment (IAEA-385) fornecida pela IAEA. Foram pesados cerca de $0,5 \mathrm{~g}$ de material de referência em balança analítica, os quais foram analisados de acordo com a metodologia descrita por Damatto et al. (2009). Os valores obtidos estão apresentados na TAB.5. 
TABELA 5 - Resultados das concentrações de ${ }^{210}$ Po determinadas no material de referência IAEA-385.

\begin{tabular}{ccccc}
\hline Amostra (N) & Valor IAEA & Valor LRA & $\begin{array}{c}\text { Desvio } \\
\text { padrão (\%) }\end{array}$ & $\begin{array}{c}\text { Erro } \\
\text { relativo (\%) }\end{array}$ \\
\hline IAEA-385(5) & 20,97 & 21,68 & 3,9 & 16,1 \\
\hline
\end{tabular}

\subsubsection{Cálculo da concentração de atividade de ${ }^{210} \mathrm{~Pb}$}

A concentração de ${ }^{210} \mathrm{~Pb}$ foi determinada a partir da seguinte expressão:

$$
A\left({ }^{210} P b\right)=\frac{R n-B G}{60 \times R Q \times E F \beta \times Q \times\left(1-e^{-\lambda t}\right)}
$$

Onde:

$\mathrm{A}\left({ }^{210} \mathrm{~Pb}\right)=$ atividade de ${ }^{210} \mathrm{~Pb}\left(\mathrm{~Bq} \mathrm{~L}^{-1}\right)$;

$\mathrm{Rn}=$ taxa de contagem beta total $(\mathrm{cpm})$;

$B G=$ taxa de radiação de fundo beta total $(\mathrm{cpm})$;

$R Q=$ rendimento químico (\%);

$\mathrm{EF} \beta=$ eficiência de contagem beta total $\left(\mathrm{cps} \mathrm{dps}^{-1}\right)$;

$\mathrm{Q}=$ quantidade de amostra $(\mathrm{L})$.

$\lambda=$ constante de desintegração do ${ }^{210} \mathrm{Bi}\left(0,183 \mathrm{~d}^{-1}\right)$;

$\mathrm{t}=$ tempo entre a data da precipitação até a data da contagem (d);

60 = fator de conversão.

\subsubsection{Determinação da eficiência da contagem beta total de ${ }^{210} \mathrm{~Pb}$}

A eficiência da contagem beta total utilizada no cálculo da atividade do ${ }^{210} \mathrm{~Pb}$ foi determinada pela equação:

$$
E F \beta=\frac{R n-B G}{A \operatorname{corr}\left({ }^{210} P b\right) \times 60 \times R Q}
$$


Onde:

$E F \beta=$ eficiência de contagem beta total para a medida ${ }^{210} \mathrm{~Pb}\left(\operatorname{cps~dps~}^{-1}\right)$;

$\mathrm{Rn}=$ taxa de contagem beta total obtida (cpm);

$B G=$ taxa de radiação de fundo beta total $(\mathrm{cpm})$;

$\left.\mathrm{A}_{\text {corr }}{ }^{210} \mathrm{~Pb}\right)=$ atividade do padrão de ${ }^{210} \mathrm{~Pb}$ corrigida para a data da medida $(\mathrm{Bq})$;

$R Q=$ rendimento químico;

60 = fator de conversão.

Os valores das eficiências de contagem beta total para a determinação de ${ }^{210} \mathrm{~Pb}$ no detector proporcional de fluxo gasoso de baixa radiação de fundo Berthold LB 770 são apresentados na TAB. 6.

TABELA 6 - Valores das eficiências de contagem beta total para ${ }^{210} \mathrm{~Pb}$ :

\begin{tabular}{cc}
\hline Detector & $\begin{array}{c}\text { Eficiência beta }{ }^{210} \mathbf{P b} \\
\left(\text { cps dps }^{-1} \text { ) }\right.\end{array}$ \\
\hline 1 & 0,2734 \\
2 & 0,2658 \\
3 & 0,1960 \\
4 & 0,2634 \\
5 & 0,2675 \\
6 & 0,2732 \\
7 & 0,2670 \\
8 & 0,2079 \\
9 & 0,2690 \\
10 & 0,2715 \\
\hline
\end{tabular}

4.4.4.9. Determinação da radiação de fundo, rendimento químico gravimétrico e limite inferior de detecção do método

A radiação de fundo do detector foi realizada pela medida do detector vazio com o mesmo tempo de contagem da amostra, 1 ciclo de 200 minutos. Devido à baixa radiação de fundo este detector permite medir amostras que contenham níveis de radiatividade ambiental.

O rendimento químico do processo foi quantificado por gravimetria, correlacionando-se a massa dos precipitados com a massa do carregador de $\mathrm{Pb}^{2+}$ 
(20 mg mL ${ }^{-1}$ ) adicionados às amostras no início de cada análise. $O$ rendimento químico do procedimento radioquímico apresentou valor médio de $82 \%$.

O limite inferior de detecção (LID) do método foi estimado utilizando-se a equação 7. O valor médio do LID foi de $4,9 \mathrm{mBq} \mathrm{L}^{-1}$.

\subsubsection{Validação da metodologia sequencial para determinação de ${ }^{210} \mathrm{~Pb}$}

A metodologia utilizada na determinação de ${ }^{210} \mathrm{~Pb}$ foi validada pela participação trimestral do LRA no Programa Nacional de Intercomparação Interlaboratorial coordenado pelo Instituto de Radioproteção e Dosimetria (IRD) da Comissão Nacional de Energia Nuclear (CNEN). Para tanto, alíquotas representativas da massa de $125 \mathrm{~g}$ das amostras de intercomparação foram diluídas com água ultrapura para o volume de $1 \mathrm{~L}$ e foram precipitadas de acordo com a metodologia descrita por Nieri Neto (1996). As amostras foram analisadas em quadruplicata. As incertezas do método foram inferiores a $10 \%$. A avaliação dos resultados obtidos tem demonstrado boa concordância com os valores de referência estabelecidos pelo IRD.

\subsection{Determinação radioquímica de ${ }^{226} \mathrm{Ra} \mathrm{e}^{228} \mathrm{Ra}$ em amostras de água do mar}

\subsubsection{Princípio do método}

Os isótopos de Ra de meias-vidas longas foram pré-concentrados por percolação em fibras de acrílico impregnadas com $\mathrm{MnO}_{2}$. A determinação de ${ }^{226} \mathrm{Ra}$ e ${ }^{228} \mathrm{Ra}$ foi realizada pela contagem alfa e beta total, respectivamente, de um precipitado de $\mathrm{Ba}(\mathrm{Ra}) \mathrm{SO}_{4}$, em detector proporcional de fluxo gasoso de baixa radiação de fundo (Oliveira, 1993). 


\subsubsection{Procedimento radioquímico}

A bordo do navio, as amostras foram percoladas em fibras de acrílico previamente impregnadas com $\mathrm{MnO}_{2}$. Após percolação das fibras, o excesso de água foi retirado e as mesmas foram armazenadas em sacos plásticos "zip lock" até retorno ao Brasil (FIG. 17 a,b,c).

No LRA, as fibras de acrílico impregnadas com $\mathrm{MnO}_{2}$ foram colocadas em béqueres de vidro, aos quais foram adicionados $400 \mathrm{~mL}$ de $\mathrm{HCl}$ concentrado e levados para aquecimento em chapa aquecedora com temperatura controlada $\left(\leq 80^{\circ} \mathrm{C}\right)$ para evitar dissolução do acrílico, até redução do $\mathrm{Mn}^{+4}$ para $\mathrm{Mn}^{+2}$ (viragem de cor de verde para amarelo) (FIG. 17 d).

Em seguida, a solução foi filtrada em sistema comum em papel de filtro de faixa preta (filtragem rápida) e ao filtrado foram adicionados $5 \mathrm{~mL}$ de cloridrato de hidroxilamina $20 \%$ para complexar o $\mathrm{Mn}$ presente na amostra, $1 \mathrm{~mL}$ de carregador de $\mathrm{Ba}^{+2}\left(20 \mathrm{mg} \mathrm{mL}^{-1}\right), 1 \mathrm{~mL}$ de carregador de $\mathrm{Pb}^{+2}\left(20 \mathrm{mg} \mathrm{mL}^{-1}\right), 5 \mathrm{~mL}$ de ácido cítrico $1 \mathrm{M}$ para complexar o $\mathrm{Fe}$, e foram levadas para aquecimento (FIG. 17 e).

Após o aquecimento, foram adicionados $50 \mathrm{~mL}$ de $\mathrm{H}_{2} \mathrm{SO}_{4} 3 \mathrm{M}$ sob agitação constante para precipitação de todos os sulfatos presentes na amostra, $\mathrm{e}$ as amostras foram deixadas decantar por uma noite.

No dia seguinte, o sobrenadante foi retirado com auxílio de bomba de vácuo e desprezado. O precipitado foi transferido com água ultrapura para um tubo de centrífuga e foi centrifugado por 15 minutos a $1.700 \mathrm{rpm}$. O sobrenadante foi novamente retirado e desprezado, o precipitado foi lavado com $40 \mathrm{~mL}$ de $\mathrm{H}_{2} \mathrm{SO}_{4} \quad 0,1 \mathrm{M}$ e centrifugado. Mais uma vez o sobrenadante foi retirado e desprezado. Foram realizadas duas etapas de purificação no precipitado para eliminar possíveis elementos interferentes presentes na amostra. 


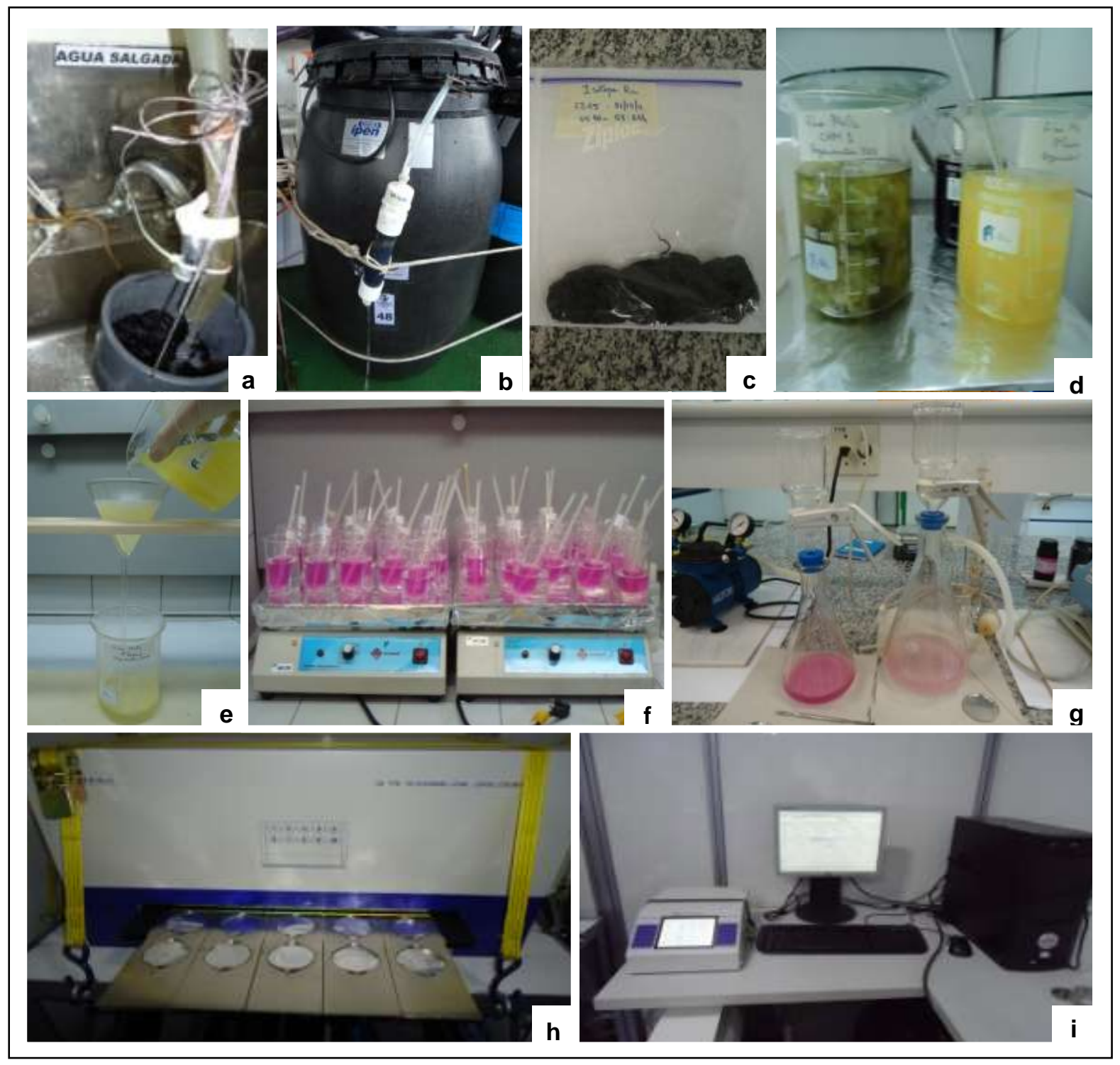

FIGURA 17 -a) Percolação da amostra pela fibra em recipiente vazado b) Tambores para coleta das amostras de água do mar e percolação da amostra pela filbra na coluna; c) Fibras de acrílico impregnadas com $\mathrm{MnO}_{2}$ após percolação das amostras; d) Amostras sob aquecimento em chapa aquecedora para redução do $\mathrm{Mn}^{+4}$ a $\mathrm{Mn}^{+2}$; e) Filtragem das amostras em sistema comum; f) Precipitação das amostras; g) Filtração a vácuo das amostras em sistema Millipore; h e i) Detector proporcional de fluxo gasoso de baixa radiação de fundo, Berthold LB 770 .

Na primeira purificação, foram adicionados ao precipitado $2,0 \mathrm{~g}$ de NTA (ácido nitrilotriacético), $40 \mathrm{~mL}$ de água ultrapura, 4 gotas de indicador de vermelho de metila, e $2 \mathrm{~mL}$ de hidróxido de sódio $6 \mathrm{M}$. As amostras foram aquecidas em banho-maria até dissolução total do precipitado e a esta solução foram 
adicionados $5 \mathrm{~mL}$ de solução de sulfato de amônio $25 \mathrm{mg} \mathrm{mL}^{-1}$ e $5 \mathrm{~mL}$ de ácido acético glacial PA para que ocorresse a precipitação. As amostras foram deixadas decantar por uma noite. Posteriormente, os tubos de centrífuga foram centrifugados por 15 minutos a $1.700 \mathrm{rpm}$, o sobrenadante foi desprezado e o precipitado foi lavado com acetato de amônio 40 \% e foi novamente centrifugado e o sobrenadante desprezado.

$\mathrm{Na}$ segunda purificação, foram adicionados ao precipitado $2,0 \mathrm{~g}$ de EDTA (ácido etileno diaminotetraacético), $40 \mathrm{~mL}$ de água ultrapura, 4 gotas de indicador de vermelho de metila, e $5 \mathrm{~mL}$ de hidróxido de amônio PA. As amostras foram aquecidas em banho-maria até dissolução total do precipitado e obtenção de uma solução límpida, e por fim foram adicionados $5 \mathrm{~mL}$ de sulfato de amônio (25 mg mL ${ }^{-1}$ ) e $5 \mathrm{~mL}$ de ácido acético glacial PA para formação do precipitado de $\mathrm{Ba}(\mathrm{Ra}) \mathrm{SO}_{4}$. As amostras foram deixadas decantar por uma noite (FIG. $17 \mathrm{f}$ ).

As amostras foram filtradas com auxílio de solução de álcool etílico PA $50 \%$ em sistema Millipore utilizando papel de filtro em microfibra de vidro Millipore AP20047 com porosidade nominal de 0,45 $\mu \mathrm{m}$ (FIG. $17 \mathrm{~g}$ ).

Os filtros foram colocados na geometria de contagem, em plaquetas de aço inox e guardados até o momento da contagem, 21 dias após a data precipitação, tempo este necessário para que os pais atingissem equilíbrio com seus filhos, em detector proporcional de fluxo gasoso de baixa radiação de fundo, modelo Berthold LB 770 (FIG. 17 h,i).

Após as contagens, os filtros foram secos em estufa a $100^{\circ} \mathrm{C}$ por 1 hora e resfriados em dessecador por 30 minutos para pesagem em balança analítica. Este procedimento foi repetido até obtenção de peso constante para determinação do rendimento químico do processo.

\subsubsection{Cálculo da concentração de atividade de ${ }^{226} \mathrm{Ra}$}

A concentração de ${ }^{226} \mathrm{Ra}$ presente nas amostras foi determinada a partir da seguinte expressão: 


$$
A\left({ }^{226} R a\right)=\frac{R n-B g}{60 . R Q \cdot E F \alpha \cdot f a b s \cdot\left[1+k\left(1-e^{-\lambda . t}\right)\right] \cdot Q}
$$

Onde:

$\mathrm{A}\left({ }^{226} \mathrm{Ra}\right)=$ atividade de ${ }^{226} \mathrm{Ra}\left(\mathrm{Bq} \mathrm{L}^{-1}\right)$;

$\mathrm{Rn}=$ taxa de contagem alfa total da amostra (cpm);

$\mathrm{Bg}=$ taxa de radiação de fundo alfa total (cpm);

$\mathrm{RQ}=$ rendimento químico;

$E F \alpha=$ eficiência de contagem alfa total, calculada pelo ${ }^{241} \mathrm{Am}\left(\mathrm{cps} \mathrm{dps}^{-1}\right)$;

$\mathrm{Q}=$ quantidade de amostra $(\mathrm{L})$;

fabs = coeficiente de autoabsorção do ${ }^{226} \mathrm{Ra}$ no precipitado de $\mathrm{Ba}(\mathrm{Ra}) \mathrm{SO}_{4}$;

$\lambda^{222} \mathrm{Rn}=0,181 \mathrm{~d}^{-1}$;

$\mathrm{t}=$ tempo entre a data da precipitação até a data da contagem (d);

$\mathrm{k}$ = constante que leva em conta a diferença entre os coeficientes de autoabsorção das 4 partículas alfa que são emitidas no decaimento do 226Ra e que tem as energias: ${ }^{226} \mathrm{Ra}$ energia de $4,8 \mathrm{MeV},{ }^{222} \mathrm{Rn}$ energia de $5,5 \mathrm{MeV},{ }^{218} \mathrm{Po}$ energia de 6,0 MeV e ${ }^{214} \mathrm{Po}$ energia de 7,7 MeV.

$$
k=\frac{f a b s\left({ }^{222} R n\right)+f a b s\left({ }^{218} \mathrm{Po}\right)+f a b s\left({ }^{214} \mathrm{Po}\right)}{f a b s\left({ }^{226} \mathrm{Ra}\right)}
$$

\subsubsection{Estimativa da eficiência da contagem alfa total para a determinação de ${ }^{226} \mathrm{Ra}$}

A eficiência da contagem alfa total para determinação das atividades de ${ }^{226}$ Ra presentes nas amostras foi calculada pela seguinte expressão:

$$
E F \alpha\left({ }^{226} R a\right)=\frac{R n-B g}{A_{c o r r}\left({ }^{241} A m\right) \cdot 60 . R Q}
$$

Onde:

$\mathrm{EFa}\left({ }^{226} \mathrm{Ra}\right)=$ eficiência de contagem alfa para a medida de ${ }^{226} \mathrm{Ra}$, calculada pelo padrão de ${ }^{241} \mathrm{Am}$ (cps dps ${ }^{-1}$ );

$\mathrm{Rn}=$ taxa de contagem alfa medida $(\mathrm{cpm})$; 
$\mathrm{Bg}=$ taxa de radiação de fundo alfa total $(\mathrm{cpm})$;

$\mathrm{A}_{\text {corr }}\left({ }^{241} \mathrm{Am}\right)=$ atividade da fonte de ${ }^{241} \mathrm{Am}$ corrigida para a data da medida $(\mathrm{Bq})$;

$R Q=$ rendimento químico da eletrodeposição do padrão de ${ }^{241} \mathrm{Am}$.

Os valores das eficiências de contagem alfa total para a determinação de ${ }^{226} \mathrm{Ra}$ no detector proporcional de fluxo gasoso de baixa radiação de fundo Berthold LB 770 são apresentados na TAB. 7.

TABELA 7 - Valores das eficiências de contagem alfa total para ${ }^{226} \mathrm{Ra}$.

\begin{tabular}{cc}
\hline Detector & $\begin{array}{c}\text { Eficiência alfa }{ }^{226} \mathbf{R a} \\
\left(\text { cps dps }^{-1} \text { ) }\right.\end{array}$ \\
\hline 1 & 0,3133 \\
2 & 0,3112 \\
3 & 0,3062 \\
4 & 0,3061 \\
5 & 0,3057 \\
6 & 0,3084 \\
7 & 0,3086 \\
8 & 0,3011 \\
9 & 0,3044 \\
10 & 0,3071 \\
\hline
\end{tabular}

\subsubsection{Cálculo da concentração de atividade de ${ }^{228} \mathrm{Ra}$}

A expressão que fornece a concentração de atividade de ${ }^{228} \mathrm{Ra}$ a partir da medida beta total é:

$$
A\left({ }^{228} R a\right)=\frac{R n-B g}{60 \cdot R Q \cdot E F \beta\left({ }^{228} R a\right) \cdot Q}-\frac{E F \beta\left({ }^{226} R a\right) \cdot A\left({ }^{226} R a\right)}{E F \beta\left({ }^{228} R a\right)}
$$

Onde:

$\mathrm{A}\left({ }^{228} \mathrm{Ra}\right)=$ atividade de ${ }^{228} \mathrm{Ra}\left(\mathrm{Bq} \mathrm{L}{ }^{-1}\right)$;

$\mathrm{Rn}=$ taxa de contagem beta total obtida (cpm);

$\mathrm{Bg}=$ taxa de radiação de fundo beta total $(\mathrm{cpm})$; 
$\mathrm{RQ}=$ rendimento químico;

$\mathrm{EF} \beta\left({ }^{228} \mathrm{Ra}\right)=$ eficiência de contagem beta total, calculada pela medida de um precipitado padrão de $\mathrm{Ba}\left({ }^{228} \mathrm{Ra}\right) \mathrm{SO}_{4}\left(\mathrm{cps} \mathrm{dps}^{-1}\right)$;

$\mathrm{EF} \beta\left({ }^{226} \mathrm{Ra}\right)=$ eficiência de contagem beta total, calculada pela medida de um precipitado padrão de $\mathrm{Ba}\left({ }^{226} \mathrm{Ra}\right) \mathrm{SO}_{4}\left(\mathrm{cps} \mathrm{dps}^{-1}\right)$;

$\mathrm{A}\left({ }^{226} \mathrm{Ra}\right)=$ atividade calculada para ${ }^{226} \mathrm{Ra}\left(\mathrm{Bq} \mathrm{L}^{-1}\right) ;$

$\mathrm{Q}=$ quantidade de amostra (L).

\subsubsection{Cálculo da eficiência da contagem beta total de ${ }^{226} \mathrm{Ra}$}

A eficiência da contagem beta total devido a presença de filhos do ${ }^{226} \mathrm{Ra}$ emissores beta presentes nas amostras foi determinada pela seguinte equação:

$$
E F \beta=\frac{R n-B g}{A_{c o r r}\left(2{ }^{26} R a\right) \cdot 60 \cdot R Q}
$$

Onde:

$\mathrm{EF} \beta\left({ }^{226} \mathrm{Ra}\right)=$ eficiência de contagem beta total para a medida ${ }^{226} \mathrm{Ra}\left(\mathrm{cps} \mathrm{dps}^{-1}\right)$;

$\mathrm{Rn}=$ taxa de contagem beta total obtida (cpm);

$\mathrm{Bg}=$ taxa de radiação de fundo beta total (cpm);

$\mathrm{A}_{\text {corr }}\left({ }^{226} \mathrm{Ra}\right)=$ atividade do padrão de ${ }^{226} \mathrm{Ra}$ corrigida para a data da medida $(\mathrm{Bq})$;

$\mathrm{RQ}=$ rendimento químico

Os valores das eficiências de contagem beta total para a determinação de ${ }^{228} \mathrm{Ra}$ devido possível contribuição de filhos emissores beta do ${ }^{226} \mathrm{Ra}\left({ }^{214} \mathrm{~Pb}\right.$ e $\left.{ }^{214} \mathrm{Bi}\right)$ no detector proporcional de fluxo gasoso de baixa radiação de fundo Berthold LB 770 são apresentados na TAB. 8. 
TABELA 8 - Valores das eficiências de contagem beta para os filhos do ${ }^{226} \mathrm{Ra}$.

\begin{tabular}{cc}
\hline Detector & $\begin{array}{c}\text { Eficiência beta }{ }^{226} \mathbf{R a} \\
\text { (cps dps }^{-1} \text { ) }\end{array}$ \\
\hline 1 & 0,6935 \\
2 & 0,7065 \\
3 & 0,7065 \\
4 & 0,7022 \\
5 & 0,6987 \\
6 & 0,7015 \\
7 & 0,7045 \\
8 & 0,7044 \\
9 & 0,7089 \\
10 & 0,6942 \\
\hline
\end{tabular}

\subsubsection{Cálculo da eficiência da contagem beta total de ${ }^{228} \mathrm{Ra}$}

A eficiência beta total para determinação das atividades de ${ }^{228} \mathrm{Ra}$ presentes nas amostras foi calculada pela equação:

$$
E F \beta\left({ }^{228} R a\right)=\frac{R n-B g}{A_{c o r r}\left({ }^{228} R a\right) \cdot 60 \cdot R Q}
$$

Onde:

$\mathrm{EF} \beta\left({ }^{228} \mathrm{Ra}\right)=$ eficiência de contagem beta total para ${ }^{228} \mathrm{Ra}$ (cps dps-1);

$\mathrm{Rn}=$ taxa de contagem beta total obtida (cpm);

$\mathrm{Bg}=$ taxa de radiação de fundo beta total $(\mathrm{cpm})$;

$\mathrm{A}_{\text {corr }}\left({ }^{228} \mathrm{Ra}\right)=$ atividade do padrão de ${ }^{228} \mathrm{Ra}$ corrigida para a data da medida $(\mathrm{Bq})$;

$\mathrm{RQ}=$ rendimento químico

Os valores das eficiências de contagem beta total para a determinação de ${ }^{228} \mathrm{Ra}$ no detector proporcional de fluxo gasoso de baixa radiação de fundo Berthold LB 770 são apresentados na TAB. 9. 
TABELA 9 - Valores das eficiências de contagem beta total para ${ }^{228} \mathrm{Ra}$.

\begin{tabular}{cc}
\hline Detector & $\begin{array}{c}\text { Eficiência beta }{ }^{228} \mathbf{R a} \\
\left(\text { cps dps }^{-1}\right)\end{array}$ \\
\hline 1 & 0,4100 \\
2 & 0,4200 \\
3 & 0,4250 \\
4 & 0,4250 \\
5 & 0,4140 \\
6 & 0,4180 \\
7 & 0,4390 \\
8 & 0,4450 \\
9 & 0,4340 \\
10 & 0,4220 \\
\hline
\end{tabular}

\subsubsection{Determinação da radiação de fundo, rendimento químico gravimétrico} e limite inferior de detecção do método

A radiação de fundo do detector foi determinada pela medida do detector vazio com o mesmo tempo de contagem da amostra, 1 ciclo de 200 minutos. O rendimento químico do processo foi quantificado por gravimetria, correlacionando-se a massa dos precipitados com a massa do carregador de $\mathrm{Ba}^{2+}$ (20 $\mathrm{mg} \mathrm{mL}^{-1}$ ) adicionado às amostras no início de cada análise. $\mathrm{O}$ rendimento químico do procedimento radioquímico variou de $87-95 \%$. O valor médio do limite inferior de detecção do método (LID) para ${ }^{226} \mathrm{Ra}$ foi de $2,2 \mathrm{mBq} \mathrm{L}^{-1}$ e para o ${ }^{228} \mathrm{Ra}$ de $3,7 \mathrm{mBq} \mathrm{L}{ }^{-1}$ (Oliveira, 1993).

\subsubsection{Validação da metodologia para determinação de ${ }^{226} \mathrm{Ra} e{ }^{228} \mathrm{Ra}$}

A metodologia foi validada através da participação do LRA em um teste de proficiência organizado pela IAEA, dentro do programa "Analytical Quality Control Services (AQCS)", chamado "Interlaboratory Study on Determination of Radium and Uranium Radionuclides in Water". Um total de 6 amostras de água (3 naturais e 3 sintéticas) foram diluídas com água ultrapura. As concentrações de ${ }^{226} \mathrm{Ra}$ presentes nestas amostras foram determinadas utilizando-se a metodologia descrita anteriormente. 
A avaliação final dos resultados reportados nesta intercomparação indicou que eles tiveram boa concordância com os valores de referência estabelecidos pela IAEA e não foram influenciados por erros sistemáticos, tanto para amostras com baixa atividade quanto para as de alta atividade de ${ }^{226} \mathrm{Ra}$.

\subsection{Determinações complementares}

Para a determinação de carbono orgânico particulado, inicialmente, foi realizada a extração do material particulado por ultrassom (Sonication) pelo Centro de Tecnologia das Radiações - CTR/IPEN. Posteriormente foi realizada a determinação de carbono orgânico total (COT) pelo método da combustão-infravermelho, onde todos os carbonos, orgânico e inorgânico, são oxidados a $\mathrm{CO}_{2}$ e $\mathrm{H}_{2} \mathrm{O}$ nas condições de análise, onde o $\mathrm{CO}_{2}$ é medido por meio de um analisador infravermelho não dispersivo, sendo o COT calculado pela diferença entre carbono total (CT) e carbono inorgânico (CI) (EN, 1997). Estas análises foram realizadas em parceria com o Laboratório de Análises Química e Ambiental do IPEN - LAQA/CQMA. Os dados de temperatura e a medida de salinidade utilizando-se salinômetro indutivo, Beckman-RS-10, foram realizados pelo LABNUT-IOUSP. 


\section{RESULTADOS E DISCUSSÃO}

Os resultados de temperatura, salinidade, carbono inorgânico, carbono orgânico total e carbono total, obtidos nas duas campanhas de amostragem (OPERANTAR XXIX e XXX) realizadas no final e início do verão Austral, são apresentados nas TAB. 10 a 13.

As concentrações de atividade de ${ }^{234} \mathrm{Th}$ total, ${ }^{238} \mathrm{U}$ dissolvido, ${ }^{210} \mathrm{Po}$ particulado, ${ }^{210} \mathrm{~Pb}$ particulado, ${ }^{226} \mathrm{Ra}$ e ${ }^{228} \mathrm{Ra}$, e as razões de atividade de ${ }^{234} \mathrm{Th}$ total $/{ }^{238} \mathrm{U}$ dissolvido, ${ }^{210} \mathrm{Po} /{ }^{210} \mathrm{~Pb},{ }^{228} \mathrm{Ra} /{ }^{226} \mathrm{Ra}$ e ${ }^{210} \mathrm{~Pb} /{ }^{226} \mathrm{Ra}$ obtidas nas duas campanhas de amostragem (OPERANTAR XXIX e XXX) realizadas no final e início do verão Austral, são apresentadas nas TAB. 14 a 17.

Para melhor interpretação dos resultados foram elaborados mapas da distribuição superficial, gráficos de dispersão e matriz de correlação dos parâmetros estudados. E foram calculados fluxos de ${ }^{234} \mathrm{Th},{ }^{210} \mathrm{Po}$ e POC exportados pelo material particulado via afundamento de partículas (TAB. 20 a 22). 
TABELA 10 - Dados de distância da costa e profundidade total e, valores de temperatura e salinidade - nas estações da OPERANTAR XXIX.

\begin{tabular}{|c|c|c|c|c|}
\hline Estação & $\begin{array}{c}\text { Distância da } \\
\text { costa (km) }\end{array}$ & $\begin{array}{c}\text { Profundidade } \\
\text { total }(\mathrm{m})\end{array}$ & $\begin{array}{c}\text { Temperatura } \\
\left({ }^{\circ} \mathrm{C}\right)\end{array}$ & Salinidade \\
\hline EB 001 & 71 & 1989,6 & 2,0 & 33,91 \\
\hline EB 002 & 48 & 2240,0 & 1,7 & 34,14 \\
\hline EB 003 & 28 & 1700,0 & 2,6 & 34,24 \\
\hline EB 004 & 19 & 1447,6 & 0,6 & 34,17 \\
\hline EB 005 & 43 & 859,2 & 1,9 & 34,30 \\
\hline EB 006 & 17 & 900,8 & 0,3 & 34,13 \\
\hline EB 007 & 65 & 1340,0 & 1,9 & 33,86 \\
\hline EB 008 & 52 & 2843,0 & 1,5 & 34,09 \\
\hline EB 009 & 34 & 1858,0 & 1,3 & 34,25 \\
\hline EB 010 & 31 & 1509,2 & 1,8 & 34,00 \\
\hline EB 011 & 17 & 513,2 & 0,0 & 34,35 \\
\hline EB 012 & 32 & 447,8 & 0,7 & 34,36 \\
\hline EB 013 & 7 & 198,0 & 2,0 & 34,08 \\
\hline EB 014 & 11 & 174,0 & 0,3 & 34,37 \\
\hline EB 015 & 15 & 559,2 & $-0,2$ & 34,32 \\
\hline EB 017 & 56 & 610,0 & 1,5 & 34,25 \\
\hline EB 018 & 31 & 1682,0 & 1,1 & 34,22 \\
\hline EB 019 & 21 & 1508,8 & 1,4 & 34,07 \\
\hline EB 020 & 4 & 58,6 & 1,8 & 34,01 \\
\hline EB 021 & 5 & 1127,2 & 1,9 & 33,96 \\
\hline EB 022 & 51 & 1067,2 & 0,9 & 34,32 \\
\hline EB 023 & 60 & 1629,6 & 1,0 & 34,37 \\
\hline EB 026 & 48 & 1745,6 & 0,7 & 34,30 \\
\hline EB 027 & 46 & 1700,0 & 1,2 & 34,27 \\
\hline EB 028 & 24 & 1654,8 & 0,4 & 34,27 \\
\hline EB 029 & 11 & 1014,0 & 0,7 & 33,99 \\
\hline EB 031 & 13 & 1345,2 & 1,4 & 33,94 \\
\hline EB 032 & 32 & 862,0 & 0,0 & 34,29 \\
\hline EB 033 & 46 & 196,4 & 0,1 & 34,00 \\
\hline EB 034 & 24 & 903,2 & - & 34,16 \\
\hline EB 035 & 18 & 660,0 & - & 34,34 \\
\hline EB 037 & 42 & 523,0 & 0,8 & 34,05 \\
\hline EB 038 & 58 & 442,8 & 1,4 & 33,70 \\
\hline EB 039 & 50 & 690,4 & 1,6 & 33,93 \\
\hline EB 040 & 17 & 220,0 & 1,7 & 34,02 \\
\hline EB 041 & 31 & 605,6 & 1,7 & 33,92 \\
\hline EB 044 & 117 & - & 0,3 & 34,03 \\
\hline EB 045 & 103 & 408,3 & 0,3 & 34,26 \\
\hline EB 046 & 50 & 480,0 & 1,8 & 34,06 \\
\hline EB 047 & 73 & 1581 & 2,4 & 33,89 \\
\hline EB 049 & 10 & 463,2 & 1,9 & 34,07 \\
\hline EB 050 & 19 & 1886,4 & 1,1 & 34,21 \\
\hline EB 051 & 30 & 955,0 & 1,4 & 34,26 \\
\hline EB 052 & 45 & 916,0 & 1,9 & 34,26 \\
\hline EB 053 & 64 & 923,0 & 1,0 & 34,41 \\
\hline EB 054 & 52 & 444,0 & 0,6 & 34,33 \\
\hline EB 055 & 41 & 225,0 & $-0,2$ & 34,54 \\
\hline
\end{tabular}


TABELA 11 - Dados de distância da costa e profundidade total e, valores de temperatura e salinidade - nas estações da OPERANTAR XXX.

\begin{tabular}{lcccc}
\hline Estação & $\begin{array}{c}\text { Distância da } \\
\text { costa }(\mathbf{k m})\end{array}$ & $\begin{array}{c}\text { Profundidade } \\
\text { total }(\mathbf{m})\end{array}$ & $\begin{array}{c}\text { Temperatura } \\
\left({ }^{\circ} \mathbf{C}\right)\end{array}$ & Salinidade \\
\hline EB 001 & 71 & 1989,6 & 0,5 & 34,10 \\
EB 001a & 84 & - & $-1,0$ & 34,05 \\
EB 002 & 48 & 2240,0 & $-1,2$ & 33,53 \\
EB 005 & 43 & 859,2 & $-1,4$ & 33,82 \\
EB 006 & 17 & 900,8 & $-1,1$ & 33,77 \\
EB 009 & 34 & 1858,0 & $-1,2$ & 33,74 \\
EB 010 & 31 & 1509,2 & $-1,4$ & 33,59 \\
EB 018 & 31 & 1682,0 & $-2,1$ & 33,55 \\
EB 019 & 21 & 1508,8 & $-1,8$ & 33,59 \\
EB 022 & 51 & 1067,2 & $-1,5$ & 33,78 \\
EB 027 & 46 & 1700,0 & 0,6 & 33,81 \\
EB 028 & 24 & 1654,8 & $-1,0$ & 34,01 \\
EB 029 & 11 & 1014,0 & $-1,4$ & 33,61 \\
EB 031 & 13 & 1345,2 & $-1,3$ & 33,58 \\
EB 032 & 32 & 862,0 & $-0,3$ & 34,16 \\
EB 038 & 58 & 442,8 & $-1,4$ & 33,45 \\
EB 051 & 30 & 955,0 & - & 33,49 \\
\hline
\end{tabular}


TABELA 12 - Concentrações de carbono inorgânico $(\mathrm{Cl})$, carbono orgânico total (COT) e carbono total (CT) - nas estações da OPERANTAR XXIX.

\begin{tabular}{|c|c|c|c|}
\hline Estação & $\mathrm{Cl}\left(\mathrm{mg} \mathrm{L}^{-1}\right)$ & COT $\left(\mathrm{mg} \mathrm{L}^{-1}\right)$ & $\mathrm{CT}\left(\mathrm{mg} \mathrm{L}^{-1}\right)$ \\
\hline EB 001 & 0,44 & 0,74 & 1,18 \\
\hline EB 002 & 0,43 & 1,21 & 1,64 \\
\hline EB 003 & 0,52 & 1,20 & 1,72 \\
\hline EB 004 & 0,43 & 0,83 & 1,25 \\
\hline EB 005 & 0,41 & 0,79 & 1,20 \\
\hline EB 006 & 0,52 & 1,40 & 1,92 \\
\hline EB 007 & 0,38 & 1,20 & 1,58 \\
\hline EB 008 & 0,41 & 1,31 & 1,72 \\
\hline EB 009 & 0,39 & 0,88 & 1,26 \\
\hline EB 010 & 0,51 & 1,31 & 1,83 \\
\hline EB 011 & 0,30 & 0,86 & 1,17 \\
\hline EB 012 & 0,34 & 0,72 & 1,06 \\
\hline EB 013 & 0,29 & 0,54 & 0,83 \\
\hline EB 014 & 0,36 & 0,75 & 1,11 \\
\hline EB 015 & 0,41 & 1,69 & 2,10 \\
\hline EB 017 & 0,23 & 1,26 & 1,49 \\
\hline EB 018 & 0,46 & 1,32 & 1,78 \\
\hline EB 019 & 0,27 & 1,28 & 1,54 \\
\hline EB 020 & 0,62 & 1,58 & 2,20 \\
\hline EB 021 & 0,45 & 1,20 & 1,64 \\
\hline EB 022 & 0,50 & 0,77 & 1,27 \\
\hline EB 023 & 0,43 & 1,25 & 1,68 \\
\hline EB 026 & 0,52 & 0,75 & 1,27 \\
\hline EB 027 & 0,49 & 1,33 & 1,82 \\
\hline EB 028 & 0,46 & 0,82 & 1,28 \\
\hline EB 029 & 0,50 & 0,72 & 1,22 \\
\hline EB 031 & 0,54 & 1,11 & 1,65 \\
\hline EB 032 & 0,41 & 0,69 & 1,10 \\
\hline EB 033 & 0,49 & 0,71 & 1,20 \\
\hline EB 034 & 0,27 & 1,21 & 1,48 \\
\hline EB 035 & 0,40 & 0,97 & 1,37 \\
\hline EB 037 & 0,60 & 1,30 & 1,90 \\
\hline EB 038 & 0,54 & 1,21 & 1,75 \\
\hline EB 039 & 0,23 & 1,48 & 1,71 \\
\hline EB 040 & 0,48 & 1,56 & 2,04 \\
\hline EB 041 & 0,51 & 0,75 & 1,25 \\
\hline EB 044 & 0,54 & 1,22 & 1,76 \\
\hline EB 045 & 0,70 & 1,27 & 1,97 \\
\hline EB 046 & 0,43 & 0,72 & 1,15 \\
\hline EB 047 & 0,46 & 1,29 & 1,75 \\
\hline EB 049 & 0,66 & 1,29 & 1,95 \\
\hline EB 050 & 0,42 & 1,58 & 1,99 \\
\hline EB 051 & 0,51 & 1,60 & 2,11 \\
\hline EB 052 & 0,31 & 17,20 & 17,50 \\
\hline EB 053 & 0,55 & 1,71 & 2,26 \\
\hline EB 054 & 0,49 & 0,78 & 1,27 \\
\hline EB 055 & 0,62 & 1,28 & 1,89 \\
\hline
\end{tabular}


TABELA 13 - Concentrações de carbono inorgânico $(\mathrm{Cl})$, carbono orgânico total (COT) e carbono total (CT) - nas estações da OPERANTAR XXX.

\begin{tabular}{cccc}
\hline Estação & $\mathbf{C l}\left(\mathbf{m g ~ L}^{-1}\right)$ & $\mathbf{C O T}\left(\mathbf{m g ~ L}^{-1}\right)$ & $\mathbf{C T}\left(\mathbf{m g ~ L}^{-1}\right)$ \\
\hline EB 001 & 0,55 & 1,43 & 1,97 \\
EB 001a & 0,44 & 1,04 & 1,47 \\
EB 002 & 0,52 & 2,41 & 2,93 \\
EB 005 & 0,70 & 1,23 & 1,93 \\
EB 006 & 0,31 & 1,99 & 2,30 \\
EB 009 & 0,30 & 1,71 & 2,02 \\
EB 010 & 0,60 & 1,78 & 2,38 \\
EB 018 & 0,29 & 1,72 & 2,02 \\
EB 019 & 0,53 & 1,49 & 2,02 \\
EB 022 & 0,56 & 6,00 & 6,60 \\
EB 027 & 0,70 & 1,70 & 2,40 \\
EB 028 & 0,52 & 1,45 & 1,97 \\
EB 029 & 0,38 & 2,30 & 2,70 \\
EB 031 & 0,81 & 1,60 & 2,40 \\
EB 032 & 0,80 & 1,25 & 2,05 \\
EB 038 & 0,52 & 1,56 & 2,08 \\
EB 051 & 0,74 & 2,40 & 3,14 \\
\hline
\end{tabular}


TABELA 14 - Concentrações de ${ }^{234} \mathrm{Th}$ total, ${ }^{238} \mathrm{U}$ dissolvido, ${ }^{210} \mathrm{Po}$ particulado e razão de atividade ${ }^{234} \mathrm{Th}$ total/ $/ 238 \mathrm{U}$ dissolvido - nas estações da OPERANTAR XXIX.

\begin{tabular}{|c|c|c|c|c|}
\hline Estação & $\begin{array}{c}{ }^{234} \mathrm{Th}^{-1} \\
(\mathrm{dpm} \mathrm{L})\end{array}$ & $\begin{array}{c}{ }^{238} U \\
\left(\mathrm{dpm} \mathrm{L} \mathrm{L}^{-1}\right)\end{array}$ & ${ }^{234} \mathrm{Th} /{ }^{238} \mathrm{U}$ & $\begin{array}{c}{ }^{210} \mathrm{Po}^{-1} \\
\left(\mathrm{dpm} \mathrm{L} \mathrm{L}^{-1}\right)\end{array}$ \\
\hline EB 001 & 1,65 & 2,34 & 0,71 & - \\
\hline EB 002 & 2,18 & 2,36 & 0,93 & - \\
\hline EB 003 & 2,53 & 2,36 & 1,07 & 1,20 \\
\hline EB 004 & 1,78 & 2,36 & 0,75 & 1,19 \\
\hline EB 005 & 1,99 & 2,37 & 0,84 & - \\
\hline EB 006 & 1,61 & 2,35 & 0,68 & - \\
\hline EB 007 & 1,76 & 2,34 & 0,76 & 2,66 \\
\hline EB 008 & 2,50 & 2,35 & 1,06 & - \\
\hline EB 009 & 2,72 & 2,36 & 1,15 & 3,36 \\
\hline EB 010 & 1,76 & 2,35 & 0,75 & - \\
\hline EB 011 & 3,71 & 2,37 & 1,57 & 1,55 \\
\hline EB 012 & 2,23 & 2,37 & 0,94 & - \\
\hline EB 013 & 2,32 & 2,35 & 0,99 & 2,86 \\
\hline EB 014 & 2,26 & 2,37 & 0,95 & 2,13 \\
\hline EB 015 & 2,47 & 2,37 & 1,04 & - \\
\hline EB 017 & 2,42 & 2,36 & 1,02 & 2,41 \\
\hline EB 018 & 2,74 & 2,36 & 1,16 & 1,72 \\
\hline EB 019 & 2,48 & 2,35 & 1,05 & 6,54 \\
\hline EB 020 & 2,08 & 2,35 & 0,89 & - \\
\hline EB 021 & 1,52 & 2,34 & 0,65 & - \\
\hline EB 022 & 2,06 & 2,37 & 0,87 & 0,97 \\
\hline EB 023 & 2,03 & 2,37 & 0,86 & - \\
\hline EB 026 & 2,12 & 2,37 & 0,90 & - \\
\hline EB 027 & 2,16 & 2,36 & 0,91 & - \\
\hline EB 028 & 2,04 & 2,36 & 0,86 & - \\
\hline EB 029 & 1,83 & 2,35 & 0,78 & - \\
\hline EB 031 & 2,02 & 2,34 & 0,86 & - \\
\hline EB 032 & 2,09 & 2,37 & 0,88 & - \\
\hline EB 033 & 2,05 & 2,35 & 0,87 & 1,89 \\
\hline EB 034 & 2,23 & 2,36 & 0,95 & - \\
\hline EB 035 & 2,13 & 2,37 & 0,90 & - \\
\hline EB 037 & 1,33 & 2,35 & 0,57 & - \\
\hline EB 038 & 1,38 & 2,33 & 0,59 & 1,24 \\
\hline EB 039 & 1,69 & 2,34 & 0,72 & 1,47 \\
\hline EB 040 & 1,77 & 2,35 & 0,76 & 1,73 \\
\hline EB 041 & 1,41 & 2,34 & 0,60 & 0,75 \\
\hline EB 044 & 2,52 & 2,35 & 1,07 & 1,99 \\
\hline EB 045 & 2,45 & 2,36 & 1,04 & 2,03 \\
\hline EB 046 & 2,00 & 2,35 & 0,85 & 1,21 \\
\hline EB 047 & 2,07 & 2,34 & 0,89 & - \\
\hline EB 049 & 2,01 & 2,35 & 0,85 & 5,87 \\
\hline EB 050 & 2,59 & 2,36 & 1,10 & 3,84 \\
\hline EB 051 & 2,55 & 2,36 & 1,08 & 1,75 \\
\hline EB 052 & 2,31 & 2,36 & 0,98 & 1,71 \\
\hline EB 053 & 2,39 & 2,37 & 1,01 & 0,59 \\
\hline EB 054 & 2,19 & 2,37 & 0,92 & 0,94 \\
\hline EB 055 & 2,76 & 2,38 & 1,16 & 0,31 \\
\hline
\end{tabular}


TABELA 15 - Concentrações de ${ }^{234} \mathrm{Th}$ total, ${ }^{238} \mathrm{U}$ dissolvido, razão de atividade ${ }^{234} \mathrm{Th}$ total//38 $\mathrm{U}$ dissolvido, ${ }^{210} \mathrm{Po}$ particulado, ${ }^{210} \mathrm{~Pb}$ particulado e razão de atividade ${ }^{210} \mathrm{Po} /{ }^{210} \mathrm{~Pb}$ - nas estações da OPERANTAR $\mathrm{XXX}$.

\begin{tabular}{|c|c|c|c|c|c|c|}
\hline Estação & $\begin{array}{c}{ }^{234} \mathrm{Th} \\
\left(\mathrm{dpm} \mathrm{L} \mathrm{L}^{-1}\right)\end{array}$ & ${ }_{\left(\mathrm{dpm} \mathrm{L} \mathrm{L}^{-1}\right)}$ & ${ }^{234} \mathrm{Th} /{ }^{238} \mathrm{U}$ & $\begin{array}{c}{ }^{210} \mathrm{Po}^{-1} \\
\left(\mathrm{dpm} \mathrm{L} \mathrm{L}^{-1}\right)\end{array}$ & $\begin{array}{c}{ }^{210} \mathrm{~Pb} \\
\left(\mathrm{dpm} \mathrm{L} \mathrm{L}^{-1}\right)\end{array}$ & ${ }^{210} \mathrm{Po} /{ }^{210} \mathrm{~Pb}$ \\
\hline EB 001 & 2,31 & 2,35 & 0,98 & 0,09 & 2,75 & 0,03 \\
\hline EB $001 \alpha$ & 2,36 & 2,35 & 1,00 & 0,08 & 5,45 & 0,01 \\
\hline EB 002 & 1,91 & 2,31 & 0,82 & 0,04 & 1,40 & 0,03 \\
\hline EB 005 & 2,19 & 2,33 & 0,94 & 0,03 & 2,08 & 0,02 \\
\hline EB 006 & 2,87 & 2,33 & 1,23 & 0,04 & 1,76 & 0,02 \\
\hline EB 009 & 2,15 & 2,33 & 0,93 & 0,02 & 2,49 & 0,01 \\
\hline EB 010 & 2,24 & 2,32 & 0,96 & 0,03 & 1,66 & 0,02 \\
\hline EB 018 & 2,08 & 2,31 & 0,90 & 0,06 & 3,04 & 0,02 \\
\hline EB 019 & 2,32 & 2,32 & 1,00 & - & 1,74 & - \\
\hline EB 022 & 2,45 & 2,33 & 1,05 & - & 1,66 & - \\
\hline EB 027 & 1,84 & 2,33 & 0,79 & 0,03 & 1,80 & 0,02 \\
\hline EB 028 & 1,79 & 2,35 & 0,76 & 0,05 & 1,31 & 0,04 \\
\hline EB 029 & 1,38 & 2,32 & 0,60 & 0,07 & 1,57 & 0,05 \\
\hline EB 031 & 2,47 & 2,32 & 1,06 & 0,05 & 2,54 & 0,02 \\
\hline EB 032 & 2,40 & 2,36 & 1,02 & 0,05 & 1,46 & 0,03 \\
\hline EB 038 & 2,42 & 2,31 & 1,05 & 0,04 & 1,68 & 0,02 \\
\hline EB 051 & 2,28 & 2,31 & 0,98 & 0,04 & 1,28 & 0,04 \\
\hline
\end{tabular}


TABELA 16 - Concentrações de ${ }^{226} \mathrm{Ra},{ }^{228} \mathrm{Ra}$ e razão de atividade ${ }^{228} \mathrm{Ra} /{ }^{226} \mathrm{Ra}-$ nas estações da OPERANTAR XXIX.

\begin{tabular}{|c|c|c|c|}
\hline Estação & $\begin{array}{c}{ }^{226} \mathrm{Ra} \\
\left(\mathrm{dpm} 100 \mathrm{~L}^{-1}\right) \\
\end{array}$ & $\begin{array}{c}{ }^{228} \mathrm{Ra} \\
\left(\mathrm{dpm} 100 \mathrm{~L}^{-1}\right)\end{array}$ & ${ }^{228} \mathrm{Ra} /{ }^{226} \mathrm{Ra}$ \\
\hline 1ª Radial & $0,32 \pm 0,3$ & $0,95 \pm 1,0$ & 2,98 \\
\hline $2^{\text {a }}$ Radial & $0,35 \pm 0,3$ & $1,94 \pm 2,0$ & 5,52 \\
\hline $3^{\text {a }}$ Radial & $0,58 \pm 0,5$ & $2,18 \pm 3,0$ & 3,78 \\
\hline 4ª Radial & $0,23 \pm 0,2$ & $0,57 \pm 1,0$ & 2,53 \\
\hline 5a Radial & $0,11 \pm 0,1$ & $0,29 \pm 0,5$ & 2,57 \\
\hline 6ª Radial & $0,62 \pm 0,5$ & $2,13 \pm 2,0$ & 3,46 \\
\hline 7ª Radial & $1,19 \pm 1,0$ & $1,22 \pm 1,0$ & 1,03 \\
\hline 8a Radial & $1,14 \pm 1,0$ & $0,94 \pm 1,0$ & 0,82 \\
\hline 9a Radial & $1,10 \pm 0,9$ & $1,28 \pm 1,0$ & 1,16 \\
\hline $10^{\mathrm{a}}$ Radial & $2,88 \pm 2,4$ & $<$ LID & - \\
\hline
\end{tabular}

LID = limite inferior de detecção do método para $0{ }^{228} \mathrm{Ra}$ foi de $3,7 \mathrm{mBq} \mathrm{L}{ }^{-1}$ (Oliveira, 1993).

TABELA 17 - Concentrações de ${ }^{226} \mathrm{Ra},{ }^{228} \mathrm{Ra}$, razões de atividade ${ }^{228} \mathrm{Ra} /{ }^{226} \mathrm{Ra}$ e ${ }^{210} \mathrm{~Pb} /{ }^{226} \mathrm{Ra}$ - nas estações da OPERANTAR XXX.

\begin{tabular}{|c|c|c|c|c|}
\hline Estação & $\begin{array}{c}{ }^{226} R a \\
\left(\mathrm{dpm} 100 \mathrm{~L}^{-1}\right)\end{array}$ & $\begin{array}{c}{ }^{228} \mathrm{Ra} \\
\left(\mathrm{dpm} 100 \mathrm{~L}^{-1}\right)\end{array}$ & ${ }^{228} \mathrm{Ra} /{ }^{226} \mathrm{Ra}$ & ${ }^{210} \mathrm{~Pb} /{ }^{226} \mathrm{Ra}$ \\
\hline EB 001 & $7,03 \pm 5,9$ & $0,28 \pm 0,5$ & 0,04 & 39,18 \\
\hline EB 001 $\alpha$ & $5,26 \pm 4-4$ & $0,42 \pm 0,5$ & 0,08 & 103,52 \\
\hline EB 002 & $6,79 \pm 5,7$ & $2,79 \pm 3,0$ & 0,41 & 20,67 \\
\hline EB 005 & $7,26 \pm 6,1$ & $1,32 \pm 2,0$ & 0,18 & 28,61 \\
\hline EB 006 & $2,96 \pm 2,5$ & $1,70 \pm 2,0$ & 0,57 & 59,37 \\
\hline EB 009 & $4,10 \pm 3,4$ & $0,97 \pm 1,0$ & 0,24 & 60,67 \\
\hline EB 010 & $6,75 \pm 5,6$ & $1,28 \pm 1,0$ & 0,19 & 24,52 \\
\hline EB 019 & $8,30 \pm 6,9$ & $0,43 \pm 0,5$ & 0,05 & 20,93 \\
\hline EB 028 & $4,11 \pm 3,4$ & $1,77 \pm 0,3$ & 0,43 & 31,95 \\
\hline EB 032 & $5,77 \pm 4,8$ & $<$ LID & - & 25,30 \\
\hline EB 051 & $3,76 \pm 3,1$ & $0,74 \pm 1,0$ & 0,20 & 33,92 \\
\hline
\end{tabular}

LID = limite inferior de detecção do método para $0{ }^{228} \mathrm{Ra}$ foi de $3,7 \mathrm{mBq} \mathrm{L}^{-1}$ (Oliveira, 1993). 


\subsection{Distribuição superficial}

Os mapas de contorno da distribuição superficial dos parâmetros estudados foram elaborados pelo software Surfer ${ }^{\circledR} 10$, que estima valores a partir da metodologia estatística de krigagem (FIG. 18 a 41), porém, neste estudo devido ao número reduzido de estações amostradas devem ser considerados apenas os valores plotados correspondentes a cada estação, ou seja, os valores estimados devem ser desconsiderados.

Nas FIG. 18 e 19 são representadas as distribuições superficiais de temperatura, os valores variaram de $-0,2$ a $2,6{ }^{\circ} \mathrm{C}$ e $-2,1$ a $0,6{ }^{\circ} \mathrm{C}$ durante o final $\mathrm{e}$ início do verão Austral, respectivamente. As águas relativamente mais frias foram observadas nas proximidades da Península Trinity e llha Nelson durante o final e início do verão Austral, respectivamente. Águas relativamente mais quentes foram observadas nas proximidades do arquipélago das Ilhas Shetland do Sul no final do verão, enquanto que no início do verão as águas mais quentes foram observadas próximas à llha Elefante e na sub-bacia central do EB, nas redondezas da llha Livingston.

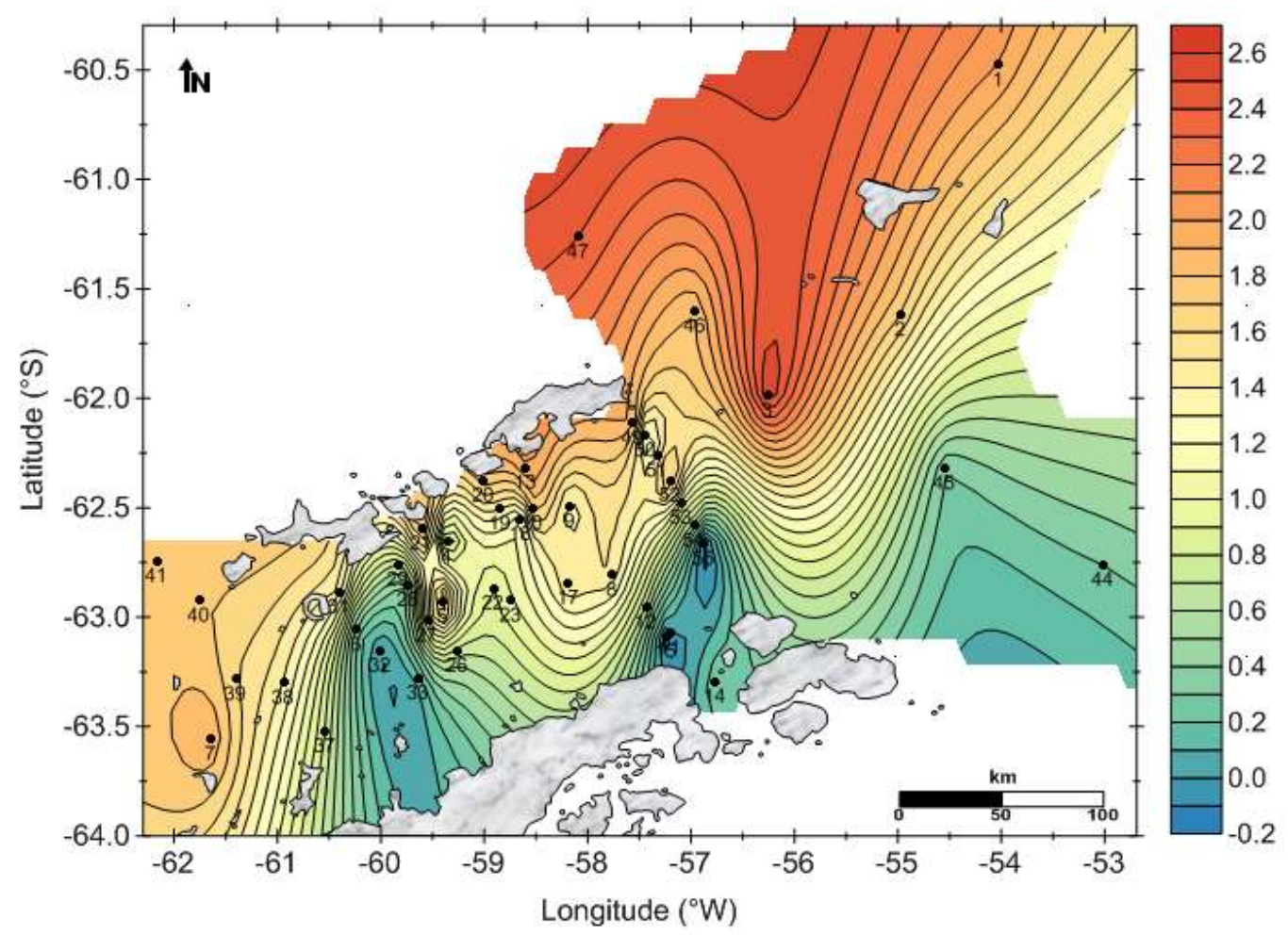

FIGURA 18 - Distribuição superficial de temperatura, em $\stackrel{\circ}{C}$-OPERANTAR XXIX. 


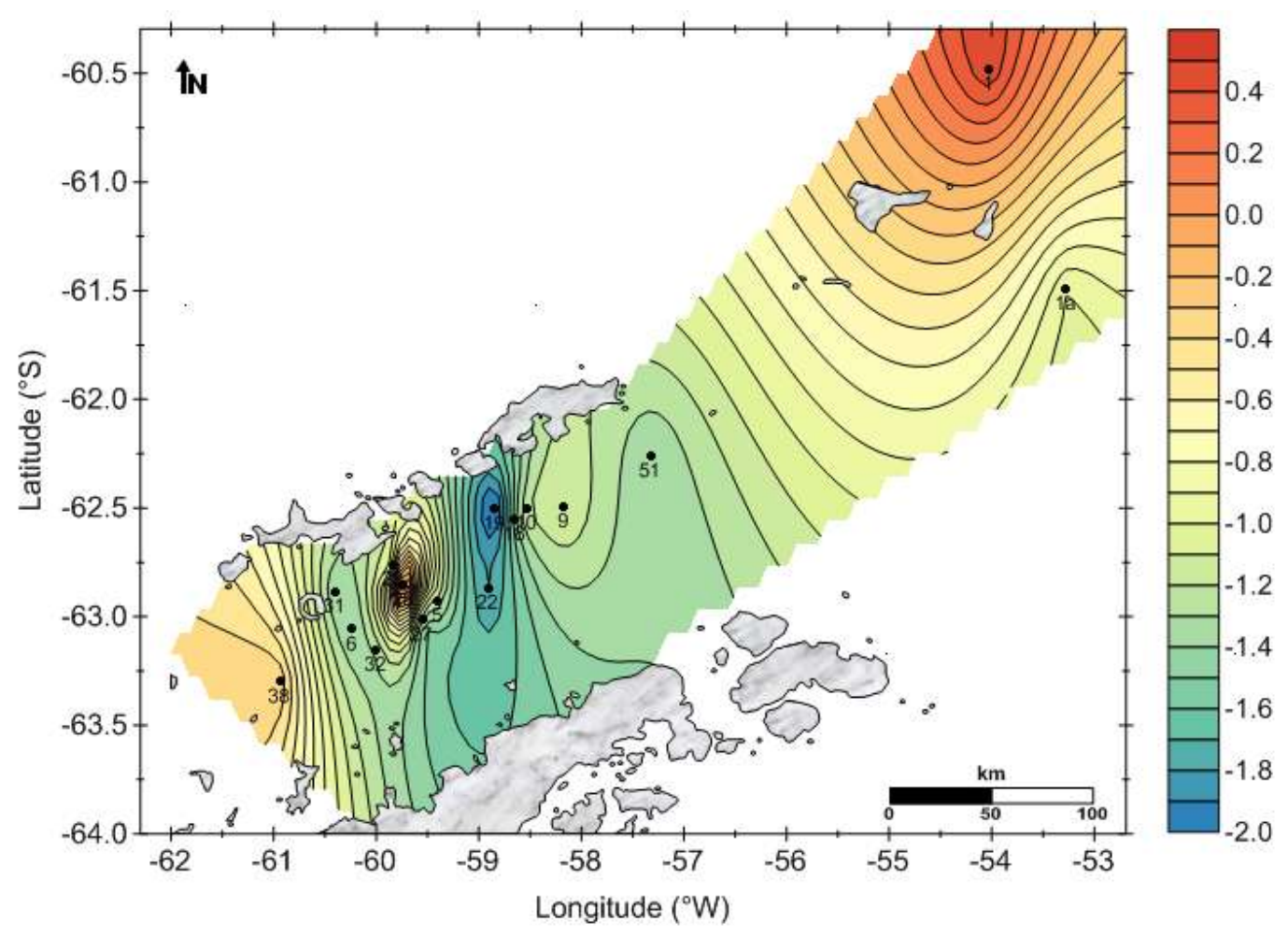

FIGURA 19 - Distribuição superficial de temperatura, em ํㅡ - OPERANTAR XXX.

As variações superficiais de salinidade são apresentadas nas FIG. 20 e 21, os dados obtidos durante o final e início do verão Austral estiveram entre 33,70 a 34,54 e 33,45 a 34,16 , respectivamente. Os menores valores de salinidade foram observados ao sul do EB e nas proximidades das llhas Shetland do Sul no início e final do verão Austral, respectivamente. Os maiores valores foram observados próximos da Península Trinity no final do verão, e no início do verão próximos da llha Elefante e na sub-bacia central do EB.

De acordo com Tokarczyk (1987) e García et al. (1994) as águas relativamente mais frias e mais salinas observadas nas proximidades da Península Trinity durante o final do verão Austral indicam influencia de águas provenientes do Mar de Weddell, e as águas relativamente mais quentes e menos salinas notadas nas imediações do arquipélago das Ilhas Shetland do Sul indicam influência de águas provindas do Mar de Bellingshausen. Devido à quantidade de estações amostradas na OPERANTAR XXX, não foi possível identificar a influência dos Mares de Weddell e Bellingshausen na região estudada. 


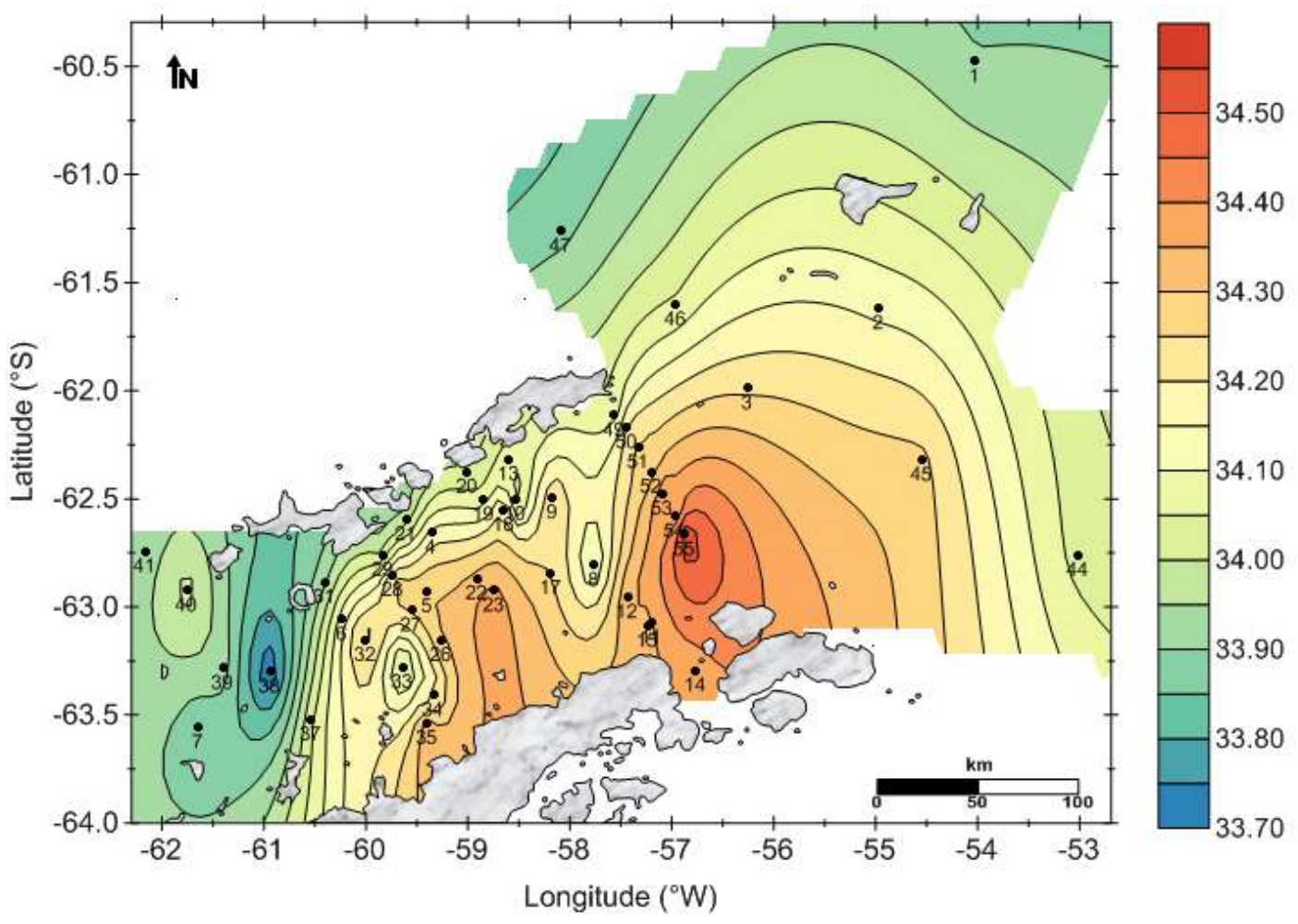

FIGURA 20 - Distribuição superficial de salinidade - OPERANTAR XXIX.

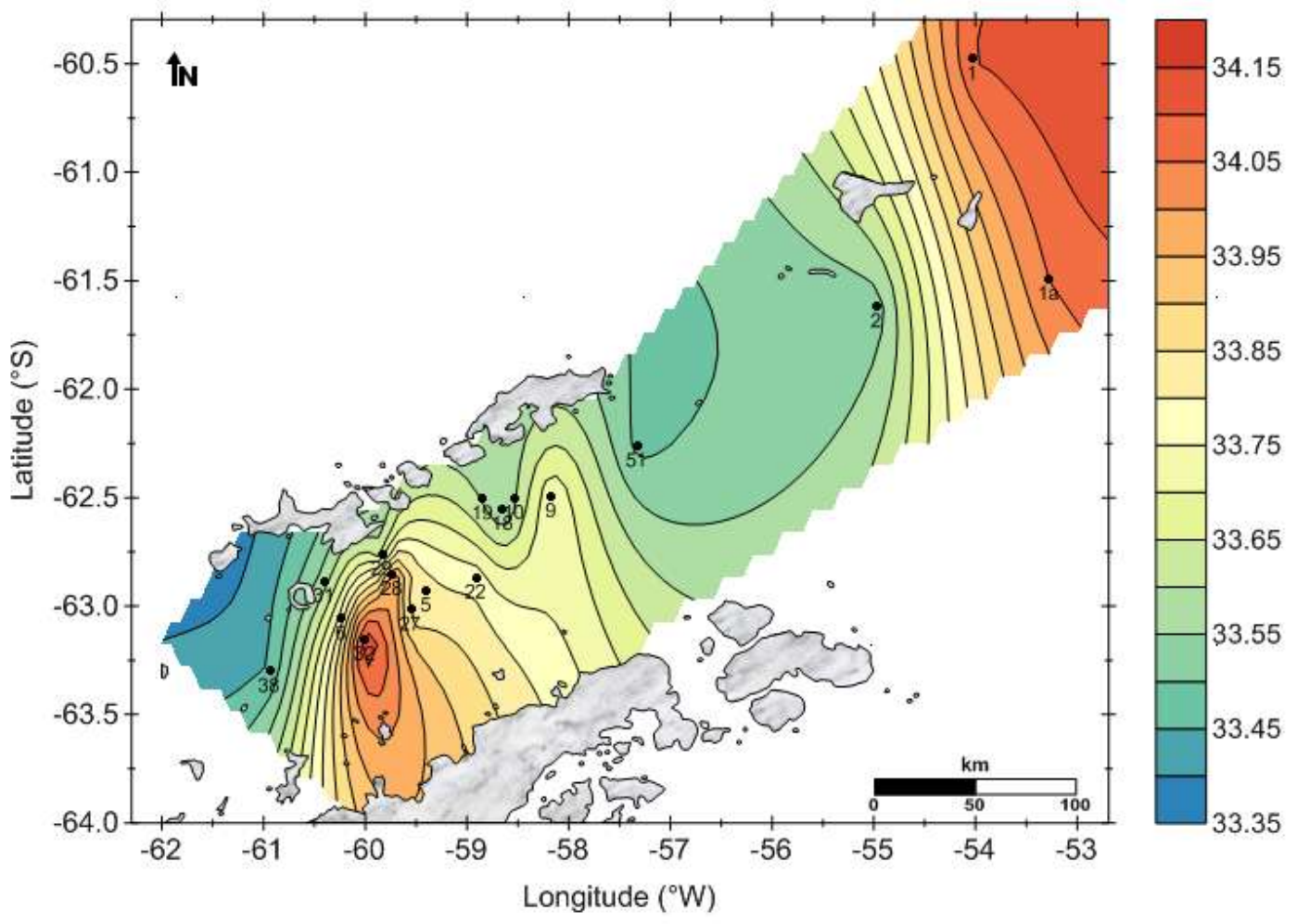

FIGURA 21 - Distribuição superficial de salinidade - OPERANTAR XXX. 
As distribuições superficiais das concentrações de $\mathrm{Cl}$, COT e CT são apresentadas nas FIG. 22 a 27. As concentrações estiveram entre 0,23 a $0,70 \mathrm{mg} \mathrm{L}^{-1}$ e 0,29 a $0,81 \mathrm{mg} \mathrm{L}^{-1}$ para $\mathrm{Cl}$, entre 0,54 a $17,20 \mathrm{mg} \mathrm{L}^{-1}$ e $1,04 \mathrm{a}$ $6,00 \mathrm{mg} \mathrm{L}^{-1}$ para COT e entre 0,83 a $17,50 \mathrm{mg} \mathrm{L}^{-1}$ e 1,47 a $6,60 \mathrm{mg} \mathrm{L}^{-1}$ para CT no final e início do verão Austral, respectivamente. As menores concentrações de $\mathrm{Cl}$ observadas estiveram próximas a Península Antártica e entre as llhas Snow e Trinity no final e início do verão, respectivamente. Elevadas concentrações foram observadas no final e início do verão ao sudeste do EB e próxima à llha Deception, respectivamente. As concentrações de COT e CT apresentaram distribuição superficial semelhante devido o $\mathrm{CO}$ corresponder cerca de $70 \%$ do $\mathrm{CT}$, as menores concentrações foram observadas próximas às llhas Rei George e Elefante no final e início do verão, respectivamente. Concentrações elevadas foram observadas nas estações EB 052 e EB 022, localizadas na sub-bacia central do EB no final e início do verão, respectivamente.

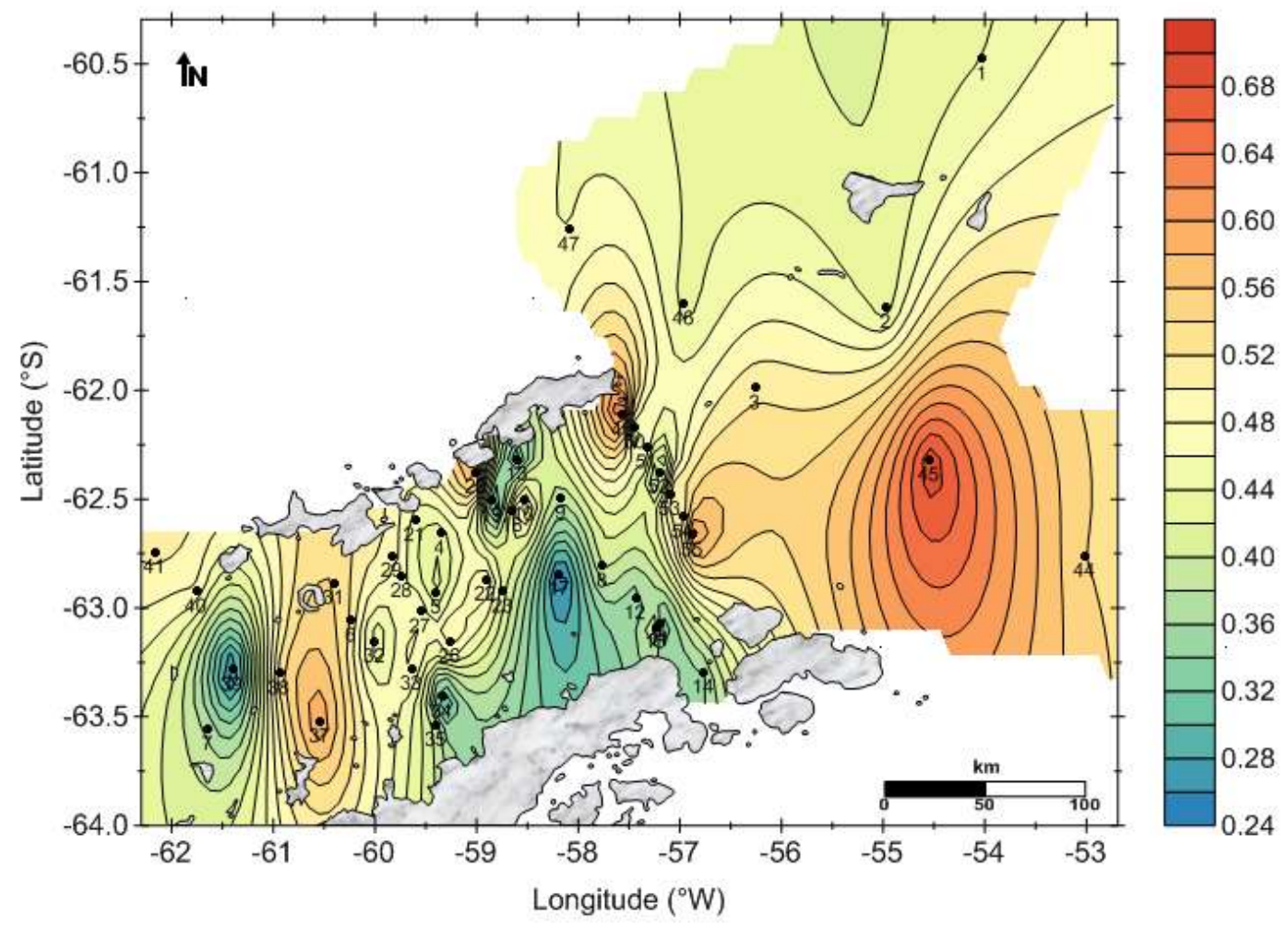

FIGURA 22 - Distribuição superficial de carbono inorgânico, em $\mathrm{mg} \mathrm{L}^{-1}-$ OPERANTAR XXIX. 


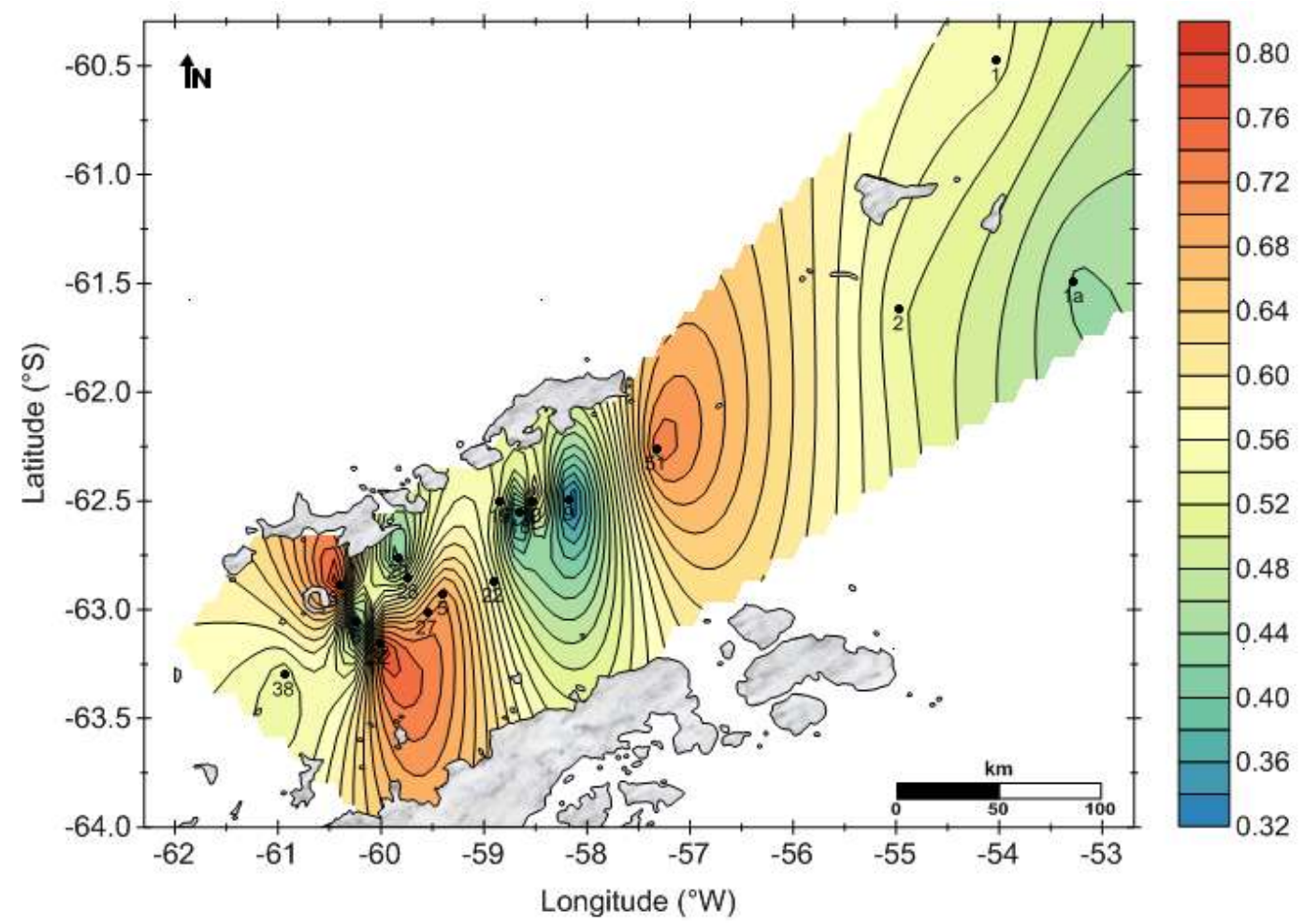

FIGURA 23 - Distribuição superficial de carbono inorgânico, em mg $\mathrm{m}^{-1}$ OPERANTAR XXIX.

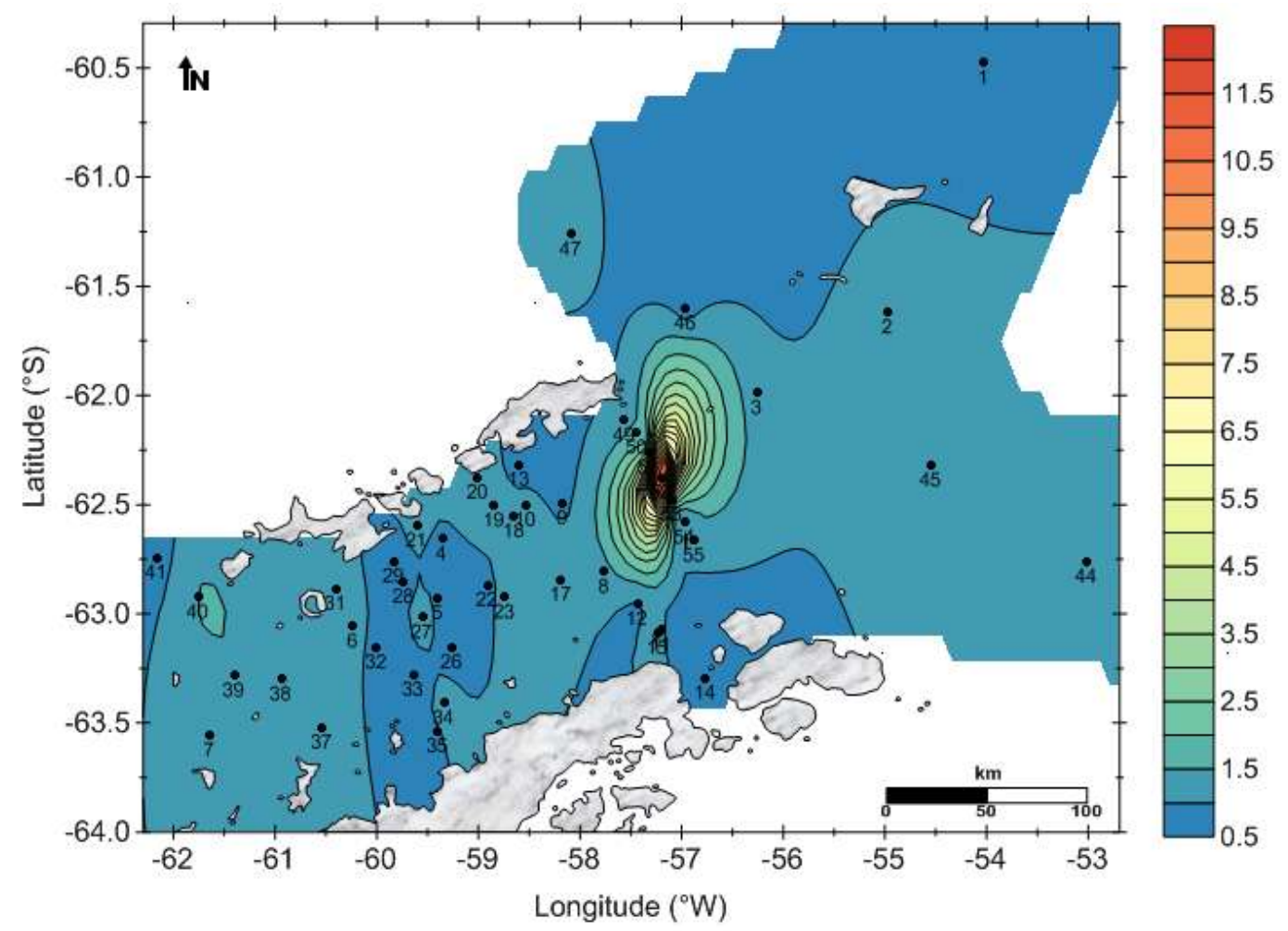

FIGURA 24 - Distribuição superficial de carbono orgânico total, em $\mathrm{mg} \mathrm{L}^{-1}$ OPERANTAR XXIX. 


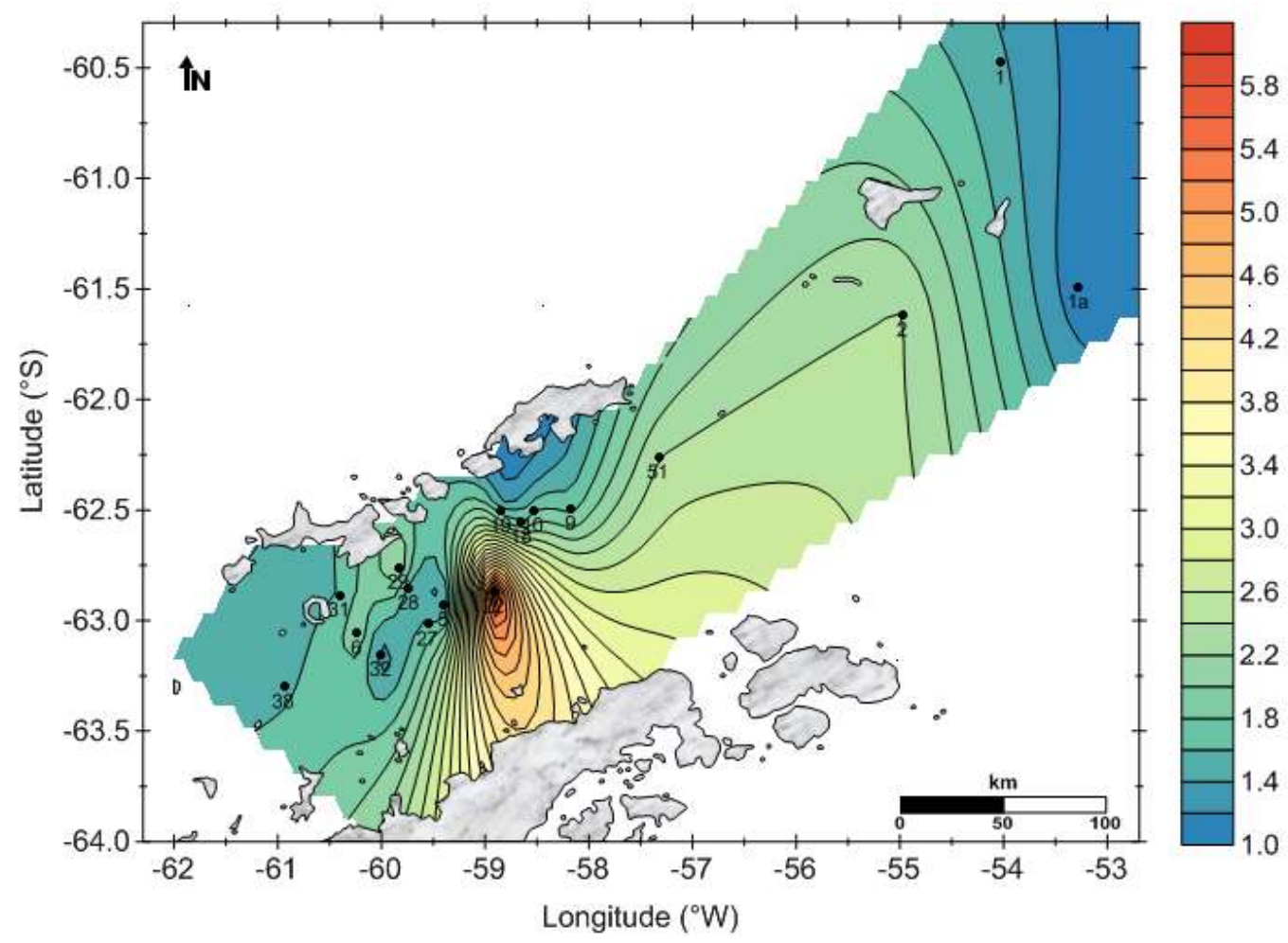

FIGURA 25 - Distribuição superficial de carbono orgânico total, em $\mathrm{mg} \mathrm{L}^{-1}$ OPERANTAR XXX.

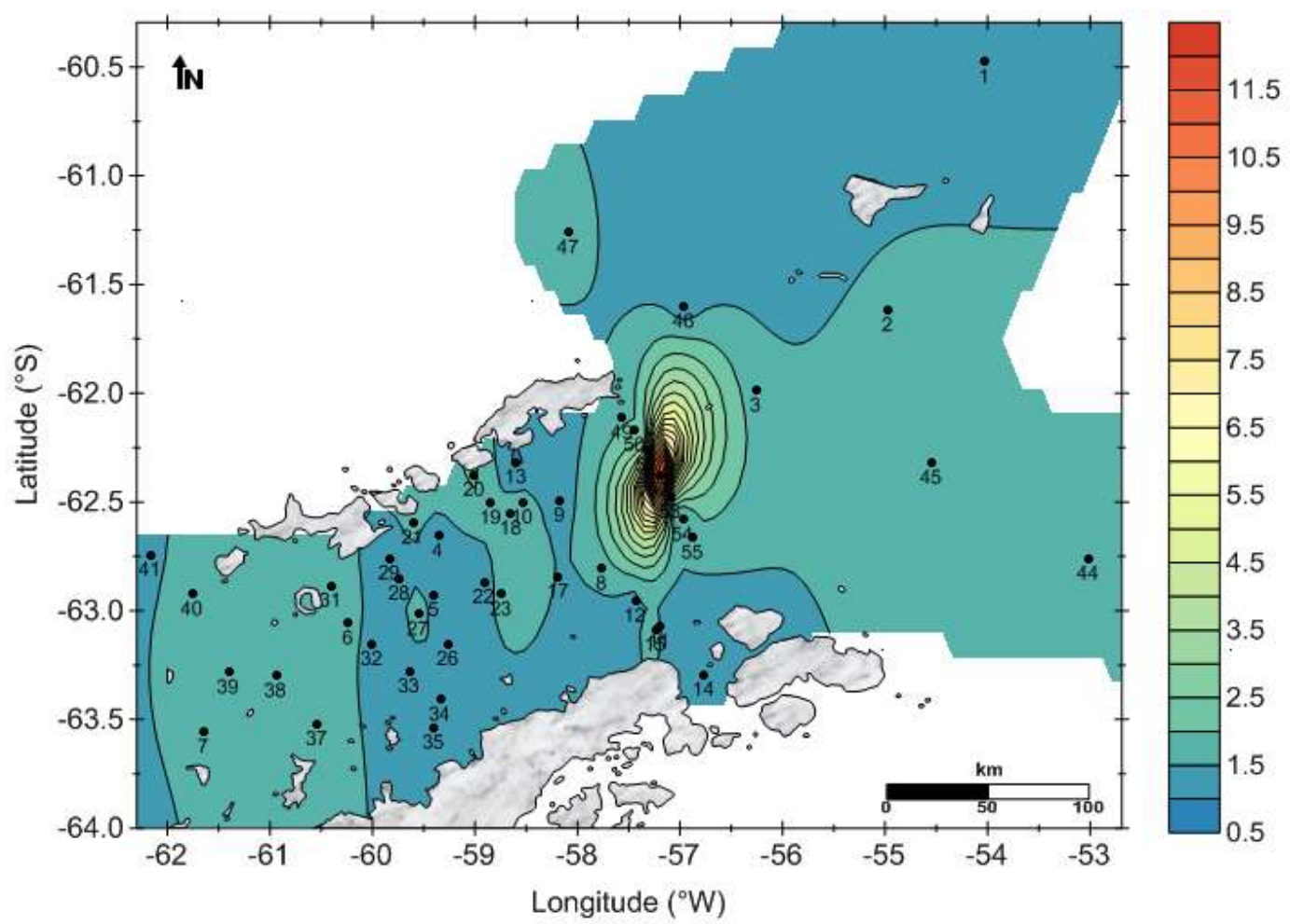

FIGURA 26 - Distribuição superficial de carbono total, em mg L $\mathrm{m}^{-1}$ - OPERANTAR XXIX. 


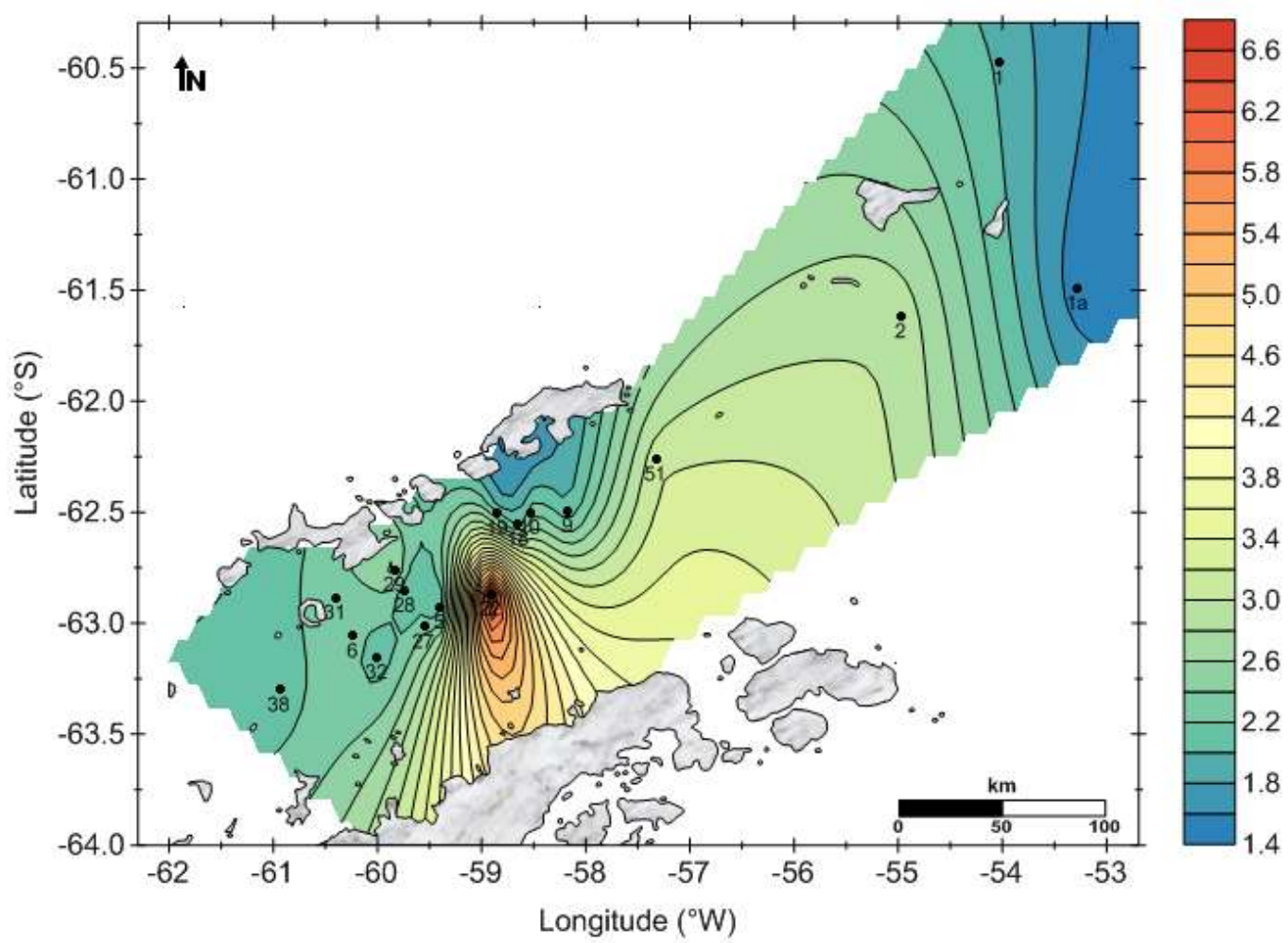

FIGURA 27 - Distribuição superficial de carbono total, em $\mathrm{mg} \mathrm{L}^{-1}$ - OPERANTAR $\mathrm{XXX}$.

As distribuições superficiais das concentrações de ${ }^{234}$ Th total estão plotadas nas FIG. 28 e 29. As concentrações variaram de 1,33 a 3,71 dpm L $\mathrm{L}^{-1}$ no

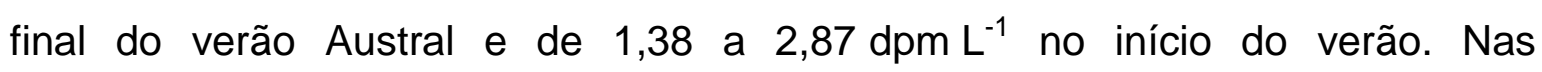
proximidades da Ilha Livingston e do Estreito de Gerlache estão destacadas as menores concentrações obtidas no final do verão, e no início do verão a menor concentração foi observada próxima das llhas Livingston e Elefante. Concentrações de ${ }^{234}$ Th total elevadas foram identificadas próximas à Península Trinity no final do verão e próximas à Ilha Deception no início do verão.

Variações superficiais das concentrações de ${ }^{238} \mathrm{U}$ dissolvido são apresentadas nas FIG. 30 e 31. As concentrações variaram de 2,33 a 2,38 dpm L $\mathrm{L}^{-1}$ no final do verão Austral e de 2,31 a 2,36 dpm L $\mathrm{L}^{-1}$ no início do verão. As distribuições superficiais de ${ }^{238} \mathrm{U}$ dissolvido foram idênticas as de salinidade devido às concentrações de atividade de ${ }^{238} \mathrm{U}$ serem estimadas a partir dos dados de salinidade. Foram observadas concentrações baixas nas proximidades das Ilhas Shetland do Sul e ao sul do EB no início e final do verão Austral. 
Concentrações mais elevadas foram observadas próximas da Península Trinity no final do verão, e no início do verão próximos da Ilha Elefante e na sub-bacia central do EB.

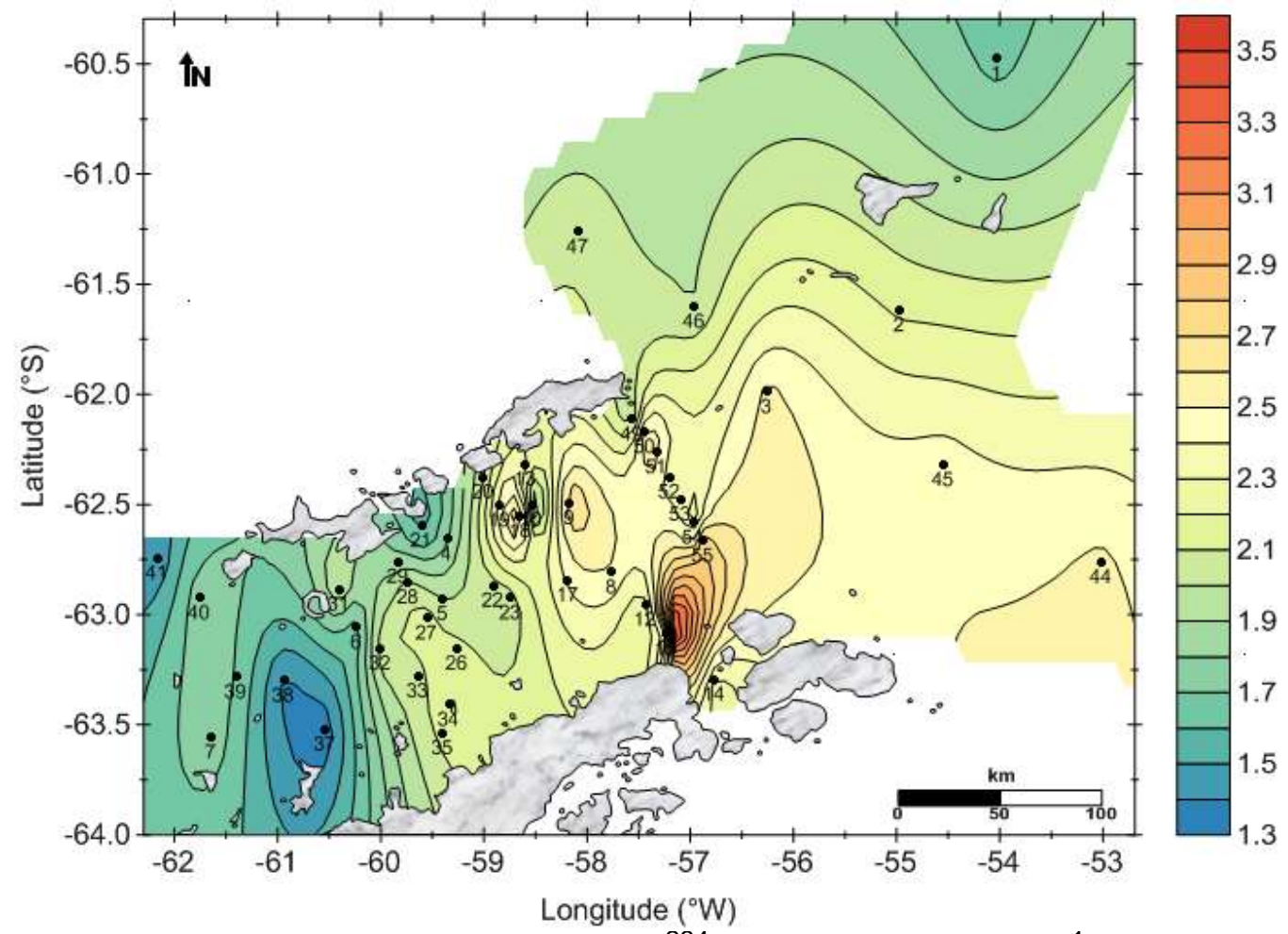

FIGURA 28 - Distribuição superficial de ${ }^{234} \mathrm{Th}$ total, em dpm L ${ }^{-1}$ - OPERANTAR XXIX.

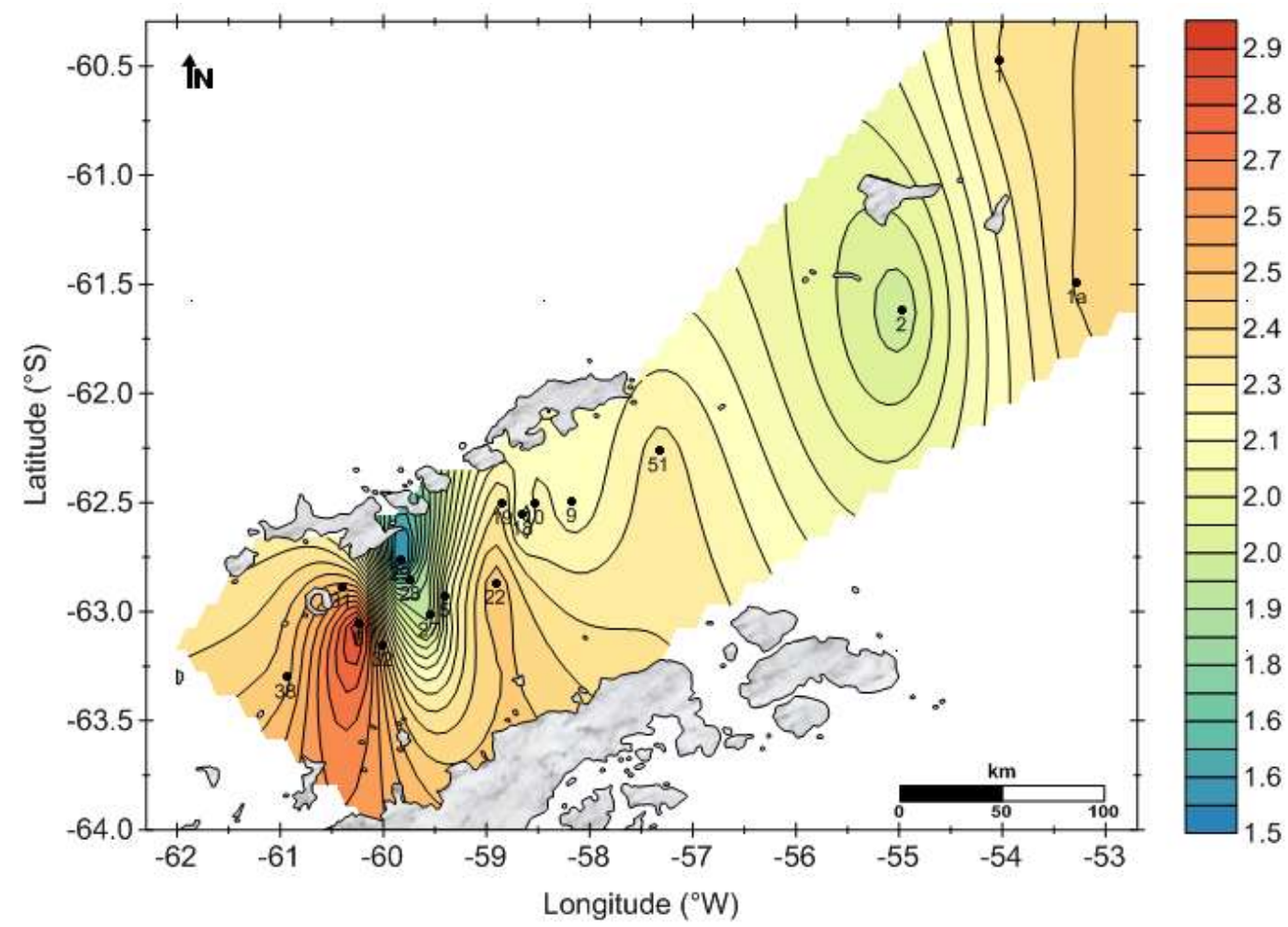

FIGURA 29 - Distribuição superficial de ${ }^{234}$ Th total, em dpm L ${ }^{-1}$ - OPERANTAR XXX. 


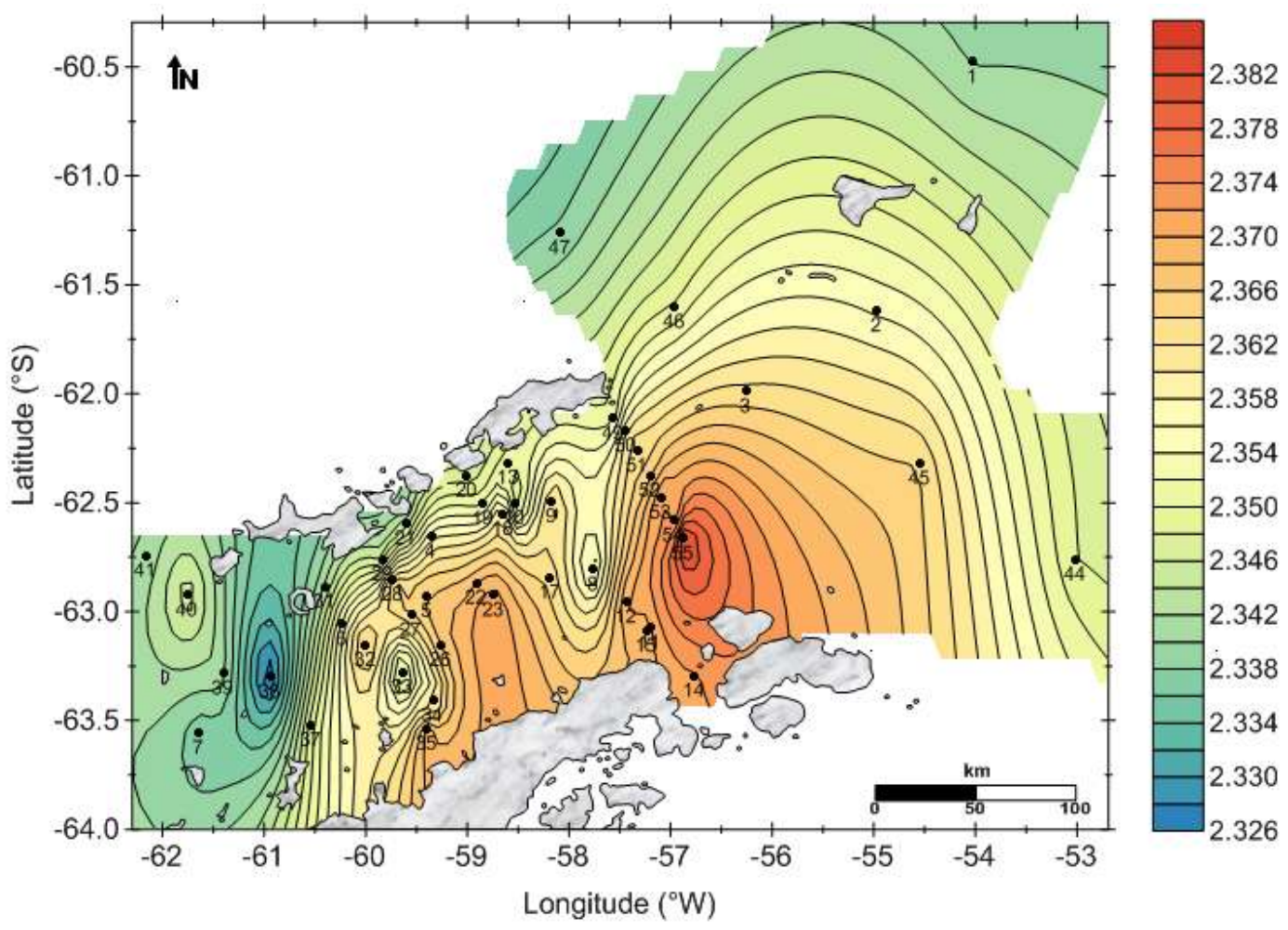

FIGURA 30 - Distribuição superficial de ${ }^{238} \mathrm{U}$ dissolvido, em dpm L ${ }^{-1}-$ OPERANTAR XXIX

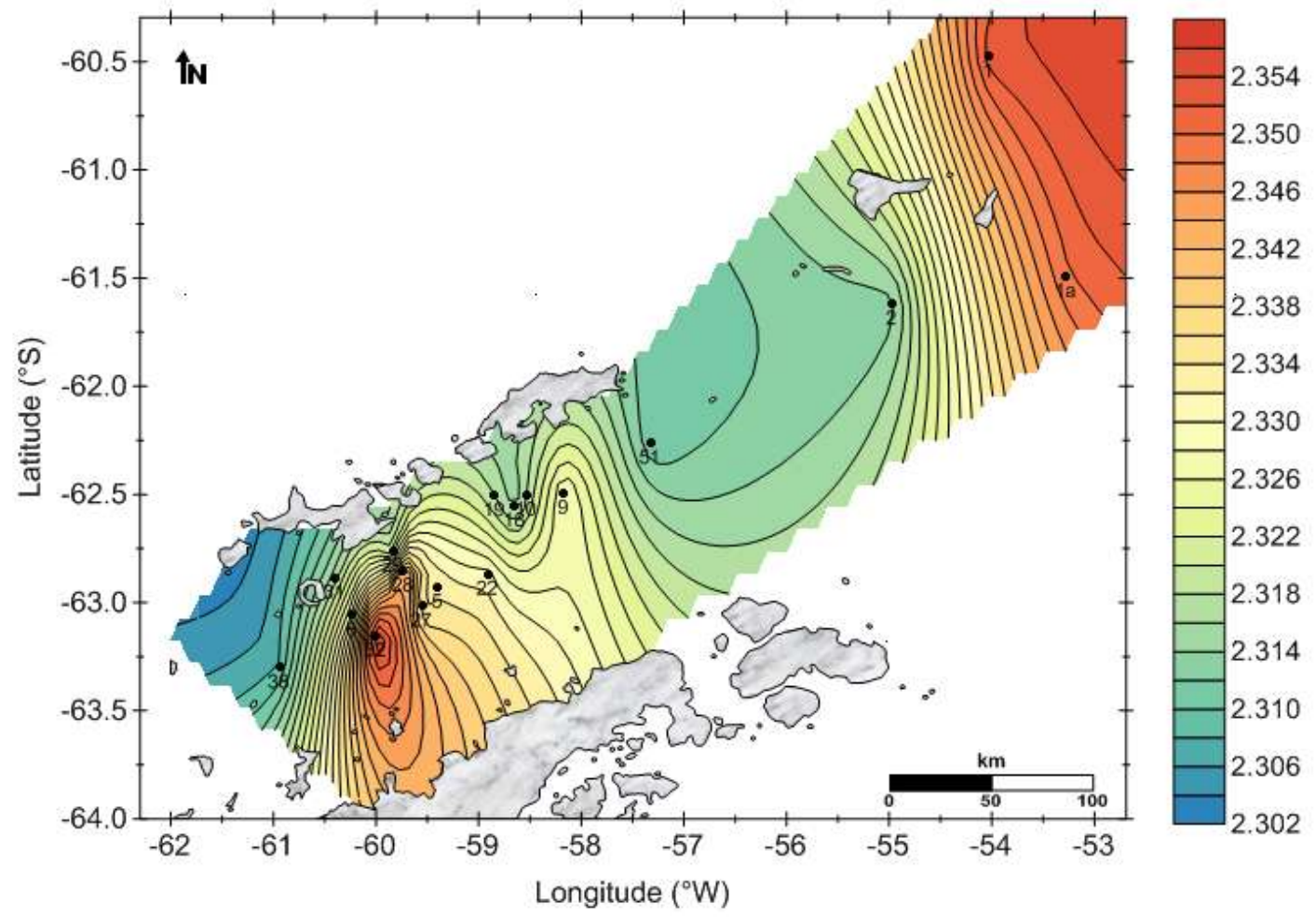

FIGURA 31 - Distribuição superficial de ${ }^{238} \mathrm{U}$ dissolvido, em dpm L ${ }^{-1}-$ OPERANTAR XXX. 
As FIG. 32 e 33 apresentam as distribuições superficiais das razões de atividade ${ }^{234} \mathrm{Th}$ total $/{ }^{238} \mathrm{U}$ dissolvido, cujos valores variaram de 0,57 a 1,52 e 0,60 a 1,23 no final e início do verão Austral, respectivamente. As distribuições superficiais da razão ${ }^{234} \mathrm{Th}$ total//238 $\mathrm{U}$ dissolvido são semelhantes as de concentrações de atividade de ${ }^{234} \mathrm{Th}$ total. Valores de razão de atividade menores que 0,8 foram observados ao norte do EB (OPERANTAR XXIX) e próximo as Ilhas Livingston e Elefante (OPERANTAR XXX), sugerindo maior remoção do ${ }^{234}$ Th pelo material particulado. Valores próximos a 1 foram observados na subbacia central se estendendo a leste do EB, indicando que ${ }^{234} \mathrm{Th}$ encontra-se em equilíbrio com seu precursor, o ${ }^{238} U$. Valores acima de 1 foram observados próximo à Península Trinity (OPERANTAR XXIX) e ao norte do EB (OPERANTAR $X X X)$, e este excesso de Th evidenciado nas águas superficiais sugere remineralização ou aporte de algas de degelo na região. Devido às diferenças sazonais e climáticas entre duas campanhas de amostragem, nota-se que durante o início do verão os processos de degelo estão ocorrendo intensamente causando maior fornecimento de ${ }^{234} \mathrm{Th}$ em relação ao ${ }^{238} \mathrm{U}$ ao norte do EB possivelmente pelas algas de degelo, as quais podem acumular $0{ }^{234} \mathrm{Th}$ em sua estrutura e após derretimento libera-lo causando excesso de ${ }^{234} \mathrm{Th}$ em águas superficiais (Rutgers van der Loeff et al., 2002). 


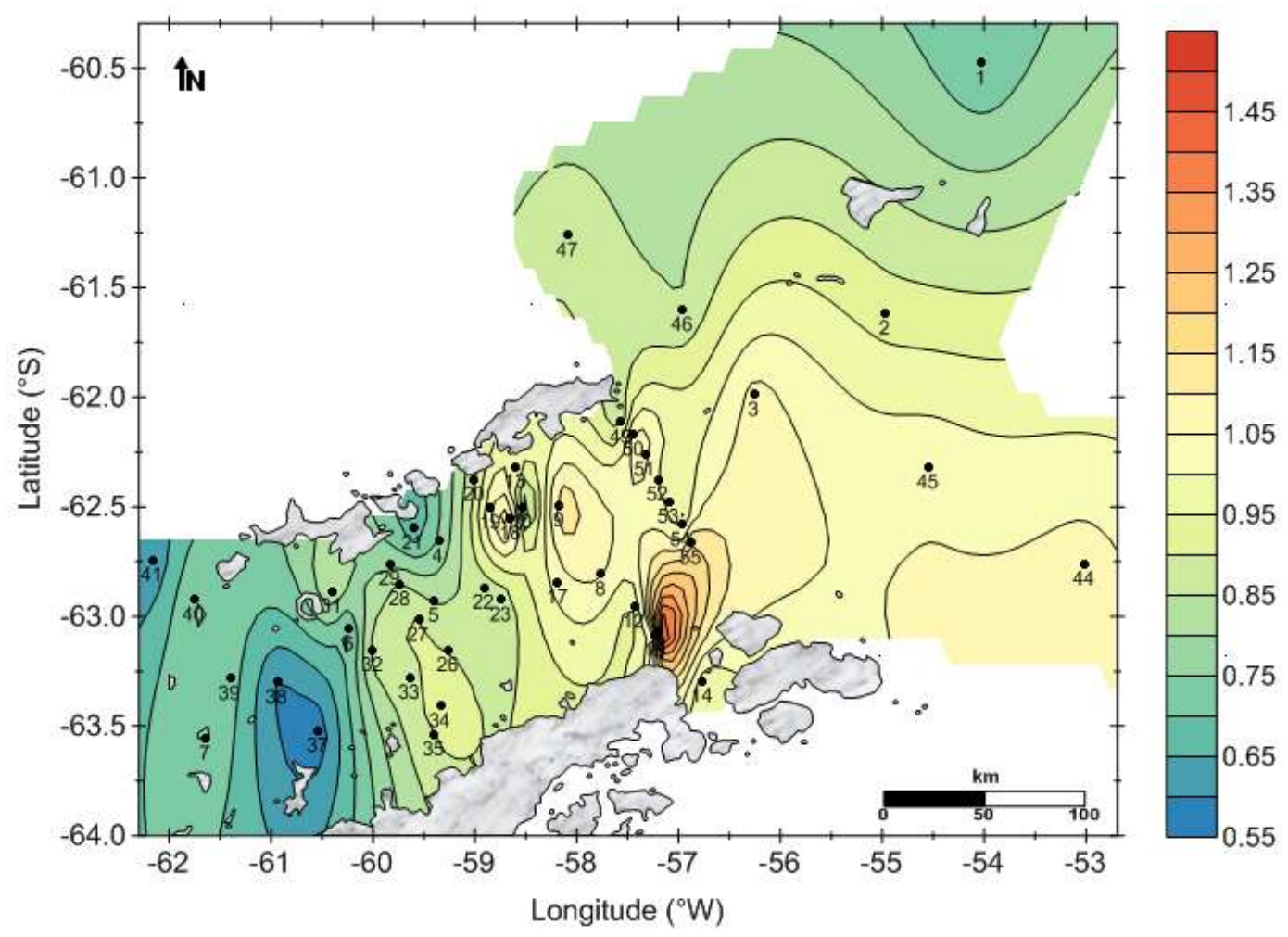

FIGURA 32 - Distribuição superficial da razão de atividade ${ }^{234} \mathrm{Th}$ total/ ${ }^{238} \mathrm{U}$ dissolvido - OPERANTAR XXIX.

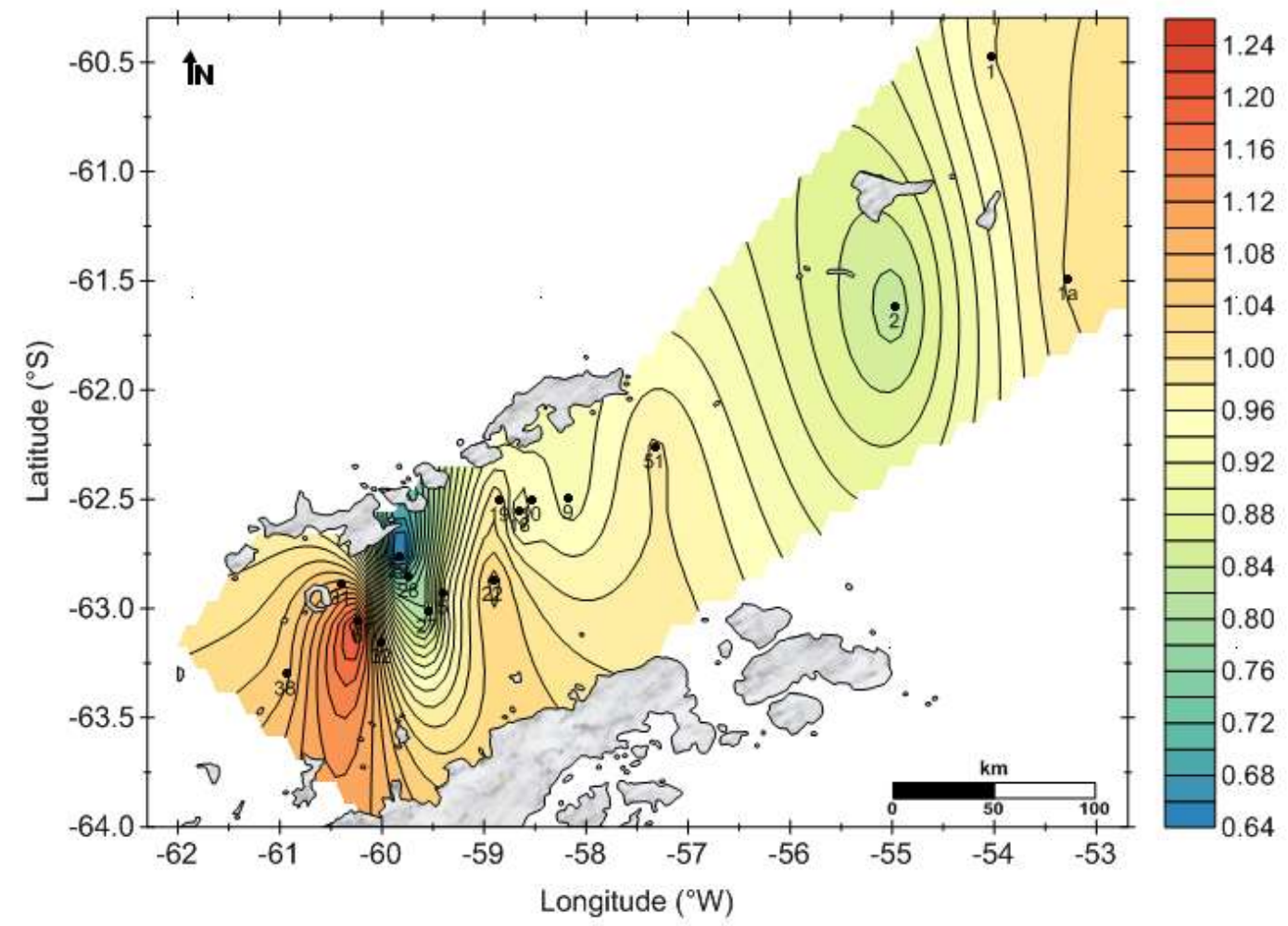

FIGURA 33 - Distribuição superficial da razão de atividade ${ }^{234} \mathrm{Th}$ total/ ${ }^{238} \mathrm{U}$ dissolvido - OPERANTAR XXX. 
As distribuições superficiais das concentrações de ${ }^{210} \mathrm{Po}$ particulado são apresentadas nas FIG. 34 e 35 . As concentrações obtidas neste estudo estiveram entre 0,31 a $6,54 \mathrm{dpm} \mathrm{L} L^{-1}$ e 0,02 a $0,09 \mathrm{dpm} \mathrm{L}^{-1}$ no final e início do verão Austral, respectivamente. As menores concentrações foram observadas aos arredores das Ilhas d'Urville e Livingston no final do verão, enquanto que no início do verão as menores concentrações foram observadas próximas a llha Rei George. No final do verão Austral, as maiores concentrações foram observadas nas proximidades da llha Rei George e ao sul do EB, enquanto que no início do verão foram observadas próximas as llhas Livingston e Elefante.

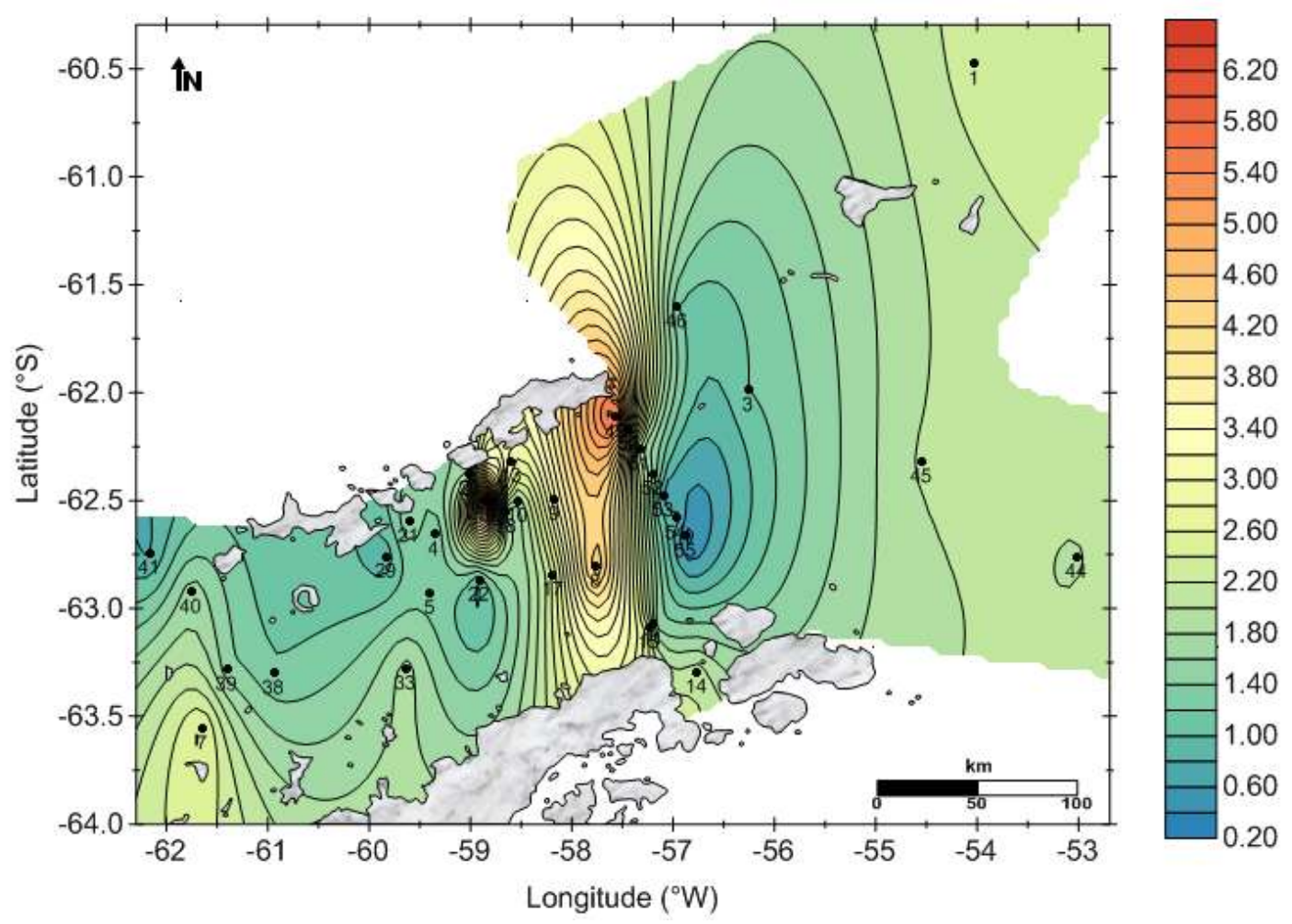

FIGURA 34 - Distribuição superficial de ${ }^{210} \mathrm{Po}$ particulado, em dpm L ${ }^{-1}-$ OPERANTAR XXIX. 


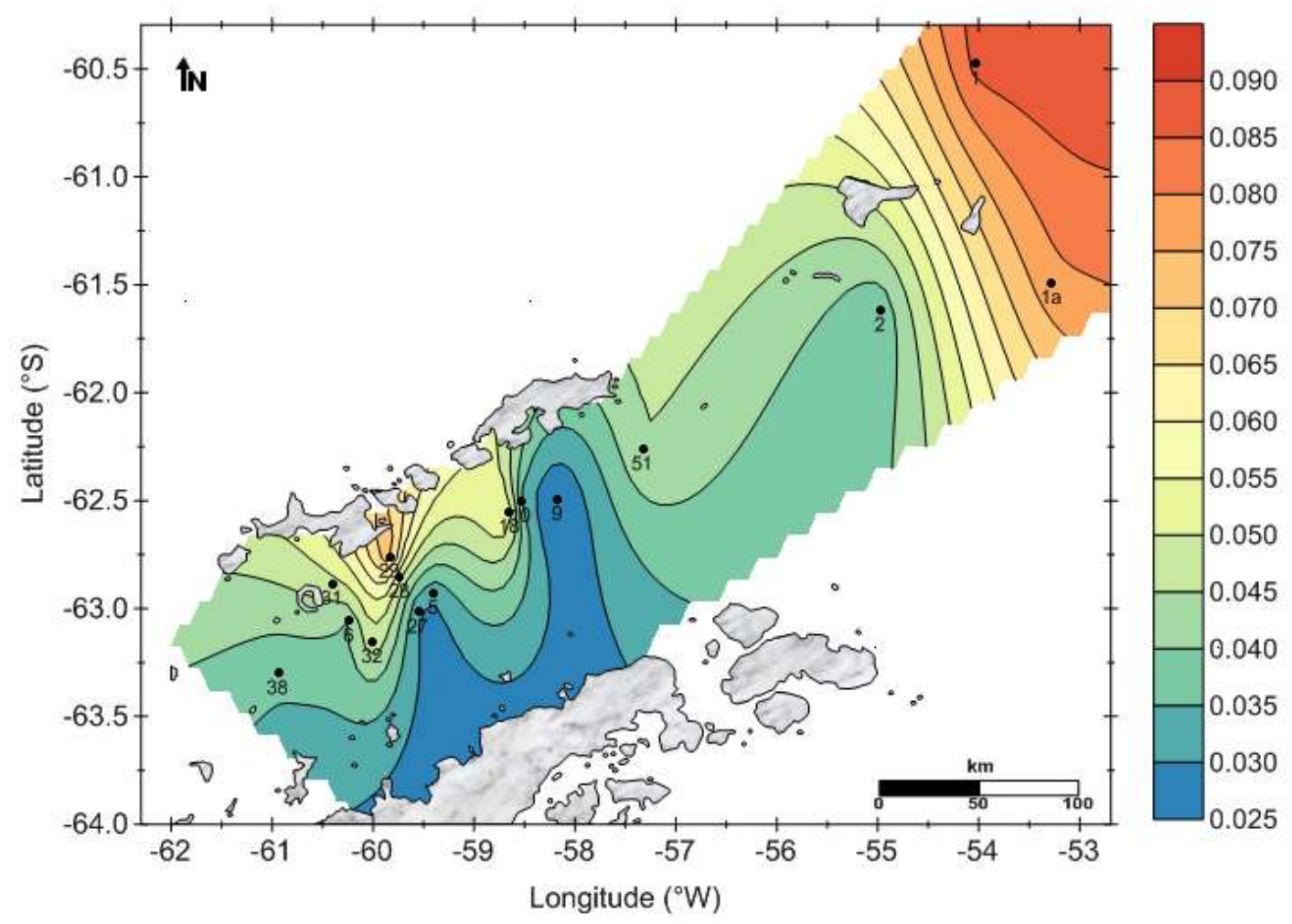

FIGURA 35 - Distribuição superficial de ${ }^{210} \mathrm{Po}$ particulado, em dpm L-1 OPERANTAR XXX.

Variações superficiais das concentrações de ${ }^{210} \mathrm{~Pb}$ particulado são mostradas na FIG. 36. As concentrações variaram de 1,28 a 5,54 dpm L ${ }^{-1}$ no início do verão Austral. Concentrações de atividade baixas foram localizadas ao sul da Ilha Elefante e estação EB 051, enquanto que elevadas concentrações de atividade foram notadas ao norte da llha Elefante.

A FIG. 37 apresenta as distribuições superficiais das razões de atividade ${ }^{210} \mathrm{Po} /{ }^{210} \mathrm{~Pb}$. As razões encontradas oscilaram de 0,01 a 0,05 no início do verão Austral. Os menores valores de razão de atividade obtidos foram destacados nas proximidades da llha Rei George e os maiores valores na llha Livingston. 


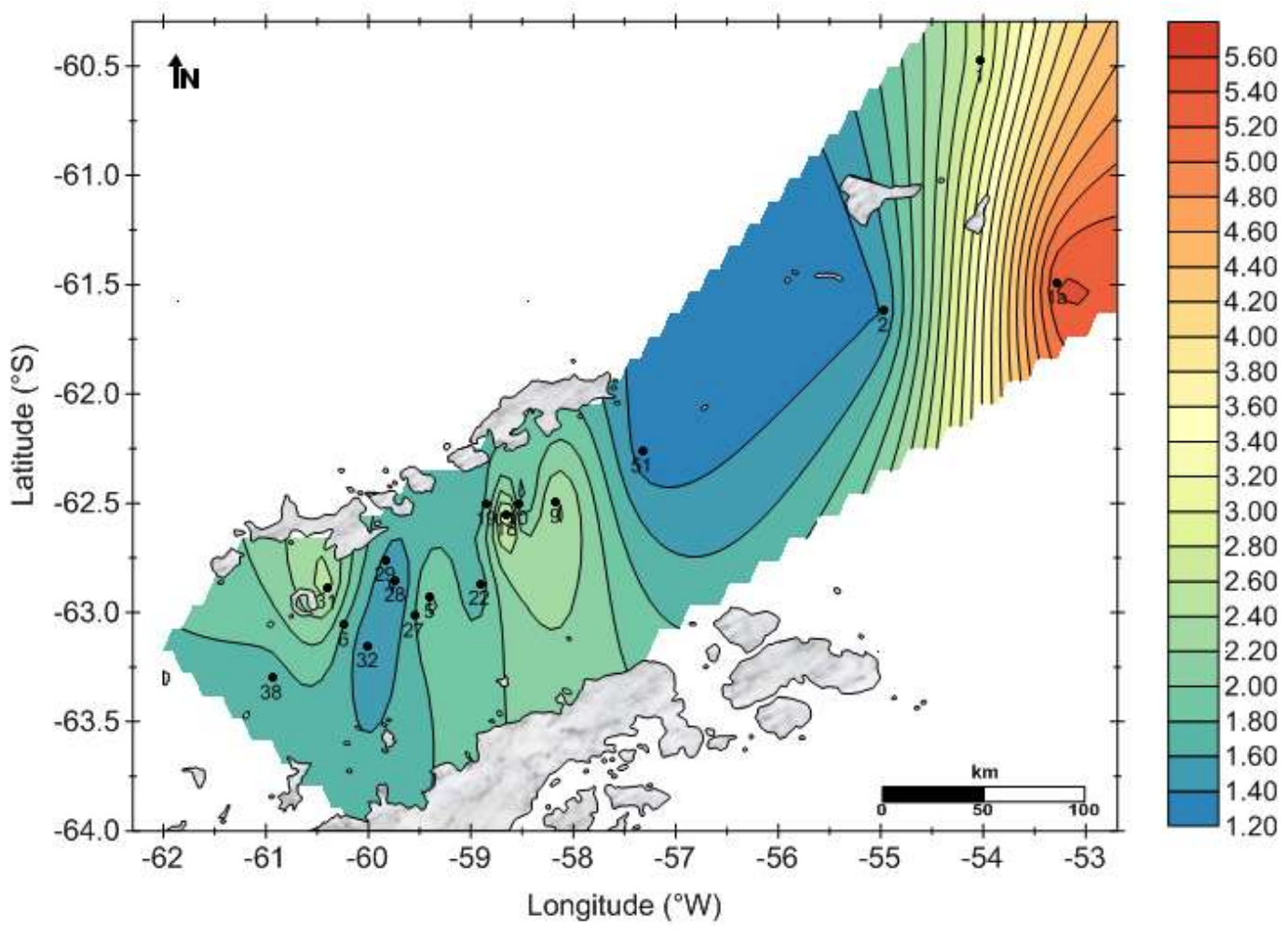

FIGURA 36 - Distribuição superficial de ${ }^{210} \mathrm{~Pb}$ particulado, em dpm L ${ }^{-1},-$ OPERANTAR XXX

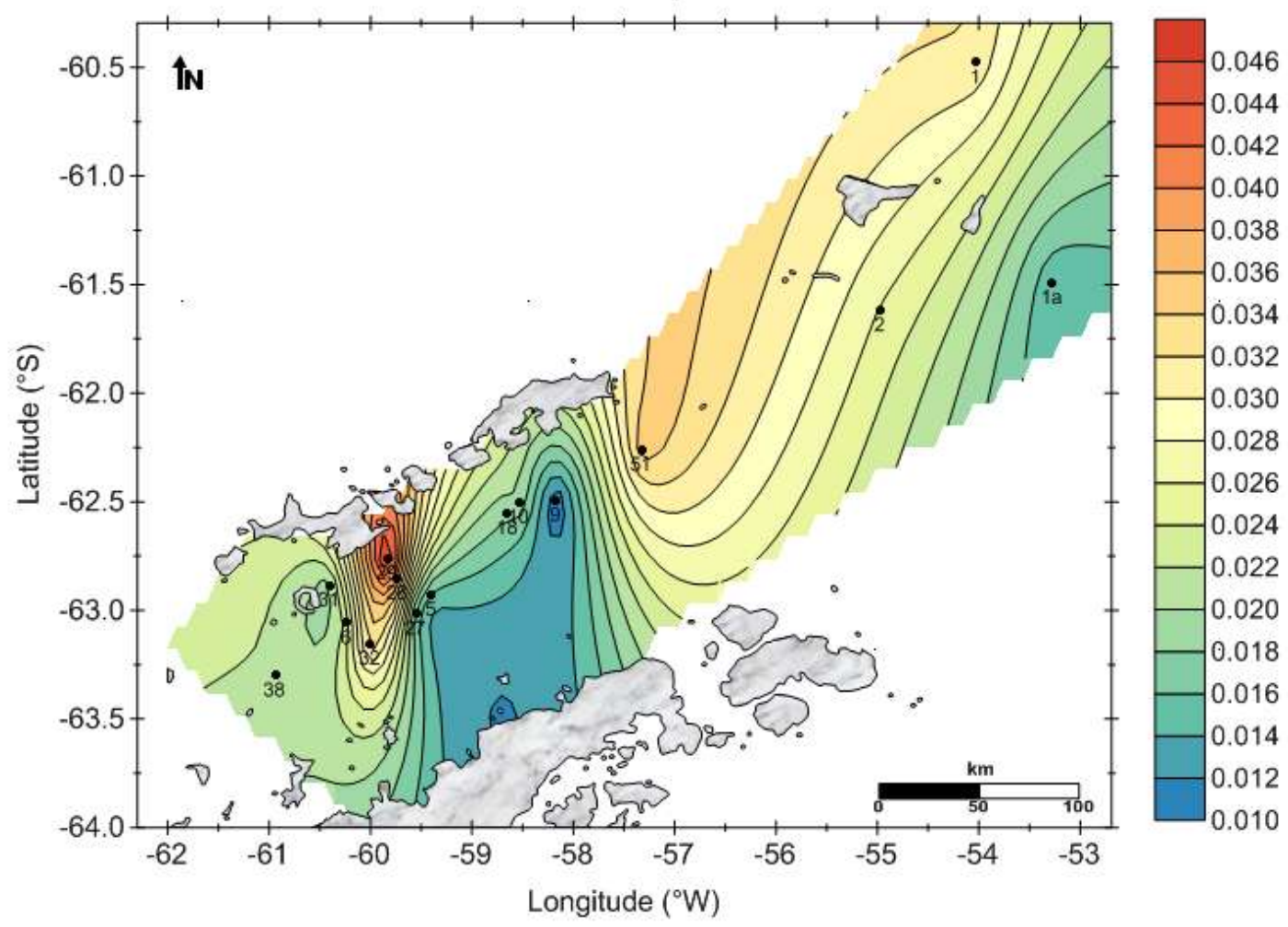

FIGURA 37- Distribuição superficial da razão de atividade ${ }^{210} \mathrm{Po} /{ }^{210} \mathrm{~Pb}-$ OPERANTAR XXX 
Na FIG. 38 apresentam-se as distribuições superficiais de ${ }^{226} \mathrm{Ra}$, cujos valores encontrados estiveram entre 0,11 a $2,88 \mathrm{dpm} 100 \mathrm{~L}^{-1}$ e 2,96 a $8,30 \mathrm{dpm} 100 \mathrm{~L}^{-1}$ no final e início do verão Austral, respectivamente. No início do verão foram encontradas concentrações baixas nas redondezas das llhas Deception e Rei George, e concentrações mais elevadas nas adjacências das Ilhas Livingston e Elefante.

As distribuições superficiais de ${ }^{228} \mathrm{Ra}$ também são mostradas na FIG. 39. Os valores obtidos neste estudo variaram de 0,29 a $2,18 \mathrm{dpm} 100 \mathrm{~L}^{-1} \mathrm{e}$ 0,28 a 2,79 dpm $100 \mathrm{~L}^{-1}$ no final e início do verão Austral, respectivamente. Baixas concentrações de atividade foram observadas próximas às llhas Nelson e Rei George e mais ao norte do EB nas proximidades da llha Clarence, e elevadas concentrações próxima à Elefante no início do verão Austral.

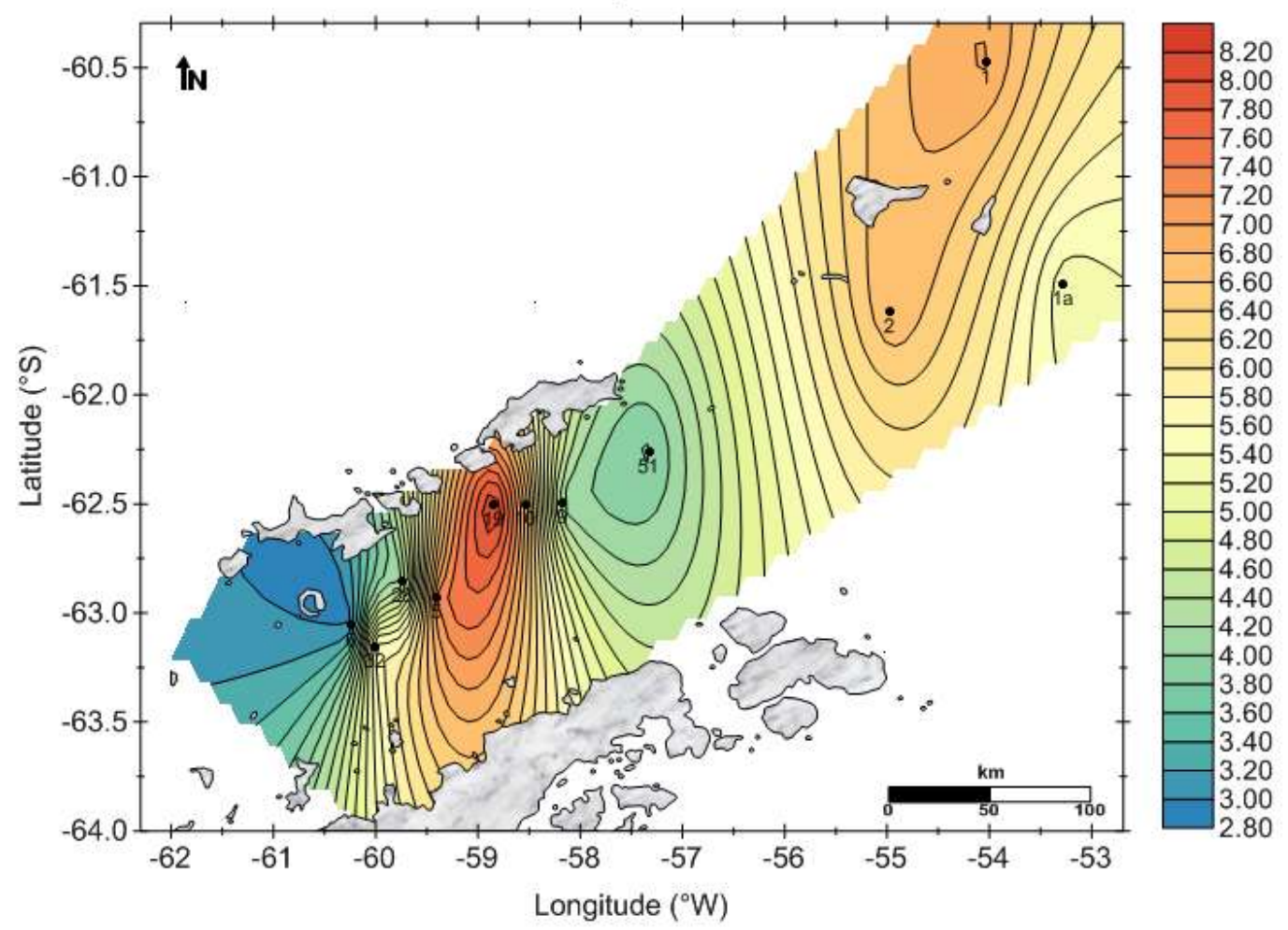

FIGURA 38 - Distribuição superficial de ${ }^{226} \mathrm{Ra}$, em dpm $100 \mathrm{~L}^{-1}$ - OPERANTAR XXX. 


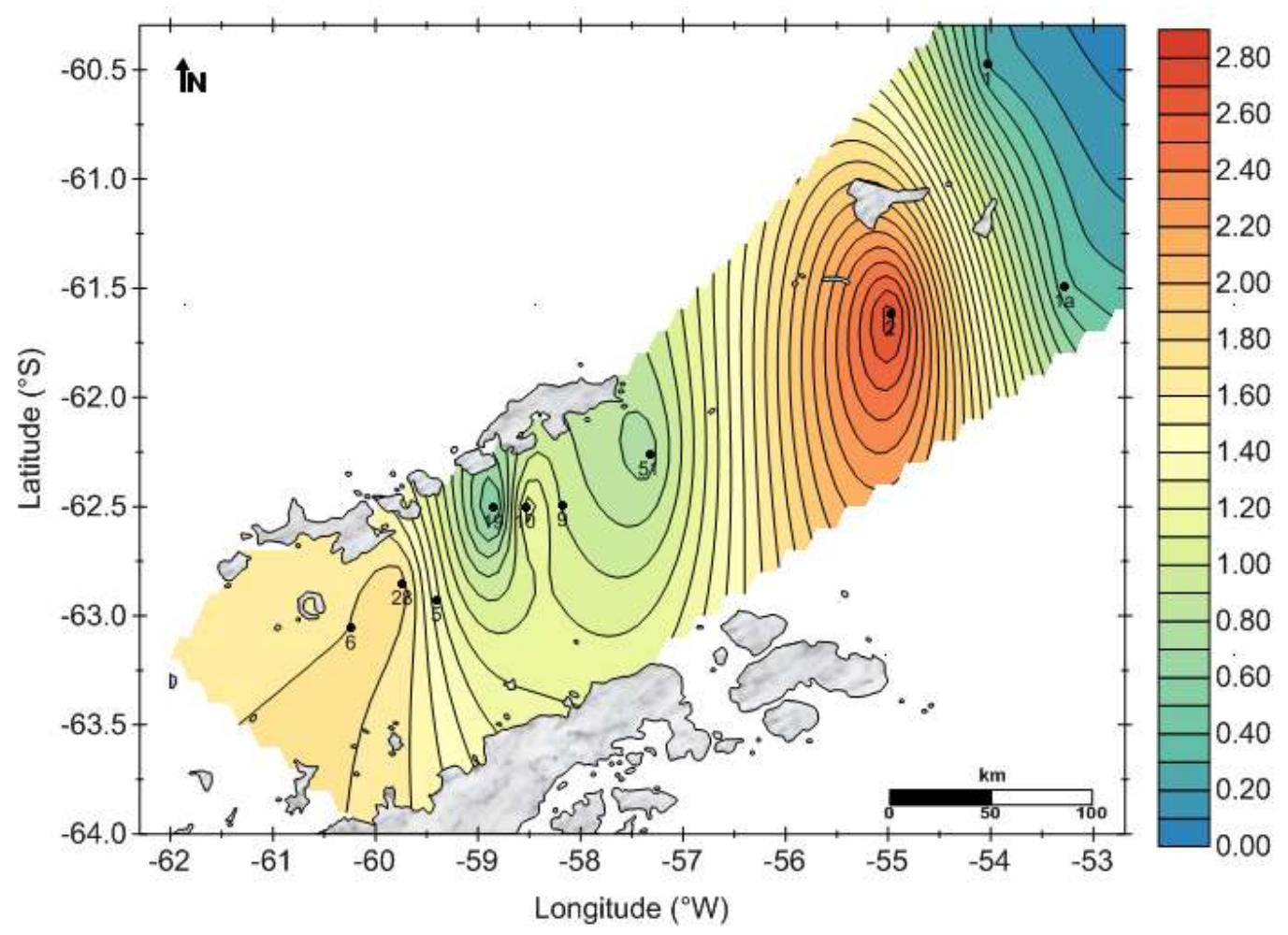

FIGURA 39 - Distribuição superficial de ${ }^{228} \mathrm{Ra}$, em dpm $100 \mathrm{~L}^{-1}$ - OPERANTAR XXX.

As variações superficiais da razão de atividade ${ }^{228} \mathrm{Ra} /{ }^{226} \mathrm{Ra}$ são apresentadas na FIG. 40. Os valores obtidos variaram de 0,82 a 5,52 e 0,04 a 0,57 no final e início do verão Austral, respectivamente. Valores baixos de razão de atividade durante o início do verão foram notados ao norte do EB evidenciando maior concentração de ${ }^{226} \mathrm{Ra}$, enquanto que razões elevadas foram notadas ao sul do EB evidenciando maior concentração de ${ }^{228} \mathrm{Ra}$ próxima do talude continental.

As razões de atividade superficiais de ${ }^{210} \mathrm{~Pb} /{ }^{226} \mathrm{Ra}$ são apresentadas na FIG. 41. Os valores encontrados neste estudo estiveram entre 20,67 a 103,52 no início do verão Austral. Valores baixos de razão de atividade foram encontrados próximos às Ilhas Nelson e Elefante, enquanto que valores maiores foram obervados próximos às Ilhas Clarence, Deception e Rei George. Esse excesso de ${ }^{210} \mathrm{~Pb}$ em relação ao ${ }^{226} \mathrm{Ra}$ em águas superficiais pode estar relacionado ao fornecimento contínuo de ${ }^{210} \mathrm{~Pb}$ a partir da atmosfera (Krishnaswami, 2001, Nozaki et al., 1998). 


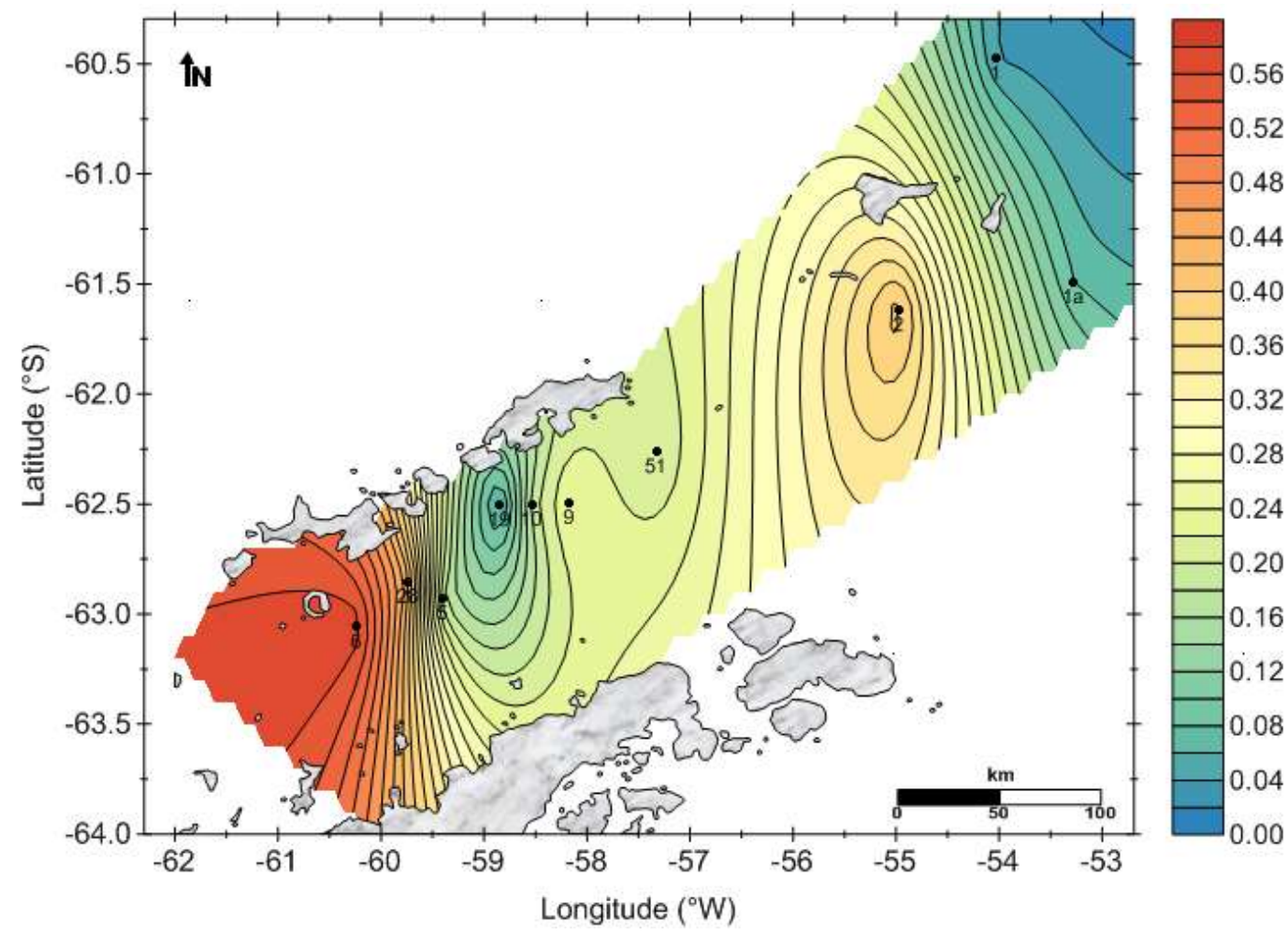

FIGURA 40 - Distribuição superficial da razão de atividade ${ }^{228} \mathrm{Ra} /{ }^{226} \mathrm{Ra}-$ OPERANTAR XXX.

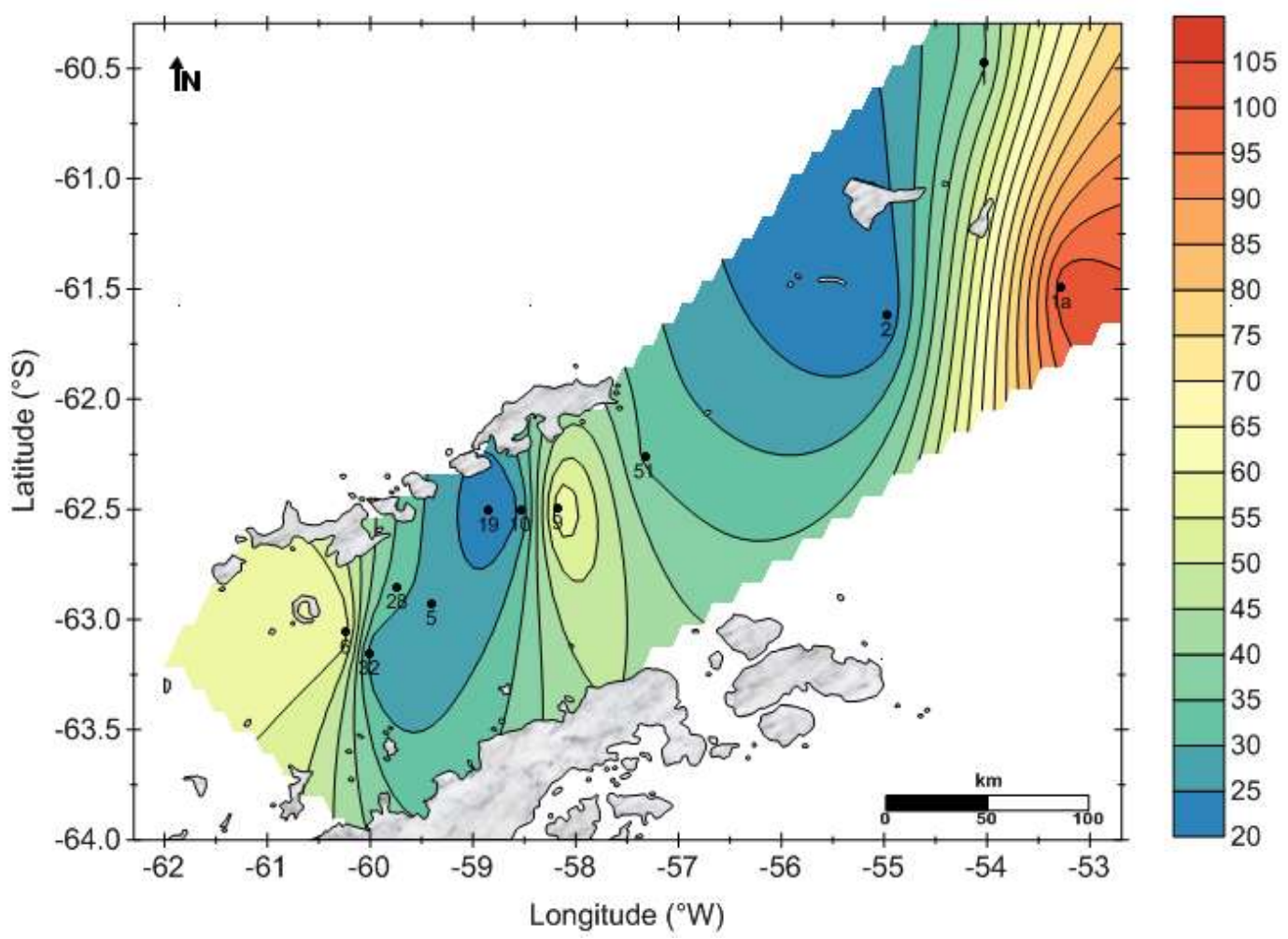

FIGURA 41 - Distribuição superficial da razão de atividade ${ }^{210} \mathrm{~Pb} /{ }^{226} \mathrm{Ra}-$ OPERANTAR XXX. 


\subsection{Análise de correlação}

O coeficiente de correlação linear ( $r$ ) é empregado para avaliar a associação linear entre duas variáveis, e o número obtido a partir da equação da reta indicará como as variáveis variam conjuntamente, considerando-se que uma variável não determina o valor da outra. $O r$ apresenta variação de $-1 \leq r \leq 1, r=1$ indica correlação forte e positiva entre as duas variáveis, enquanto que $r=-1$ indica correlação forte e negativa, ou seja, se uma variável aumenta a outra sempre diminui, e $r=0$ indica fraca correlação, isto é, as variáveis não dependem linearmente uma da outra (Silva, 2004).

Foram realizadas correlações lineares de profundidade total, distância da costa, temperatura, salinidade, carbono inorgânico e carbono orgânico total com os radionuclídeos determinados $0{ }^{234} \mathrm{Th},{ }^{238} \mathrm{U},{ }^{210} \mathrm{Po},{ }^{210} \mathrm{~Pb},{ }^{226} \mathrm{Ra}$ e ${ }^{228} \mathrm{Ra}$ (FIG. 42 a 50).

Para melhor interpretação dos gráficos de dispersão foram elaboradas matrizes de correlação das variáveis estudadas com seu respectivo nível de significância, o qual evidencia o quão significativa é a correlação entre as variáveis, neste estudo foi utilizado um nível de significância de $p<0,05$ (TAB. 18 e 19). De maneira geral, as correlações obtidas neste estudo apresentaram baixos coeficientes de correlação linear e níveis de significância maiores que 0,05 .

Os coeficientes de correlação para as relações entre ${ }^{228} \mathrm{Ra}$ e ${ }^{226} \mathrm{Ra}$, e ${ }^{234} \mathrm{Th}$ e ${ }^{238} \mathrm{U}$ durante o início do verão Austral apresentaram valores muito baixos, correlação fraca. Porém no final do verão a relação entre ${ }^{234} \mathrm{Th} \mathrm{e}^{238} \mathrm{U}$ apresentou boa correlação positiva, e no início do verão a relação entre ${ }^{210} \mathrm{Po}$ e ${ }^{210} \mathrm{~Pb}$ apresentou correlação positiva, enquanto que a relação ${ }^{210} \mathrm{~Pb}$ versus ${ }^{226} \mathrm{Ra}$ não apresentou boa correlação entre as variáveis (FIG. 42). 


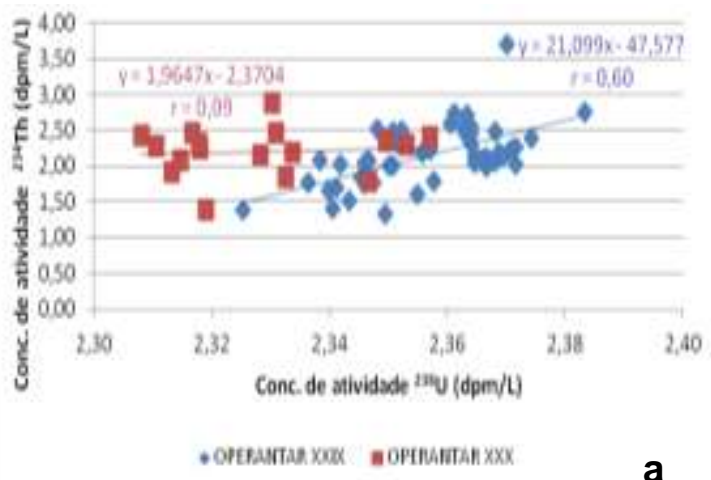

a

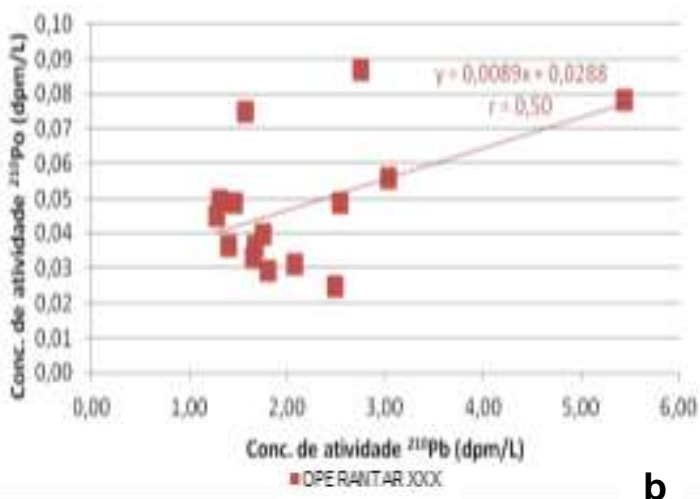

b
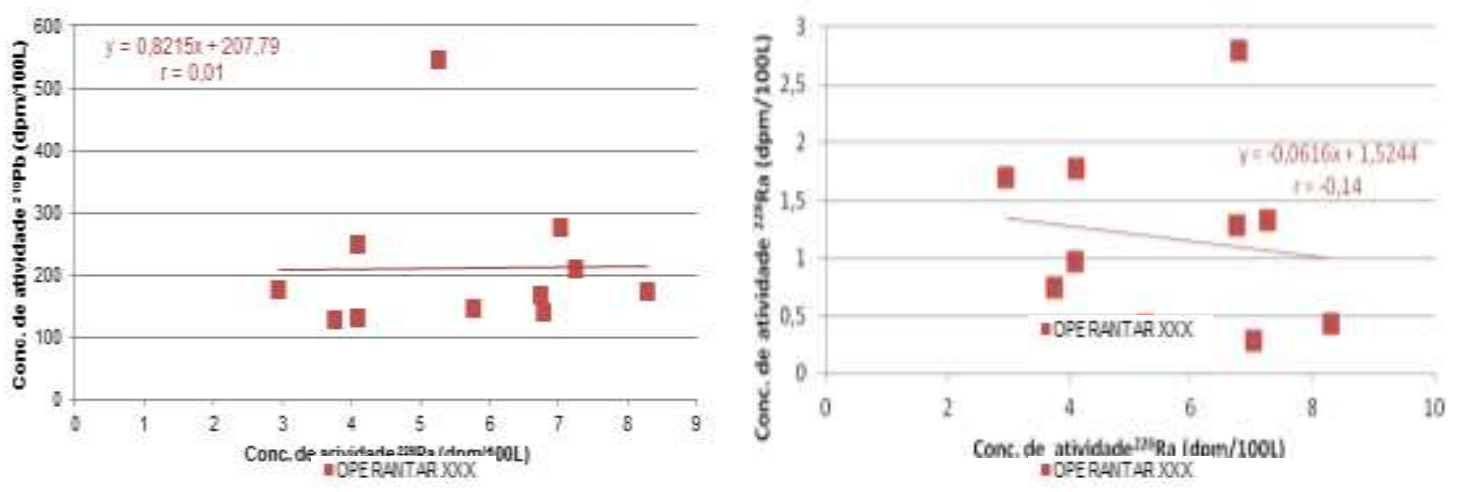

C

d

FIGURA 42 - a) Correlação da concentração de atividade de ${ }^{234} \mathrm{Th}^{230}\left(\mathrm{dpm} \mathrm{\textrm {L } ^ { - 1 } )}\right.$ em função da concentração de atividade de ${ }^{238} \mathrm{U}\left(\mathrm{dpm} \mathrm{L}^{-1}\right)$; b) Correlação da concentração de atividade de ${ }^{210} \mathrm{Po}\left(\mathrm{dpm} \mathrm{L} \mathrm{L}^{-1}\right) \mathrm{em}$ função da concentração de atividade de ${ }^{210} \mathrm{~Pb}\left(\mathrm{dpm} \mathrm{L}^{-1}\right)$; c) Correlação da concentração de atividade de ${ }^{210} \mathrm{~Pb}\left(\mathrm{dpm} 100 \mathrm{~L}^{-1}\right)$; em função da concentração de atividade de ${ }^{226} \mathrm{Ra}\left(\mathrm{dpm} 100 \mathrm{~L}^{-1}\right)$; d) Correlação da concentração de atividade de ${ }^{228} \mathrm{Ra}\left(\mathrm{dpm} 100 \mathrm{~L}^{-1}\right)$ em função da concentração de atividade de ${ }^{226} \mathrm{Ra}\left(\mathrm{dpm} 100 \mathrm{~L}^{-1}\right)$.

As concentrações de ${ }^{234} \mathrm{Th}$ total $\mathrm{e}{ }^{238} \mathrm{U}$ dissolvido em função da profundidade total não demonstraram boas correlações entre as variáveis. Apenas os valores de ${ }^{238} \mathrm{U}$ estimados na OPERANTAR XXX apresentaram correlação positiva com a distância da costa sugerindo intensificação do processo degelo próximo da plataforma continental (FIG. 43). 

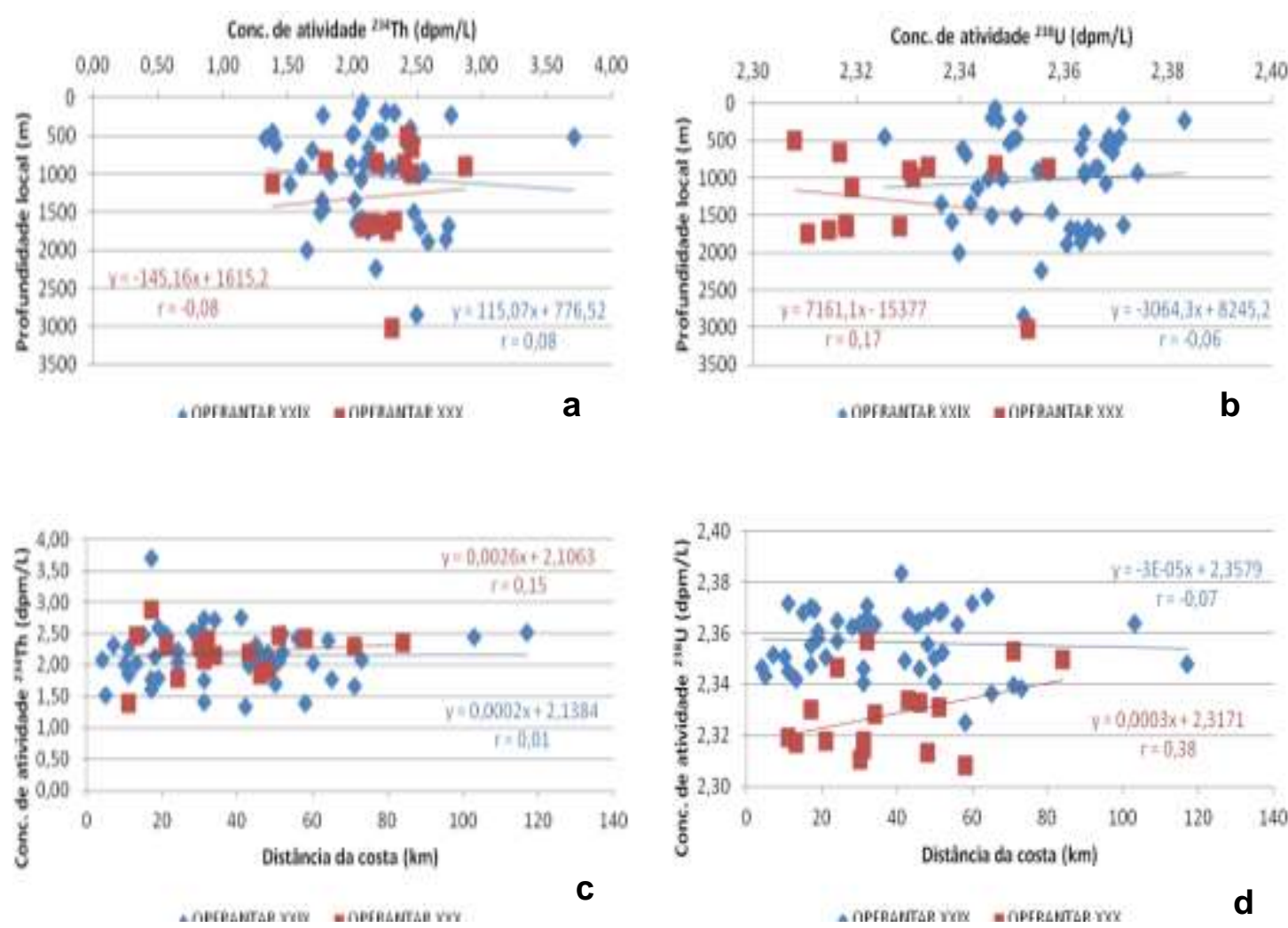

FIGURA 43 - a) Correlação da concentração de atividade de ${ }^{234} \mathrm{Th}\left(\mathrm{dpm} \mathrm{L} \mathrm{L}^{-1}\right)$ em função da profundidade total $(\mathrm{m})$; b) Correlação da concentração de atividade de ${ }^{238} \mathrm{U}\left(\mathrm{dpm} \mathrm{\textrm {L } ^ { - 1 }}\right.$ ) em função da profundidade total $(\mathrm{m})$; c) Correlação da concentração de atividade de ${ }^{234} \mathrm{Th}\left(\mathrm{dpm} \mathrm{L} \mathrm{L}^{-1}\right)$ em função da distância da costa $(\mathrm{km})$; d) Correlação da concentração de atividade de ${ }^{238} \mathrm{U}\left(\mathrm{dpm} \mathrm{L}{ }^{-1}\right)$ em função da distância da costa $(\mathrm{km})$.

Boa correlação positiva foi demonstrada entre as concentrações de ${ }^{210} \mathrm{Po}$ e ${ }^{210} \mathrm{~Pb}$ em função da profundidade total, evidenciando possível contribuição de sedimentos de fundo. As concentrações de ${ }^{210} \mathrm{Po}$ e ${ }^{210} \mathrm{~Pb}$ em relação a distância da costa durante a OPERANTAR XXX apresentaram correlação positiva, indicando maior influência da plataforma continental. No entanto, as concentrações de ${ }^{210} \mathrm{Po}$ em relação a distância da costa durante a OPERANTAR XXIX apresentaram correlação negativa (FIG. 44). 

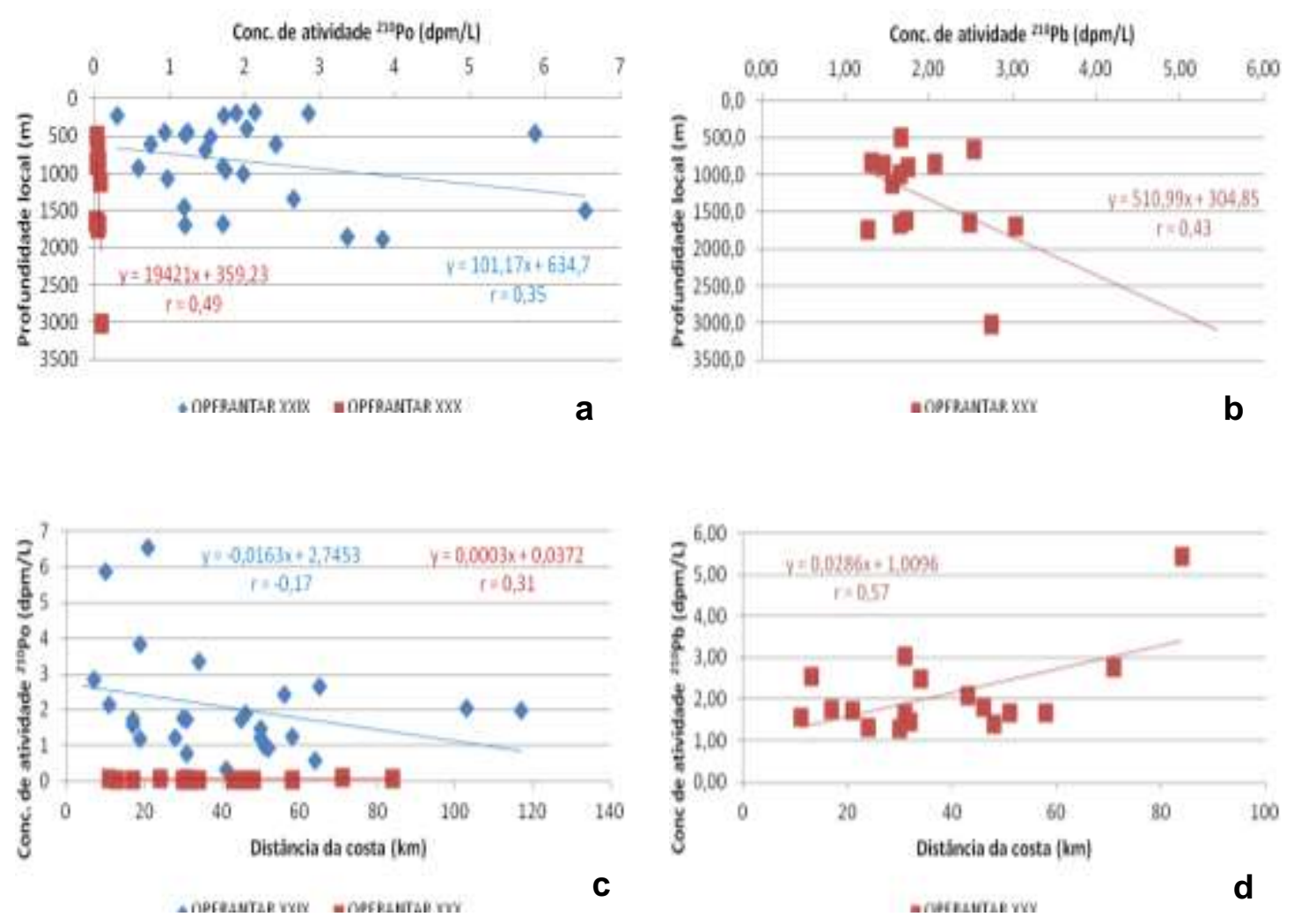

FIGURA 44 - a) Correlação da concentração de atividade de ${ }^{210} \mathrm{Po}\left(\mathrm{dpm} \mathrm{L} \mathrm{L}^{-1}\right)$ em função da profundidade total $(\mathrm{m})$; b) Correlação da concentração de atividade de ${ }^{210} \mathrm{~Pb}\left(\mathrm{dpm} \mathrm{L} \mathrm{L}^{-1}\right)$ em função da profundidade total $(\mathrm{m})$; c) Correlação da concentração de atividade de ${ }^{210} \mathrm{Po}\left(\mathrm{dpm} \mathrm{L} \mathrm{L}^{-1}\right)$ em função da distância da costa $(\mathrm{km})$; d) Correlação da concentração de atividade de ${ }^{210} \mathrm{~Pb}\left(\mathrm{dpm} \mathrm{L} \mathrm{L}^{-1}\right)$ em função da distância da costa $(\mathrm{km})$.

Como esperado, as concentrações de atividade de ${ }^{226}$ Ra apresentaram boas correlações positivas com a profundidade total e distância da costa indicando possíveis processos de ressurgência, enquanto que as concentrações de atividade de ${ }^{228} \mathrm{Ra}$ apresentaram correlações negativas, devido sua meia-vida relativamente curta e sua maior contribuição ocorrer próxima aos sedimentos e talude continental (Rutgers van der Loeff, 2001) (FIG. 45). 

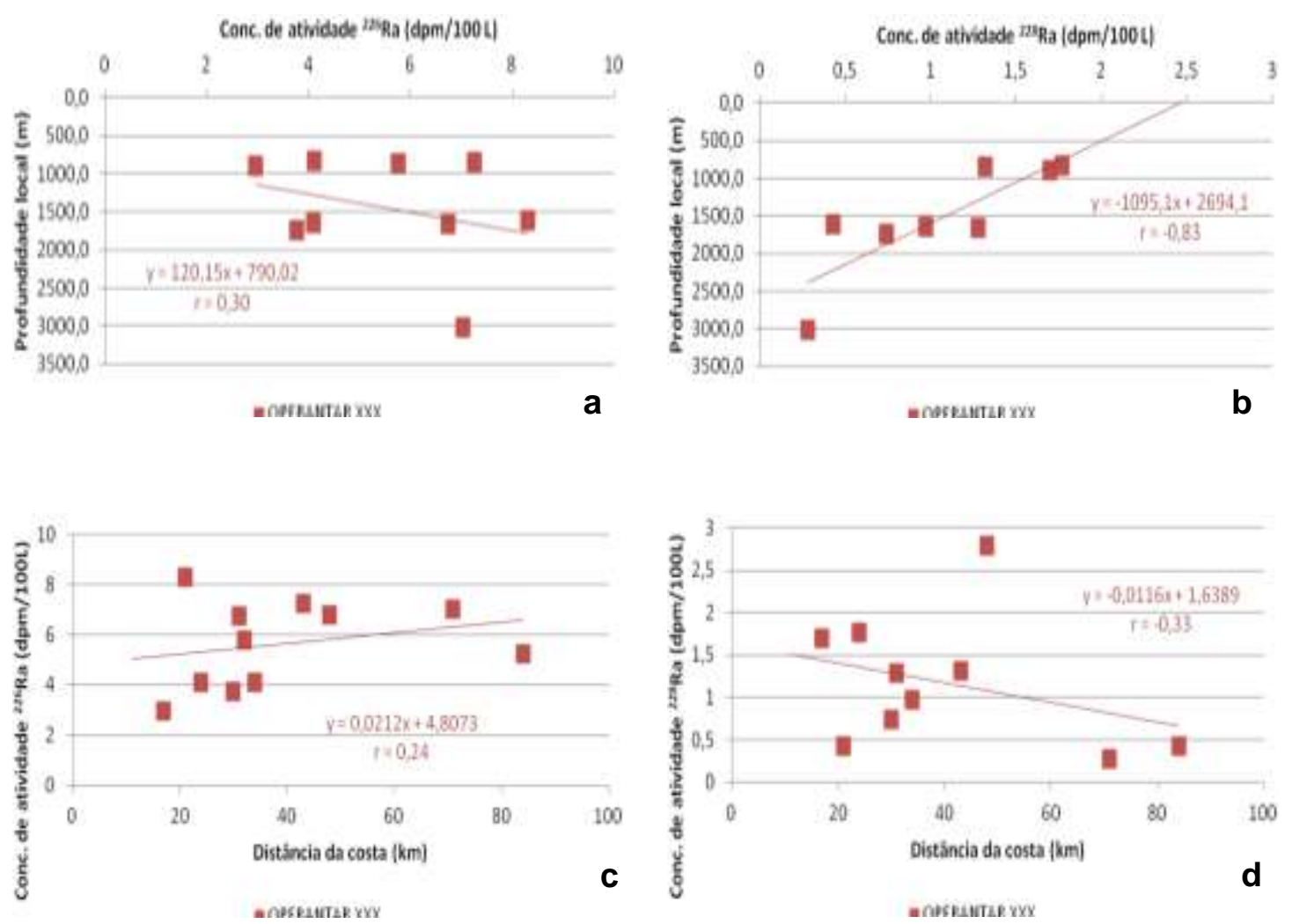

FIGURA 45 - a) Correlação da concentração de atividade de ${ }^{226} \mathrm{Ra}\left(\mathrm{dpm} 100 \mathrm{~L}^{-1}\right)$ em função da profundidade total $(\mathrm{m})$; b) Correlação da concentração de atividade de ${ }^{228} \mathrm{Ra}\left(\mathrm{dpm} 100 \mathrm{~L}^{-1}\right)$ em função da profundidade total $(\mathrm{m})$; c) Correlação da concentração de atividade de ${ }^{226} \mathrm{Ra}\left(\mathrm{dpm} 100 \mathrm{~L}^{-1}\right.$ ) em função da distância da costa $(\mathrm{km})$; d) Correlação da concentração de atividade de ${ }^{228} \mathrm{Ra}\left(\mathrm{dpm} 100 \mathrm{~L}^{-1}\right)$ em função da distância da costa $(\mathrm{km})$.

As atividades de ${ }^{234} \mathrm{Th}$ total apresentaram baixa correlação negativa com a temperatura indicando intensificação do processo de fotossíntese e consequentemente maior remoção de ${ }^{234} \mathrm{Th}$ governanda pela bomba biológica. No entanto, $0{ }^{238} \mathrm{U}$ apresentou melhores correlações negativa e positiva com a temperatura no final e início do verão Austral, respectivamente. As concentrações de atividade de ${ }^{210} \mathrm{Po}$ apresentaram correlações positivas com os dados de temperatura durante as duas campanhas de amostragens (FIG. 46). 


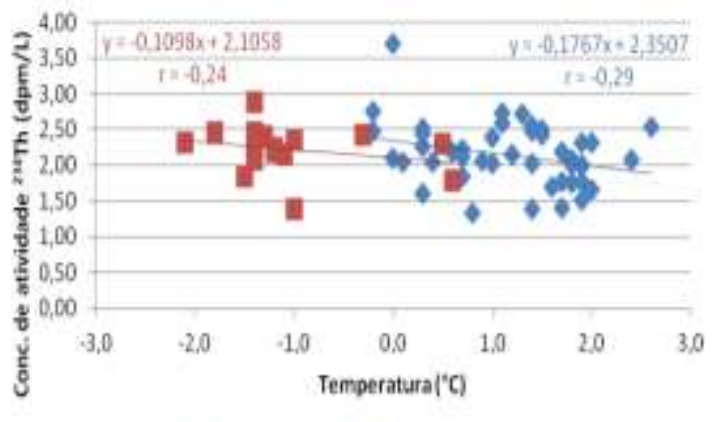

a

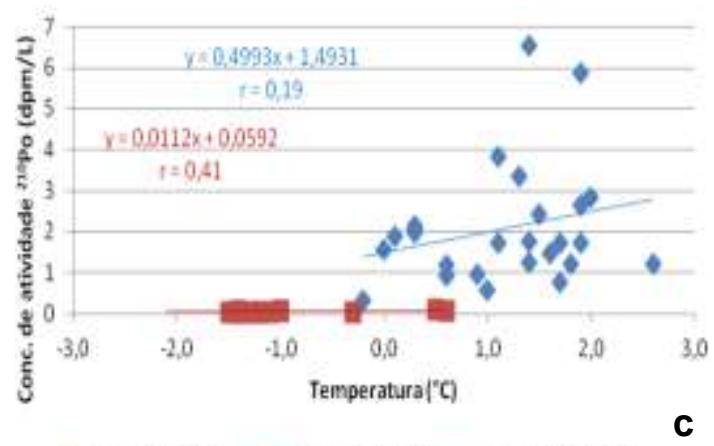

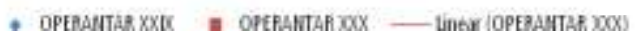

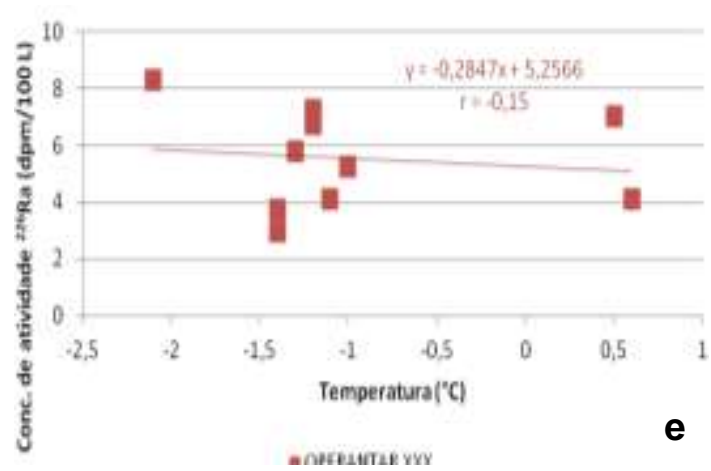

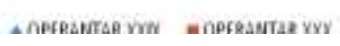

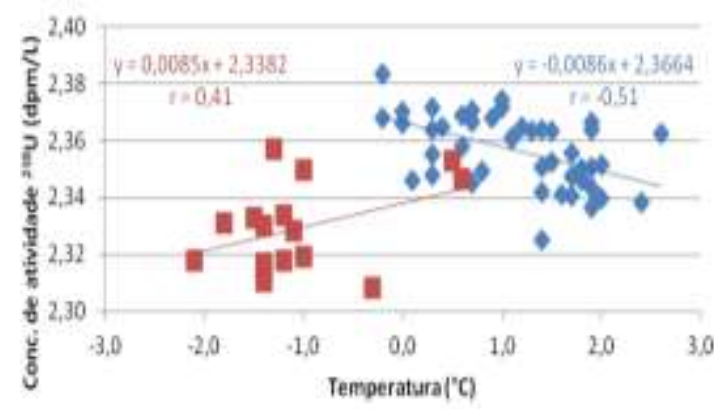

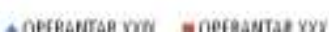

b

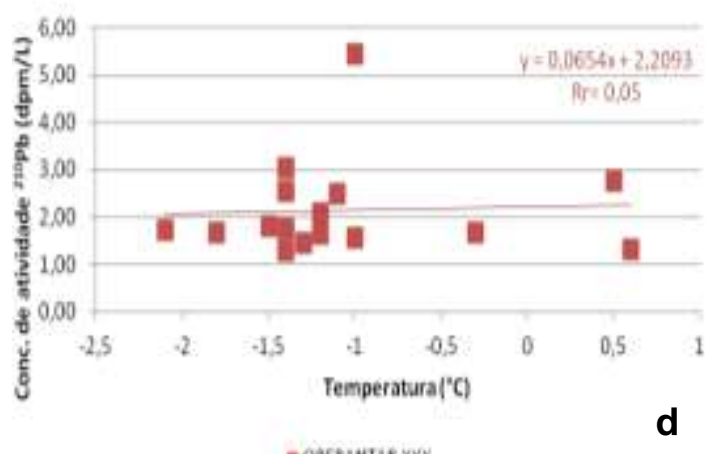

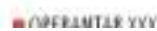

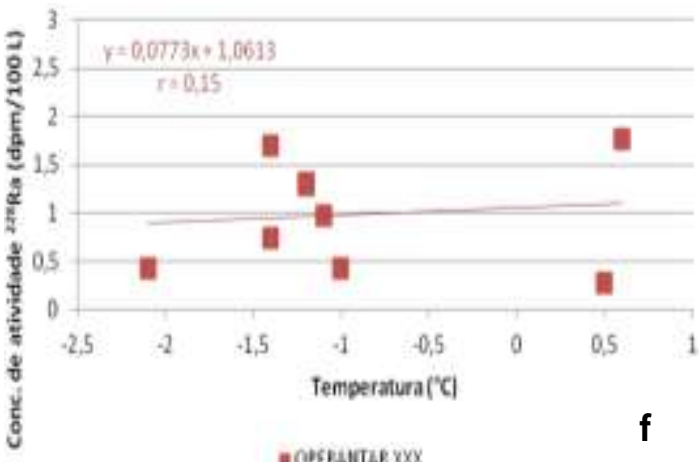

FIGURA 46 - a) Correlação da concentração de atividade de ${ }^{234} \mathrm{Th}\left(\mathrm{dpm} \mathrm{L} \mathrm{L}^{-1}\right)$ em função da temperatura $\left({ }^{\circ} \mathrm{C}\right)$; b) Correlação da concentração de atividade de ${ }^{238} \mathrm{U}$ (dpm L $\mathrm{L}^{-1}$ ) em função da temperatura $\left({ }^{\circ} \mathrm{C}\right)$; c) Correlação da concentração de atividade de ${ }^{210} \mathrm{Po}\left(\mathrm{dpm} \mathrm{L}^{-1}\right)$ em função da temperatura $\left({ }^{\circ} \mathrm{C}\right)$; d) Correlação da concentração de atividade de ${ }^{210} \mathrm{~Pb}\left(\mathrm{dpm} \mathrm{L} \mathrm{L}^{-1}\right.$ ) em função da temperatura $\left({ }^{\circ} \mathrm{C}\right)$; e) Correlação da concentração de atividade de ${ }^{226} \mathrm{Ra}\left(\mathrm{dpm} 100 \mathrm{~L}^{-1}\right)$ em função da temperatura $\left({ }^{\circ} \mathrm{C}\right)$; f) Correlação da concentração de atividade de ${ }^{228} \mathrm{Ra}\left(\mathrm{dpm} 100 \mathrm{~L}^{-1}\right)$ em função da temperatura $\left({ }^{\circ} \mathrm{C}\right)$. 
Durante o início do verão não foi notada nenhuma relação considerável do ${ }^{234} \mathrm{Th}$ com a salinidade, enquanto que no final do verão foi observada boa correlação positiva das concentrações de ${ }^{234} T h$ em função da salinidade. Com o aumento de salinidade nota-se que a concentração de ${ }^{210} \mathrm{Po}$ decresce na OPERANTAR XXIX (correlação negativa), enquanto que na OPERANTAR XXX as concentrações de ${ }^{210} \mathrm{Po}$ e ${ }^{210} \mathrm{~Pb}$ apresentaram correlações positivas em função da salinidade. As concentrações ${ }^{228} \mathrm{Ra}$ apresentaram correlações negativas com a salinidade quando comparado com as concentrações de ${ }^{226} \mathrm{Ra}$ (FIG. 47).
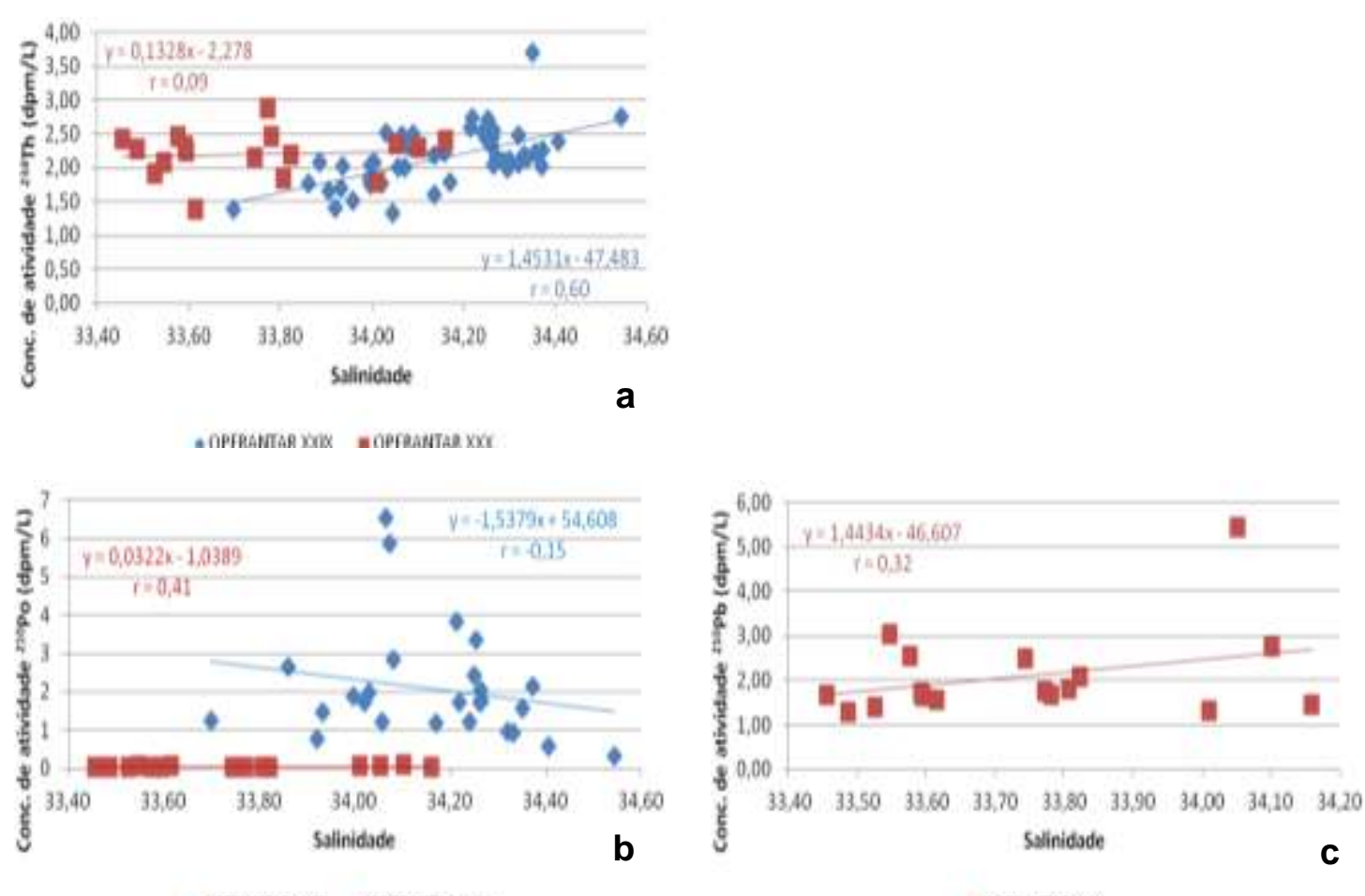

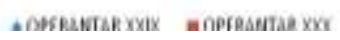

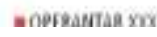
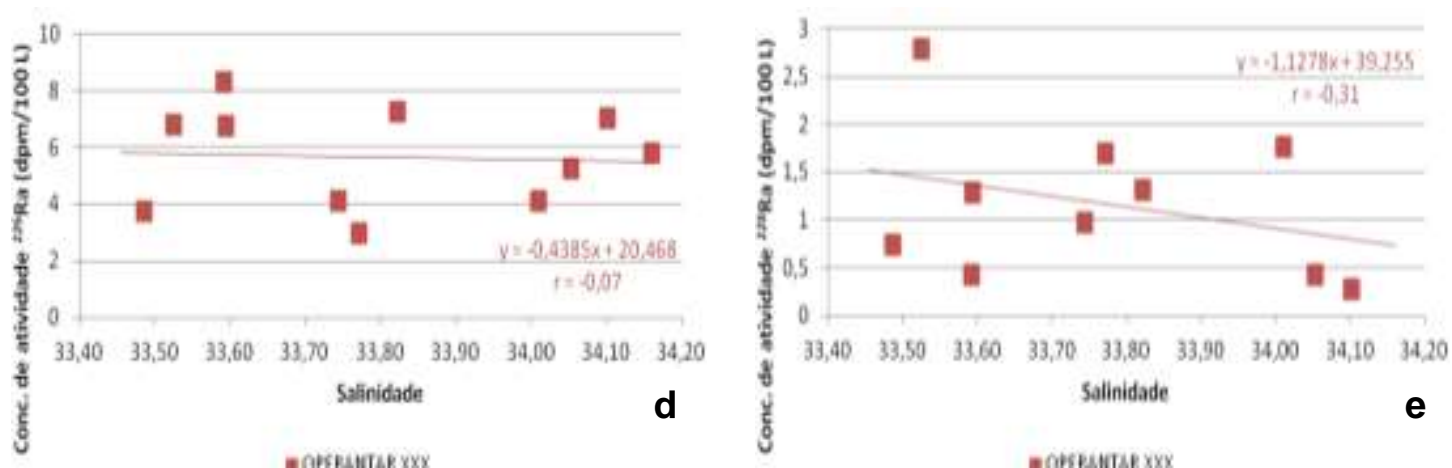

FIGURA 47 - a) Correlação da concentração de ${ }^{234} T h\left(d p m L^{-1}\right)$ em função da salinidade; b) Correlação da concentração de ${ }^{210} \mathrm{Po}\left(\mathrm{dpm} \mathrm{L}{ }^{-1}\right)$ em função da salinidade; c) Correlação da concentração de ${ }^{210} \mathrm{~Pb}$ $\left(\mathrm{dpm} \mathrm{L}^{-1}\right.$ ) em função da salinidade; d) Correlação da concentração de ${ }^{226} \mathrm{Ra}\left(\mathrm{dpm} 100 \mathrm{~L}^{-1}\right.$ ) em função da salinidade; e) Correlação da concentração de ${ }^{228} \mathrm{Ra}\left(\mathrm{dpm} 100 \mathrm{~L}^{-1}\right)$ em função da salinidade. 
Correlações fracas foram observadas entre as concentrações de ${ }^{234} \mathrm{Th}$ e ${ }^{238} \mathrm{U}$ com relação ao $\mathrm{Cl}$ e COT (FIG. 48). Correlações significativas negativas foram observadas entre as concentrações ${ }^{210} \mathrm{Po}$ e ${ }^{210} \mathrm{~Pb}$ em função dos valores de $\mathrm{Cl}$, e de ${ }^{210} \mathrm{Po}$ em função do COT (FIG. 49). Apenas as concentrações de ${ }^{226} \mathrm{Ra}$ apresentaram correlação significativa positiva com $\mathrm{Cl}$. Para a relação entre ${ }^{226} \mathrm{Ra}$ e COT foi observado correlação negativa, enquanto que para o ${ }^{228} \mathrm{Ra}$ foi observado correlação positiva evidenciando uma maior contribuição do ${ }^{228} \mathrm{Ra}$ próxima aos sedimentos e plataforma continental (FIG. 50).

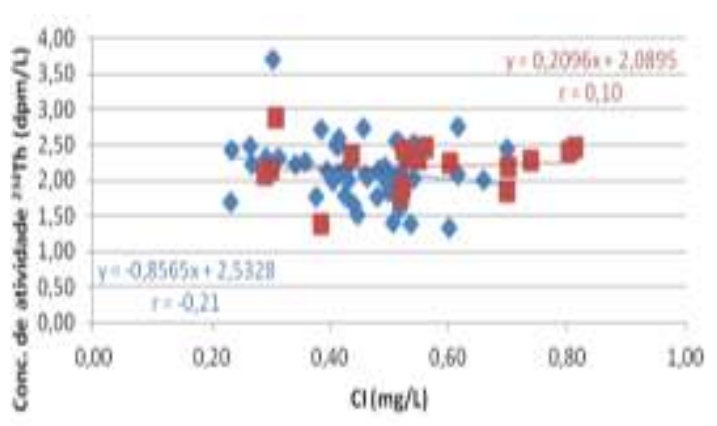

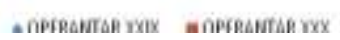

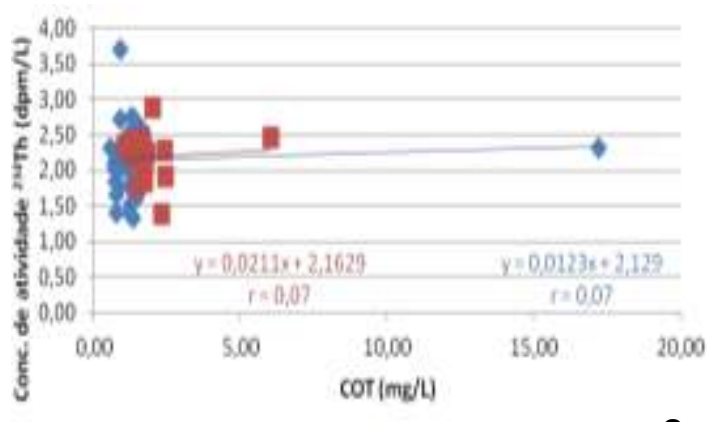

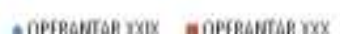

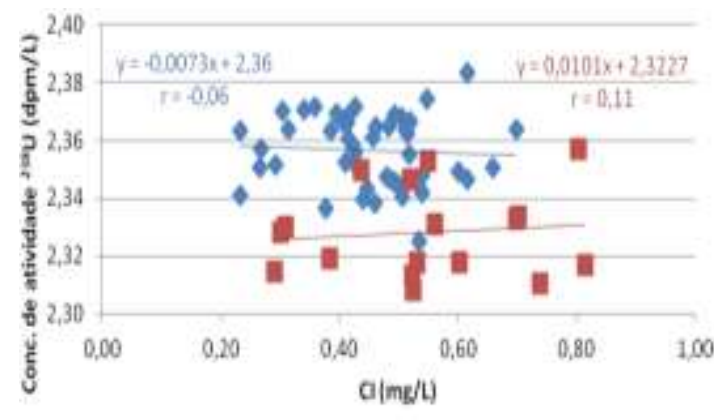

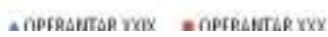

b

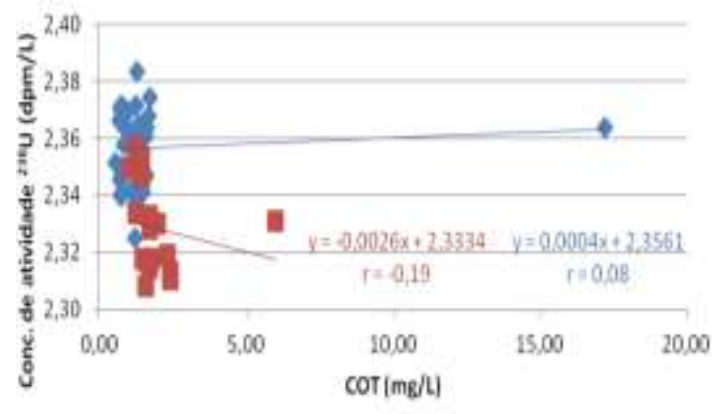

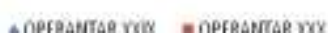

d

FIGURA 48 - a) Correlação da concentração de atividade de ${ }^{234} \mathrm{Th}\left(\mathrm{dpm} \mathrm{L} \mathrm{L}^{-1}\right.$ ) em função do carbono inorgânico $\left(\mathrm{mg} \mathrm{L}^{-1}\right)$; b) Correlação da concentração de atividade de ${ }^{238} \mathrm{U}\left(\mathrm{dpm} \mathrm{L}^{-1}\right)$ em função do carbono inorgânico (mg L $\left.{ }^{-1}\right)$; c) Correlação da concentração de atividade de ${ }^{234} \mathrm{Th}$ (dpm L ${ }^{-1}$ ) em função do carbono orgânico total $\left(\mathrm{mg} \mathrm{L}^{-1}\right)$; d) Correlação da concentração de atividade de ${ }^{238} \cup\left(\mathrm{dpm} \mathrm{L} \mathrm{L}^{-1}\right) \mathrm{em}$ função do carbono orgânico total $\left(\mathrm{mg} \mathrm{L}^{-1}\right)$. 


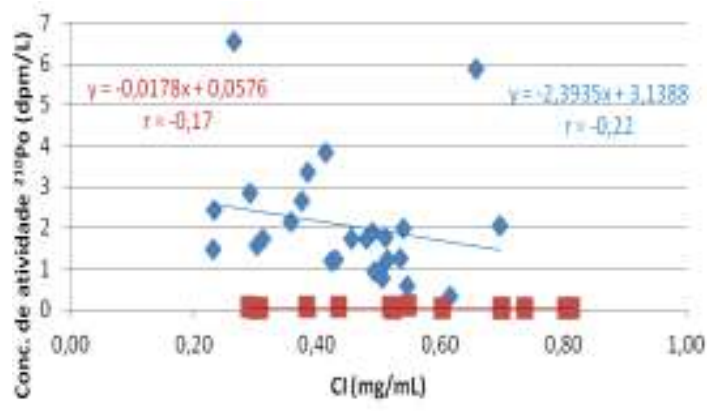

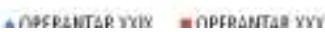

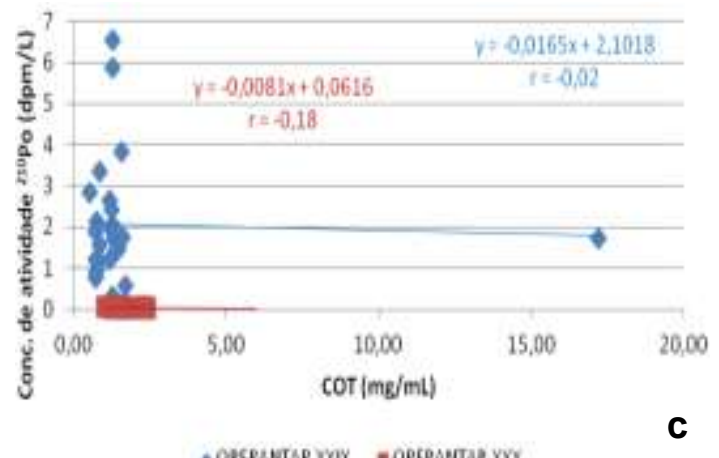

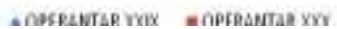

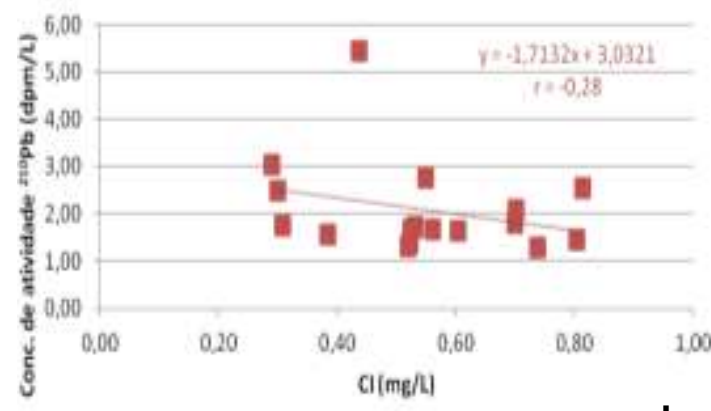

b

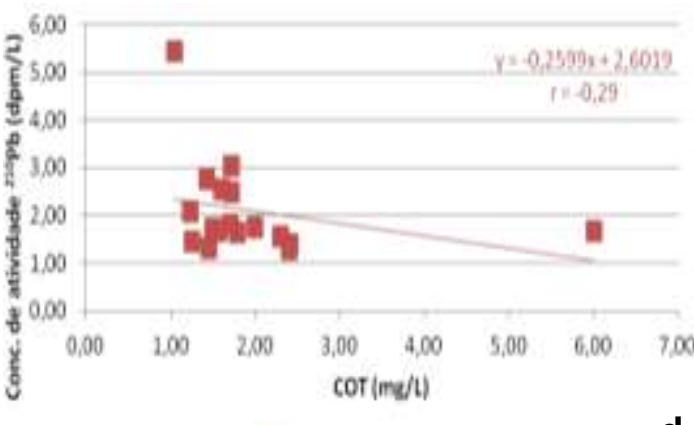

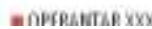

d

FIGURA 49 - a) Correlação da concentração de atividade de ${ }^{210} \mathrm{Po}\left(\mathrm{dpm} \mathrm{L}{ }^{-1}\right)$ em função do carbono inorgânico $\left(\mathrm{mg} \mathrm{L}^{-1}\right)$; b) Correlação da concentração de atividade de ${ }^{210} \mathrm{~Pb}\left(\mathrm{dpm} \mathrm{L} \mathrm{L}^{-1}\right)$ em função do carbono inorgânico $\left(\mathrm{mg} \mathrm{L}^{-1}\right)$; c) Correlação da concentração de atividade de ${ }^{210} \mathrm{Po}\left(\mathrm{dpm} \mathrm{L} \mathrm{L}^{-1}\right)$ em função do carbono orgânico total $\left(\mathrm{mg} \mathrm{L}^{-1}\right)$; d) Correlação da concentração de atividade de ${ }^{210} \mathrm{~Pb}$ (dpm $\left.\mathrm{L}^{-1}\right)$ em função do carbono orgânico total $\left(\mathrm{mg} \mathrm{L}^{-1}\right)$. 

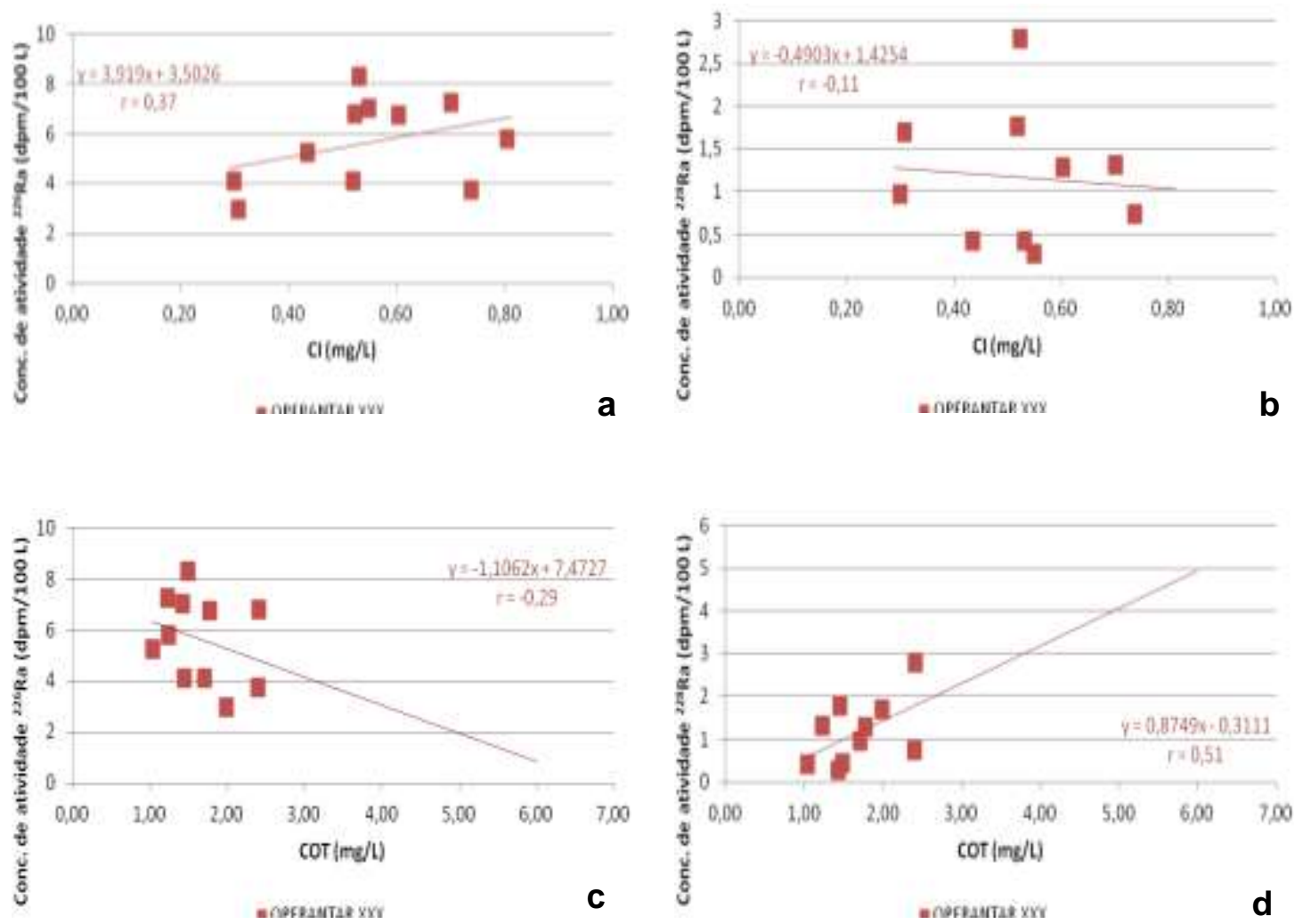

FIGURA 50 - a) Correlação da concentração de atividade de ${ }^{226} \mathrm{Ra}\left(\mathrm{dpm} 100 \mathrm{~L}^{-1}\right)$ em função do carbono inorgânico $\left(\mathrm{mg} \mathrm{L}^{-1}\right)$; b) Correlação da concentração de atividade de ${ }^{228} \mathrm{Ra}\left(\mathrm{dpm} 100 \mathrm{~L}^{-1}\right)$ em função do carbono inorgânico ( $\left.\mathrm{mg} \mathrm{L}^{-1}\right)$; c) Correlação da concentração de atividade de ${ }^{226} \mathrm{Ra}\left(\mathrm{dpm} 100 \mathrm{~L}^{-1}\right.$ ) em função do carbono orgânico total $\left(\mathrm{mg} \mathrm{L}^{-1}\right)$; d) Correlação da concentração de atividade de ${ }^{228} \mathrm{Ra}$ (dpm $\left.100 \mathrm{~L}^{-1}\right)$ em função do carbono orgânico total $\left(\mathrm{mg} \mathrm{L}^{-1}\right)$.

Nas TAB. 18 e 19 são apresentadas as matrizes de correlação das variáveis estudadas durante o final e início do verão Austral, respectivamente. Os valores em destaque na matriz de correlação indicam as melhores correlações obtidas com um nível de siginificância inferior a 0,05. 
TABELA 18 - Matriz de correlação dos parâmetros estudados na OPERANTAR XXIX, os valores em destaque apresentaram nível de significância $p<0,05$.

\begin{tabular}{|c|c|c|c|c|c|c|c|c|c|}
\hline & Prof. total & Dist. costa & Temp. & Sal. & $\mathrm{Cl}$ & СОT & CT & ${ }^{234} \mathrm{Th}$ & ${ }^{210} \mathrm{Po}$ \\
\hline Prof. total & $\begin{array}{l}1,00 \\
p=-\end{array}$ & & & & & & & & \\
\hline Dist. costa & $\begin{array}{c}0,19 \\
p=0,21\end{array}$ & $\begin{array}{l}1,00 \\
p=-\end{array}$ & & & & & & & \\
\hline Temp. & $\begin{array}{c}0,27 \\
p=0,07\end{array}$ & $\begin{array}{c}-0,03 \\
p=0,84\end{array}$ & $\begin{array}{l}1,00 \\
p=-\end{array}$ & & & & & & \\
\hline Sal. & $\begin{array}{c}-0,06 \\
p=0,69\end{array}$ & $\begin{array}{c}-0,07 \\
p=0,66\end{array}$ & $\begin{array}{c}-0,51 \\
p=0,00\end{array}$ & $\begin{array}{l}1,00 \\
p=-\end{array}$ & & & & & \\
\hline $\mathrm{Cl}$ & $\begin{array}{c}-0,11 \\
p=0,46\end{array}$ & $\begin{array}{c}0,18 \\
p=0,23\end{array}$ & $\begin{array}{c}-0,14 \\
p=0,37\end{array}$ & $\begin{array}{c}-0,06 \\
p=0,68\end{array}$ & $\begin{array}{l}1,00 \\
p=-\end{array}$ & & & & \\
\hline СOT & $\begin{array}{c}-0,01 \\
p=0,93\end{array}$ & $\begin{array}{c}0,05 \\
p=0,74\end{array}$ & $\begin{array}{c}0,17 \\
p=0,26\end{array}$ & $\begin{array}{c}0,08 \\
p=0,58\end{array}$ & $\begin{array}{c}-0,16 \\
p=0,27\end{array}$ & $\begin{array}{l}1,00 \\
p=-\end{array}$ & & & \\
\hline CT & $\begin{array}{c}-0,02 \\
p=0,90\end{array}$ & $\begin{array}{c}0,06 \\
p=0,69\end{array}$ & $\begin{array}{c}0,17 \\
p=0,27\end{array}$ & $\begin{array}{c}0,08 \\
p=0,60\end{array}$ & $\begin{array}{c}-0,12 \\
p=0,43\end{array}$ & $\begin{array}{c}0,99 \\
p=0,00\end{array}$ & $\begin{array}{l}1,00 \\
p=-\end{array}$ & & \\
\hline${ }^{234} \mathrm{Th}$ & $\begin{array}{c}0,08 \\
p=0,60\end{array}$ & $\begin{array}{c}0,01 \\
p=0,93\end{array}$ & $\begin{array}{c}-0,29 \\
p=0,05\end{array}$ & $\begin{array}{c}0,60 \\
p=0,00\end{array}$ & $\begin{array}{c}-0,21 \\
p=0,15\end{array}$ & $\begin{array}{c}0,07 \\
p=0,65\end{array}$ & $\begin{array}{c}0,06 \\
p=0,70\end{array}$ & $\begin{array}{l}1,00 \\
p=-\end{array}$ & \\
\hline${ }^{210} \mathrm{Po}$ & $\begin{array}{c}0,35 \\
p=0,05\end{array}$ & $\begin{array}{c}-0,17 \\
p=0,34\end{array}$ & $\begin{array}{c}0,19 \\
p=0,28\end{array}$ & $\begin{array}{c}-0,15 \\
p=0,38\end{array}$ & $\begin{array}{c}-0,22 \\
p=0,22\end{array}$ & $\begin{array}{c}-0,02 \\
p=0,89\end{array}$ & $\begin{array}{c}-0,03 \\
p=0,85\end{array}$ & $\begin{array}{c}0,17 \\
p=0,33\end{array}$ & $\begin{array}{l}1,00 \\
p=-\end{array}$ \\
\hline
\end{tabular}


TABELA 19 - Matriz de correlação dos parâmetros estudados na OPERANTAR XXX, os valores em destaque apresentaram nível de significância $p<0,05$.

\begin{tabular}{|c|c|c|c|c|c|c|c|c|c|c|c|c|}
\hline & Prof. total & Dist. costa & Temp. & Sal. & $\mathrm{Cl}$ & СOT & CT & ${ }^{234} \mathrm{Th}$ & ${ }^{210} \mathrm{Po}$ & ${ }^{210} \mathrm{~Pb}$ & ${ }^{226} \mathrm{Ra}$ & ${ }^{228} \mathrm{Ra}$ \\
\hline Prof. total & $\begin{array}{l}1,00 \\
p=-\end{array}$ & & & & & & & & & & & \\
\hline Dist. costa & $\begin{array}{c}0,38 \\
p=0.18\end{array}$ & $\begin{array}{l}1,00 \\
p=-\end{array}$ & & & & & & & & & & \\
\hline & $\begin{array}{c}0,20 \\
p=0.49\end{array}$ & $\begin{array}{c}0,31 \\
\mathrm{n}=0.23\end{array}$ & $\begin{array}{l}1,00 \\
p=-\end{array}$ & & & & & & & & & \\
\hline Sal. & $\begin{array}{c}0,17 \\
p=0,57\end{array}$ & $\begin{array}{c}0,38 \\
p=0,13\end{array}$ & $\begin{array}{c}0,41 \\
p=0,12\end{array}$ & $\begin{array}{l}1,00 \\
p=-\end{array}$ & & & & & & & & \\
\hline Cl & $\begin{array}{c}-0,18 \\
p=0,52\end{array}$ & $\begin{array}{c}-0,02 \\
p=0,95\end{array}$ & $\begin{array}{c}-0,11 \\
p=0,69\end{array}$ & $\begin{array}{c}0,11 \\
p=0,68\end{array}$ & $\begin{array}{l}1,00 \\
p=-\end{array}$ & & & & & & & \\
\hline СОT & $\begin{array}{c}-0,10 \\
p=0,73\end{array}$ & $\begin{array}{c}0,007 \\
p=0,98\end{array}$ & $\begin{array}{c}-0,32 \\
p=0,23\end{array}$ & $\begin{array}{c}-0,19 \\
p=0,46\end{array}$ & $\begin{array}{c}-0,04 \\
p=0,88\end{array}$ & $\begin{array}{l}1,00 \\
p=-\end{array}$ & & & & & & \\
\hline CT & $\begin{array}{c}-0,13 \\
p=0,67\end{array}$ & $\begin{array}{c}0,003 \\
p=0,99\end{array}$ & $\begin{array}{c}-0,33 \\
p=0,21\end{array}$ & $\begin{array}{c}-0,17 \\
p=0,51\end{array}$ & $\begin{array}{c}0,10 \\
p=0,69\end{array}$ & $\begin{array}{c}0,99 \\
p=0,00\end{array}$ & $\begin{array}{l}1,00 \\
p=-\end{array}$ & & & & & \\
\hline${ }^{234} \mathrm{Th}$ & $\begin{array}{c}-0,08 \\
p=0,80\end{array}$ & $\begin{array}{c}0,15 \\
p=0,55\end{array}$ & $\begin{array}{c}-0,24 \\
p=0,37\end{array}$ & $\begin{array}{c}0,09 \\
p=0,73\end{array}$ & $\begin{array}{c}0,10 \\
p=0,69\end{array}$ & $\begin{array}{c}0,07 \\
p=0,79\end{array}$ & $\begin{array}{c}0,08 \\
p=0,75\end{array}$ & $\begin{array}{l}1,00 \\
p=-\end{array}$ & & & & \\
\hline${ }^{210} \mathrm{Po}$ & $\begin{array}{c}0,49 \\
p=0,10\end{array}$ & $\begin{array}{c}0,31 \\
p=0,27\end{array}$ & $\begin{array}{c}0,41 \\
p=0,15\end{array}$ & $\begin{array}{c}0,41 \\
p=0,13\end{array}$ & $\begin{array}{c}-0,17 \\
p=0,54\end{array}$ & $\begin{array}{c}-0,18 \\
p=0,52\end{array}$ & $\begin{array}{c}-0,25 \\
p=0,37\end{array}$ & $\begin{array}{c}-0,13 \\
p=0,65\end{array}$ & $\begin{array}{l}1,00 \\
p=-\end{array}$ & & & \\
\hline${ }^{210} \mathrm{~Pb}$ & $\begin{array}{c}0,43 \\
p=0,12\end{array}$ & $\begin{array}{c}0,57 \\
p=0,02\end{array}$ & $\begin{array}{c}0,05 \\
p=0,86\end{array}$ & $\begin{array}{c}0,32 \\
p=0,21\end{array}$ & $\begin{array}{c}-0,28 \\
p=0,27\end{array}$ & $\begin{array}{c}-0,29 \\
p=0,26\end{array}$ & $\begin{array}{c}-0,33 \\
p=0,20\end{array}$ & $\begin{array}{c}0,18 \\
p=0,49\end{array}$ & $\begin{array}{c}0,50 \\
p=0,06\end{array}$ & $\begin{array}{l}1,00 \\
p=-\end{array}$ & & \\
\hline${ }^{226} \mathrm{Ra}$ & $\begin{array}{c}0,30 \\
p=0,44\end{array}$ & $\begin{array}{c}0,24 \\
p=0,47\end{array}$ & $\begin{array}{c}-0,15 \\
p=0,67\end{array}$ & $\begin{array}{c}-0,07 \\
p=0,83\end{array}$ & $\begin{array}{c}0,37 \\
p=0,26\end{array}$ & $\begin{array}{c}-0,29 \\
p=0,38\end{array}$ & $\begin{array}{c}-0,16 \\
p=0,64\end{array}$ & $\begin{array}{c}-0,24 \\
p=0,48\end{array}$ & $\begin{array}{c}0,13 \\
p=0,71\end{array}$ & $\begin{array}{c}0,01 \\
p=0,97\end{array}$ & $\begin{array}{l}1,00 \\
p=-\end{array}$ & \\
\hline${ }^{228} \mathrm{Ra}$ & $\begin{array}{c}-0,83 \\
p=0,10\end{array}$ & $\begin{array}{c}-0,33 \\
p=0,35\end{array}$ & $\begin{array}{c}0,15 \\
p=0,70\end{array}$ & $\begin{array}{c}-0,31 \\
p=0,39\end{array}$ & $\begin{array}{c}-0,11 \\
p=0,76\end{array}$ & $\begin{array}{c}0,51 \\
p=0,13\end{array}$ & $\begin{array}{c}0,44 \\
p=0,20\end{array}$ & $\begin{array}{c}-0,34 \\
p=0,33\end{array}$ & $\begin{array}{c}-0,57 \\
p=0,11\end{array}$ & $\begin{array}{c}-0,51 \\
p=0,13\end{array}$ & $\begin{array}{c}-0,14 \\
p=0,70\end{array}$ & $\begin{array}{l}1,00 \\
p=-\end{array}$ \\
\hline
\end{tabular}




\subsection{Estimativa dos fluxos de POC, ${ }^{234} \mathrm{Th}$ e ${ }^{210} \mathrm{Po}$ exportados no material particulado}

O fluxo de ${ }^{234} \mathrm{Th}$ e ${ }^{210} \mathrm{Po}$ exportado na coluna d'água foi estimado a partir de um modelo proposto por Coale \& Bruland (1985):

$$
\frac{\partial A_{D}}{\partial t}=\lambda_{D}\left(A_{P}-A_{D}\right)_{d z} \quad-J_{D}
$$

Onde:

$\partial \mathrm{A}_{\mathrm{D}} / \partial \mathrm{t}=$ variação da concentração de ${ }^{234} \mathrm{Th}$ ou ${ }^{210} \mathrm{Po}$ em função do tempo (d); $\left(A_{P}-A_{D}\right)_{d z}=$ déficit de atividade do radionuclídeo pai ${ }^{238} \mathrm{U}$ ou ${ }^{210} \mathrm{~Pb}\left(\mathrm{dpm} \mathrm{m} \mathrm{m}^{-2}\right)$ em relação ao radionuclídeo filho ${ }^{234} \mathrm{Th}$ ou ${ }^{210} \mathrm{Po}\left(\mathrm{dpm} \mathrm{m}^{-2}\right)$ em função da variação de profundidade $(\mathrm{m})$;

$A_{D}=$ atividade do radionuclídeo filho ${ }^{234} \mathrm{Th}$ ou ${ }^{210} \mathrm{Po}\left(\mathrm{dpm} \mathrm{L} \mathrm{L}^{-1}\right)$;

$J_{D}=$ fluxo de ${ }^{234} \mathrm{Th} \mathrm{ou}^{210} \mathrm{Po}$ removido pelo material particulado $\left(\mathrm{dpm} \mathrm{m}^{-2} \mathrm{~d}^{-1}\right)$.

Considerando-se que os processos de advecção e difusão dos radionuclídeos são insignificantes em comparação com a exportação de partículas assumiu-se um estado estacionário, $\partial A_{D} / \partial t=0$ :

$$
J_{D}=\left(A_{P}-A_{D}\right)_{d z} \quad \cdot \lambda_{D}
$$

Onde:

$J_{D}=$ fluxo de ${ }^{234}$ Th ou ${ }^{210} \mathrm{Po}$ removido pelo material particulado $\left(\mathrm{dpm} \mathrm{m}^{-2} \mathrm{~d}^{-1}\right)$; $\left(A_{P}-A_{D}\right)_{d z}=$ déficit de atividade do radionuclídeo pai ${ }^{238} \mathrm{U}$ ou ${ }^{210} \mathrm{~Pb}\left(\mathrm{dpm} \mathrm{m} \mathrm{m}^{-2}\right)$ em relação ao radionuclídeo filho ${ }^{234} \mathrm{Th}$ ou ${ }^{210} \mathrm{Po}\left(\mathrm{dpm} \mathrm{m}^{-2}\right)$ em função da variação de profundidade $(\mathrm{m})$; $\lambda_{D}=$ constante de decaimento de ${ }^{234} \mathrm{Th}\left(0,0288 \mathrm{~d}^{-1}\right)$ ou ${ }^{210} \mathrm{Po}\left(0,0050 \mathrm{~d}^{-1}\right)$.

Os fluxos de POC são derivados pela multiplicação do valor $J$ pela razão $\mathrm{POC} /{ }^{234} \mathrm{Th}$ ou $\mathrm{POC} /{ }^{210} \mathrm{Po}$ em partículas que afundam:

$$
J_{P O C}=J_{D} \cdot\left(P O C /{ }^{234} T h,{ }^{210} P o\right)
$$

Onde: 
$J_{P O C}=$ fluxo de POC $\left(\mathrm{mmol} \mathrm{C} \mathrm{L}^{-1}\right)$;

$\mathrm{J}_{\mathrm{D}}=$ fluxo de ${ }^{234} \mathrm{Th}$ ou ${ }^{210} \mathrm{Po}$ removido pelo material particulado $\left(\mathrm{mmol} \mathrm{C} \mathrm{dpm}{ }^{-1}\right)$; $\mathrm{POC} /{ }^{234} \mathrm{Th},{ }^{210} \mathrm{Po}=$ razão POC/ $/{ }^{234} \mathrm{Th}$ ou $\mathrm{POC} /{ }^{210} \mathrm{Po}\left(\mathrm{mmol} \mathrm{C} \mathrm{m}{ }^{-2} \mathrm{~d}^{-1}\right)$.

As razões isotópicas ${ }^{234} \mathrm{Th}$ total/ $/{ }^{238} \mathrm{U}$ dissolvido e ${ }^{210} \mathrm{Po} /{ }^{210} \mathrm{~Pb}$ foram utilizadas para avaliar a exportação de ${ }^{234} \mathrm{Th}$ total $\mathrm{e}^{210} \mathrm{Po}$ particulado. Em geral, os valores obtidos no final do verão do fluxo de ${ }^{234} \mathrm{Th}$ removido pelo material particulado variaram de $-38,59$ a $29,35 \mathrm{dpm} \mathrm{m}^{-2} \mathrm{~d}^{-1}$. A razão de atividade $\mathrm{POC} /{ }^{234} \mathrm{Th}$ total variou de 0,02 a $0,62 \mathrm{mmol} \mathrm{C} \mathrm{dpm}^{-1}$. O fluxo de POC exportado oscilou de $-0,75$ a 2,39 mmol C m $\mathrm{m}^{-2} \mathrm{~d}^{-1}$. Os parâmetros apresentaram distribuições superficiais semelhantes, aonde os menores valores foram encontrados próximos a Península Trinity e llha Rei George, enquanto que os maiores valores foram observados ao sul do EB e nas proximidades da llha Rei George (TAB. 20).

Os valores obtidos no início do verão para o fluxo de ${ }^{234} \mathrm{Th}$ removido pelo material particulado estiveram entre $-15,65$ a $26,96 \mathrm{dpm} \mathrm{m}^{-2} \mathrm{~d}^{-1}$, para a razão de atividade $\mathrm{POC} /{ }^{234} \mathrm{Th}$ total entre 0,04 a $0,20 \mathrm{mmol} \mathrm{C} \mathrm{dpm}^{-1}$ e para fluxo de POC exportado os valores oscilaram de $-0,90$ a $3,73 \mathrm{mmol} \mathrm{C} \mathrm{m}^{-2} \mathrm{~d}^{-1}$. Todos os parâmetros demonstraram distribuições superficiais parecidas, os menores valores foram observados nas imediações da llha Livingston, enquanto que os maiores valores foram encontrados na sub-bacia central do EB próximo a Ilha Rei George. Para o fluxo de ${ }^{210} \mathrm{Po}$ removido pelo material particulado, os valores encontrados estiveram entre 6,15 a $26,83 \mathrm{dpm} \mathrm{m}^{-2} \mathrm{~d}^{-1}$. A razão de atividade $\mathrm{POC} /{ }^{210} \mathrm{Po}$ total variou de 1,11 a $5,73 \mathrm{mmol} \mathrm{C} \mathrm{dpm}^{-1}$ e o fluxo de POC exportado de 15,08 a $70,55 \mathrm{mmol} \mathrm{C} \mathrm{m}^{-2} \mathrm{~d}^{-1}$. As distribuições superficiais dos fluxos de ${ }^{210} \mathrm{Po}$ foram semelhantes às distribuições dos fluxos de ${ }^{234} \mathrm{Th}$ obtidos no mesmo período de investigação, onde os menores valores foram encontrados nas imediações das Ilhas Livingston e Clarence, enquanto que os maiores valores próximos as llhas Rei George e Elefante (TAB. 21 e 22).

Nas duas campanhas de amostragem foram observados fluxos negativos de ${ }^{234} \mathrm{Th}$ removido pelo material particulado evidenciando um excesso de ${ }^{234} \mathrm{Th}$ na região, possivelmente, por aporte de algas de degelo ou remineralização. 
TABELA 20 - Estimativas dos fluxos de ${ }^{234} \mathrm{Th}$ removido pelo material particulado $\left(\mathrm{dpm} \mathrm{m} \mathrm{m}^{-2} \mathrm{~d}^{-1}\right)$ e carbono orgânico particulado exportado $\left(\mathrm{mmol} \mathrm{C} \mathrm{m}^{-2} \mathrm{~d}^{-1}\right)$ e razão $\mathrm{POC} /{ }^{234} \mathrm{Th}$ total $\left(\mathrm{mmol} \mathrm{C} \mathrm{m}^{-2} \mathrm{~d}^{-1}\right)$ - nas estações da OPERANTAR XXIX.

\begin{tabular}{|c|c|c|c|}
\hline Estação & 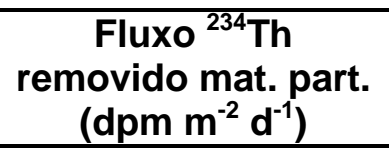 & $\begin{array}{l}\text { POC/ }{ }^{234} \text { Th total }^{-1} \\
\left(\mathrm{mmol} \mathrm{C} \mathrm{dpm}^{-1}\right)\end{array}$ & 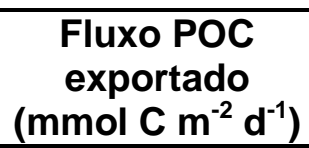 \\
\hline EB 001 & 19,77 & 0,04 & 0,74 \\
\hline EB 002 & 4,96 & 0,05 & 0,23 \\
\hline EB 003 & $-4,72$ & 0,04 & $-0,19$ \\
\hline EB 004 & 16,66 & 0,04 & 0,64 \\
\hline EB 005 & 10,74 & 0,03 & 0,35 \\
\hline EB 006 & 21,50 & 0,07 & 1,56 \\
\hline EB 007 & 16,46 & 0,06 & 0,93 \\
\hline EB 008 & $-4,17$ & 0,04 & $-0,18$ \\
\hline EB 009 & $-10,31$ & 0,03 & $-0,28$ \\
\hline EB 010 & 17,00 & 0,06 & 1,06 \\
\hline EB 011 & $-38,59$ & 0,02 & $-0,75$ \\
\hline EB 012 & 3,97 & 0,03 & 0,11 \\
\hline EB 013 & 0,81 & 0,02 & 0,02 \\
\hline EB 014 & 3,35 & 0,03 & 0,09 \\
\hline EB 015 & $-3,06$ & 0,06 & $-0,17$ \\
\hline EB 017 & $-1,66$ & 0,04 & $-0,07$ \\
\hline EB 018 & $-10,95$ & 0,04 & $-0,44$ \\
\hline EB 019 & $-3,61$ & 0,04 & $-0,16$ \\
\hline EB 020 & 7,71 & 0,06 & 0,49 \\
\hline EB 021 & 23,67 & 0,07 & 1,55 \\
\hline EB 022 & 8,75 & 0,03 & 0,27 \\
\hline EB 023 & 9,80 & 0,05 & 0,50 \\
\hline EB 026 & 7,03 & 0,03 & 0,21 \\
\hline EB 027 & 6,03 & 0,05 & 0,31 \\
\hline EB 028 & 9,48 & 0,03 & 0,32 \\
\hline EB 029 & 14,75 & 0,03 & 0,48 \\
\hline EB 031 & 9,39 & 0,05 & 0,43 \\
\hline EB 032 & 7,89 & 0,03 & 0,22 \\
\hline EB 033 & 8,48 & 0,03 & 0,25 \\
\hline EB 034 & 3,70 & 0,05 & 0,17 \\
\hline EB 035 & 6,98 & 0,04 & 0,26 \\
\hline EB 037 & 29,35 & 0,08 & 2,39 \\
\hline EB 038 & 27,15 & 0,07 & 1,98 \\
\hline EB 039 & 18,65 & 0,07 & 1,36 \\
\hline EB 040 & 16,54 & 0,07 & 1,21 \\
\hline EB 041 & 26,71 & 0,04 & 1,17 \\
\hline EB 044 & $-4,95$ & 0,04 & $-0,20$ \\
\hline EB 045 & $-2,46$ & 0,04 & $-0,11$ \\
\hline EB 046 & 10,04 & 0,03 & 0,30 \\
\hline EB 047 & 7,62 & 0,05 & 0,39 \\
\hline EB 049 & 9,84 & 0,05 & 0,53 \\
\hline EB 050 & $-6,47$ & 0,05 & $-0,33$ \\
\hline EB 051 & $-5,33$ & 0,05 & $-0,28$ \\
\hline EB 052 & 1,46 & 0,62 & 0,90 \\
\hline EB 053 & $-0,48$ & 0,06 & $-0,03$ \\
\hline EB 054 & 5,12 & 0,03 & 0,15 \\
\hline EB 055 & $-10,86$ & 0,04 & $-0,42$ \\
\hline
\end{tabular}


TABELA 21 - Estimativas dos fluxos de ${ }^{234} \mathrm{Th}$ removido pelo material particulado $\left(\mathrm{dpm} \mathrm{m} \mathrm{m}^{-2} \mathrm{~d}^{-1}\right)$ e carbono orgânico particulado exportado $\left(\mathrm{mmol} \mathrm{C} \mathrm{m} \mathrm{m}^{-2} \mathrm{~d}^{-1}\right)$ e razão $\mathrm{POC} /{ }^{234} \mathrm{Th}$ total $\left(\mathrm{mmol} \mathrm{C} \mathrm{m}^{-2} \mathrm{~d}^{-1}\right)$ - nas estações da OPERANTAR XXX.

\begin{tabular}{|c|c|c|c|}
\hline Estação & 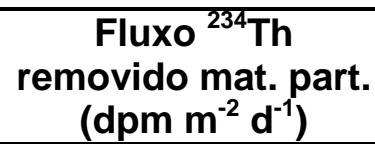 & $\begin{array}{l}\text { POC/ } /^{234} \mathrm{Th}_{\text {total }} \\
\left(\mathrm{mmol} \mathrm{C} \mathrm{dpm}{ }^{-1}\right)\end{array}$ & 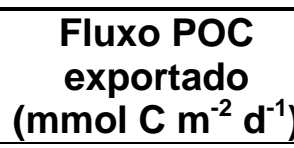 \\
\hline EB 001 & 1,36 & 0,05 & 0,07 \\
\hline EB 001a & $-0,30$ & 0,04 & $-0,01$ \\
\hline EB 002 & 11,66 & 0,11 & 1,23 \\
\hline EB 005 & 4,14 & 0,05 & 0,19 \\
\hline EB 006 & $-15,65$ & 0,06 & $-0,90$ \\
\hline EB 009 & 5,03 & 0,07 & 0,33 \\
\hline EB 010 & 2,35 & 0,07 & 0,16 \\
\hline EB 018 & 6,68 & 0,07 & 0,46 \\
\hline EB 019 & $-0,16$ & 0,05 & $-0,01$ \\
\hline EB 022 & $-3,52$ & 0,20 & $-0,72$ \\
\hline EB 027 & 14,19 & 0,08 & 1,09 \\
\hline EB 028 & 16,01 & 0,07 & 1,08 \\
\hline EB 029 & 26,96 & 0,14 & 3,73 \\
\hline EB 031 & $-4,27$ & 0,05 & $-0,23$ \\
\hline EB 032 & $-1,31$ & 0,04 & $-0,06$ \\
\hline EB 038 & $-3,32$ & 0,05 & $-0,18$ \\
\hline EB 051 & 1,02 & 0,09 & 0,09 \\
\hline
\end{tabular}

TABELA 22 - Estimativas dos fluxos de ${ }^{210} \mathrm{Po}$ removido pelo material particulado $\left(\mathrm{dpm} \mathrm{m} \mathrm{m}^{-2} \mathrm{~d}^{-1}\right)$ e carbono orgânico particulado exportado $\left(\mathrm{mmol} \mathrm{C} \mathrm{m} \mathrm{m}^{-2} \mathrm{~d}^{-1}\right)$ e razão $\mathrm{POC} /{ }^{210} \mathrm{Po}$ total $\left(\mathrm{mmol} \mathrm{C} \mathrm{m} \mathrm{m}^{-2} \mathrm{~d}^{-1}\right)$ - nas estações da OPERANTAR XXX.

\begin{tabular}{|c|c|c|c|}
\hline Estação & 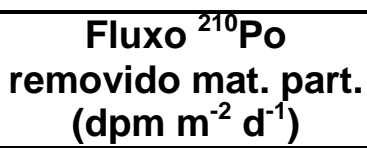 & $\begin{array}{c}\mathrm{POC} /{ }^{210} \mathrm{Po} \\
\text { particulado } \\
\left(\mathrm{mmol} \mathrm{C} \mathrm{dpm}^{-1}\right)\end{array}$ & 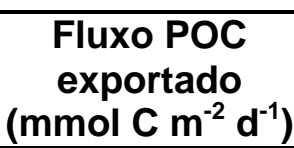 \\
\hline EB 001 & 13,34 & 1,37 & 18,33 \\
\hline EB 001a & 26,83 & 1,11 & 29,67 \\
\hline EB 002 & 6,83 & 5,54 & 37,85 \\
\hline EB 005 & 10,23 & 3,28 & 33,53 \\
\hline EB 006 & 8,59 & 4,16 & 35,71 \\
\hline EB 009 & 12,31 & 5,73 & 70,55 \\
\hline EB 010 & 8,11 & 4,50 & 36,47 \\
\hline EB 018 & 14,91 & 2,57 & 38,32 \\
\hline EB 019 & 8,69 & - & - \\
\hline EB 022 & 8,28 & - & - \\
\hline EB 027 & 8,85 & 4,82 & 42,66 \\
\hline EB 028 & 6,32 & 2,43 & 15,38 \\
\hline EB 029 & 7,47 & 2,56 & 19,15 \\
\hline EB 031 & 12,44 & 2,74 & 34,12 \\
\hline EB 032 & 7,05 & 2,14 & 15,08 \\
\hline EB 038 & 8,20 & 3,57 & 29,27 \\
\hline EB 051 & 6,15 & 4,46 & 27,47 \\
\hline
\end{tabular}




\section{CONCLUSÕES}

A realização deste projeto permitiu construir um banco de dados a respeito da distribuição das concentrações dos radionuclídeos naturais partículo-reativos e solúveis ao longo do Estreito de Bransfield, Península Antártica. Até o presente momento, estas informações não estavam disponíveis para o Programa Antártico Brasileiro (PROANTAR).

Para tanto, duas expedições oceanográficas ao Estreito de Bransfield foram realizadas em 2011, a primeira cobrindo o final do Verão Austral e a segunda o início do Verão seguinte.

Razões de atividade ${ }^{234} \mathrm{Th}$ total/ ${ }^{238} \mathrm{U}$ menores que 0,8 foram observados ao norte do EB (OPERANTAR XXIX) e próximo as llhas Livingston e Elefante (OPERANTAR XXX), sugerindo maior remoção do ${ }^{234}$ Th pelo material particulado. Valores próximos a 1 foram observados na sub-bacia central se estendendo a leste do $\mathrm{EB}$, indicando que ${ }^{234} \mathrm{Th}$ encontra-se em equilíbrio com seu precursor, $0{ }^{238} \mathrm{U}$. Valores acima de 1 foram observados próximo à Península Trinity (OPERANTAR XXIX) e ao norte do EB (OPERANTAR XXX), e este excesso de Th evidenciado nas águas superficiais sugere remineralização ou aporte de algas de degelo na região. Devido às diferenças sazonais e climáticas entre duas campanhas de amostragem, nota-se que durante o início do verão os processos de degelo estão ocorrendo intensamente causando maior fornecimento de ${ }^{234} \mathrm{Th}$ em relação ao ${ }^{238} \mathrm{U}$ ao norte do EB possivelmente pelas algas de degelo, as quais podem acumular o ${ }^{234} \mathrm{Th}$ em sua estrutura e após derretimento libera-lo causando excesso de ${ }^{234} \mathrm{Th}$ em águas superficiais.

Os menores valores de razão de atividade ${ }^{210} \mathrm{Po} /{ }^{210} \mathrm{~Pb}$ obtidos no início do verão Austral (OPERANTAR XXX) foram observados nas proximidades da llha Rei George e os maiores valores de razão de atividade nas imediações da llha Livingston. 
Valores baixos de razão de atividade ${ }^{228} \mathrm{Ra} /{ }^{226} \mathrm{Ra}$ durante $\mathrm{o}$ início do verão (OPERANTAR XXX) foram notados ao norte do EB evidenciando maior concentração de ${ }^{226} \mathrm{Ra}$, enquanto que razões elevadas foram notadas ao sul do EB evidenciando maior concentração de ${ }^{228}$ Ra próxima do talude continental.

Razões de atividade superficiais de ${ }^{210} \mathrm{~Pb} /{ }^{226} \mathrm{Ra}$ apresentaram baixos valores próximos às llhas Nelson e Elefante, enquanto que valores maiores foram obervados próximos às llhas Clarence, Deception e Rei George. Esse excesso de ${ }^{210} \mathrm{~Pb}$ em relação ao ${ }^{226} \mathrm{Ra}$ em águas superficiais pode estar relacionado ao fornecimento contínuo de ${ }^{210} \mathrm{~Pb}$ a partir da atmosfera (Krishnaswami, 2001, Nozaki et al., 1998).

Conclui-se que as diferentes épocas das campanhas de amostragem interferem no comportamento e mobilização dos radionuclídeos. Uma vez que no início do verão os processos de degelo e biogeoquímicos estão iniciando, enquanto que no final do verão o degelo é mínimo e os processos biogeoquímicos já se encontram em funcionamento.

Vale ressaltar a importância de um estudo mais detalhado da distribuição dos radionuclídeos estudados e seus respectivos fluxos, com amostragem de perfis verticais para melhor entender o comportamento desses radionuclídeos na coluna d'água, nos processos biológicos e físicos do oceano. 


\section{REFERÊNCIAS BIBLIOGRÁFICAS}

ÁLVAREZ, M.; RÍOS, A.F. \& ROSÓN, G. Spatio-temporal variability of air-sea carbon dioxide and oxygen fluxes in the Bransfield and Gerlache Straits during austral summer. Deep-Sea Research Part II, p. 95-96, 2002.

ANDERSON, R.F.; BACON, M.P. \& BREWER, P.G. Removal of ${ }^{230} \mathrm{Th}$ and ${ }^{231} \mathrm{~Pa}$ from the open ocean. Earth and Planetary Science Letters, v. 62, p. 7-23, 1983.

ANDERSON, R.F. \& FLEER, A.P. Determination of natural actinides and plutonium in marine particulate material. Analytical Chemistry, v. 54, n. 7, p. 1142-1147, 1982.

ANADÓN, R. \& ESTRADA, M. The FRUELA cruises. A carbon flux study in productive areas of the Antarctic Peninsula (December 1995 - February 1996). Deep-Sea Research II, v. 49, p. 567-583, 2002.

BACON, M.P. \& ANDERSON, R.F. Distribution of thorium isotopes between dissolved and particulate forms in the deep sea. Journal of Geophysical Research, v. 87, p. 2045-2056, 1982.

BENITEZ-NELSON, C.R.; BUESSELER, K.O.; RUTGERS VAN DER LOEFF, M.; ANDREWS, J.; BALL, L.; CROSSIN, G. \& CHARETTE, M.A. Testing a new smallvolume technique for determining ${ }^{234} \mathrm{Th}$ in seawater. Journal Radioanalytical and Nuclear Chemistry, v. 248, n. 3, p. 795-799, 2001.

BENITEZ-NELSON, C.R. \& MOORE, W.S. Future applications of ${ }^{234} \mathrm{Th}$ in aquatic ecosystems. Marine Chemistry, v. 100, p. 163-165, 2006.

BHAT, S.G.; KRISHNASWAMY, S.; LAL, D.; RAMA \& MOORE, W.S. ${ }^{234} \mathrm{Th} /{ }^{238} \mathrm{U}$ ratios in the ocean. Earth and Planetary Science Letters, v. 5 p. 483-491, 1969.

BUESSELER, K.O.; ANDREWS, J.E.; PIKE, S.; CHARETTE, M.A.; GOLDSON, L.E.; BRZEZINSKI, M.A \& LANCE, V.P. Particle export during the Southern Ocean Iron Experiment (SOFeX). Limnology and Oceanography, v. 50, n. 1, p. 311327, 2005.

BUESSELER, K.O.; BARBER,R.T.; DICKSON,M.L.; HISCOCK,M.R.; MOORE, J.K. \& SAMBROTTO, R. The effect of marginal ice-edge dynamics on production 
and export in the Southern Ocean along $170^{\circ} \mathrm{W}$. Deep Sea Research Part II: Topical Studies in Oceanography, v. 50, p. 579-603, 2003.

BUESSELER, K.O.; BENITEZ-NELSON, C.; RUTGERS VAN DER LOEFF, M.; ANDREWS, J.; BALL, L.; CROSSIN, G. \& CHARETTE, M.A. Marine Chemistry, v. 74, p. 15-28, 2001

CANALS, M.; URGELES, R. \& CALAFAT, A.M. Deep-sea floor evidence of past ice streams off the Antarctic Peninsula. Geology, v. 28, n. 1, p. 31-34, 2000.

CHEN, J.H.; EDWARDS, R.L. \& WASSERBURG, G.J. ${ }^{238} U,{ }^{234} U$ and ${ }^{232} T h$ in seawater. Earth and Planetary Science Letters, v.80, p. 241-251, 1986.

CHOPPIN, G. R. \& P. J. WONG. The chemistry of actinide behavior in marine systems. Aquatic Geochemistry, v. 4, p. 77-101, 1998.

COALE, K.H. \& BRULAND, K.W. ${ }^{234} T h:{ }^{238} \mathrm{U}$ disequilibria within the California current. Limnology and Oceanography, v. 30, p. 22-33, 1985.

COALE, K.H. \& BRULAND, K.W. Oceanic stratified euphotic zone as elucidated by ${ }^{234} \mathrm{Th}:{ }^{238} \mathrm{U}$ disequilibria Limnology and Oceanography, v. 32, n. 1, p. 189200, 1987.

COSTA, A.M.R. Variação temporal dos isótopos naturais de Ra de meiasvidas longas em amostras de água superficial do Estreito de Bransfield, Península Antártica. 2012. Monografia - Instituto Oceanográfico da Universidade de São Paulo, São Paulo.

DAMATTO, S. R.; LEONARDO, L. \& MAZZILLI, B. Monitoring anthropogenic airborne ${ }^{210} \mathrm{~Pb}$ and ${ }^{210} \mathrm{Po}$ in the vicinity of a TENORM industry using lichen as bioindicator. In: INTERNATIONAL TOPICAL CONFERENCE ON Po AND RADIOACTIVE Pb ISOTOPES, 2009, Sevilla, v. 1. p. 53-59.

DINNIMAN, M.S. \& KLINCK, J.M. A model study of circulation and cross-shelf exchange on the west Antarctic Peninsula continental shelf. Deep-Sea Research II, v. 51, p. 2003-22, 2004.

DUCKLOW, H. W.; STEINBERG, D. K. \& BUESSELER,K.O. Upper Ocean Carbon Export and the Biological Pump. Oceanography, v. 4, n. 4, p. 50-58, 2001.

DUCKLOW, H.W.; BAKER, K.; MARTINSON, D.G.; QUETIN, L. G.; ROSS, R.M.; SMITH, R.C.; STAMMERJOHN, S.E.; VERNET, M. \& FRASER, W. Marine pelagic ecosystems: the West Antarctic Peninsula. Philosophical Transactions of the Royal Society Biological Sciences, v. 362, n. 1477, p. 67-94, 2007.

EN, 1997. Water analysis - Guidelines for the determination of total organic carbon (TOC) and dissolved organic carbon (DOC). EN 1484. 
EPPLEY, R. W. \& PETERSON, B. J. Particulate organic matter flux and planktonic new production in the deep ocean. Nature, v. 282, p. 677-680, 1979.

ERNST, W.G. \& MORIN, J.G. 1980. The Environment of the Deep Sea. Englewood Cliffs, NJ: Prentice Hall.

FIGUEIRAS, F.G.; ESTRADA, M.; LÓPEZ, O. \& ARBONES, B. Photosynthetic parameters and primary production in the Bransfield Strait: relationships with mesoscale hydrographic structures. Journal of Marine Systems, v. 17, p. 129141, 1998.

FRIEDRICH, J. \& RUTGERS VAN DER LOEFF, M. A two-tracer $\left({ }^{210} \mathrm{Po}^{234} \mathrm{Th}\right)$ approach to distinguish organic carbon and biogenic silica export flux in the Antarctic Circumpolar Current. Deep-Sea Research I, v. 49, p. 101-120, 2002.

GARCIA, M.A.; CASTRO, C.G.; RIOS, A.F.; DOVAL, M.D.; ROSON, G.; GOMIS, D. \& LÓPEZ, O. Water masses and distribution of physico-chemical properties in the Western Bransfield Strait and Gerlache Strait during Austral Summer 1995/96.

Deep-Sea Research II, v. 49, n. 4-5, p. 585-602, 2002.

GARCÍA, M.A.; LÓPEZ, O.; SOSPEDRA, J.; ESPINO, M.; GRACIA, V.; MORRISON, G.; ROJAS, P.; FIGA, J.; PUIGDEFÁBREGAS, J.S. \& ARCILLA, A. Mesoscale variability in the Bransfield Strait region (Antarctica) during Austral summer. Annales Geophysicae, v. 12, n. 9, p. 856-867, 1994.

GORDON, A.L. \& NOWLIN JR, W.D. The basin waters of the Bransfield Strait. Journal of Physical Oceanography, v.8, p. 258-264, 1978.

GRÀCIA, E.; CANALS, M.; FARRÀN, M.; SORRIBAS, J. \& PALLÀS, R. Central and Eastern Bransfield Basins (Antarctica) from high resolution swath-bathymetry data. Antarctic Science, v. 9, p. 168-180, 1997.

GRELOWSKI, A.; MAJEWICZ, A. \& PASTUSZACK, M. Mesoscale hydrodynamic processes in the region of the Bransfield Strait and the southern part of the Drake Passage during BIOMASS-SIBEX 1983/84. Polish Polar Research, v. 7, p. 353369, 1986.

GRELOWSKI, A. \& TOKARCZYK, R. Hydrological conditions in the region of Bransfield Strait and southern part of Drake Passage in the period from December 10, 1983 and January 8, 1984 (BIOMASS-SIBEX). Polish Polar Research (Pol. Polar Res.), v. 6, n. 1-2, p. 31-41, 1985.

HAAS, H.; VAN WEERING, T.C.E. \& STIGTER, H. Organic carbon in shelf seas: sinks or sources, processes and products. Continental Shelf Research, v. 22, p. 691-717, 2002.

HANFLAND, C. Radium-226 and radium-228 in the Atlantic sector of the Southern Ocean. 2002. Thesis (PhD) - Universität Bremen, Alfred-Wegener Institut fur Polar und Meeresforschung, Fachbereich Geowissenschaften, Germany, Bremerhaven. 
HOFMANN, E.E.; KLINCK, J.M.; LASCARA, C.M. \& SMITH, D.A. Water mass distribution and circulation west of the Antarctic Peninsula and including Bransfield Strait. In ROSS, R.M., HOFMANN, E.E. e QUETIN, L.B. (eds) Foundations for ecological research west of the Antarctic Peninsula. Antarctic Research Series, v. 70, p. 61-80, 1996.

HONJO, S.; MANGANINI, S.J.; KRISHFIELD, R.A. \& FRANCOIS, R. Particulate organic carbon fluxes to the ocean interior and factors controlling the biological pump: A synthesis of global sediment trap programs since 1983. Progress in Oceanography, v. 76, p. 217-285, 2008.

HOUGHTON, J.; DING, Y.; GRIGGS, J.; NOGUER, M.; VAN DER LINDEN, P.; DAI, X.; MASKELL, K. \& JOHNSON, C.A. Climate change 2001: The scientific basis: Contribution of working group I to the third assessment report of the Intergovernmental Panel on Climate Change. Cambridge University Press. 2001

HUNTLEY, M., KARL, .D.M., NILER, P., HOLM-HANSEN, O. Research on Antarctic ecosystem rates (RACER): an interdisciplinary field experiment. DeepSea Research, v. 38, n. 8-9, p. 911-941, 1991.

INTERNATIONAL ATOMIC ENERGY AGENCY. A Procedure for the determination of Po-210 in water samples by alpha spectrometry. Vienna: IAEA, 2009.

IPCC - Cap. 3 The carbon cycle and atmospheric carbon dioxide. In: Climate Change 2001: The Scientific Basis. Contribution of Working Group I to the Third Assessment Report of the Intergovernmental Panel on Climate Change [Houghton, J.T., Y. Ding, D.J. Griggs, M. Noguer, P.J. van der Linden, X. Dai, K. Maskell, and C.A. Johnson (eds.)]. Cambridge University Press, Cambridge, United Kingdom and New York, NY, USA, p. 183-224.

JGOFS - U.S. Joint Global Ocean Flux Study. Ocean biogeochemistry and global change. International Geosphere-Biosphere Programme Science, n. 2, 2000.

JGOFS - U.S. Joint Global Ocean Flux Study. A new wave of Ocean Science Ocean biogeochemistry and global change. 2001.

KAUFMAN, A.; LI, Y. H. \& TUREKIAN, K. K. The removal rates of ${ }^{234}$ Th and ${ }^{228} \mathrm{Th}$ from waters of the New York Bight. Earth and Planetary Science Letters, v. 54, n. 3, p. 385-392, 1981.

KLINKHAMMER, G.O.; CHIN, C.S. \& WILSON, C. Hydrothermal and hydrographic surveys of the Bransfield Strait: Results from cruise NBP95-07. Antarctic Journal, p. 92-94, 1996.

KRISHNASWAMI, S. Uranium-thorium series isotopes in ocean profiles. Physical Research Laboratory, p. 3146-3156, 2001. 
LALLI, C.M. \& PARSONS, T.R. Biologocial oceanography: an introduction. The Open University 2nd ed., 1997.

LIVINGSTON, H.D. Marine Radioactivity. Radioactivity in the Environment, v. 6 , 2004.

LÓPEZ, O.; GÁRCIA, M.A.; GOMIS, D.; ROJAS, P.; SOSPEDRA, J. \& SÁNCHEZARCILLA, A. Hydrographic and hydrodynamic characteristics of the eastern basin of the Bransfield Strait (Antarctica). Deep-Sea Research I, v. 46, n.10, p. 17551778, 1999.

MARTIN, J.H.; FITZWATER, S.E. \& GORDON, R.M. Iron deficiency limits phytoplankton growth in Antarctic waters. Global Biogeochimal Cycles, v. 4, p. $5-12,1990$

MASQUÉ, P.; ISLA, E.; SANCHEZ-CABEZA, J.A.; PALANQUES, A.; BRUACH, J.M.; PUIG, P. \& GUILLÉN, J. Sediment accumulation rates and carbon fluxes to bottom sediments at the Western Bransfield Strait (Antarctica). Deep-Sea Research II, v. 49, p. 921-933, 2002a.

MASQUÉ, P.; SANCHES-CABEZA, J.A.; BRUACH, J.M.; PALACIOS, E. \& CANALS, M. Balance and residence times of $210 \mathrm{~Pb}$ and $210 \mathrm{Po}$ in surface waters of the northwestern Mediterranean Sea. Continental Shelf Research, v. 22, p. 2127-2146, 2002b.

MATSUMOTO, E. ${ }^{234}{ }^{T h}-{ }^{238} \mathrm{U}$ radioactive disequilibrium in the surface layer of the ocean. Geochimica et Cosmochimica Acta, v. 39, p. 205-212, 1975.

MOORE, W.S. \& OLIVEIRA, J. Determination of residence time and mixing processes of the Tbatuba, Brazil, inner shelf Waters using natural Ra isotopes. Estuarine. Costal ad Shelf Waters, v. 76, p. 512-521, 2008.

MORAN, S.B.; WEINSTEIN, S.E.; EDMONDS, H.N.; SMITH J.N.; KELLY, R.P.; PILSON, M.E.Q. \& HARRISON, W.G. Does 234Th/238U disequilibrium provide an accurate record of the export flux of particulate organic carbon from the upper ocean? Limnology Oceanography, v. 48, n. 3, p. 1018-1029, 2003.

MOROZOV, E.G. Currents in Bransfield Strait. Doklady Earth Sciences, v.415A, n. 6, p. $984-986,2007$

NIERE NETO, A. Determinação de ${ }^{210} \mathrm{~Pb}$ e ${ }^{210} \mathrm{Po}$ em águas minerais radioativas. 1996. Dissertação (Mestrado) - Instituto de Pesquisas Energéticas e Nucleares, São Paulo.

NIILER, P.P.; AMOS, A. \& HU, J.H. Water masses and $200 \mathrm{~m}$ relative geostrophic circulation in the western Bransfield Strait region. Deep-Sea, v. 38, p. 943-959, 1991. 
NOZAKI, Y.; DOBASHI, F.; KATO, Y. \& YAMAMOTO, Y. Distribution of Ra isotopes and the ${ }^{210} \mathrm{Po}$ balance in surface seawaters of the mid Northern Hemisphere. Deep-Sea Research I, v. 45, p. 1263-1284, 1998.

OLIVEIRA, J.; CHATERETTE, M.; ALLEN, M; BRAGA, E.S. \& FURTADO, V.V. Coastal water Exchange rate studies at the southeastern Brazilian margin using $\mathrm{Ra}$ isotopes as tracers. Radioactivity in the Environment, v. 8, p.345-359, 2006.

OLIVEIRA, J. Determinação de ${ }^{226}$ Ra e ${ }^{228}$ Ra em águas minerais da Região de Águas da Prata. 1993. Dissertação (Mestrado) - Instituto de Pesquisas Energéticas e Nucleares, São Paulo.

OWENS, S.A.; BUESSELER, K.O. \& SIMS, K.W.W. Re-evaluating the ${ }^{238} U$-salinity relationship in seawater: Implications for the ${ }^{238} \mathrm{U} /{ }^{234} \mathrm{Th}$ disequilibrium method. Marine Chemistry, v. 127, p. 31-39, 2011.

PAREKH, P.; DUTKIEWICZ, S.; FOLLOWS, M.J. \& ITO, T. Atmospheric carbon dioxide in a less dusty world. Geophysical Research Letters, v. 33, 2006.

PRIETO, M.J.; GRÀCIA, E.; CANALS, M.; ERCILLA, G \& DE BATIST, M. Sedimentary history of the Central Bransfield Basin (NW Antarctic Peninsula). The Antarctic Region: Geological Evolution and Processes, p. 711-717, 1997.

RIEBESELL, U.; FABRY, V.J.; HANSSON, L. \& GATTUSO, J.P. Guide to best practices for ocean acidification research and data reporting. Luxembourg: Publications Office of the European Union, 2010.

RODRIGUEZ Y BAENA, A.M.; MIQUEL, J.C.; MASQUE, P.; POVINEC, P.P. \& LA ROSA, J. A single VS Double Spike approach to improve the accuracy of ${ }^{234} \mathrm{Th}$ measurements in small-volume seawater samples. Marine Chemistry, v. 100, p. 269-281, 2006.

RUTGERS VAN DER LOEFF, M.M. Uranium-thorium decay series in the oceans overview. Alfred-Wegener-Institut für Polar und Meeresforschung, Bremerhaven, Germany, p. 3135-3145, 2001.

RUYGERS VAN DER LOEFF, M.M.; KEN, B.; BATHMANN, U. \& HENSE, I.; ANDREWS, J. Comparison of carbon and opal export rates between summer and spring bloom periods in the region of the Antarctic Polar Front, SE Atlantic. DeepSea Research II, v. 49, p. 3849-3869, 2002.

RUTGERS VAN DER LOEFF, M.M. \& GEIBERT, W. U- and Th-Series Nuclides as Tracers of Particle Dynamics, Scavenging and Biogeochemical Cycles in the Oceans. Radioactivity in the Environment, v. 13, p. 227-268, 2008.

RUTGERS VAN DER LOEFF, M. \& MOORE, W. S. Methods of Seawater Analysis. Verlag Chemie, Weinheim, 1999. Cap. 13, Determination of natural radioactive tracers. 
SANGRÀ, P.; GORDO, C.; HERNÁNDEZ-ARENCIBIA, M.; MARRERO-DÍAZ, A.; RODRÍGUEZ-SANTANA, A.; STEGNER, A.; MARTÍNEZ-MARRERO, A.; PELEGRÍ, J.L., \& PICHON, T. The Bransfield current system. Deep-Sea Research I, v. 58, n. 4, p. 390-402, 2011.

SANTSCHI, P. H.; LI, Y. H. \& BELL, J. Natural radionuclides in the water of Narragansett Bay. Earth and Planetary Science Letters, v. 45, n. 1, p. 201-213, 1979.

SARMIENTO, J.L. \& TOGGWEILER, J.R. A new model for the role of the oceans in determining pCO2. Nature, v. 308, p. 621-624, 1984.

SARMIENTO, J.L.; HUGHES, T.M.C.; STOUFFER \& R.J., MANABE, S. Simulated response of the ocean carbon cycling to anthropogenic carbon warming. Nature, v. 393, p. 245-249, 1998.

SHANNON, L. V.; CHERRY, R. D. \& ORREN, M. J. Polonium-210 and lead-210 in the marine environment. Geochimica et Cosmochimica Acta, v. 34, n. 6, p. 701$711,1970$.

SHIMMIELD, G. B.; RITCHIE, G. D. \& FILEMAN, T. W. The impact of marginal ice zone processes on the distribution of 210Pb, 210Po and 234Th and implications for new production in the Bellingshausen Sea, Antarctica. Deep-Sea Research II, v. 42 , p. $1313-1335,1995$.

SILVA, P.S.C. Caracterização química e radiológica dos sedimentos do estuário de Santos, São Vicente e Baía de Santos. 2004. Tese (Doutorado) Instituto de Pesquisas Energéticas e Nucleares, São Paulo.

SMITH, J.N.; MORAN, S.B. \& MACDONALD, R.W. Shelf-basin interactions in the Arctic Ocean based on ${ }^{210} \mathrm{~Pb}$ and $\mathrm{Ra}$ isotope tracer distributions. Deep-Sea Research I, v.50, p. 397-416, 2003.

SOUZA, J.E.B. Brasil na Antártica - 25 anos de história. São Carlos: Vento Verde Editora, 2008.

STAMMERJOHN, S.E. \& SMITH, R.C. Spatial and temporal variability of western Antarctic Peninsula sea ice coverage. In Ross, R.M., Hofmann, E.E. and Quetin, L.B. (eds) Foundations for ecological research west of the Antarctic Peninsula. Antarctic Research Series, v. 70, p. 81-104, 1996.

STEVENSON, P.C. Processing of counting data. National Academy of Sciences, Nuclear Science Series, NAS-NS 3109, 1965.

TIWARI, A.; KRISHNAN K.P. \& RAVINDRA, R. The Story of Antarctica. National Centre for Antarctic and Ocean Research, 2008.

TOKARCZYK, R. Classification of water masses in the Bransfield Strait and Southern part of the Drake Passage using a method of statistical multidimensional analysis. Polish Polar Research, v. 8, p. 333-336, 1987. 
TSUNOGAI, S.; TAGUCHI, K. \& HARADA, K. Seasonal variation in the difference between observed and calculated particulate fluxes of Th-234 in Funka Bay, Japan. Journal of the Oceanographical Society of Japan, v. 42, p. 91-98, 1986.

TURNER, J.; BINDSCHADLER, R.; VONVEY, O.; DI PRISCO, G., FAHRBACH, E.; GUIT, J.; HODGSON, D.; MAYEWSKI, O. \& SUMMERHAYES, C.P. 2009. Antarctic Climate change and the environment: A contribution to the International Polar Year 2007-2008.

VIEIRA, H.L. Aplicação dos isótopos naturais de Ra e do ${ }^{234}$ Th como traçadores do carbono orgânico exportado para o Estreito de Bransfield, Antártica. 2011. Dissertação (Mestrado) - Instituto de Pesquisas Energéticas e Nucleares, São Paulo.

VILLELA, F.N.J. Análise decadal do fluxo de $\mathrm{CO}_{2}$ entre o oceano e a atmosfera na passagem de Drake, Oceano Austral. 2011. Dissertação (Mestrado) - Ciência Ambiental Universidade de São Paulo, São Paulo.

WAPLES, J.T. \& BENITEZ-NELSON. C.; SAVOYE, N.; RUTGERS VAN DER LOEFF, M.; BASKARAN, M. \& GUSTAFSSON, O. An introduction to the application and future use of ${ }^{234} \mathrm{Th}$ in aquatic systems. Marine Chemistry, v. 100, p. 166-189, 2006.

WHITWORTH III, T.; NOWLIN JR.; W.D., ORSI, A.H.; LOCARNINI, R.A. \& SMITH, S.G. Weddell Sea shelf water in the Bransfield Strait and Weddell Scotia confluence. Deep-Sea Research I, v. 41, p. 629-641, 1994.

YI, P.; BATTEN, D.J. \& LEE, S.J. Provenance of recycled palynomorph assemblages recovered from surficial glaciomarine sediments in Bransfield Strait, offshare Antarctic Peninsula. Cretaceous Research, v. 26, p. 906-919, 2005.

ZHOU, M.; NIILER, P.P.; ZHU, Y. \& DORLAND, R.D. The western boundary current in the Bransfield Strait, Antarctica. Deep-Sea Research I, v. 53, p. 12441252, 2006. 